\title{
Investigation of the underlying hub genes and molecular pathogenesis in gastric cancer by integrated bioinformatic analyses
}

Basavaraj Vastrad ${ }^{1}$, Chanabasayya Vastrad ${ }^{* 2}$

1. Department of Biochemistry, Basaveshwar College of Pharmacy, Gadag, Karnataka 582103, India.

2. Biostatistics and Bioinformatics, Chanabasava Nilaya, Bharthinagar, Dharwad 580001, Karanataka, India.

* Chanabasayya Vastrad

channu.vastrad@gmail.com

$\mathrm{Ph}:+919480073398$

Chanabasava Nilaya, Bharthinagar,

Dharwad 580001 , Karanataka, India 


\begin{abstract}
The high mortality rate of gastric cancer (GC) is in part due to the absence of initial disclosure of its biomarkers. The recognition of important genes associated in $\mathrm{GC}$ is therefore recommended to advance clinical prognosis, diagnosis and and treatment outcomes. The current investigation used the microarray dataset GSE113255 RNA seq data from the Gene Expression Omnibus database to diagnose differentially expressed genes (DEGs). Pathway and gene ontology enrichment analyses were performed, and a protein $\square$ protein interaction network, modules, target genes - miRNA regulatory network and target genes - TF regulatory network were constructed and analyzed. Finally, validation of hub genes was performed. The 1008 DEGs identified consisted of 505 up regulated genes and 503 down regulated genes. The pathways and $\mathrm{GO}$ functions of the up and down regulated genes were mainly enriched in pyrimidine deoxyribonucleosides degradation, extracellular structure organization, allopregnanolone biosynthesis and digestion. FN1, PLK1, ANLN, MCM7, MCM2, EEF1A2, PTGER3, CKB, ERBB4 and PRKAA2 were identified as the most important genes of GC, and validated by TCGA database, The Human Protein Atlas database, receiver operating characteristic curve (ROC) analysis and RT-PCR. Bioinformatics analysis might be useful method to explore the molecular pathogensis of GC. In addition, FN1, PLK1, ANLN, MCM7, MCM2, EEF1A2, PTGER3, CKB, ERBB4 and PRKAA2 might be the most important genes of GC.
\end{abstract}

Keywords: gastric cancer; bioinformatics analysis; proliferation; Gene Expression Omnibus (GEO); hub genes 


\section{Introduction}

Gastric cancer (GC) presents the major cause of cancer deaths in the past few decades and has been a major public health problem [1]. GC is the fifth most frequently detected cancer in worldwide [2]. Since GC absence reliable clinical and biochemical features in the initial stages, the majority of patients are only definitively identified with GC at a leading stage. Although some routine treatments such as surgery and chemotherapy can be used, the recurrence rate is still as high [3]. Thus, investigation on GC is important, especially on its molecular pathogenesis and the identification of biomarkers that are useful for early detection, risk stratification, determination of appropriate intervention, prognostication and identification of novel therapeutic targets.

Investigation has exposed key pathways and interactions between gene modfications, and tumorigenesis and tumor advancement of various types of cancers [4]. Pathways such as Wnt pathways [5], PI3K and MAPK signaling pathways [6], Notch1 signal pathway [7], STAT and ERK2 pathways [8] and Src/FAK pathway [9] were responsible for pathogenesis of GC. Genes such as IL10 and TNF-A [10], p53 and TGF-,RII [11], IL-17A and IL-17F [12], PFKFB-3 and PFKFB-4 [13], and Runx3 and CHFR [14] were liable for pathogenesis of GC. Thus, a complete understanding of the transcriptional modification may add to the advancement of preventive, diagnostic and therapeutic strategies for GC.

The prognosis and diagnosis of GC mainly depends on the extent of disease. With the fast advancement of gene or RNA sequencing technology, GEO, ArrayExpress and TCGA have been playing enhancing key roles in bioinformatics analysis [15-17]. These databases provide sequencing data for research of novel functional genes and pathways and for analyzing the effect of these genes on prognosis, diagnosis and therapeutic.

The current investigation aimed to improve the understanding of the molecular basis of GC and to identify novel prognostic factors for GC. The GSE113255 RNA seq dataset was downloaded from the Gene Expression Omnibus (GEO) database, in order to determine the up regulated and down regulated differentially expressed genes (DEGs) in the tumor tissues of patients with GC. Several prognosis and diagnosis related genes and pathways of GC were 
obtained through, pathway and gene ontology (GO) enrichment analysis, proteinprotein interaction (PPI) network analysis, module analysis, target genes - miRNA regulatory network analysis and target genes - TF regulatory network analysis. To verify the prognostic roles of hub genes in GC, the GC dataset from The Cancer Genome Atlas (TCGA) was used to perform survival analysis, expression analysis, stage analysis, mutation analysis, immune histochemical (ICH) analysis and immune infiltration analysis. Secondly, the current investigation confirmed the selected findings using receiver operating characteristic (ROC) analysis), with the aim of prognostic and diagnostic value of hub genes. Finally, the most key expressed hub genes were selected and conducted for preliminary validation by real-time PCR ( RT-PCR). In summery we believe that it is feasible to identify new genes linked with GC with the explained method, providing key intuition into the $\mathrm{GC}$ at the molecular level that guided the GC advancement and progression to full blown stages.

\section{Materials and methods}

\section{Microarray data}

RNA-seq Data relevant to GC was obtained from the GEO database and the GSE113255 (https://www.ncbi.nlm.nih.gov/geo/query/acc.cgi?acc=GSE113255) dataset was selected [18]. This dataset was established on a GPL18573 Illumina NextSeq 500 (Homo sapiens) platform. The GSE113255 dataset contains 107 diffuse type gastric cancer tissues samples and 10 normal gastric tissues samples.

\section{Data pre $\square$ processing and identification of DEGs in GC}

Microarray data preprocessing is associated with quality assessment, quality control, background correction and normalization. Quantile method was used to perform background correction, normalization and probe summarization [19]. The empirical Bayesian method in limma package [20] was used to perform the differential analysis, $\mid \log 2$ fold change $(\mathrm{FC}) \mid>1.5$ for up regulated genes, $\mid \log 2$ fold change $(\mathrm{FC}) \mid<-1.13$ for down regulated genes and adjusted $\mathrm{P}<0.05$ were considered as statistically significant. Since dataset was diagnosed to have a larger sample size of both GC and healthy tissues, heat maps and volcano plots were further established from the RNA-seq data of this dataset in order to visualize DEGs. 


\section{Pathway enrichment analysis of DEGs}

BIOCYC (https://biocyc.org/) [21], Kyoto Encyclopedia of Genes and Genomes (KEGG) (http://www.genome.jp/kegg/pathway.html) [22], Pathway Interaction Database

(https://wiki.nci.nih.gov/pages/viewpage.action?pageId=315491760) REACTOME (https://reactome.org/) [24], GenMAPP (http://www.genmapp.org/) [25], MSigDB

$\mathrm{C} 2$

BIOCARTA (http://software.broadinstitute.org/gsea/msigdb/collections.jsp) [26], PantherDB (http://www.pantherdb.org/) [27], Pathway Ontology (http://www.obofoundry.org/ontology/pw.html) [28] and Small Molecule Pathway Database (SMPDB) (http://smpdb.ca/) [29] are a databases collection which can be used to analyze genomes, biological pathways, diseases, chemical substances and drugs. ToppGene (ToppFun) (https://toppgene.cchmc.org/enrichment.jsp) [30] was used for annotation of the pathway results. For this analyses, $p<0.05$ was considered to indicate a statistically significant difference.

\section{Gene ontology (GO) enrichment analysis of DEGs}

ToppGene (ToppFun) (https://toppgene.cchmc.org/enrichment.jsp) [30] was used to perform GO enrichment analysis. GO (http://www.geneontology.org/) enrichment analysis is extensively used to annotate specific genes and gene products for high throughput genome and transcriptome data [31]. In the current investigation, GO enrichment analysis was implemented to predict the probable functions of the DEGs based on biological process (BP), molecular function (MF) and cellular component $(\mathrm{CC}) . \mathrm{p}<0.05$ was set as the cutoff criterion.

\section{PPI network construction and module analysis}

We evaluated the protein-protein interaction (PPI) data using the Human Integrated Protein-Protein Interaction rEference (HIPPIE) (http://cbdm.unimainz.de/hippie/) database [32], which integrates with various PPI data bases such as IntAct (https://www.ebi.ac.uk/intact/) [33], BioGRID (https://thebiogrid.org/) [34], HPRD (http://www.hprd.org/) [35], MINT (https://mint.bio.uniroma2.it/) [36], BIND (http://download.baderlab.org/BINDTranslation/) [37], MIPS (http://mips.helmholtz-muenchen.de/proj/ppi/) [38] and DIP (http://dip.doembi.ucla.edu/dip/Main.cgi) [39]. Cytoscape software (http://www.cytoscape.org/) 
[40] was applied to visualize the protein interaction network relationships. With the plugin Network analyzer the gene lists of the top ranked in node degree [41], betweenness centrality [42], stress centrality [43], closeness centrality [44] and clustering coefficient [45] were obtained. PEWCC1 (http://apps.cytoscape.org/apps/PEWCC1), a plug-in used to produce the best results for considerate correlation levels, was subsequently utilized to identify modules in the network [46].

\section{Target genes - miRNA regulatory network construction}

Relevant miRNA targets were predicted using miRNet database (available online: (https://www.mirnet.ca/) [47], which is a comprehensive atlas of predicted and validated target - miRNA interactions. The potential targets of miRNA were identified by 10 miRNA databases such as TarBase (http://diana.imis.athenainnovation.gr/DianaTools/index.php? $r=$ tarbase/index) [48], miRTarBase (http://mirtarbase.mbc.nctu.edu.tw/php/download.php) [49], miRecords (http://miRecords.umn.edu/miRecords) [50], miR2Disease (http://www.mir2disease.org/) [51], HMDD (http://www.cuilab.cn/hmdd) [52], PhenomiR (http://mips.helmholtz-muenchen.de/phenomir/) [53], SM2miR (http://bioinfo.hrbmu.edu.cn/SM2miR/) [54], (http://www.pharmaco-mir.org/) $[55]$, PharmacomiR (http://bioinfo.hrbmu.edu.cn/EpimiR/) [56] and EpimiR (http://starbase.sysu.edu.cn/) [57]. The integrated regulatory networks were then visualized by Cytoscape (http://www.cytoscape.org/) [40].

\section{Target genes - TF regulatory network construction}

Relevant TF targets were predicted using (https://www.networkanalyst.ca/) [58], which is a comprehensive atlas of predicted and validated target - TF interactions. The potential targets of TF were identified by $\mathrm{TF}$ database ChEA (http://amp.pharm.mssm.edu/lib/chea.jsp) [59]. The integrated regulatory networks were then visualized by Cytoscape (http://www.cytoscape.org/) [40].

\section{Validations of hub genes}

The probability of survival and importance was determined using the UALCAN (http://ualcan.path.uab.edu/analysis.html) [60] database. UALCAN is a newly 
created online interactive web server which implements users to examine the RNA sequencing expression data of tumors/normal tissues or samples from The Cancer Genome Atlas (TCGA), based on a criterion processing pipeline. The overall survival analyses of hub gene were performed in UALCAN. The RNA expression level of hub genes between GC samples and normal control samples was visualized by UALCAN. The RNA expression level of hub genes between different stages of GC samples compared to normal control samples was visualized by UALCAN. The cBio Cancer Genomics Portal (cBioPortal) (http://www.cbioportal.org) [61] is a key tool for online analysis, visualization, and examination of cancer genomics data. cBioPortal, which is the database used in this investigation, scrutinize genetic modifications of prognostic and diagnostic hub genes in TCGA GC patients. The expression levels of hub genes in cancerous and non cancerous tissue were validated using the Human Protein Atlas (HPA) database (http://www.proteinatlas.org/) [62]. To calculate whether established hub genes had key diagnostic and prognostic values for $\mathrm{GC}$, the receiver operating characteristic (ROC) analyses was accomplished using the R "pROC" package [63]. The area under the ROC curve (AUC) of hub gene was determined. The diagnostic and prognostic accuracy of hub genes for GC was calculated with AUC value. Herein, when AUC value was larger than 0.8, the hub gene could differentiate GC from normal control. Hub genes were further validated by real time polymer chain reaction (RT-PCR). According to the manufacturer's instruction, total RNA of gastric tissues in both GC groups and controls were extracted using the TRI Reagent ${ }^{\circledR}$ (Sigma, USA) and reversely transcribed to complementary DNA using the FastQuant RT kit (with gDNase; Tiangen Biotech Co., Ltd.). RT-PCR was completed by using QuantStudio 7 Flex real-time PCR system (Thermo Fisher Scientific, Waltham, MA, USA). The RT-PCR amplification reaction protocol was as follows: A total of 40 cycles at $95^{\circ} \mathrm{C}$ for 5 $\mathrm{sec}$ and $60^{\circ} \mathrm{C}$ for $10 \mathrm{sec}$. Relative quantification was achieved by using the comparative $2^{\square \Delta \Delta \mathrm{Cq}}$ method [64] with $\beta$-actin as the reference gene. The sequences of all primer pairs are given in Table 1. Immune infiltration analysis was performed for hub genes using the TIMER online analysis tool (https://cistrome.shinyapps.io/timer/) [65], which incorporates the prognostic and diagnostic data from the RNA-Seq expression profiling database from The Cancer Genome Atlas (TCGA). Immune infiltration analysis was assigned to check the 
immune infiltrates (B cells, CD4+ $\mathrm{T}$ cells, CD8+ $\mathrm{T}$ cells, neutrophils, macrophages, and dendritic cells) across GC.

\section{Results}

\section{Data pre $\square$ processing and identification of DEGs in GC}

NCBI-GEO is a free database of gene expression profiles and RNA-seq, from which GC and normal control RNA-seq data of GSE113255 were obtained. The expression values for all the genes from the $107 \mathrm{GC}$ samples and 10 normal control samples were normalized using the Quantile method, and values with an unchanged position in the boxplot were used for consequent analysis, as this can be used as a intermediary for normalization (Fig. 1A and Fig. 1B). Using $\mathrm{P}<0.05$, $\mid \log 2$ fold change $(\mathrm{FC}) \mid>1.5$ for up regulated genes, $\mid \log 2$ fold change $(\mathrm{FC}) \mid<-$ 1.13 for down regulated genes as the cutoff criteria, after integrated bioinformatics analysis. A total of 1008 DEGs were identified in the active group, including 505 up regulated genes and 503 down regulated genes and are given in Table 2. Fig. 2 and Fig. 3 shows the heat maps of those up and down regulated genes, and reveals that the up and down regulated genes can be easily distinguished from each of the samples. The distribution patterns of expressed genes in GSE113255 data is displayed in Fig. 4, respectively. Red dots in the volcano plots mean significantly up regulated genes, while green dots mean significantly down regulated genes.

\section{Pathway enrichment analysis of DEGs}

To analyze the biological importance of DEGs, pathway enrichment analyses were executed. Pathway enrichment analysis was predicted that up and down regulated genes were associated with several key physiological processes and are listed in Table 3 and Table 4. Up regulated genes were significantly enriched in pyrimidine deoxyribonucleosides degradation, aspirin triggered resolvin D biosynthesis, ECMreceptor interaction, protein digestion and absorption, syndecan-4-mediated signaling events, PLK1 signaling events, extracellular matrix organization, hemostasis, glutamate metabolism, pyrimidine metabolism, ensemble of genes encoding extracellular matrix and extracellular matrix-associated proteins, ensemble of genes encoding core extracellular matrix including ECM glycoproteins, collagens and proteoglycans, integrin signalling pathway, plasminogen activating cascade, altered lipoprotein metabolic, ammonia recycling 
and MNGIE (Mitochondrial Neurogastrointestinal Encephalopathy), while down regulated genes were significantly enriched in allopregnanolone biosynthesis, gluconeogenesis, drug metabolism - cytochrome P450, chemical carcinogenesis, FOXA2 and FOXA3 transcription factor networks, RhoA signaling pathway, biological oxidations, phase 1 - functionalization of compounds, carbon fixation, fatty acid metabolism, ensemble of genes encoding extracellular matrix and extracellular matrix-associated proteins, ensemble of genes encoding ECMassociated proteins including ECM-affilaited proteins, ECM regulators and secreted factors, 5-Hydroxytryptamine degredation, fructose galactose metabolism, lipoprotein metabolic, pirenzepine pathway and tyrosine metabolism.

\section{Gene ontology (GO) enrichment analysis of DEGs}

We uploaded all up and down regulated genes to the online software ToppGene to identify overrepresented GO categories. GO analysis results showed that up regulated genes were significantly enriched in $\mathrm{BP}, \mathrm{CC}$ and $\mathrm{MF}$, including extracellular structure organization, cell adhesion, extracellular matrix, collagencontaining extracellular matrix, extracellular matrix structural constituent and structural molecule activity, while down regulated genes were significantly enriched in $\mathrm{BP}, \mathrm{CC}$ and $\mathrm{MF}$, including digestion, organic acid metabolic process, apical part of cell, extracellular matrix, oxidoreductase activity and transition metal ion binding and are listed in Table 5 and Table 6.

\section{PPI network construction and module analysis}

All the up and down regulated genes were entered into the HIPPIE database to obtain the interaction data. The protein-protein interaction (PPI) network of up regulated genes exhibited 3222 nodes and 4943 edges and is shown in Fig 5. The hub genes with highest node degree distribution, betweenness centrality, stress centrality, closeness centrality and lowest clustring coefficient were as follows: FN1, NOTCH1, PLK1, ANLN, MDFI, CPZ, PRKDC, TREM1, TREM2, CYP2W1, CST1, CCL3, PLXDC2, AMIGO2 and GPR161, and are listed in Table 7. The statistical scores of node degree distribution, betweenness centrality, stress centrality, closeness centrality and clustring coefficient are shown as scatter plot in Fig. 6A - 6E. The functional enrichment analysis showed that these hub genes were significantly involved in ECM-receptor interaction, microRNAs in cancer, PLK1 
signaling events, cell migration, animal organ morphogenesis, extracellular matrix, phosphotransferase activity, alcohol group as acceptor, molecular transducer activity, axon guidance, endoplasmic reticulum lumen, peptidase activity, identical protein binding, ensemble of genes encoding extracellular matrix and extracellular matrix-associated proteins, cell adhesion and whole membrane. Similarly, protein-protein interaction (PPI) network of down regulated genes exhibited 5142 nodes and 8412 edges and is shown in Fig 7. The hub genes with highest node degree distribution, betweenness centrality, stress centrality, closeness centrality and lowest clustring coefficient were as follows: SOX2, RIPK4, FOXA1, EEF1A2, ANG, FGB, CNTD1, GGT6, PTGDR2, ADH1C, DCAF12L1, CAPN9 and TTC39A, and are listed in Table 7. The statistical scores of node degree distribution, betweenness centrality, stress centrality, closeness centrality and clustring coefficient are shown as scatter plot in Fig. 8A - 8E. The functional enrichment analysis showed that these hub genes were significantly involved in developmental biology, kinase activity, FOXA2 and FOXA3 transcription factor networks, metabolism of proteins, ensemble of genes encoding extracellular matrix and extracellular matrix-associated proteins, hemostasis, metabolic pathways, intrinsic component of plasma membrane, drug metabolism cytochrome $\mathrm{P} 450$ and digestion.

Furthermore, the PEWCC1 plugin was applied to investigate highly interconnected regions, known as modules, in the PPI network. Total 668 modules were isolated from PPI network of up regulated genes and four significant modules with the highest scores are shown in Fig. 9. Module 2, consisting of 156 nodes and 175 edges, was highly enriched in microRNAs in cancer, innate immune system, pathways in cancer and notch signaling pathway. Module 5, consisting of 133 nodes and 165 edges, was highly enriched in cell migration, microRNAs in cancer, signaling by Rho GTPases, focal adhesion and cell junction. Module 6, consisting of 118 nodes and 120 edges, was highly enriched in animal organ morphogenesis, $\mathrm{G}$ alpha (i) signalling events, water transport, notch signaling pathway and cell migration. Module 9, consisting of 81 nodes and 40 edges, was highly enriched in cell cycle, ATP binding, E2F transcription factor network, identical protein binding, regulation of cell population proliferation and pyrophosphatase activity. Similarly, total 1078 modules were isolated from PPI network of down regulated genes and four significant modules with the highest scores are shown in Fig. 10. Module 6, consisting of 120 nodes and 154 edges, was highly enriched in 
metabolism of proteins, hemostasis, developmental biology, ensemble of genes encoding extracellular matrix and extracellular matrix-associated proteins and ensemble of genes encoding core extracellular matrix including ECM glycoproteins, collagens and proteoglycans. Module 7, consisting of 114 nodes and 115 edges, was highly enriched in neuroactive ligand-receptor interaction, oxidation-reduction process, gastric acid secretion and metabolism of proteins. Module 10, consisting of 100 nodes and 116 edges, was highly enriched in developmental biology, molecular function regulator, ensemble of genes encoding extracellular matrix and extracellular matrix-associated proteins, metabolism of proteins and biological adhesion. Module 15, consisting of 91 nodes and 95 edges, was highly enriched in gastric acid secretion, nitrogen metabolism, FOXA2 and FOXA3 transcription factor networks, metabolism of proteins, transmembrane transport of small molecules, chemical homeostasis, apical part of cell, secretion, pirenzepine pathway, digestion, and protein digestion and absorption.

\section{Target genes - miRNA regulatory network construction}

The target genes - miRNA regulatory network of up regulated genes was shown in Fig. 11, consisting of 2669 nodes and 10414 interactions. The nodes with high degree score (interaction with maximum number of miRNAs) can be regarded as essential network nodes. The top target genes with higher degree included FOXK1 interacts with 259 miRNAs (ex,hsa-mir-5693), CCND2 interacts with 179 miRNAs (ex,hsa-mir-3976), RCC2 interacts with 135 miRNAs (ex,hsa-mir-3911), CCDC80 interacts with 135 miRNAs (ex,hsa-mir-6083) and E2F3 interacts with 135 miRNAs (ex,hsa-mir-4271), and are listed in Table 7. The functional enrichment analysis showed that these target genes were significantly involved in peptidase activity, PI3K-Akt signaling pathway, cell cycle, extracellular structure organization and regulation of cell population proliferation. Similarly, target genes - miRNA regulatory network of down regulated genes was shown in Fig. 12, consisting of 2220 nodes and 5985 interactions. The top target genes with higher degree included GATA6 interacts with 207 miRNAs (ex, hsa-mir-4284), SULT1B1 interacts with 131 miRNAs (ex, hsa-mir-4643), GLUL interacts with 126 miRNAs (ex, hsa-mir-4459), ENPP5 interacts with 114 miRNAs (ex,hsa-mir8082) and KLF2 interacts with 107 miRNAs (ex,hsa-mir-5193) and are listed in Table 7. The functional enrichment analysis showed that these target genes were 
significantly involved in notch-mediated HES/HEY network, biological oxidations, metabolic pathways, intrinsic component of plasma membrane and response to endogenous stimulus.

\section{Target genes - TF regulatory network construction}

The target genes - TF regulatory network of up regulated genes was shown in Fig. 13, consisting of 657 nodes and 10767 interactions. The nodes with high degree score (interaction with maximum number of TFs) can be regarded as essential network nodes. The top target genes with higher degree included ABCA13 interacts with 247 TFs (ex, SOX2), ACTN1 interacts with 215 TFs (ex, MYC), ABCD1 interacts with 202 TFs (ex, EGR1), ADAMTS14 interacts with 202 TFs (ex, SPI1) and ADAMTS4 interacts with 194 TFs (ex, NANOG) and are listed in Table 8. The functional enrichment analysis showed that these target genes were significantly involved in neutrophil degranulation, focal adhesion, regulation of phosphate metabolic process, peptidase activity and extracellular matrix organization. Similarly, target genes - TF regulatory network of down regulated genes was shown in Fig. 14, consisting of 639 nodes and 7623 interactions. The top target genes with higher degree included DNER interacts with 177 (ex, TP63), CKB interacts with 169 (ex, STAT3), PKIB interacts with 165 (ex, HNF4A), RAB27B interacts with 164 (ex, AR) and IRX3 interacts with 150 (ex, SUZ12) and are listed in Table 8. The functional enrichment analysis showed that these target genes were significantly involved in neuron projection, gastric acid secretion, molecular function regulator and pancreatic secretion.

\section{Validations of hub genes}

Up regulated hub genes and down regulated hub genes were then validated in database TCGA to confirm the outcomes. We tried to analysis the relationship between hub genes and the survival in GC. The prognostic and diagnostics value of hub genes was determined by UALCAN database. Patients with high expression of FN1 (Fig. 15A), PLK1 (Fig. 15B), ANLN (Fig. 15C), MCM7 (Fig. 15D), MCM2 (Fig. 15E), EEF1A2 (Fig. 16A), PTGER3 (Fig. 16B), CKB (Fig. 16C), ERBB4 (Fig. 16D) and PRKAA2 (Fig. 16E) were associated with shorter overall survival. The UALCAN box plot analysis investigated the level of expression of the hub genes in 415 GC tissue samples and 34 normal tissue samples. The boxplot in Fig. 
17A - Fig. 17E shows a considerable increase in the level of hub gene expression (FN1, PLK1, ANLN, MCM7 and MCM2) in the GC, while boxplot in Fig. 17F Fig. 17J shows a considerable decrease in the level of hub gene expression (EEF1A2, PTGER3, CKB, ERBB4 and PRKAA2) in the GC. Furthermore, the UALCAN box plot analysis investigated the level of expression of the hub genes in individual GC stages (stage 1 (18 GC samples), stage 2 (123 GC samples), stage 3 (169 GC samples) and stage 4 (41 GC samples)) and 34 normal tissue samples. The boxplot in Fig. 18A - Fig. 18E shows a considerable increase in the level of hub gene expression (FN1, PLK1, ANLN, MCM7 and MCM2) in all four individual stages of GC, while boxplot in Fig. 18F - Fig. 18J shows a considerable decrease in the level of hub gene expression (EEF1A2, PTGER3, CKB, ERBB4 and PRKAA2) in all four individual stages of GC. Based on the results of the cBioPortal database, results of genomic modifications for these hub genes were depicted by using the cBioPortal. We found $6 \%, 5 \%, 3 \%, 8 \%, 4 \%, 5 \%, 1.4 \%$, $0.7 \%, 13 \%$ and $2.5 \%$ of GC cases exhibited FN1, PLK1, ANLN, MCM7, MCM2, EEF1A2, PTGER3, CKB, ERBB4 and PRKAA2 hub genes modification including inframe mutation (unknown significance), missense mutation (putative driver), deep deletion, missense mutation (unknown significance), amplification and truncating mutation (unknown significance) and are shown in Fig. 19. Additionally, the expression and distribution of the hub genes (proteins) in GC samples and nontumor samples were measured through immunohistochemistry (IHC). IHC analysis of FN1, PLK1, ANLN, MCM7, MCM2, EEF1A2, PTGER3, $\mathrm{CKB}, \mathrm{ERBB} 4$ and PRKAA2 in GC samples were found in the HPA database. The antibodies used were as follows: FN1 (CAB000126), PLK1 (HPA051638), ANLN (HPA050556), MCM7 (CAB016312), MCM2 (CAB000303), EEF1A2 (CAB034019), PTGER3 (HPA010689), CKB (HPA001254), ERBB4 (CAB000276) and PRKAA2 (HPA044540). Up regulated hub genes such as FN1, PLK1, ANLN, MCM7 and MCM2 were highly expressed in GC tissue but undetectable or expressed at low levels in normal tissue (Fig. 20A - Fig. 20E). Down regulated hub genes such as EEF1A2, PTGER3, CKB, ERBB4 and PRKAA2 were less expressed in GC tissue but detectable or expressed at high levels in normal tissue (Fig. 20F - Fig. 20J). The ROC curve analysis was accomplished to assess the diagnostic and prognostic values of hub genes. Our finding revealed that FN1 (AUC = 0.979), PLK1 (AUC = 0.921), ANLN (AUC = 0.946), MCM7 (AUC $=0.978), \operatorname{MCM} 2(\mathrm{AUC}=0.961), \mathrm{EEF} 1 \mathrm{~A} 2(\mathrm{AUC}=0.955)$, 
PTGER3 (AUC $=0.934), \mathrm{CKB}(\mathrm{AUC}=0.869), \mathrm{ERBB} 4(\mathrm{AUC}=0.769)$ and PRKAA2 (AUC $=0.761$ ) had significant diagnostic and prognostic values for discriminating GC samples and normal controls (Fig. 21). Furthermore, RT $\square$ PCR was used to verify the expression levels of the hub genes in primary GC and normal control tissue. In the GC tissues, FN1, PLK1, ANLN, MCM7 and MCM2 were significantly up regulated as compared with those in their normal control tissue, while in GC samples EEF1A2, PTGER3, CKB, ERBB4 and PRKAA2 were significantly down regulated as compared with those in their normal control tissue. These results indicated that, consistent with the TCGA results, most of these hub genes were dysregulated in GC samples compared with those in the normal control samples (Fig. 22). Finally, we investigated whether FN1, PLK1, ANLN, MCM7, MCM2, EEF1A2, PTGER3, CKB, ERBB4 and PRKAA2 expression were associated with tumor immune infiltration level by using the TIMER database. Interestingly, we found that the high expression of FN1, PLK1, ANLN, MCM7 and MCM2 were significantly negatively related to tumor purity, while low expression EEF1A2, PTGER3, CKB, ERBB4 and PRKAA2 were significantly positively related to tumor purity (Fig. 23).

\section{Discussion}

The frequency and fatality of GC were still on the increase in many countries. Gene alterations and abnormal expression have been exhibited in the advancement of GC. Understanding the molecular pathogenesis of GC is very essential for prognosis, diagnosis and treatment. With the advancement of microarray and high throughput RNA sequencing, the alternative expression levels of thousands of genes could be together examined. Consolidate and reanalyzing microarray data provide key data including hub genes, biological functions, and signaling pathways, which reveal novel clues for the prognosis, diagnosis and treatment of GC.

In this investigation, we extracted the RNA-seq data of GSE113255 from the GEO dataset with high-quality data and clinical characters. A total of 1008 DEGs were identified following RRA analysis, including 505 up and 503 down regulated genes. Genes such as COL4A1 [66], INHBA (inhibin subunit beta A) [67], RCC2 [68], THY1 [69], ADH7 [70], ATP4A [71], MAL (mal, T cell differentiation protein) [72] and ATP4B [73] were linked with development of GC. Polymorphic 
gene MSR1 was liable for advancement of prostate cancer [74], but this polymorphic gene may be involved in development of GC. Increases expression of CCKAR (cholecystokinin A receptor) was responsible for pathogenesis of gallbladder cancer [75], but over expression this gene may be important for advancement for GC.

To explore the possible role of up and down regulated genes in GC, we performed pathway enrichment analysis. Enriched up regulated genes such as TYMP (thymidine phosphorylase) [76], COL1A1 [77], COL1A2 [78], COL6A3 [79], FN1 [80], SPP1 [81], ITGA5 [82], THBS1 [83], THBS2 [78], THBS4 [84], MMP9 [85], ADAM12 [86], MFAP2 [87], FBN1 [88], MMP1 [89], MMP3 [90], MMP7 [91], MMP11 [92], MMP14 [93], MMP16 [94], NID2 [95], COL10A1 [96], COL11A1 [97], COL12A1 [98], ADAMTS2 [99], ICAM1 [100], VCAN (versican) [101], CTSK (cathepsin K) [102], HTRA1 [103], ASPN (asporin) [101], P4HA3 [104], BGN (biglycan) [105], BMP1 [106], ADAMTS9 [107], SERPINH1 [108], TIMP1 [109], LOXL2 [110], SERPINE1 [111], LTBP2 [112], LUM (lumican) [113], CLEC5A [114], EMILIN2 [115], SERPINB5 [116], SERPINE2 [117], MGP (matrix Gla protein) [118], AEBP1 [119], SPON2 [120], AGT (angiotensinogen) [121], CXCL9 [122] CTHRC1 [123], CCL3 [124], PLAU (plasminogen activator, urokinase) [125], C1QTNF6 [126], CCL18 [127], CXCL6 [128], SFRP2 [129], ANGPT2 [130], GDF15 [131], WNT2 [132], IGFBP7 [133], IL6 [134], IL11 [135], SPOCK1 [136], FNDC1 [137], SRPX2 [138], SULF2 [139], SULF1 [140], PLXDC1 [141], MUC16 [142], ESM1 [143], CXCL1 [144], TGFBI (transforming growth factor beta induced) [145], OSM (oncostatin M) [146], ANGPTL2 [147], FSTL1 [148], HMCN1 [149], PLXNC1 [150], GREM1 [151] and ITGBL1 [152] were involved in development of GC. Enriched up regulated genes such as COL4A2 [153], ITGA11 [154], LAMA5 [155], COL5A2 [156], ADAMTS4 [157], ADAMTS14 [158], ANXA13 [159], HTRA3 [160] and ADAMTS12 [161] were responsible for invasion of various types of cancer cells, but these genes may be associated with invasion of GC cells. Enriched up regulated genes such as COMP (cartilage oligomeric matrix protein) [162], TNC (tenascin C) [163], ITGB8 [164], FSTL3 [165] and PLXNA1 [166] were important for proliferation of many cancer cells types, but these genes may be liable for proliferation of GC cells. High expression of enriched genes such as COL3A1 [167], COL5A1 [168], COL7A1 [169], COL8A1 [170], CTSB (cathepsin B) 
[171], ELN (elastin) [172], CD109 [173], SERPINB9 [174], BMP8A [175], SEMA6B [176], MXRA5 [177], SFRP4 [178], CHRDL2 [179], CST1 [180], HAPLN3 [181], PXDN (peroxidasin) [182] and TGM2 [183] were liable for progression of many cancer types, but over expression of these genes may be responsible for pathogenesis of GC. Polymorphic gene COL18A1 was associated with progression of breast cancer [184], but this polymorphic gene may be linked with development of GC. Methylation inactivation of CPS1 was linked with development of hepatocellular carcinoma [185], but inactivation of this gene may be culpable for progression of GC. PGF (placental growth factor) was linked with angiogenesis in hepatocellular carcinoma [186], but this gene may be involved in angiogenesis in GC. Our investigation established that UPP1, ACTN1, ACAN (aggrecan), COL15A1, COL16A1, COL5A3, SPARC (secreted protein acidic and cysteine rich), ITGAX (integrin subunit alpha X), PCOLCE (procollagen Cendopeptidase enhancer), CAD (carbamoyl-phosphate synthetase 2, aspartate transcarbamylase, and dihydroorotase), CLEC7A, CRISPLD1, OMD (osteomodulin), LIF (LIF interleukin 6 family cytokine), PLXDC2, LGI2, TNFAIP6, PARVG (parvin gamma) and SDS (serine dehydratase) are up regulated in $\mathrm{GC}$ and has possible as a new diagnostic and prognostic biomarker, and therapeutic target. Enriched down regulated genes such as AKR1C3 [187], AKR1C2 [188], ADH1C [189], CYP2C19 [190], CYP3A4 [191], CYP3A5 [191], GSTA1 [192], GSTA3 [193], FOXA1 [194], FOXA2 [195], TTR (transthyretin) [196], ALDOB (aldolase, fructose-bisphosphate B) [197], APOA1 [198], ALDH1A1 [199], FBP2 [200], S100P [201], CCL28 [202], FGA (fibrinogen alpha chain) [193], FGB (fibrinogen beta chain) [203], FGG (fibrinogen gamma chain) [193], IGFBP2 [204], SCUBE2 [205], PDGFD (platelet derived growth factor D) [206], CTSE (cathepsin E) [207], MUC1 [208], MUC6 [209], SERPINB7 [210], NRG4 [211], SEMA3B [212], MUC5B [213], ANXA10 [214], REG3A [215], HRH2 [216], SST (somatostatin) [217] and CCKBR (cholecystokinin B receptor) [218] were associated with advancement of GC. Enriched down regulated genes such as AKR1C1 [219], MAOA (monoamine oxidase A) [220], ALDH3A1 [221], UGT1A10 [222], CYP2S1 [223], ME1 [224], FBP1 [225], GPT (glutamic--pyruvic transaminase) [226], COL2A1 [227], COL17A1 [228], HYAL1 [229], CSTA (cystatin A) [230], ADAM28 [231], BMP5 [232], ANGPTL3 [233], DPT (dermatopontin) [234] and APOBEC1 [235] were linked with invasion of many types of cancer cells, but these genes may be involved in invasion of GC cells. 
Enriched polymorphic genes such as UGT1A6 [236], CYP2C8 [237], CYP2C9 [238], GSTA2 [239], SULT2A1 [240], ADAMTSL1 [241], SERPINA5 [242] and APOC3 [243] were important for pathogenesis of many cancer types, but these polymorphic genes may be responsible for development of GC. Low expression of enriched genes such as AKR7A3 [244], ALDOC (aldolase, fructose-bisphosphate C) [245], SERPINA4 [246], ADAMTS15 [247], CCBE1 [248] and CLEC3B [249] were liable for progression of many cancer types, but decrease expression of these genes may be responsible for advancement of GC. Methylation inactivation of CXCL14 was linkes with progression of colorectal cancer [250], but loss of this gene may be key foe development of GC. Our investigation established that FMO5, FOXA3, CMBL (carboxymethylenebutenolidase homolog), AADAC (arylacetamidedeacetylase), GGT6, CYP4F12, CYP2C18, ACSM1, SULT1B1, SULT1C2, LGALS9C, COL6A5, F13A1, PAPPA2, COL4A6, HAPLN1, IGFALS (insulin like growth factor binding protein acid labile subunit), SLPI (secretory leukocyte peptidase inhibitor), LGALS9B and APOA4 are down regulated in GC and has possible as a new diagnostic and prognostic biomarker, and therapeutic target.

To explore the possible role of up and down regulated genes in GC, we performed GO enrichment analysis. Methylation inactivation of enriched up regulated genes such as ABCA1 [251], FLRT2 [252] and CDH13 [253] were liable for progression of many cancer types, but inactivation of these genes may be involved in growth of GC. Enriched up regulated genes such as FAP (fibroblast activation protein alpha) [254], ANTXR1 [255], FOXC1 [256], OLFML2B [257], APOC1 [258], APOE (apolipoprotein E) [259], PDPN (podoplanin) [260], FSCN1 [261], NOTCH1 [262], TNFRSF11B [263], CHI3L1 [264] and CD248 [265] were responsible for progression of GC. LIPG (lipase G, endothelial type) was liable for proliferation of breast cancer [266], but this gene may be liable for proliferation of GC cells. Enriched up regulated genes such as CCDC80 [267], PLA2G7 [268] and ENTPD1 [269] were associated with invasion of many types of cancer cells, but these genes may be linked with invasion of GC cells. Our investigation established that SH3PXD2B, CPZ (carboxypeptidase Z) and LRRC32 are up regulated in GC and has possible as a new diagnostic and prognostic biomarker, and therapeutic target. Enriched down regulated genes such as PGC (progastricsin) [270], AQP5 [271], CAPN9 [272], VSIG1 [273], KCNQ1 [274], TFF1 [275], TFF2 [276], CD36 
[277], GKN1 [278], SCNN1B [279], FOLR1 [280], DUOX2 [281], RAB27A [282], HPGD (15-hydroxyprostaglandin dehydrogenase) [283], FA2H [284], LIPF (lipase F, gastric type) [285], GCKR (glucokinase regulator) [286], AKR1B10 [287], NQO1 [288], SELENBP1 [289] and GPX3 [290] were involved in development of GC. Enriched down regulated genes such as PBLD (phenazine biosynthesis like protein domain containing) [291], HPN (hepsin) [292], HOMER2 [293], DUOXA2 [294], SLC9A1 [295], DUOX1 [296], CA2 [297], CDH2 [298], ACADL (acyl-CoA dehydrogenase long chain) [299], PDIA2 [300], CYB5A [301], GALE (UDP-galactose-4-epimerase) [302], DHCR24 [303] and HBB (hemoglobin subunit beta) [304] were liable for invasion of many types of cancer cells, but these genes may be involved in invasion of GC cells. Low expression of enriched genes such as PTGER3 [305], RAB27B [306], ESRRB (estrogen related receptor beta) [307], ALDH6A1 [308], DHRS7 [309], LDHD (lactate dehydrogenase D) [310], DHRS9 [311] and ENTPD5 [312] were important for progression of many cancer types, but decrease expression of these genes may be responsible for advancement of GC. Enriched down regulated genes such as PRKAA2 [313], PTGR1 [314], ADHFE1 [315] and RGN (regucalcin) [316] were involved in proliferation of many types of cancer cells, but these genes may be associated with proliferation of GC cells. Our investigation established that PGA5, ASAH2, SLC26A7, CHIA (chitinase acidic), GHRL (ghrelin and obestatinprepropeptide), CAPN8, PGA3, PGA4, SLC9A4, GUCA2B, PROM2, UPK1B, SCNN1G, EPB41L4B, MYRIP (myosin VIIA and rab interacting protein), SLC26A9, SLC9A3, CDHR2, CA4, AQP10, PDZD3, HGD (homogentisate 1,2-dioxygenase), ERO1B, RDH12, AKR1B15 and TM7SF2 are down regulated in $\mathrm{GC}$ and has possible as a new diagnostic and prognostic biomarker, and therapeutic target.

The PPI network and module analysis found that DEGs were considered as up and down regulated hub genes in the network and modules. Up regulated hub genes such PLK1 [317], ANLN (anillin actin binding protein) [318], TREM2 [319], AMIGO2 [320], LEF1 [321], NOTCH3 [322], RAI14 [323], AQP1 [324], HOXB9 [325], MCM7 [326], MCM2 [327], CDC6 [328] and GINS4 [329] were liable for advancement of GC. Methylation inactivation of up regulated hub genes such as MDFI (MyoD family inhibitor) [330] and HEYL (hes related family bHLH transcription factor with YRPW motif like) [331] were involved in the progression 
of many cancer types, but inactivation of these genes may be key for advancement of GC. Increased expression of hub genes such as TREM1 [332], CYP2W1 [333], GPR161 [334], ARHGAP11A [335], APLN (apelin) [336], CBX2 [337], ORC1 [338] and MCM10 [339] were linked with development of many cancer types, but over expression of these genes may be liable for advancement of GC. Our investigation established that PRKDC (protein kinase, DNA-activated, catalytic subunitprotein kinase, DNA-activated, catalytic subunit) is up regulated in GC and has possible as a new diagnostic and prognostic biomarker, and therapeutic target. Down regulated hub genes such as SOX2 [340], EEF1A2 [341], ANG (angiogenin) [342], PTGDR2 [343], ERBB4 [344], KCNE2 [345], CA9 [346] and PSCA (prostate stem cell antigen) [347] were linked with pathogenesis of GC. Down regulated hub genes such as RIPK4 [348] and FAM3B [349] were involved in invasion of cells of many cancer types, but this gene may be associated with invasion of GC cells. Our investigation established that CNTD1, DCAF12L1, TTC39A, DUSP19, PTPRR (protein tyrosine phosphatase receptor type R) and TFR2 are down regulated in GC and has possible as a new diagnostic and prognostic biomarker, and therapeutic target.

The target genes - miRNA regulatory network analysis found that DEGs were considered as up and down regulated target genes in the network. Up regulated target genes such MYB (MYB proto-oncogene, transcription factor) [350] and SALL4 [351] were responsible for pathogenesis of GC. High expression of CLDN4 was key for progression of pancreatic cancer [352], but elevated expression this gene may be liable for progression of GC. Our investigation established that ARHGAP39 is up regulated in GC and has possible as a new diagnostic and prognostic biomarker, and therapeutic target. Down regulated target genes such as GATA6 [353] and KLF2 [354] were linked with development of GC. GLUL (glutamate-ammonia ligase) was involved in invasion of glioma cells [355], but this gene may be associated with invasion of GC cells. Our investigation established that ENPP5 is down regulated in GC and has possible as a new diagnostic and prognostic biomarker, and therapeutic target.

The target genes - TF regulatory network analysis found that DEGs were considered as up and down regulated target genes in the network. ABCA13 was responsible for advancement of GC [356]. Up regulated target geneABCD1 was associated with invasion of renal cancer cells [357], but this gene may be liable for 
invasion of GC cells. Down regulated target genes DNER (delta/notch like EGF repeat containing) [358] and IRX3 [359] were key for proliferation of many types of cancer cells, but these genes may be involved in proliferation of GC cells. CKB (creatine kinase B) was linked with progression of GC [360]. Down regulated target gene PKIB (cAMP-dependent protein kinase inhibitor beta) was important for invasion of breast cancer cells [361], but this gene may be linked with invasion of GC cells.

In our investigation, we screened FN1, PLK1, ANLN, MCM7, MCM2, EEF1A2, PTGER3, CKB, ERBB4 and PRKAA2 as important hub genes of GC by integrated bioinformatics analysis. Internal validation (survival analysis, expression analysis, stage analysis, mutation analysis, immunio infiltration analysis, immunio histochemical analysis and ROC analysis) and external validation (RT-PCR) of RNA and protein levels showed that they were higher or lower in cancerous than in normal control tissues. Over expression of the five hub genes and lower expression of the five hub genes were also associated with an advanced clinical stage and poor overall survival rate. Thus, the important hub genes explored in our investigation are likely to become a group of probale therapeutic targets of GC.

In conclusion, the current investigation identifird important hub genes linked with the various clinical stage and overall survival of GC patients. Our investigation attempts a profound perceptive of the molecular pathogensis linked with the adavancement of GC and implements probale biomarkers for early prognosis, diagnosis and individualized treatment of patients at various stages of GC.

\section{Acknowledgement}

I thank Seon-Kyu Kim, Korea Research Institutue of Bioscience \& Biotechnology, Personalized Genomic Medicine Research Center, Daejeon, South Korea, very much, the author who deposited their microarray dataset, GSE113255, into the public GEO database.

\section{Conflict of interest}


The authors declare that they have no conflict of interest.

\section{Ethical approval}

This article does not contain any studies with human participants or animals performed by any of the authors.

\section{Informed consent}

No informed consent because this study does not contain human or animals participants.

\section{Author Contributions}

Basavaraj Vastrad was associated with methodology and review and editing. Ali Chanabasayya Vastrad was performed software, supervision, formal analysis and validation.

\section{Availability of data and materials}

The datasets supporting the conclusions of this article are available in the GEO (Gene Expression Omnibus) (https://www.ncbi.nlm.nih.gov/geo/) repository. [(GSE113255) (https://www.ncbi.nlm.nih.gov/geo/query/acc.cgi?acc=GSE113255]

\section{Consent for publication}

Not applicable.

\section{Competing interests}

The authors declare that they have no competing interests.

\section{Authors}

Basavaraj Vastrtsad

ORCID ID: 0000-0003-2202-7637

Chanabasayya Vastrtsad

ORCID ID: $\underline{\text { 0000-0003-3615-4450 }}$

\section{References}

1. Ang TL, Fock KM. Clinical epidemiology of gastric cancer. Singapore Med J. 2014;55(12):621-628. doi:10.11622/smedj.2014174 
2. Rawla P, Barsouk A. Epidemiology of gastric cancer: global trends, risk factors and prevention. Prz Gastroenterol. 2019;14(1):26-38. doi:10.5114/pg.2018.80001

3. Saka M, Katai H, Fukagawa T, Nijjar R, Sano T. Recurrence in early gastric cancer with lymph node metastasis. Gastric Cancer. 2008;11(4):214-218. doi:10.1007/s10120-008-0485-4

4. Jin X, Guan Y, Zhang Z, Wang H. Microarray data analysis on gene and miRNA expression to identify biomarkers in non-small cell lung cancer. BMC Cancer. 2020;20(1):329. doi:10.1186/s12885-020-06829-X

5. Kim JH, Shin HS, Lee SH, Lee I, Lee YS, Park JC, Kim YJ, Chung JB, Lee YC. Contrasting activity of Hedgehog and Wnt pathways according to gastric cancer cell differentiation: relevance of crosstalk mechanisms. Cancer Sci. 2010;101(2):328-335. doi:10.1111/j.1349-7006.2009.01395.x

6. Huang KH, Sung I, Fang WL, Chi CW, Yeh TS, Lee HC, Yin PH, Li AF, Wu CW, Shyr YM et al. Correlation between HGF/c-Met and Notch1 signaling pathways in human gastric cancer cells. Oncol Rep. 2018;40(1):294-302. doi:10.3892/or.2018.6447

7. Pai R, Lin C, Tran T, Tarnawski A. Leptin activates STAT and ERK2 pathways and induces gastric cancer cell proliferation. Biochem Biophys Res Commun. 2005;331(4):984-992. doi:10.1016/j.bbrc.2005.03.236

8. Peng L, Ran YL, Hu H, Yu L, Liu Q, Zhou Z, Sun YM, Sun LC, Pan J, Sun LX, et al. Secreted LOXL2 is a novel therapeutic target that promotes gastric cancer metastasis via the Src/FAK pathway. Carcinogenesis. 2009;30(10):1660-1669. doi:10.1093/carcin/bgp178

9. Lee JY, Kim HY, Kim KH, Kim SM, Jang MK, Park JY, Lee JH, Kim JH, Yoo JY. Association of polymorphism of IL-10 and TNF-A genes with gastric cancer in Korea. Cancer Lett. 2005;225(2):207-214. doi:10.1016/j.canlet.2004.11.028

10.Renault B, Calistri D, Buonsanti G, Nanni O, Amadori D, Ranzani GN. Microsatellite instability and mutations of p53 and TGF-beta RII genes in gastric cancer. Hum Genet. 1996;98(5):601-607. doi:10.1007/s004390050267

11. Shibata T, Tahara T, Hirata I, Arisawa T. Genetic polymorphism of interleukin-17A and $-17 \mathrm{~F}$ genes in gastric carcinogenesis. Hum Immunol. 2009;70(7):547-551. doi:10.1016/j.humimm.2009.04.030 
12.Bobarykina AY, Minchenko DO, Opentanova IL, Moenner M, Caro J, Esumi H, Minchenko OH. Hypoxic regulation of PFKFB-3 and PFKFB-4 gene expression in gastric and pancreatic cancer cell lines and expression of PFKFB genes in gastric cancers. Acta Biochim Pol. 2006;53(4):789-799.

13.Hu SL, Huang DB, Sun YB, Wu L, Xu WP, Yin S, Chen J, Jiang XD, Shen G. Pathobiologic implications of methylation and expression status of Runx3 and CHFR genes in gastric cancer. Med Oncol. 2011;28(2):447-454. doi:10.1007/s12032-010-9467-6

14.Barrett T, Wilhite SE, Ledoux P, Evangelista C, Kim IF, Tomashevsky M, Marshall KA, Phillippy KH, Sherman PM, Holko M et al. NCBI GEO: archive for functional genomics data sets--update. Nucleic Acids Res. 2013;41(Database issue):D991-D995. doi:10.1093/nar/gks1193

15.Kolesnikov N, Hastings E, Keays M, Melnichuk O, Tang YA, Williams E, Dylag M, Kurbatova N, Brandizi M, Burdett T et al. ArrayExpress update-simplifying data submissions. Nucleic Acids Res. 2015;43(Database issue):D1113-D1116. doi:10.1093/nar/gku1057

16. Rau A, Flister M, Rui H, Auer PL. Exploring drivers of gene expression in the Cancer Genome Atlas. Bioinformatics. 2019;35(1):62-68. doi:10.1093/bioinformatics/bty551

17. Kim SK, Kim HJ, Park JL, Heo H, Kim SY, Lee SI, Song KS, Kim WH, Kim YS. Identification of a molecular signature of prognostic subtypes in diffuse-type gastric cancer. Gastric Cancer. 2020;23(3):473-482. doi:10.1007/s10120-019-01029-4

18.Lu X, Li Y, Li X, Aisa HA. Luteolin induces apoptosis in vitro through suppressing the MAPK and PI3K signaling pathways in gastric cancer. Oncol Lett. 2017;14(2):1993 $\square$ 2000. doi:10.3892/ol.2017.6380

19.Hansen KD, Irizarry RA, Wu Z. Removing technical variability in RNA-seq data using conditional quantile normalization. Biostatistics. 2012;13(2):204216. doi:10.1093/biostatistics/kxr054

20. Ritchie ME, Phipson B, Wu DI, Hu Y, Law CW, Shi W, Smyth GK. limma powers differential expression analyses for RNA-sequencing and microarray studies. Nucleic Acids Res. 2015;43(7):e47. doi:10.1093/nar/gkv007

21.Caspi R, Billington R, Ferrer L, Foerster H, Fulcher CA, Keseler IM, Kothari A, Krummenacker M, Latendresse M, Mueller LA et al The MetaCyc database of metabolic pathways and enzymes and the BioCyc 
collection of pathway/genome databases. Nucleic Acids Res. 2016;44(D1):D471-D480. doi:10.1093/nar/gkv1164

22.Kanehisa M, Sato Y, Furumichi M, Morishima K, Tanabe M. New approach for understanding genome variations in KEGG. Nucleic Acids Res. 2019;47(D1):D590-D595. doi:10.1093/nar/gky962

23. Schaefer CF, Anthony K, Krupa S, Buchoff J, Day M, Hannay T, Buetow KH. PID: the Pathway Interaction Database. Nucleic Acids Res. 2009;37(Database issue):D674-D679. doi:10.1093/nar/gkn653

24.Fabregat A, Jupe S, Matthews L, Sidiropoulos K, Gillespie M, Garapati P, Haw R, Jassal B, Korninger F, May B et al The Reactome Pathway Knowledgebase. Nucleic Acids Res. 2018;46(D1):D649-D655. doi:10.1093/nar/gkx1132

25.Dahlquist KD, Salomonis N, Vranizan K, Lawlor SC, Conklin BR. GenMAPP, a new tool for viewing and analyzing microarray data on biological pathways. Nat Genet. 2002;31(1):19-20. doi:10.1038/ng0502-19

26. Subramanian A, Tamayo P, Mootha VK, Mukherjee S, Ebert BL, Gillette MA, Paulovich A, Pomeroy SL, Golub TR, Lander ES et al Gene set enrichment analysis: a knowledge-based approach for interpreting genomewide expression profiles. Proc Natl Acad Sci U S A. 2005;102(43):1554515550. doi:10.1073/pnas.0506580102

27.Mi H, Huang X, Muruganujan A, Tang H, Mills C, Kang D, Thomas PD. PANTHER version 11: expanded annotation data from Gene Ontology and Reactome pathways, and data analysis tool enhancements. Nucleic Acids Res. 2017;45(D1):D183-D189. doi:10.1093/nar/gkw1138

28.Petri V, Jayaraman P, Tutaj M, Hayman GT, Smith JR, De Pons J, Laulederkind SJ, Lowry TF, Nigam R, Wang SJ et al The pathway ontology - updates and applications. J Biomed Semantics. 2014;5(1):7. doi:10.1186/2041-1480-5-7

29.Jewison T, Su Y, Disfany FM, Liang Y, Knox C, Maciejewski A, Poelzer J, Huynh J, Zhou Y, Arndt D et al SMPDB 2.0: big improvements to the Small Molecule Pathway Database. Nucleic Acids Res. 2014;42(Database issue):D478-D484. doi:10.1093/nar/gkt1067

30. Chen J, Bardes EE, Aronow BJ, Jegga AG. ToppGene Suite for gene list enrichment analysis and candidate gene prioritization. Nucleic Acids Res. 2009;37(Web Server issue):W305-W311. doi:10.1093/nar/gkp427 
31.Lewis SE. The Vision and Challenges of the Gene Ontology. Methods Mol Biol. 2017;1446:291-302. doi:10.1007/978-1-4939-3743-1_21

32. Alanis-Lobato G, Andrade-Navarro MA, Schaefer MH. HIPPIE v2.0: enhancing meaningfulness and reliability of protein-protein interaction networks. Nucleic Acids Res 2017;45(D1):D408-D414. doi:10.1093/nar/gkw985

33. Orchard S, Ammari M, Aranda B, Breuza L, Briganti L, Broackes-Carter F, Campbell NH, Chavali G, Chen C, del-Toro N, et al. The MIntAct project-IntAct as a common curation platform for 11 molecular interaction databases. Nucleic Acids Res 2014;42(Database issue):D358-D363. doi:10.1093/nar/gkt1115

34.Chatr-Aryamontri A, Oughtred R, Boucher L, Rust J, Chang C, Kolas NK, O'Donnell L, Oster S, Theesfeld C, Sellam A, et al. The BioGRID interaction database: 2017 update. Nucleic Acids Res 2017;45(D1):D369D379. doi:10.1093/nar/gkw1102

35. Keshava Prasad TS, Goel R, Kandasamy K, Keerthikumar S, Kumar S, Mathivanan S, Telikicherla D, Raju R, Shafreen B, Venugopal A, et al. Human Protein Reference Database--2009 update. Nucleic Acids Res 2009;37(Database issue):D767-D772. doi:10.1093/nar/gkn892

36.Licata L, Briganti L, Peluso D, Perfetto L, Iannuccelli M, Galeota E, Sacco F, Palma A, Nardozza AP, Santonico E, et al. MINT, the molecular interaction database: 2012 update. Nucleic Acids Res 2012;40(Database issue):D857-D861. doi:10.1093/nar/gkr930

37.Isserlin R, El-Badrawi RA, Bader GD. The Biomolecular Interaction Network Database in PSI-MI 2.5. Database (Oxford). 2011;2011:baq037. doi:10.1093/database/baq037

38.Pagel P, Kovac S, Oesterheld M, Brauner B, Dunger-Kaltenbach I, Frishman G, Montrone C, Mark P, Stümpflen V, Mewes HW, et al. The MIPS mammalian protein-protein interaction database. Bioinformatics. 2005;21(6):832-834. doi:10.1093/bioinformatics/bti115

39. Salwinski L, Miller CS, Smith AJ, Pettit FK, Bowie JU, Eisenberg D. The Database of Interacting Proteins: 2004 update. Nucleic Acids Res. 2004;32(Database issue):D449-D451. doi:10.1093/nar/gkh086

40. Shannon P, Markiel A, Ozier O, Baliga NS, Wang JT, Ramage D, Amin N, Schwikowski B, Ideker T. Cytoscape: a software environment for 
integrated models of biomolecular interaction networks. Genome Res 2003;13(11):2498-2504. doi:10.1101/gr.1239303

41.Przulj N, Wigle DA, Jurisica I. Functional topology in a network of protein interactions. Bioinformatics. 2004;20(3):340-348. doi:10.1093/bioinformatics/btg415

42.Nguyen TP, Liu WC, Jordán F. Inferring pleiotropy by network analysis: linked diseases in the human PPI network. BMC Syst Biol. 2011;5:179. Published 2011 Oct 31. doi:10.1186/1752-0509-5-179

43. Shi Z, Zhang B. Fast network centrality analysis using GPUs. BMC Bioinformatics. 2011;12:149. doi:10.1186/1471-2105-12-149

44.Nguyen TP, Liu WC, Jordán F. Inferring pleiotropy by network analysis: linked diseases in the human PPI network. BMC Syst Biol. 2011;5:179. doi:10.1186/1752-0509-5-179

45.Wang J, Li M, Wang H, Pan Y. Identification of essential proteins based on edge clustering coefficient. IEEE/ACM Trans Comput Biol Bioinform. 2012;9(4):1070-1080. doi:10.1109/TCBB.2011.147

46.Zaki N, Efimov D, Berengueres J. Protein complex detection using interaction reliability assessment and weighted clustering coefficient. BMC Bioinformatics. 2013;14:163. doi:10.1186/1471-2105-14-163

47.Fan Y, Xia $\mathrm{J}$ miRNet-Functional Analysis and Visual Exploration of miRNA-Target Interactions in a Network Context. Methods Mol Biol. 2018;1819:215-233. doi:10.1007/978-1-4939-8618-7_10

48. Vlachos IS, Paraskevopoulou MD, Karagkouni D, Georgakilas G, Vergoulis T, Kanellos I, Anastasopoulos IL, Maniou S, Karathanou K, Kalfakakou D et al DIANA-TarBase v7.0: indexing more than half a million experimentally supported miRNA:mRNA interactions. Nucleic Acids Res. 2015;43(Database issue):D153-D159. doi:10.1093/nar/gku1215

49. Chou CH, Shrestha S, Yang CD, Chang NW, Lin YL, Liao KW, Huang WC, Sun TH, Tu SJ, Lee WH et al miRTarBase update 2018: a resource for experimentally validated microRNA-target interactions. Nucleic Acids Res. 2018;46(D1):D296-D302. doi:10.1093/nar/gkx1067

50.Xiao F, Zuo Z, Cai G, Kang S, Gao X, Li T. miRecords: an integrated resource for microRNA-target interactions. Nucleic Acids Res. 2009;37(Database issue):D105-D110. doi:10.1093/nar/gkn851 
51.Jiang Q, Wang Y, Hao Y, Juan L, Teng M, Zhang X, Li M, Wang G, Liu Y. miR2Disease: a manually curated database for microRNA deregulation in human disease. Nucleic Acids Res. 2009;37(Database issue):D98-104. doi:10.1093/nar/gkn714

52.Huang Z, Shi J, Gao Y, Cui C, Zhang S, Li J, Zhou Y, Cui Q. HMDD v3.0: a database for experimentally supported human microRNA-disease associations. Nucleic Acids Res. 2019;47(D1):D1013-D1017. doi:10.1093/nar/gky1010Z

53.Ruepp A, Kowarsch A, Schmidl D, Buggenthin F, Brauner B, Dunger I, Fobo G, Frishman G, Montrone C, Theis FJ. PhenomiR: a knowledgebase for microRNA expression in diseases and biological processes. Genome Biol. 2010;11(1):R6. doi:10.1186/gb-2010-11-1-r6

54.Liu X, Wang S, Meng F, Wang J, Zhang Y, Dai E, Yu X, Li X, Jiang W. SM2miR: a database of the experimentally validated small molecules' effects on microRNA expression. Bioinformatics. 2013;29(3):409-411. doi:10.1093/bioinformatics/bts698

55.Rukov JL, Wilentzik R, Jaffe I, Vinther J, Shomron N. Pharmaco-miR: linking microRNAs and drug effects. Brief Bioinform. 2014;15(4):648-659. doi:10.1093/bib/bbs082

56.Dai E, Yu X, Zhang Y, Meng F, Wang S, Liu X, Liu D, Wang J, Li X, Jiang W. EpimiR: a database of curated mutual regulation between miRNAs and epigenetic modifications. Database (Oxford). 2014;2014:bau023. doi:10.1093/database/bau023

57.Li JH, Liu S, Zhou H, Qu LH, Yang JH. starBase v2.0: decoding miRNAceRNA, miRNA-ncRNA and protein-RNA interaction networks from largescale CLIP-Seq data. Nucleic Acids Res. 2014;42(Database issue):D92-D97. doi:10.1093/nar/gkt1248

58.Zhou G, Soufan O, Ewald J, Hancock REW, Basu N, Xia J. NetworkAnalyst 3.0: a visual analytics platform for comprehensive gene expression profiling and meta-analysis. Nucleic Acids Res. 2019. doi:10.1093/nar/gkz240

59.Lachmann A, Xu H, Krishnan J, Berger SI, Mazloom AR, Ma'ayan A. ChEA: transcription factor regulation inferred from integrating genome-wide ChIP-X experiments. Bioinformatics. 2010;26(19):2438-2444. doi:10.1093/bioinformatics/btq466. 
60.Chandrashekar DS, Bashel B, Balasubramanya SAH, Creighton CJ, PonceRodriguez I, Chakravarthi BVSK, Varambally S. UALCAN: A Portal for Facilitating Tumor Subgroup Gene Expression and Survival Analyses. Neoplasia. 2017;19(8):649-658. doi:10.1016/j.neo.2017.05.002

61.Gao J, Aksoy BA, Dogrusoz U, Dresdner G, Gross B, Sumer SO, Sun Y, Jacobsen A, Sinha R, Larsson E et al Integrative analysis of complex cancer genomics and clinical profiles using the cBioPortal. Sci Signal. 2013;6(269):pl1. doi:10.1126/scisignal.2004088

62.Uhlen M, Oksvold P, Fagerberg L, Lundberg E, Jonasson K, Forsberg M, Zwahlen M, Kampf C, Wester K, Hober S et al. Towards a knowledge-based Human Protein Atlas. Nat Biotechnol. 2010;28(12):1248-1250. doi:10.1038/nbt1210-1248

63. Robin X, Turck N, Hainard A, Tiberti N, Lisacek F, Sanchez JC, Müller M. (2011) pROC: an open-source package for $\mathrm{R}$ and $\mathrm{S}+$ to analyze and compare ROC curves. BMC Bioinformatics 12:77. doi:10.1186/1471-2105-12-77

64.Livak KJ, Schmittgen TD. Analysis of relative gene expression data using real-time quantitative PCR and the 2(-Delta Delta C(T)) Method. Methods. 2001;25(4):402-408. doi:10.1006/meth.2001.1262

65.Li T, Fan J, Wang B, Traugh N, Chen Q, Liu JS, Li B, Liu XS. TIMER: A Web Server for Comprehensive Analysis of Tumor-Infiltrating Immune Cells. Cancer Res. 2017;77(21):e108-e110. doi:10.1158/0008-5472.CAN17-0307

66.Li DF, Wang NN, Chang X, Wang SL, Wang LS, Yao J, Li ZS, Bai Y. Bioinformatics analysis suggests that COL4A1 may play an important role in gastric carcinoma recurrence. J Dig Dis. 2019;20(8):391-400. doi:10.1111/1751-2980.12758

67. Katayama Y, Oshima T, Sakamaki K, Aoyama T, Sato T, Masudo K, Shiozawa M, Yoshikawa T, Rino Y, Imada T et al. Clinical Significance of INHBA Gene Expression in Patients with Gastric Cancer who Receive Curative Resection Followed by Adjuvant S-1 Chemotherapy. In Vivo. 2017;31(4):565-571. doi:10.21873/invivo.11095

68. Matsuo M, Nakada C, Tsukamoto Y, Noguchi T, Uchida T, Hijiya N, Matsuura K, Moriyama M. MiR-29c is downregulated in gastric carcinomas and regulates cell proliferation by targeting RCC2. Mol Cancer. 2013;12:15. doi:10.1186/1476-4598-12-15 
69.Wu K, Zou J, Lin C, Jie ZG. MicroRNA-140-5p inhibits cell proliferation, migration and promotes cell apoptosis in gastric cancer through the negative regulation of THY1-mediated Notch signaling. Biosci Rep. 2019;39(7):BSR20181434. doi:10.1042/BSR20181434

70.Duell EJ, Sala N, Travier N, Muñoz X, Boutron-Ruault MC, ClavelChapelon F, Barricarte A, Arriola L, Navarro C, Sánchez-Cantalejo E et al. Genetic variation in alcohol dehydrogenase (ADH1A, ADH1B, ADH1C, ADH7) and aldehyde dehydrogenase (ALDH2), alcohol consumption and gastric cancer risk in the European Prospective Investigation into Cancer and Nutrition (EPIC) cohort. Carcinogenesis. 2012;33(2):361-367. doi:10.1093/carcin/bgr285

71.Cao D, Zhao D, Jia Z, Su T, Zhang Y, Wu Y, Wu M, Tsukamoto T, Oshima $\mathrm{M}$, Jiang $\mathrm{J}$ et al. Reactivation of Atp4a concomitant with intragenic DNA demethylation for cancer inhibition in a gastric cancer model. Life Sci. 2020;242:117214. doi:10.1016/j.lfs.2019.117214

72.Choi B, Han TS, Min J, Hur K, Lee SM, Lee HJ, Kim YJ, Yang HK. MAL and TMEM220 are novel DNA methylation markers in human gastric cancer. Biomarkers. 2017;22(1):35-44. doi:10.1080/1354750X.2016.1201542

73.Lin S, Lin B, Wang X, Pan Y, Xu Q, He JS, Gong W, Xing R, He Y, Guo L, et al. Silencing of ATP4B of ATPase H+/K+ Transporting Beta Subunit by Intragenic Epigenetic Alteration in Human Gastric Cancer Cells. Oncol Res. 2017;25(3):317-329. doi:10.3727/096504016X14734735156265

74. Beuten J, Gelfond JA, Franke JL, Shook S, Johnson-Pais TL, Thompson IM, Leach RJ. ingle and multivariate associations of MSR1, ELAC2, and RNASEL with prostate cancer in an ethnic diverse cohort of men. Cancer Epidemiol Biomarkers Prev. 2010;19(2):588-599. doi:10.1158/10559965.EPI-09-0864

75.Kazmi HR, Chandra A, Baghel K, Singh A, Nigam J, Parmar D, Mahdi AA, Goel SK, Kumar S. Differential expression of cholecystokinin A receptor in gallbladder cancer in the young and elderly suggests two subsets of the same disease?. Biomed Res Int. 2014;2014:625695. doi:10.1155/2014/625695

76.Huang L, Liu S, Lei Y, Wang K, Xu M, Chen Y, Liu B, Chen Y, Fu Q, Zhang $\mathrm{P}$, et al. Systemic immune-inflammation index, thymidine phosphorylase and survival of localized gastric cancer patients after curative 
resection. Oncotarget. 2016;7(28):44185-44193. doi:10.18632/oncotarget.9923

77. Shi Y, Duan Z, Zhang X, Zhang X, Wang G, Li F. Down-regulation of the let-7i facilitates gastric cancer invasion and metastasis by targeting COL1A1. Protein Cell. 2019;10(2):143-148. doi:10.1007/s13238-018-05507

78.Ao R, Guan L, Wang Y, Wang JN. Silencing of COL1A2, COL6A3, and THBS2 inhibits gastric cancer cell proliferation, migration, and invasion while promoting apoptosis through the PI3k-Akt signaling pathway. J Cell Biochem. 2018;119(6):4420-4434. doi:10.1002/jcb.26524

79. Sun $X$, Zhang $X$, Zhai H, Zhang D, Ma S. A circular RNA derived from COL6A3 functions as a ceRNA in gastric cancer development. Biochem Biophys Res Commun. 2019;515(1):16-23. doi:10.1016/j.bbrc.2019.05.079

80.Jiang K, Liu H, Xie D, Xiao Q. Differentially expressed genes ASPN, COL1A1, FN1, VCAN and MUC5AC are potential prognostic biomarkers for gastric cancer. Oncol Lett. 2019;17(3):3191-3202. doi:10.3892/ol.2019.9952

81.Song SZ, Lin S, Liu JN, Zhang MB, Du YT, Zhang DD, Xu WH, Wang HB. Targeting of SPP1 by microRNA-340 inhibits gastric cancer cell epithelialmesenchymal transition through inhibition of the PI3K/AKT signaling pathway. J Cell Physiol. 2019;234(10):18587-18601. doi:10.1002/jcp.28497

82.Zhang XB, Song L, Wen HJ, Bai XX, Li ZJ, Ma LJ. Upregulation of microRNA-31 targeting integrin $\alpha 5$ suppresses tumor cell invasion and metastasis by indirectly regulating PI3K/AKT pathway in human gastric cancer SGC7901 cells. Tumour Biol. 2016;37(6):8317-8325. doi:10.1007/s13277-015-4511-y

83.Hong BB, Chen SQ, Qi YL, Zhu JW, Lin JY. Association of THBS1 rs1478605 $\mathrm{T}>\mathrm{C}$ in 5'-untranslated regions with the development and progression of gastric cancer. Biomed Rep. 2015;3(2):207-214. doi:10.3892/br.2015.414

84.Chen X, Huang Y, Wang Y, Wu Q, Hong S, Huang Z. THBS4 predicts poor outcomes and promotes proliferation and metastasis in gastric cancer. $\mathbf{J}$ Physiol Biochem. 2019;75(1):117-123. doi:10.1007/s13105-019-00665-9

85. Kang MH, Oh SC, Lee HJ, Kang HN, Kim JL, Kim JS, Yoo YA. Metastatic function of BMP-2 in gastric cancer cells: the role of PI3K/AKT, MAPK, 
the NF- $\kappa$ B pathway, and MMP-9 expression. Exp Cell Res. 2011;317(12):1746-1762. doi:10.1016/j.yexcr.2011.04.006

86. Shimura T, Dagher A, Sachdev M, Ebi M, Yamada T, Yamada T, Joh T, Moses MA. Urinary ADAM12 and MMP-9/NGAL complex detect the presence of gastric cancer. Cancer Prev Res (Phila). 2015;8(3):240-248. doi:10.1158/1940-6207.CAPR-14-0229

87. Yao LW, Wu LL, Zhang LH, Zhou W, Wu L, He K, Ren JC, Deng YC, Yang DM, Wang $\mathrm{J}$ et al. MFAP2 is overexpressed in gastric cancer and promotes motility via the MFAP2/integrin $\alpha 5 \beta 1 /$ FAK/ERK pathway. Oncogenesis. 2020;9(2):17. doi:10.1038/s41389-020-0198-Z

88. Yang D, Zhao D, Chen X. MiR-133b inhibits proliferation and invasion of gastric cancer cells by up-regulating FBN1 expression. Cancer Biomark. 2017;19(4):425-436. doi:10.3233/CBM-160421

89.Holmberg C, Ghesquière B, Impens F, Gevaert K, Kumar JD, Cash N, Kandola S, Hegyi P, Wang TC, Dockray GJ et al. Mapping proteolytic processing in the secretome of gastric cancer-associated myofibroblasts reveals activation of MMP-1, MMP-2, and MMP-3. J Proteome Res. 2013;12(7):3413-3422. doi:10.1021/pr400270q

90.Dey S, Stalin S, Gupta A, Saha D, Kesh K, Swarnakar S. Matrix metalloproteinase 3 gene promoter polymorphisms and their haplotypes are associated with gastric cancer risk in eastern Indian population. Mol Carcinog. 2012;51 Suppl 1:E42-E53. doi:10.1002/mc.21837

91.Liu G, Jiang C, Li D, Wang R, Wang W. MiRNA-34a inhibits EGFRsignaling-dependent MMP7 activation in gastric cancer. Tumour Biol. 2014;35(10):9801-9806. doi:10.1007/s13277-014-2273-6

92.Xu G, Zhang B, Ye J, Cao S, Shi J, Zhao Y, Wang Y, Sang J, Yao Y, Guan $\mathrm{W}$ et al. Exosomal miRNA-139 in cancer-associated fibroblasts inhibits gastric cancer progression by repressing MMP11 expression. Int J Biol Sci. 2019;15(11):2320-2329. doi:10.7150/ijbs.33750

93.Zheng L, Chen Y, Ye L, Jiao W, Song H, Mei H, Li D, Yang F, Li H, Huang $\mathrm{K}$ et al. miRNA-584-3p inhibits gastric cancer progression by repressing Yin Yang 1- facilitated MMP-14 expression. Sci Rep. 2017;7(1):8967. doi:10.1038/s41598-017-09271-5

94.Cao L, Chen C, Zhu H, Gu X, Deng D, Tian X, Liu J, Xiao Q. MMP16 is a marker of poor prognosis in gastric cancer promoting proliferation and 
invasion.

Oncotarget.

2016;7(32):51865-51874.

doi:10.18632/oncotarget.10177

95.Yu ZH, Wang YM, Jiang YZ, Ma SJ, Zhong Q, Wan YY, Wang XW.. NID2 can serve as a potential prognosis prediction biomarker and promotes the invasion and migration of gastric cancer. Pathol Res Pract. 2019;215(10):152553. doi:10.1016/j.prp.2019.152553

96.Li T, Huang H, Shi G, Zhao L, Li T, Zhang Z, Liu R, Hu Y, Liu H, Yu J, et al. TGF- $31-S O X 9$ axis-inducible COL10A1 promotes invasion and metastasis in gastric cancer via epithelial-to-mesenchymal transition. Cell Death Dis. 2018;9(9):849. doi:10.1038/s41419-018-0877-2

97.Li A, Li J, Lin J, Zhuo W, Si J. COL11A1 is overexpressed in gastric cancer tissues and regulates proliferation, migration and invasion of HGC-27 gastric cancer cells in vitro. Oncol Rep. 2017;37(1):333-340. doi:10.3892/or.2016.5276

98.Jiang X, Wu M, Xu X, Zhang L, Huang Y, Xu Z, He K, Wang H, Wang H, Teng L. COL12A1, a novel potential prognostic factor and therapeutic target in gastric cancer. Mol Med Rep. 2019;20(4):3103-3112. doi:10.3892/mmr.2019.10548

99.Jiang C, Zhou Y, Huang Y, Wang Y, Wang W, Kuai X. Overexpression of ADAMTS-2 in tumor cells and stroma is predictive of poor clinical prognosis in gastric cancer. Hum Pathol. 2019;84:44-51. doi:10.1016/j.humpath.2018.08.030

100. Dong Z, Fu S, Xu X, Yang Y, Du L, Li W, Kan S, Li Z, Zhang X, Wang $L$ et al. Leptin-mediated regulation of ICAM-1 is Rho/ROCK dependent and enhances gastric cancer cell migration. $\mathrm{Br} \mathrm{J}$ Cancer. 2014;110(7):1801-1810. doi:10.1038/bjc.2014.70

101. Jiang K, Liu H, Xie D, Xiao Q. Differentially expressed genes ASPN, COL1A1, FN1, VCAN and MUC5AC are potential prognostic biomarkers for gastric cancer. Oncol Lett. 2019;17(3):3191-3202. doi:10.3892/ol.2019.9952

102. Ren G, Tian Q, An Y, Feng B, Lu Y, Liang J, Li K, Shang Y, Nie Y, Wang $\mathrm{X}$ et al. Coronin 3 promotes gastric cancer metastasis via the upregulation of MMP-9 and cathepsin K. Mol Cancer. 2012;11:67. doi:10.1186/1476-4598-11-67 
103. Wu H, Ma S, Xiang M, Tong S. HTRA1 promotes transdifferentiation of normal fibroblasts to cancer-associated fibroblasts through activation of the NF- $\kappa \mathrm{B} / \mathrm{bFGF}$ signaling pathway in gastric cancer. Biochem Biophys Res Commun. 2019;514(3):933-939. doi:10.1016/j.bbrc.2019.05.076

104. Song H, Liu L, Song Z, Ren Y, Li C, Huo J. P4HA3 is Epigenetically Activated by Slug in Gastric Cancer and its Deregulation is Associated With Enhanced Metastasis and Poor Survival. Technol Cancer Res Treat. 2018;17:1533033818796485. doi:10.1177/1533033818796485

105. Hu L, Duan YT, Li JF, Su LP, Yan M, Zhu ZG, Liu BY, Yang QM. Biglycan enhances gastric cancer invasion by activating FAK signaling pathway. Oncotarget. 2014;5(7):1885-1896. doi:10.18632/oncotarget.1871

106. Hsieh YY, Tung SY, Pan HY, Yen CW, Xu HW, Deng YF, Lin YJ, Hsu WT, Wu CS, Li C. Upregulation of bone morphogenetic protein 1 is associated with poor prognosis of late-stage gastric Cancer patients. BMC Cancer. 2018;18(1):508. doi:10.1186/s12885-018-4383-9

107. Cao B, Liu C, Yang G. Down-regulation of lncRNA ADAMTS9-AS2 contributes to gastric cancer development via activation of PI3K/Akt pathway. Biomed Pharmacother. 2018;107:185-193. doi:10.1016/j.biopha.2018.06.146

108. Kawagoe K, Wada M, Idichi T, Okada R, Yamada Y, Moriya S, Okubo K, Matsushita D, Arigami T, Kurahara $\mathrm{H}$ et al. Regulation of aberrantly expressed SERPINH1 by antitumor miR-148a-5p inhibits cancer cell aggressiveness in gastric cancer. J Hum Genet. 2020;10.1038/s10038020-0746-6. doi:10.1038/s10038-020-0746-6

109. Cai QW, Li J, Li XQ, Wang JQ, Huang Y. Expression of STAT3, MMP-1 and TIMP-1 in gastric cancer and correlation with pathological features. Mol Med Rep. 2012;5(6):1438-1442. doi:10.3892/mmr.2012.849

110. Kasashima H, Yashiro M, Kinoshita H, Fukuoka T, Morisaki T, Masuda G, Sakurai K, Kubo N, Ohira M, Hirakawa K. Lysyl oxidase-like 2 (LOXL2) from stromal fibroblasts stimulates the progression of gastric cancer. Cancer Lett. 2014;354(2):438-446. doi:10.1016/j.canlet.2014.08.014 111. Liao P, Li W, Liu R, Teer JK, Xu B, Zhang W, Li X, Mcleod HL, He Y. Genome-scale analysis identifies SERPINE1 and SPARC as diagnostic and prognostic biomarkers in gastric cancer. Onco Targets Ther. 2018;11:6969-6980. doi:10.2147/OTT.S173934 
112. Wang J, Liang WJ, Min GT, Wang HP, Chen W, Yao N. LTBP2 promotes the migration and invasion of gastric cancer cells and predicts poor outcome of patients with gastric cancer. Int J Oncol. 2018;52(6):1886-1898. doi:10.3892/ijo.2018.4356

113. Chen L, Zhang Y, Zuo Y, Ma F, Song H. Lumican expression in gastric cancer and its association with biological behavior and prognosis. Oncol Lett. 2017;14(5):5235-5240. doi:10.3892/ol.2017.6842

114. Wang Q, Shi M, Sun S, Zhou Q, Ding L, Jiang C, Bian T, Jia F, Liu Y, Qin J. CLEC5A promotes the proliferation of gastric cancer cells by activating the PI3K/AKT/mTOR pathway. Biochem Biophys Res Commun. 2020;524(3):656-662. doi:10.1016/j.bbrc.2019.10.122

115. Andreuzzi E, Capuano A, Pellicani R, Poletto E, Doliana R, Maiero S, Fornasarig M, Magris R, Colombatti A, Cannizzaro R, et al. Loss of Multimerin-2 and EMILIN-2 Expression in Gastric Cancer Associate with Altered Angiogenesis. Int J Mol Sci. 2018;19(12):3983. Published 2018 Dec 11. doi:10.3390/ijms 19123983

116. Lei KF, Liu BY, Wang YF, Chen XH, Yu BQ, Guo Y, Zhu ZG. SerpinB5 interacts with KHDRBS3 and FBXO32 in gastric cancer cells. Oncol Rep. 2011;26(5):1115-1120. doi:10.3892/or.2011.1369

117. Wang K, Wang B, Xing AY, Xu KS, Li GX, Yu ZH. Prognostic significance of SERPINE2 in gastric cancer and its biological function in SGC7901 cells. J Cancer Res Clin Oncol. 2015;141(5):805-812. doi:10.1007/s00432-014-1858-1

118. Wang M, Chen L, Chen Y, Wei R, Guo Q, Zhu S, Guo S, Zhu S, Zhang S, Min L. Intracellular matrix Gla protein promotes tumor progression by activating JAK2/STAT5 signaling in gastric. Mol Oncol. 2020;10.1002/1878-0261.12652. doi:10.1002/1878-0261.12652

119. Liu JY, Jiang L, Liu JJ, He T, Cui YH, Qian F, Yu PW. AEBP1 promotes epithelial-mesenchymal transition of gastric cancer cells by activating the NF- $\kappa \mathrm{B}$ pathway and predicts poor outcome of the patients. Sci Rep. 2018;8(1):11955. doi:10.1038/s41598-018-29878-6

120. Lu H, Feng Y, Hu Y, Guo Y, Liu Y, Mao Q, Xue W. Spondin 2 promotes the proliferation, migration and invasion of gastric cancer cells. J Cell Mol Med. 2020;24(1):98-113. doi:10.1111/jcmm.14618 
121. Shibata T, Tahara T, Arisawa T, Hirata I. Polymorphism of the salt sensitivity gene angiotensinogen and gastric cancer risk. Mol Med Rep. 2011;4(4):723-726. doi:10.3892/mmr.2011.495

122. Zhang C, Li Z, Xu L, Che X, Wen T, Fan Y, Li C, Wang S, Cheng Y, Wang X et al. CXCL9/10/11, a regulator of PD-L1 expression in gastric cancer. BMC Cancer. 2018;18(1):462. doi:10.1186/s12885-018-4384-8

123. Yu J, Feng J, Zhi X, Tang J, Li Z, Xu Y, Yang L, Hu Z, Xu Z. Let-7b inhibits cell proliferation, migration, and invasion through targeting Cthrc1 in gastric cancer. Tumour Biol. 2015;36(5):3221-3229. doi:10.1007/s13277014-2950-5

124. He S, Wang L, Wu Y, Li D, Zhang Y. CCL3 and CCL20-recruited dendritic cells modified by melanoma antigen gene-1 induce anti-tumor immunity against gastric cancer ex vivo and in vivo. J Exp Clin Cancer Res. 2010;29(1):37. doi:10.1186/1756-9966-29-37

125. Wu CY, Wu MS, Chen YJ, Chen HP, Chen CJ, Chang CS, Lin JT. Clinicopathological significance of urokinase-type plasminogen activator genotypes in gastric cancer. Hepatogastroenterology. 2008;55(86-87):18901894.

126. Qu HX, Cui L, Meng XY, Wang ZJ, Cui YX, Yu YP, Wang D, Jiang XJ. C1QTNF6 is overexpressed in gastric carcinoma and contributes to the proliferation and migration of gastric carcinoma cells. Int $\mathrm{J}$ Mol Med. 2019;43(1):621-629. doi:10.3892/ijmm.2018.3978

127. Hou X, Zhang Y, Qiao H. CCL18 promotes the invasion and migration of gastric cancer cells via ERK1/2/NF- $\kappa \mathrm{B}$ signaling pathway. Tumour Biol. 2016;37(1):641-651. doi:10.1007/s13277-015-3825-0

128. Yamamoto Y, Kuroda K, Sera T, Sugimoto A, Kushiyama S, Nishimura S, Togano S, Okuno T, Yoshii M, Tamura $T$, et al. The Clinicopathological Significance of the CXCR2 Ligands, CXCL1, CXCL2, CXCL3, CXCL5, CXCL6, CXCL7, and CXCL8 in Gastric Cancer. Anticancer Res. 2019;39(12):6645-6652. doi:10.21873/anticanres.13879 129. Wang $\mathrm{H}$, Duan XL, Qi XL, Meng L, Xu YS, Wu T, Dai PG. Concurrent Hypermethylation of SFRP2 and DKK2 Activates the Wnt/ $\beta$ Catenin Pathway and Is Associated with Poor Prognosis in Patients with Gastric Cancer. Mol Cells. 2017;40(1):45-53. doi:10.14348/molcells.2017.2245 
130. Chen Z, Zhu S, Hong J, Soutto M, Peng D, Belkhiri A, Xu Z, El-Rifai W. Gastric tumour-derived ANGPT2 regulation by DARPP-32 promotes angiogenesis. Gut. 2016;65(6):925-934. doi:10.1136/gutjnl-2014-308416

131. Han M, Dai D, Yousafzai NA, Wang F, Wang H, Zhou Q, Lu H, Xu W, Feng L, Jin $\mathrm{H}$ et al. CXXC4 activates apoptosis through up-regulating GDF15 in gastric cancer. Oncotarget. 2017;8(61):103557-103567. doi:10.18632/oncotarget.21581

132. Zhang Z, Wang J, Dong X. Wnt2 contributes to the progression of gastric cancer by promoting cell migration and invasion. Oncol Lett. 2018;16(3):2857-2864. doi:10.3892/ol.2018.9050

133. Kim J, Kim WH, Byeon SJ, Lee BL, Kim MA. Epigenetic Downregulation and Growth Inhibition of IGFBP7 in Gastric Cancer. Asian Pac J Cancer Prev. 2018;19(3):667-675. Published 2018 Mar 27. doi:10.22034/APJCP.2018.19.3.667

134. Wu X, Tao P, Zhou Q, Li J, Yu Z, Wang X, Li J, Li C, Yan M, Zhu Z, et al. IL-6 secreted by cancer-associated fibroblasts promotes epithelialmesenchymal transition and metastasis of gastric cancer via JAK2/STAT3 signaling pathway. Oncotarget. 2017;8(13):20741-20750. doi:10.18632/oncotarget.15119

135. Ma J, Song X, Xu X, Mou Y. Cancer-Associated Fibroblasts Promote the Chemo-resistance in Gastric Cancer through Secreting IL-11 Targeting JAK/STAT3/Bcl2 Pathway. Cancer Res Treat. 2019;51(1):194-210. doi:10.4143/crt.2018.031

136. Chen D, Zhou H, Liu G, Zhao Y, Cao G, Liu Q. SPOCK1 promotes the invasion and metastasis of gastric cancer through Slug-induced epithelial-mesenchymal transition. J Cell Mol Med. 2018;22(2):797-807. doi: $10.1111 /$ jcmm.13357

137. Liu YP, Chen WD, Li WN, Zhang M. Overexpression of FNDC1 Relates to Poor Prognosis and Its Knockdown Impairs Cell Invasion and Migration in Gastric Cancer. Technol Cancer Res Treat. 2019;18:1533033819869928. doi:10.1177/1533033819869928

138. Yamada T, Oshima T, Yoshihara K, Sato T, Nozaki A, Shiozawa M, Ota M, Yoshikawa T, Akaike M, Numata K, et al. Impact of overexpression of Sushi repeat-containing protein X-linked 2 gene on outcomes of gastric cancer. J Surg Oncol. 2014;109(8):836-840. doi:10.1002/jso.23602 
139. Wang L, Xie L, Wang J, Shen J, Liu B. Correlation between the methylation of SULF2 and WRN promoter and the irinotecan chemosensitivity in gastric cancer. BMC Gastroenterol. 2013;13:173. doi:10.1186/1471-230X-13-173

140. Hur K, Han TS, Jung EJ, Yu J, Lee HJ, Kim WH, Goel A, Yang HK. Up-regulated expression of sulfatases (SULF1 and SULF2) as prognostic and metastasis predictive markers in human gastric cancer. J Pathol. 2012;228(1):88-98. doi:10.1002/path.4055

141. Zhang ZZ, Hua R, Zhang JF, Zhao WY, Zhao EH, Tu L, Wang CJ, Cao H, Zhang ZG. TEM7 (PLXDC1), a key prognostic predictor for resectable gastric cancer, promotes cancer cell migration and invasion. Am J Cancer Res. 2015;5(2):772-781.

142. Li X, Pasche B, Zhang W, Chen K. Association of MUC16 Mutation With Tumor Mutation Load and Outcomes in Patients With Gastric Cancer. JAMA Oncol. 2018;4(12):1691-1698. doi:10.1001/jamaoncol.2018.2805

143. Lv Z, Fan Y, Chen H, Zhao D. Endothelial cell-specific molecule-1: a potential serum marker for gastric cancer. Tumour Biol. 2014;35(10):10497-10502. doi:10.1007/s13277-014-2319-9

144. Shrestha S, Yang CD, Hong HC, Chou CH, Tai CS, Chiew MY, Chen WL, Weng SL, Chen CC, Chang YA et al. Integrated MicroRNA-mRNA Analysis Reveals miR-204 Inhibits Cell Proliferation in Gastric Cancer by Targeting CKS1B, CXCL1 and GPRC5A. Int J Mol Sci. 2017;19(1):87. doi:10.3390/ijms19010087

145. Suzuki M, Yokobori T, Gombodorj N, Yashiro M, Turtoi A, Handa T, Ogata K, Oyama T, Shirabe K, Kuwano H. High stromal transforming growth factor $\beta$-induced expression is a novel marker of progression and poor prognosis in gastric cancer. J Surg Oncol. 2018;118(6):966-974. doi:10.1002/jso.25217

146. Yu Z, Li Z, Wang C, Pan T, Chang X, Wang X, Zhou Q, Wu X, Li J, Zhang J, et al. Oncostatin $M$ receptor, positively regulated by SP1, promotes gastric cancer growth and metastasis upon treatment with Oncostatin M. Gastric Cancer. 2019;22(5):955-966. doi:10.1007/s10120-019-00934-y

147. Sheng WZ, Chen YS, Tu CT, He J, Zhang B, Gao WD. ANGPTL2 expression in gastric cancer tissues and cells and its biological behavior. 
World J $\quad$ Gastroenterol. 2016;22(47):10364-10370. doi:10.3748/wjg.v22.i47.10364

148. Peng X, Wang P, Li S, Jiang Y, Wu C. Follistatin $\square$ like protein 1 knockdown elicits human gastric cancer cell apoptosis via a STAT6 $\square$ dependent pathway. Oncol Rep. 2019;42(6):2806-2813. doi:10.3892/or.2019.7334

149. Lee SH, Je EM, Yoo NJ, Lee SH. HMCN1, a cell polarity-related gene, is somatically mutated in gastric and colorectal cancers. Pathol Oncol Res. 2015;21(3):847-848. doi:10.1007/s12253-014-9809-3

150. Chen J, Liu H, Chen J, Sun B, Wu J, Du C. PLXNC1 Enhances Carcinogenesis Through Transcriptional Activation of IL6ST in Gastric Cancer. Front Oncol. 2020;10:33. doi:10.3389/fonc.2020.00033

151. Sun Z, Cai S, Liu C, Cui Y, Ji J, Jiang WG, Ye L. Increased Expression of Gremlin1 Promotes Proliferation and Epithelial Mesenchymal Transition in Gastric Cancer Cells and Correlates With Poor Prognosis of Patients With Gastric Cancer. Cancer Genomics Proteomics. 2020;17(1):4960. doi:10.21873/cgp.20167

152. Li R, Zhuang C, Jiang S, Du N, Zhao W, Tu L, Cao H, Zhang Z, Chen X. ITGBL1 Predicts a Poor Prognosis and Correlates EMT Phenotype in Gastric Cancer. J Cancer. 2017;8(18):3764-3773. doi:10.7150/jca.20900

153. JingSong H, Hong G, Yang J, Duo Z, Li F, WeiCai C, XueYing L, YouSheng $\mathrm{M}$, YiWen $\mathrm{O}$, Yue $\mathrm{P}$ et al. siRNA-mediated suppression of collagen type iv alpha 2 (COL4A2) mRNA inhibits triple-negative breast cancer cell proliferation and migration. Oncotarget. 2017;8(2):2585-2593. doi:10.18632/oncotarget.13716

154. Wu P, Wang Y, Wu Y, Jia Z, Song Y, Liang N. Expression and prognostic analyses of ITGA11, ITGB4 and ITGB8 in human non-small cell lung cancer. PeerJ. 2019;7:e8299. doi:10.7717/peerj.8299

155. Gordon-Weeks A, Lim SY, Yuzhalin A, Lucotti S, Vermeer JA, Jones K, Chen J, Muschel RJ. Tumour-Derived Laminin a5 (LAMA5) Promotes Colorectal Liver Metastasis Growth, Branching Angiogenesis and Notch Pathway Inhibition. Cancers (Basel). 2019;11(5):630. doi:10.3390/cancers11050630

156. Meng XY, Shi MJ, Zeng ZH, Chen C, Liu TZ, Wu QJ, Li S, Li S. The Role of COL5A2 in Patients With Muscle-Invasive Bladder Cancer: A 
Bioinformatics Analysis of Public Datasets Involving 787 Subjects and 29 Cell Lines. Front Oncol. 2019;8:659. doi:10.3389/fonc.2018.00659

157. Chen J, Luo Y, Zhou Y, Qin S, Qiu Y, Cui R, Yu M, Qin J, Zhong M. Promotion of Tumor Growth by ADAMTS4 in Colorectal Cancer: Focused on Macrophages. Cell Physiol Biochem. 2018;46(4):1693-1703. doi:10.1159/000489245

158. Lin YM, Lin CW, Lu JW, Yeh KT, Lin SH, Yang SF. Decreased Cytoplasmic Expression of ADAMTS14 Is Correlated with Reduced Survival Rates in Oral Squamous Cell Carcinoma Patients. Diagnostics (Basel). 2020;10(2):122. Published $2020 \quad$ Feb 23. doi:10.3390/diagnostics10020122

159. Jiang G, Wang P, Wang W, Li W, Dai L, Chen K. Annexin A13 promotes tumor cell invasion in vitro and is associated with metastasis in human colorectal cancer. Oncotarget. 2017;8(13):21663-21673. doi:10.18632/oncotarget.15523

160. Zhao M, Ding JX, Nie GY, Wei J, Li Y, Yin XY, Chen Q. HTRA3 is reduced in ovarian cancers regardless of stage. Cancer Invest. 2014;32(9):464-469. doi:10.3109/07357907.2014.958496

161. Wang D, Zhu T, Zhang FB, He C. Expression of ADAMTS12 in colorectal cancer-associated stroma prevents cancer development and is a good prognostic indicator of colorectal cancer. Dig Dis Sci. 2011;56(11):3281-3287. doi:10.1007/s10620-011-1723-x

162. Liu TT, Liu XS, Zhang M, Liu XN, Zhu FX, Zhu FM, Ouyang SW, Li SB, Song CL, Sun HM et al Cartilage oligomeric matrix protein is a prognostic factor and biomarker of colon cancer and promotes cell proliferation by activating the Akt pathway. J Cancer Res Clin Oncol. 2018;144(6):1049-1063. doi:10.1007/s00432-018-2626-4

163. Ni WD, Yang ZT, Cui CA, Cui Y, Fang LY, Xuan YH. Tenascin-C is a potential cancer-associated fibroblasts marker and predicts poor prognosis in prostate cancer. Biochem Biophys Res Commun. 2017;486(3):607-612. doi:10.1016/j.bbrc.2017.03.021

164. Wei CM, Zhao XF, Qiu HB, Ming Z, Liu K, Yan J. The long noncoding RNA PVT1/miR-145-5p/ITGB8 axis regulates cell proliferation, apoptosis, migration and invasion in non-small cell lung cancer cells. Neoplasma. 2020;190723N657.doi:10.4149/neo_2020_190723N657 
165. Gao L, Chen X, Wang Y, Zhang J. Up-Regulation of FSTL3, Regulated by IncRNA DSCAM-AS1/miR-122-5p Axis, Promotes Proliferation and Migration of Non-Small Cell Lung Cancer Cells. Onco Targets Ther. 2020;13:2725-2738. doi:10.2147/OTT.S236359

166. Wang WW, Zhao ZH, Wang L, Li P, Chen KS, Zhang JY, Li WC, Jiang GZ, Li XN. MicroRNA-134 prevents the progression of esophageal squamous cell carcinoma via the PLXNA1-mediated MAPK signalling pathway. EBioMedicine. 2019;46:66-78. doi:10.1016/j.ebiom.2019.07.050

167. Yuan L, Shu B, Chen L, Qian K, Wang Y, Qian G, Zhu Y, Cao X, Xie $\mathrm{C}$, Xiao $\mathrm{Y}$ et al. Overexpression of COL3A1 confers a poor prognosis in human bladder cancer identified by co-expression analysis. Oncotarget. 2017;8(41):70508-70520. doi:10.18632/oncotarget.19733

168. Wu M, Sun Q, Mo CH, Pang JS, Hou JY, Pang LL, Lu HP, Dang YW, Fang SJ, Tang D et al. Prospective molecular mechanism of COL5A1 in breast cancer based on a microarray, RNA sequencing and immunohistochemistry. Oncol Rep. 2019;42(1):151-175. doi:10.3892/or.2019.7147

169. Kita Y, Mimori K, Tanaka F, Matsumoto T, Haraguchi N, Ishikawa K, Matsuzaki S, Fukuyoshi Y, Inoue H, Natsugoe $S$ et al. Clinical significance of LAMB3 and COL7A1 mRNA in esophageal squamous cell carcinoma. Eur J Surg Oncol. 2009;35(1):52-58. doi:10.1016/j.ejso.2008.01.025

170. Shang J, Wang F, Chen P, Wang X, Ding F, Liu S, Zhao Q. Coexpression Network Analysis Identified COL8A1 Is Associated with the Progression and Prognosis in Human Colon Adenocarcinoma. Dig Dis Sci. 2018;63(5):1219-1228. doi:10.1007/s10620-018-4996-5

171. Bengsch F, Buck A, Günther SC, Seiz JR, Tacke M, Pfeifer D, Von Elverfeldt D, Sevenich L, Hillebrand LE, Kern U et al. Cell type-dependent pathogenic functions of overexpressed human cathepsin B in murine breast cancer progression. Oncogene. 2014;33(36):4474-4484. doi:10.1038/onc.2013.395

172. Li J, Xu X, Jiang Y, Hansbro NG, Hansbro PM, Xu J, Liu G. Elastin is a key factor of tumor development in colorectal cancer. BMC Cancer. 2020;20(1):217. doi:10.1186/s12885-020-6686-X 
173. Tao J, Li H, Li Q, Yang Y. CD109 is a potential target for triplenegative breast cancer. Tumour Biol. 2014;35(12):12083-12090. doi:10.1007/s13277-014-2509-5

174. Vycital O, Pitule P, Hosek P, Kriz T, Treska V, Liska V. Expression of Serpin B9 as a Prognostic Factor of Colorectal Cancer. Anticancer Res. 2019;39(11):6063-6066. doi:10.21873/anticanres.13813

175. Yu YP, Cai LC, Wang XY, Cheng SY, Zhang DM, Jian WG, Wang TD, Yang JK, Yang KB, Zhang C. BMP8A promotes survival and drug resistance via Nrf2/TRIM24 signaling pathway in clear cell renal cell carcinoma. Cancer Sci. 2020;10.1111/cas.14376. doi:10.1111/cas.14376

176. D'Apice L, Costa V, Valente C, Trovato M, Pagani A, Manera S, Regolo L, Zambelli A, Ciccodicola A, De Berardinis P. Analysis of SEMA6B gene expression in breast cancer: identification of a new isoform. Biochim Biophys Acta. 2013;1830(10):4543-4553. doi:10.1016/j.bbagen.2013.05.003

177. Wang GH, Yao L, Xu HW, Tang WT, Fu JH, Hu XF, Cui L, Xu XM. Identification of MXRA5 as a novel biomarker in colorectal cancer. Oncol Lett. 2013;5(2):544-548. doi:10.3892/ol.2012.1038

178. Huang D, Yu B, Deng Y, Sheng W, Peng Z, Qin W, Du X. SFRP4 was overexpressed in colorectal carcinoma. J Cancer Res Clin Oncol. 2010;136(3):395-401. doi:10.1007/s00432-009-0669-2

179. Sun J, Liu X, Gao H, Zhang L, Ji Q, Wang Z, Zhou L, Wang Y, Sui $\mathrm{H}$, Fan $\mathrm{Z}$ et al. Overexpression of colorectal cancer oncogene CHRDL2 predicts a poor prognosis. Oncotarget. 2017;8(7):11489-11506. doi:10.18632/oncotarget.14039

180. Dai DN, Li Y, Chen B, Du Y, Li SB, Lu SX, Zhao ZP, Zhou AJ, Xue $\mathrm{N}$, Xia TL,Elevated expression of CST1 promotes breast cancer progression and predicts a poor prognosis. J Mol Med (Berl). 2017;95(8):873-886. doi:10.1007/s00109-017-1537-1 et al

181. Kuo SJ, Chien SY, Lin C, Chan SE, Tsai HT, Chen DR. Significant elevation of CLDN16 and HAPLN3 gene expression in human breast cancer. Oncol Rep. 2010;24(3):759-766. doi:10.3892/or_00000918

182. Dougan J, Hawsawi O, Burton LJ, Edwards G, Jones K, Zou J, Nagappan P, Wang G, Zhang Q, Danaher A, et al. Proteomics-Metabolomics Combined Approach Identifies Peroxidasin as a Protector against Metabolic 
and Oxidative Stress in Prostate Cancer. Int J Mol Sci. 2019;20(12):3046. doi:10.3390/ijms20123046

183. Kang S, Oh SC, Min BW, Lee DH. Transglutaminase 2 Regulates Self-renewal and Stem Cell Marker of Human Colorectal Cancer Stem Cells. Anticancer Res. 2018;38(2):787-794. doi:10.21873/anticanres. 12285

184. Lourenço GJ, Cardoso-Filho C, Gonçales NS, Shinzato JY, Zeferino LC, Nascimento H, Costa FF, Gurgel MS, Lima CS. A high risk of occurrence of sporadic breast cancer in individuals with the 104NN polymorphism of the COL18A1 gene. Breast Cancer Res Treat. 2006;100(3):335-338. doi:10.1007/s10549-006-9259-z

185. Liu H, Dong H, Robertson K, Liu C. DNA methylation suppresses expression of the urea cycle enzyme carbamoyl phosphate synthetase 1 (CPS1) in human hepatocellular carcinoma. Am J Pathol. 2011;178(2):652661. doi:10.1016/j.ajpath.2010.10.023

186. Heindryckx F, Coulon S, Terrie E, Casteleyn C, Stassen JM, Geerts A, Libbrecht L, Allemeersch J, Carmeliet P, Colle I, et al. The placental growth factor as a target against hepatocellular carcinoma in a diethylnitrosamine-induced mouse model. J Hepatol. 2013;58(2):319-328. doi:10.1016/j.jhep.2012.09.032

187. Frycz BA, Murawa D, Borejsza-Wysocki M, Wichtowski M, Spychała A, Marciniak R, Murawa P, Drews M, Jagodziński PP. Transcript level of AKR1C3 is down-regulated in gastric cancer. Biochem Cell Biol. 2016;94(2):138-146. doi:10.1139/bcb-2015-0096

188. Li C, Tian ZN, Cai JP, Chen KX, Zhang B, Feng MY, Shi QT, Li R, Qin Y, Geng JS. Panax ginseng polysaccharide induces apoptosis by targeting Twist/AKR1C2/NF-1 pathway in human gastric cancer. Carbohydr Polym. 2014;102:103-109. doi:10.1016/j.carbpol.2013.11.016

189. Hidaka A, Sasazuki S, Matsuo K, Ito H, Sawada N, Shimazu T, Yamaji T, Iwasaki M, Inoue $\mathrm{M}$, Tsugane $\mathrm{S}$ et al. Genetic polymorphisms of $\mathrm{ADH} 1 \mathrm{~B}, \mathrm{ADH} 1 \mathrm{C}$ and ALDH2, alcohol consumption, and the risk of gastric cancer: the Japan Public Health Center-based prospective study. Carcinogenesis. 2015;36(2):223-231. doi:10.1093/carcin/bgu244

190. Tamer L, Ercan B, Ercan S, Ateș N, Ateş C, Öcal K, Dirlik M, Aydin $\mathrm{S}$, Atik U. CYP2C19 polymorphisms in patients with gastric and colorectal 
carcinoma. Int J Gastrointest Cancer. 2006;37(1):1-5. doi:10.1385/IJGC:37:1:1

191. Gervasini G, García-Martín E, Ladero JM, Pizarro R, Sastre J, Martínez C, García M, Diaz-Rubio M, Agúndez JA. Genetic variability in CYP3A4 and CYP3A5 in primary liver, gastric and colorectal cancer patients. BMC Cancer. 2007;7:118. doi:10.1186/1471-2407-7-118

192. Nguyen TV, Janssen MJ, van Oijen MG, Bergevoet SM, Te Morsche

RH, van Asten H, Laheij RJ, Peters WH, Jansen JB. Genetic polymorphisms in GSTA1, GSTP1, GSTT1, and GSTM1 and gastric cancer risk in a Vietnamese population. Oncol Res. 2010;18(7):349-355. doi:10.3727/096504010x12626118080064

193. Duan S, Gong B, Wang P, Huang H, Luo L, Liu F. Novel prognostic biomarkers of gastric cancer based on gene expression microarray: COL12A1, GSTA3, FGA and FGG. Mol Med Rep. 2018;18(4):3727-3736. doi:10.3892/mmr.2018.9368

194. Lin M, Pan J, Chen Q, Xu Z, Lin X, Shi C. Overexpression of FOXA1 inhibits cell proliferation and EMT of human gastric cancer AGS cells. Gene. 2018;642:145-151. doi:10.1016/j.gene.2017.11.023

195. Li C, Lu S, Shi Y. MicroRNA-187 promotes growth and metastasis of gastric cancer by inhibiting FOXA2. Oncol Rep. 2017;37(3):1747-1755. doi:10.3892/or.2017.5370

196. Shimura T, Shibata M, Gonda K, Okayama H, Saito M, Momma T, Ohki S, Kono K. Serum transthyretin level is associated with prognosis of patients with gastric cancer. J Surg Res. 2018;227:145-150. doi:10.1016/j.jss.2018.02.035

197. He J, Jin Y, Chen Y, Yao HB, Xia YJ, Ma YY, Wang W, Shao QS. Downregulation of ALDOB is associated with poor prognosis of patients with gastric cancer. Onco Targets Ther. 2016;9:6099-6109. doi:10.2147/OTT.S110203

198. Ma MZ, Yuan SQ, Chen YM, Zhou ZW. Preoperative apolipoprotein B/apolipoprotein A1 ratio: a novel prognostic factor for gastric cancer. Onco Targets Ther. 2018;11:2169-2176. doi:10.2147/OTT.S156690

199. Li XS, Xu Q, Fu XY, Luo WS. ALDH1A1 overexpression is associated with the progression and prognosis in gastric cancer. BMC Cancer. 2014;14:705. doi:10.1186/1471-2407-14-705 
200. Li H, Wang J, Xu H, Xing R, Pan Y, Li W, Cui J, Zhang H, Lu Y. Decreased fructose-1,6-bisphosphatase-2 expression promotes glycolysis and growth in gastric cancer cells. Mol Cancer. 2013;12(1):110. doi:10.1186/1476-4598-12-110

201. Zhang Q, Hu H, Shi X, Tang W. Knockdown of S100P by lentiviralmediated RNAi promotes apoptosis and suppresses the colony-formation ability of gastric cancer cells. Oncol Rep. 2014;31(5):2344-2350. doi:10.3892/or.2014.3104

202. Ji L, Qian W, Gui L, Ji Z, Yin P, Lin GN, Wang Y, Ma B, Gao WQ. Blockade of $\beta$-catenin-induced CCL28 suppresses gastric cancer progression via inhibition of Treg cell infiltration. Cancer Res. 2020;canres.3074.2019. doi:10.1158/0008-5472.CAN-19-3074

203. Repetto O, Maiero S, Magris R, Miolo G, Cozzi MR, Steffan A, Canzonieri V, Cannizzaro R, De Re V. Quantitative Proteomic Approach Targeted to Fibrinogen $\beta$ Chain in Tissue Gastric Carcinoma. Int J Mol Sci. 2018;19(3):759. doi:10.3390/ijms19030759

204. Hur H, Yu EJ, Ham IH, Jin HJ, Lee D. Preoperative serum levels of insulin-like growth factor-binding protein 2 predict prognosis of gastric cancer patients. Oncotarget. 2017;8(7):10994-11003. doi:10.18632/oncotarget.14202

205. Wang X, Zhong RY, Xiang XJ. Reduced expression of SCUBE2 predicts poor prognosis in gastric cancer patients. Int J Clin Exp Pathol. 2018;11(2):972-980.

206. Liu F, Zhang Y, Men T, Jiang X, Yang C, Li H, Wei X, Yan D, Feng G, Yang J, et al. Quantitative proteomic analysis of gastric cancer tissue reveals novel proteins in platelet-derived growth factor $\mathrm{b}$ signaling pathway. Oncotarget. 2017;8(13):22059-22075. doi:10.18632/oncotarget.15908

207. Konno-Shimizu M, Yamamichi N, Inada KI, Kageyama-Yahara N, Shiogama K, Takahashi Y, Asada-Hirayama I, Yamamichi-Nishina M, Nakayama C, Ono S, Kodashima S. Cathepsin E is a marker of gastric differentiation and signet-ring cell carcinoma of stomach: a novel suggestion on gastric tumorigenesis. PLoS One. 2013;8(2):e56766. doi:10.1371/journal.pone.0056766 
208. Saeki N, Sakamoto H, Yoshida T. Mucin 1 gene (MUC1) and gastriccancer susceptibility. Int J Mol Sci. 2014;15(5):7958-7973. doi:10.3390/ijms 15057958

209. Kwon JA, Lee SY, Ahn EK, Seol SY, Kim MC, Kim SJ, Kim SI, Chu IS, Leem SH. Short rare MUC6 minisatellites-5 alleles influence susceptibility to gastric carcinoma by regulating gene. Hum Mutat. 2010;31(8):942-949. doi:10.1002/humu.21289

210. Bianconi D, Herac M, Spies D, Kieler M, Brettner R, Unseld M, Fürnkranz K, Famler B, Schmeidl M, Minichsdorfer C et al. SERPINB7 Expression Predicts Poor Pancreatic Cancer Survival Upon Gemcitabine Treatment. Transl Oncol. 2019;12(1):15-23. doi:10.1016/j.tranon.2018.08.019

211. Nielsen TO, Friis-Hansen L, Poulsen SS, Federspiel B, Sorensen BS. Expression of the EGF family in gastric cancer: downregulation of HER4 and its activating ligand NRG4. PLoS One. 2014;9(4):e94606. doi:10.1371/journal.pone.0094606

212. Chen R, Zhuge X, Huang Z, Lu D, Ye X, Chen C, Yu J, Lu G. Analysis of SEMA3B methylation and expression patterns in gastric cancer tissue and cell lines. Oncol Rep. 2014;31(3):1211-1218. doi:10.3892/or.2014.2972

213. Perrais M, Pigny P, Buisine MP, Porchet N, Aubert JP, Van Seuningen-Lempire I. Aberrant expression of human mucin gene MUC5B in gastric carcinoma and cancer cells. Identification and regulation of a distal promoter. J Biol Chem. 2001;276(18):15386-15396. doi:10.1074/jbc.M010534200

214. Ishikawa A, Sakamoto N, Honma R, Taniyama D, Fukada K, Hattori T, Sentani K, Oue N, Yanagihara K, Tanabe K, et al. Annexin A10 is involved in the induction of pancreatic duodenal homeobox $\square 1$ in gastric cancer tissue, cells and organoids. Oncol Rep. 2020;43(2):581-590. doi:10.3892/or.2019.7422

215. Qiu YS, Liao GJ, Jiang NN. REG3A overexpression suppresses gastric cancer cell invasion, proliferation and promotes apoptosis through PI3K/Akt signaling pathway. Int J Mol Med. 2018;41(6):3167-3174. doi:10.3892/ijmm.2018.3520 
216. Arisawa T, Tahara T, Ozaki K, Matsue Y, Minato T, Yamada H, Nomura T, Hayashi R, Matsunaga K, Fukumura A, et al. Association between common genetic variant of $\mathrm{HRH} 2$ and gastric cancer risk. Int J Oncol. 2012;41(2):497-503. doi:10.3892/ijo.2012.1482

217. Shi X, Li X, Chen L, Wang C. Analysis of somatostatin receptors and somatostatin promoter methylation in human gastric cancer. Oncol Lett. 2013;6(6):1794-1798. doi:10.3892/ol.2013.1614

218. Rai R, Kim JJ, Tewari M, Shukla HS. Heterogeneous expression of cholecystokinin and gastrin receptor in stomach and pancreatic cancer: An immunohistochemical study. J Cancer Res Ther. 2016;12(1):411-416. doi:10.4103/0973-1482.168970

219. Hong ZH, Chang LL, Fang-Jie YA, Yan HU, Chen-Ming ZE, Tian-Yi ZH, Tao YU, Mei-Dan YI, Ji CA, Qiao-Jun HE et al. AKR1C1 Activates STAT3 to Promote the Metastasis of Non-Small Cell Lung Cancer. Theranostics. 2018;8(3):676-692. doi:10.7150/thno.21463

220. Wu JB, Yin L, Shi C, Li Q, Duan P, Huang JM, Liu C, Wang F, Lewis M, Wang Y, et al. MAOA-Dependent Activation of Shh-IL6-RANKL Signaling Network Promotes Prostate Cancer Metastasis by Engaging Tumor-Stromal Cell Interactions. Cancer Cell. 2017;31(3):368-382. doi:10.1016/j.ccell.2017.02.003

221. Counihan JL, Wiggenhorn AL, Anderson KE, Nomura DK. Chemoproteomics-Enabled Covalent Ligand Screening Reveals ALDH3A1 as a Lung Cancer Therapy Target. ACS Chem Biol. 2018;13(8):1970-1977. doi:10.1021/acschembio.8b00381

222. Oguri T, Takahashi T, Miyazaki M, Isobe T, Kohno N, Mackenzie PI, Fujiwara Y. UGT1A10 is responsible for SN-38 glucuronidation and its expression in human lung cancers. Anticancer Res. 2004;24(5A):28932896.

223. Yang C, Zhou Q, Li M, Tong X, Sun J, Qing Y, Sun L, Yang X, Hu $\mathrm{X}$, Jiang J, et al. Upregulation of CYP2S1 by oxaliplatin is associated with p53 status in colorectal cancer cell lines. Sci Rep. 2016;6:33078. doi:10.1038/srep33078

224. Lu YX, Ju HQ, Liu ZX, Chen DL, Wang Y, Zhao Q, Wu QN, Zeng ZL, Qiu HB, Hu PS, et al. ME1 Regulates NADPH Homeostasis to Promote 
Gastric Cancer Growth and Metastasis. Cancer Res. 2018;78(8):1972-1985. doi:10.1158/0008-5472.CAN-17-3155

225. Yu J, Li J, Chen Y, Cao W, Lu Y, Yang J, Xing E. Snail Enhances Glycolysis in the Epithelial-Mesenchymal Transition Process by Targeting FBP1 in Gastric Cancer. Cell Physiol Biochem. 2017;43(1):31-38. doi:10.1159/000480314

226. Shimokawa Y, Okuda K, Kubo Y, Kaneko A, Arishima T, Nagata E, Hashimoto M, Sawa Y, Nagasaki Y, Kojiro M, et al. erum glutamic oxalacetic transaminase/glutamic pyruvic transaminase ratios in hepatocellular carcinoma. Cancer. 1977;40(1):319-324. doi:10.1002/10970142(197707)40:1<319::aid-cncr2820400145>3.0.co;2-q

227. Ganapathi MK, Jones WD, Sehouli J, Michener CM, Braicu IE, Norris EJ, Biscotti CV, Vaziri SA, Ganapathi RN. Expression profile of COL2A1 and the pseudogene SLC6A10P predicts tumor recurrence in highgrade serous ovarian cancer. Int J Cancer. 2016;138(3):679-688. doi:10.1002/ijc.29815

228. Yodsurang V, Tanikawa C, Miyamoto T, Lo PHY, Hirata M, Matsuda K. Identification of a novel p53 target, COL17A1, that inhibits breast cancer cell migration and invasion. Oncotarget. 2017;8(34):55790-55803. doi:10.18632/oncotarget.18433

229. Tan JX, Wang XY, Li HY, Su XL, Wang L, Ran L, Zheng K, Ren GS. HYAL1 overexpression is correlated with the malignant behavior of human breast cancer. Int J Cancer. 2011;128(6):1303-1315. doi:10.1002/ijc.25460

230. Ma Y, Chen Y, Li Y, Grün K, Berndt A, Zhou Z, Petersen I. Cystatin A suppresses tumor cell growth through inhibiting epithelial to mesenchymal transition in human lung cancer. Oncotarget. 2017;9(18):14084-14098. doi:10.18632/oncotarget.23505

231. Nowakowska-Zajdel E, Mazurek U, Wierzgoń J, Kokot T, Fatyga E, Ziółko E, Klakla K, Błażelonis A, Waniczek D, Głogowski Ł, et al. Expression of ADAM28 and IGFBP-3 genes in patients with colorectal cancer - a preliminary report. Int $\mathrm{J}$ Immunopathol Pharmacol. 2013;26(1):223-228. doi:10.1177/039463201302600122 
232. Chen E, Li Q, Wang H, Zhang P, Zhao X, Yang F, Yang J. MiR-32 promotes tumorigenesis of colorectal cancer by targeting BMP5. Biomed Pharmacother. 2018;106:1046-1051. doi:10.1016/j.biopha.2018.07.050

233. Koyama T, Ogawara K, Kasamatsu A, Okamoto A, Kasama H, Minakawa Y, Shimada K, Yokoe H, Shiiba M, Tanzawa H, et al. ANGPTL3 is a novel biomarker as it activates ERK/MAPK pathway in oral cancer. Cancer Med. 2015;4(5):759-769. doi:10.1002/cam4.418

234. Guo Y, Li H, Guan H, Ke W, Liang W, Xiao H, Li Y. Dermatopontin inhibits papillary thyroid cancer cell proliferation through MYC repression. Mol Cell Endocrinol. 2019;480:122-132. doi:10.1016/j.mce.2018.10.021

235. Lee RM, Hirano $\mathrm{K}$, Anant $\mathrm{S}$, Baunoch $\mathrm{D}$, Davidson NO. An alternatively spliced form of apobec-1 messenger RNA is overexpressed in human colon cancer. Gastroenterology. 1998;115(5):1096-1103. doi:10.1016/s0016-5085(98)70080-0

236. Kua LF, Ross S, Lee SC, Mimura K, Kono K, Goh BC, Yong WP. UGT1A6 polymorphisms modulated lung cancer risk in a Chinese population. PLoS One. 2012;7(8):e42873. doi:10.1371/journal.pone.0042873

237. Alcazar-González GA, Calderón-Garcidueñas AL, Garza-Rodríguez ML, Rubio-Hernández G, Escorza-Treviño S, Olano-Martin E, Cerda-Flores RM, Castruita-Avila AL, González-Guerrero JF, Le Brun S, Simon-Buela L. Comparative study of polymorphism frequencies of the CYP2D6, CYP3A5, CYP2C8 and IL-10 genes in Mexican and Spanish women with breast cancer. Pharmacogenomics. 2013;14(13):1583-1592. doi:10.2217/pgs.13.83

238. Lim JS, Chen XA, Singh O, Yap YS, Ng RC, Wong NS, Wong M, Lee EJ, Chowbay B. Impact of CYP2D6, CYP3A5, CYP2C9 and CYP2C19 polymorphisms on tamoxifen pharmacokinetics in Asian breast cancer patients. Br J Clin Pharmacol. 2011;71(5):737-750. doi:10.1111/j.13652125.2011.03905.x

239. Silva SN, Azevedo AP, Teixeira V, Pina JE, Rueff J, Gaspar JF. The role of GSTA2 polymorphisms and haplotypes in breast cancer susceptibility: a case-control study in the Portuguese population. Oncol Rep. 2009;22(3):593-598. doi:10.3892/or_00000477

240. Wilborn TW, Lang NP, Smith M, Meleth S, Falany CN. Association of SULT2A1 allelic variants with plasma adrenal androgens and prostate 
cancer in African American men. J Steroid Biochem Mol Biol. 2006;99(45):209-214. doi:10.1016/j.jsbmb.2006.01.006

241. Kadalayil L, Khan S, Nevanlinna H, Fasching PA, Couch FJ, Hopper JL, Liu J, Maishman T, Durcan L, Gerty S, et al. Germline variation in ADAMTSL1 is associated with prognosis following breast cancer treatment in young women. Nat Commun. 2017;8(1):1632. doi:10.1038/s41467-01701775-y

242. Sigurdson AJ, Brenner AV, Roach JA, Goudeva L, Müller JA, Nerlich K, Reiners C, Schwab R, Pfeiffer L, Waldenberger M, et al. Selected single-nucleotide polymorphisms in FOXE1, SERPINA5, FTO, EVPL, TICAM1 and SCARB1 are associated with papillary and follicular thyroid cancer risk: replication study in a German population. Carcinogenesis. 2016;37(7):677-684. doi:10.1093/carcin/bgw047

243. Launonen V, Laake K, Huusko P, Niederacher D, Beckmann MW, Barkardottir RB, Geirsdottir EK, Gudmundsson J, Rio P, Bignon YJ et al. European multicenter study on LOH of APOC3 at 11q23 in 766 breast cancer patients: relation to clinical variables. Breast Cancer Somatic Genetics Consortium. $\quad \mathrm{Br} \quad \mathrm{J}$ Cancer. 1999;80(5-6):879-882. doi:10.1038/sj.bjc.6690435

244. Chow RK, Sin ST, Liu M, Li Y, Chan TH, Song Y, Chen L, Kwong DL, Guan XY. AKR7A3 suppresses tumorigenicity and chemoresistance in hepatocellular carcinoma through attenuation of ERK, c-Jun and NF- $\mathrm{B}$ signaling pathways. Oncotarget. 2016;8(48):83469-83479. doi:10.18632/oncotarget.12726

245. Li YJ, Huang TH, Hsiao M, Lin BR, Cheng SJ, Yang CN, Lai WT, Wu TS, Fan JR, Kuo MY, et al. Suppression of fructose-bisphosphate aldolase $\mathrm{C}$ expression as a predictor of advanced oral squamous cell carcinoma. Head Neck. 2016;38 Suppl 1:E1075-E1085. doi:10.1002/hed.24161

246. Sun HM, Mi YS, Yu FD, Han Y, Liu XS, Lu S, Zhang Y, Zhao SL, Ye L, Liu TT, et al. SERPINA4 is a novel independent prognostic indicator and a potential therapeutic target for colorectal cancer. Am J Cancer Res. 2016;6(8):1636-1649.

247. Molokwu CN, Adeniji OO, Chandrasekharan S, Hamdy FC, Buttle DJ. Androgen regulates ADAMTS15 gene expression in prostate cancer 
cells. Cancer Invest. 2010;28(7):698-710. doi:10.3109/07357907.2010.489538

248. Li P, Cong Z, Qiang Y, Xiong L, Tang L, Zhang Y, Wu H, Yi J, Jing $\mathrm{H}$, Li D, et al. Clinical significance of CCBE1 expression in lung cancer. Mol Med Rep. 2018;17(2):2107-2112. doi:10.3892/mmr.2017.8187

249. Sun J, Xie T, Jamal M, Tu Z, Li X, Wu Y, Li J, Zhang Q, Huang X. CLEC3B as a potential diagnostic and prognostic biomarker in lung cancer and association with the immune microenvironment. Cancer Cell Int. 2020;20:106. doi:10.1186/s12935-020-01183-1

250. Cao B, Yang Y, Pan Y, Jia Y, Brock MV, Herman JG, Guo M. Epigenetic silencing of CXCL14 induced colorectal cancer migration and invasion. Discov Med. 2013;16(88):137-147.

251. Lee BH, Taylor MG, Robinet P, Smith JD, Schweitzer J, Sehayek E, Falzarano SM, Magi-Galluzzi C, Klein EA, Ting AH. Dysregulation of cholesterol homeostasis in human prostate cancer through loss of ABCA1. Cancer Res. 2013;73(3):1211-1218. doi:10.1158/0008-5472.CAN-12-3128

252. Bae H, Kim B, Lee H, Lee S, Kang HS, Kim SJ. Epigenetically regulated Fibronectin leucine rich transmembrane protein 2 (FLRT2) shows tumor suppressor activity in breast cancer cells. Sci Rep. 2017;7(1):272. doi:10.1038/s41598-017-00424-0

253. Moelans CB, Verschuur-Maes AH, van Diest PJ. Frequent promoter hypermethylation of BRCA2, CDH13, MSH6, PAX5, PAX6 and WT1 in ductal carcinoma in situ and invasive breast cancer. $J$ Pathol. 2011;225(2):222-231. doi:10.1002/path.2930

254. Dong R, Guo J, Zhang Z, Zhou Y, Hua Y. Polyphyllin I inhibits gastric cancer cell proliferation by downregulating the expression of fibroblast activation protein alpha (FAP) and hepatocyte growth factor (HGF) in cancer-associated fibroblasts. Biochem Biophys Res Commun. 2018;497(4):1129-1134. doi:10.1016/j.bbrc.2018.02.193

255. Sotoudeh M, Shirvani SI, Merat S, Ahmadbeigi N, Naderi M. MSLN (Mesothelin), ANTXR1 (TEM8), and MUC3A are the potent antigenic targets for CAR T cell therapy of gastric adenocarcinoma. J Cell Biochem. 2019;120(4):5010-5017. doi:10.1002/jcb.27776 
256. Xu Y, Shao QS, Yao HB, Jin Y, Ma YY, Jia LH. Overexpression of FOXC1 correlates with poor prognosis in gastric cancer patients. Histopathology. 2014;64(7):963-970. doi:10.1111/his.12347

257. Liu J, Liu Z, Zhang X, Gong T, Yao D. Bioinformatic exploration of OLFML2B overexpression in gastric cancer base on multiple analyzing tools. BMC Cancer. 2019;19(1):227. doi:10.1186/s12885-019-5406-X

258. Yi J, Ren L, Wu J, Li W, Zheng X, Du G, Wang J. Apolipoprotein C1 (APOC1) as a novel diagnostic and prognostic biomarker for gastric cancer. Ann Transl Med. 2019;7(16):380. doi:10.21037/atm.2019.07.59

259. Zheng P, Luo Q, Wang W, Li J, Wang T, Wang P, Chen L, Zhang P, Chen $\mathrm{H}$, Liu Y, et al. Tumor-associated macrophages-derived exosomes promote the migration of gastric cancer cells by transfer of functional Apolipoprotein E. Cell Death Dis. 2018;9(4):434. doi:10.1038/s41419-0180465-5

260. Maruyama S, Furuya S, Shiraishi K, Shimizu H, Akaike H, Hosomura N, Kawaguchi Y, Amemiya H, Kawaida H, Sudo M, et al. Podoplanin Expression as a Prognostic Factor in Gastric Cancer. Anticancer Res. 2018;38(5):2717-2722. doi:10.21873/anticanres.12513

261. Zhang M, Dong BB, Lu M, Zheng MJ, Chen H, Ding JZ, Xu AM, Xu YH. miR-429 functions as a tumor suppressor by targeting FSCN1 in gastric cancer cells. Onco Targets Ther. 2016;9:1123-1133. doi:10.2147/OTT.S91879

262. Hsu KW, Fang WL, Huang KH, Huang TT, Lee HC, Hsieh RH, Chi CW, Yeh TS. Notch1 pathway-mediated microRNA-151-5p promotes gastric cancer progression. Oncotarget. 2016;7(25):38036-38051. doi:10.18632/oncotarget.9342

263. Wang X, Liu Y, Shao D, Qian Z, Dong Z, Sun Y, Xing X, Cheng X, $\mathrm{Du} \mathrm{H}, \mathrm{Hu} \mathrm{Y}$, et al. Recurrent amplification of MYC and TNFRSF11B in $8 \mathrm{q} 24$ is associated with poor survival in patients with gastric cancer. Gastric Cancer. 2016;19(1):116-127. doi:10.1007/s10120-015-0467-2

264. Geng B, Pan J, Zhao T, Ji J, Zhang C, Che Y, Yang J, Shi H, Li J, Zhou $\mathrm{H}$, et al. Chitinase 3-like 1-CD44 interaction promotes metastasis and epithelial-to-mesenchymal transition through $\beta$-catenin/Erk/Akt signaling in gastric cancer. J Exp Clin Cancer Res. 2018;37(1):208. doi:10.1186/s13046018-0876-2 
265. Aquea G, Bresky G, Lancellotti D, Madariaga JA, Zaffiri V, Urzúa

Tobar U, Haberle S, Bernal G. Increased expression of P2RY2, CD248 and EphB1 in gastric cancers from Chilean patients. Asian Pac J Cancer Prev. 2014;15(5):1931-1936. doi:10.7314/apjcp.2014.15.5.1931

266. Lo PK, Yao Y, Lee JS, Zhang Y, Huang W, Kane MA, Zhou Q. LIPG signaling promotes tumor initiation and metastasis of human basal-like triple-negative breast cancer. Elife. 2018;7:e31334. doi:10.7554/eLife. 31334

267. Grill JI, Neumann J, Ofner A, et al. Dro1/Ccdc80 inactivation promotes AOM/DSS-induced colorectal carcinogenesis and aggravates colitis by DSS in mice. Carcinogenesis. 2018;39(9):1176-1184. doi:10.1093/carcin/bgy077

268. Lehtinen L, Vainio P, Wikman H, Huhtala H, Mueller V, Kallioniemi $\mathrm{A}$, Pantel K, Kronquist $\mathrm{P}$, Kallioniemi $\mathrm{O}$, Carpèn $\mathrm{O}$, et al. PLA2G7 associates with hormone receptor negativity in clinical breast cancer samples and regulates epithelial-mesenchymal transition in cultured breast cancer cells. J Pathol Clin Res. 2017;3(2):123-138. doi:10.1002/cjp2.69

269. Zhang B, Cheng B, Li FS, Ding JH, Feng YY, Zhuo GZ, Wei HF, Zhao K. High expression of CD39/ENTPD1 in malignant epithelial cells of human rectal adenocarcinoma. Tumour Biol. 2015;36(12):9411-9419. doi:10.1007/s13277-015-3683-9

270. Ning PF, Liu HJ, Yuan Y. Dynamic expression of pepsinogen C in gastric cancer, precancerous lesions and Helicobacter pylori associated gastric diseases. World J Gastroenterol. 2005;11(17):2545-2548. doi:10.3748/wjg.v11.i17.2545

271. Watanabe T, Fujii T, Oya T, Horikawa N, Tabuchi Y, Takahashi Y, Morii M, Takeguchi N, Tsukada K, Sakai H. Involvement of aquaporin-5 in differentiation of human gastric cancer cells. J Physiol Sci. 2009;59(2):113122. doi:10.1007/s12576-008-0017-3

272. Peng P, Wu W, Zhao J, Song S, Wang X, Jia D, Shao M, Zhang M, Li L, Wang L, et al. Decreased expression of Calpain-9 predicts unfavorable prognosis in patients with gastric cancer. Sci Rep. 2016;6:29604. doi:10.1038/srep29604

273. Inoue Y, Matsuura S, Yoshimura K, Iwashita Y, Kahyo T, Kawase A, Tanahashi M, Maeda M, Ogawa H, Inui N, et al. Characterization of V-set 
and immunoglobulin domain containing 1 exerting a tumor suppressor function in gastric, lung, and esophageal cancer cells. Cancer Sci. 2017;108(8):1701-1714. doi:10.1111/cas.13295

274. Liu X, Chen Z, Zhao X, Huang M, Wang C, Peng W, Yin J, Li J, He $\mathrm{G}, \mathrm{Li} \mathrm{X}$, et al. Effects of IGF2BP2, KCNQ1 and GCKR polymorphisms on clinical outcome in metastatic gastric cancer treated with EOF regimen. Pharmacogenomics. 2015;16(9):959-970. doi:10.2217/pgs.15.49

275. Soutto M, Chen Z, Saleh MA, Katsha A, Zhu S, Zaika A, Belkhiri A, El-Rifai W. TFF1 activates p53 through down-regulation of miR-504 in gastric cancer. Oncotarget. 2014;5(14):5663-5673. doi:10.18632/oncotarget.2156

276. Peterson AJ, Menheniott TR, O'Connor L, Walduck AK, Fox JG, Kawakami K, Minamoto T, Ong EK, Wang TC, Judd LM, et al. Helicobacter pylori infection promotes methylation and silencing of trefoil factor 2, leading to gastric tumor development in mice and humans. Gastroenterology. 2010;139(6):2005-2017. doi:10.1053/j.gastro.2010.08.043

277. Pan J, Fan Z, Wang Z, Dai Q, Xiang Z, Yuan F, Yan M, Zhu Z, Liu B, Li C. CD36 mediates palmitate acid-induced metastasis of gastric cancer via AKT/GSK-3 $\beta / \beta$-catenin pathway. J Exp Clin Cancer Res. 2019;38(1):52. doi:10.1186/s13046-019-1049-7

278. Di Stadio CS, Altieri F, Minopoli G, Miselli G, Rippa E, Arcari P. Role of human GKN1 on APP processing in gastric cancer. Biochimie. 2017;135:149-153. doi:10.1016/j.biochi.2017.02.007

279. Qian Y, Wong CC, Xu J, Chen H, Zhang Y, Kang W, Wang H, Zhang L, Li W, Chu ES, et al. Sodium Channel Subunit SCNN1B Suppresses Gastric Cancer Growth and Metastasis via GRP78 Degradation. Cancer Res. 2017;77(8):1968 $\square$ 1982. doi:10.1158/0008-5472.CAN-16-1595

280. Kim M, Pyo S, Kang CH, Lee CO, Lee HK, Choi SU, Park CH.

Folate receptor 1 (FOLR1) targeted chimeric antigen receptor (CAR) T cells for the treatment of gastric cancer. PLoS One. 2018;13(6):e0198347. doi:10.1371/journal.pone.0198347

281. Nguyen DM, Parekh PR, Chang ET, Sharma NK, Carrier F. Contribution of Dual Oxidase 2 (DUOX2) to Hyper-Radiosensitivity in 
Human Gastric Cancer Cells. Radiat Res. 2015;184(2):151 $\square 160$. doi:10.1667/rr13661.1

282. Li Y, Chen S, Shan Z, Bi L, Yu S, Li Y, Xu S. miR-182-5p improves the viability, mitosis, migration, and invasion ability of human gastric cancer cells by down-regulating RAB27A. Biosci Rep. 2017;37(3):BSR20170136. doi:10.1042/BSR20170136

283. Park YS, Lee JH, Jung DB, Kim HB, Jung JH, Pak S, Ryu YM, Park HJ, Park YY, Jung HY, et al. MicroRNA-21 induces loss of 15hydroxyprostaglandin dehydrogenase in early gastric tubular adenocarcinoma. Sci Rep. 2018;8(1):17717. doi:10.1038/s41598-01836139-z

284. Yao Y, Yang X, Sun L, Sun S, Huang X, Zhou D, Li T, Zhang W, Abumrad NA, Zhu X, et al. Fatty acid 2-hydroxylation inhibits tumor growth and increases sensitivity to cisplatin in gastric cancer. EBioMedicine. 2019;41:256 $\square$ 267. doi:10.1016/j.ebiom.2019.01.066

285. Kong Y, Zheng Y, Jia Y, Li P, Wang Y. Decreased LIPF expression is correlated with DGKA and predicts poor outcome of gastric cancer. Oncol Rep. 2016;36(4):1852 $\square$ 1860. doi:10.3892/or.2016.4989

286. Liu X, Chen Z, Zhao X, Huang M, Wang C, Peng W, Yin J, Li J, He $\mathrm{G}, \mathrm{Li} \mathrm{X}$, et al. Effects of IGF2BP2, KCNQ1 and GCKR polymorphisms on clinical outcome in metastatic gastric cancer treated with EOF regimen. Pharmacogenomics. 2015;16(9):959 $\square 970$. doi:10.2217/pgs.15.49

287. Ahmed SMU, Jiang ZN, Zheng ZH, Li Y, Wang XJ, Tang X. AKR1B10 expression predicts response of gastric cancer to neoadjuvant chemotherapy. Oncol Lett. 2019;17(1):773 $\square 780$. doi:10.3892/ol.2018.9705

288. Hu WG, Hu JJ, Cai W, Zheng MH, Zang L, Wang ZT, Zhu ZG. The $\mathrm{NAD}(\mathrm{P}) \mathrm{H}$ : quinine oxidoreductase 1 (NQO1) gene $609 \mathrm{C}>\mathrm{T}$ polymorphism is associated with gastric cancer risk: evidence from a case-control study and a meta-analysis. Asian Pac J Cancer Prev. 2014;15(5):2363 $\square 2367$. doi:10.7314/apjcp.2014.15.5.2363

289. Zhang C, Xu W, Pan W, Wang N, Li G, Fan X, Xu X, Shen S, Das UN. Selenium-binding protein 1 may decrease gastric cellular proliferation and migration. Int J Oncol. 2013;42(5):1620 $\square 1629$. doi:10.3892/ijo.2013.1850 
290. Min SY, Kim HS, Jung EJ, Jung EJ, Jee CD, Kim WH. Prognostic significance of glutathione peroxidase 1 (GPX1) down-regulation and correlation with aberrant promoter methylation in human gastric cancer. Anticancer Res. 2012;32(8):3169 $\square 3175$.

291. Wu J, Niu Q, Yuan J, Xu X, Cao L. Novel compound cedrelone inhibits hepatocellular carcinoma progression via PBLD and Ras/Rap1. Exp Ther Med. 2019;18(6):4209-4220. doi:10.3892/etm.2019.8080

292. Tang X, Mahajan SS, Nguyen LT, Béliveau F, Leduc R, Simon JA, Vasioukhin V. Targeted inhibition of cell-surface serine protease Hepsin blocks prostate cancer bone metastasis. Oncotarget. 2014;5(5):1352 $\square 1362$. doi:10.18632/oncotarget.1817

293. Mhawech-Fauceglia P, Walia S, Yessaian A, Machida H, Matsuo K, Lawrenson K. Overexpression of HOMER2 predicts better outcome in lowgrade endometrioid endometrial adenocarcinoma. Pathology. 2018;50(5):499 $\square$ 503. doi:10.1016/j.pathol.2018.03.004

294. $\mathrm{Wu} \mathrm{Y,} \mathrm{Antony} \mathrm{S,} \mathrm{Juhasz} \mathrm{A,} \mathrm{et} \mathrm{al.} \mathrm{Up-regulation} \mathrm{and} \mathrm{sustained}$ activation of Stat1 are essential for interferon-gamma (IFN-gamma)-induced dual oxidase 2 (Duox2) and dual oxidase A2 (DuoxA2) expression in human pancreatic cancer cell lines. J Biol Chem. 2011;286(14):12245 $\square 12256$. doi:10.1074/jbc.M110.191031

295. Guan X, Luo L, Begum G, Kohanbash G, Song Q, Rao A, Amankulor $\mathrm{N}$, Sun B, Sun D, Jia W. Elevated Na/H exchanger 1 (SLC9A1) emerges as a marker for tumorigenesis and prognosis in gliomas. J Exp Clin Cancer Res. 2018;37(1):255. doi:10.1186/s13046-018-0923-z

296. Little AC, Sham D, Hristova M, Danyal K, Heppner DE, Bauer RA, Sipsey LM, Habibovic A, Van Der Vliet A. DUOX1 silencing in lung cancer promotes EMT, cancer stem cell characteristics and invasive properties. Oncogenesis. 2016;5(10):e261. doi:10.1038/oncsis.2016.61

297. Zhang C, Wang H, Chen Z, Zhuang L, Xu L, Ning Z, Zhu Z, Wang P, Meng Z. Carbonic anhydrase 2 inhibits epithelial-mesenchymal transition and metastasis in hepatocellular carcinoma. Carcinogenesis. 2018;39(4):562 $\square$ 570. doi:10.1093/carcin/bgx148

298. Gao S, Zhao Z, Wu R, Wu L, Tian X, Zhang Z. MicroRNA-194 regulates cell viability and apoptosis by targeting $\mathrm{CDH} 2$ in prostatic cancer. Onco Targets Ther. 2018;11:4837 $\square$ 4844. doi:10.2147/OTT.S169101 
299. Yu DL, Li HW, Wang Y, Li CQ, You D, Jiang L, Song YP, Li XH. Acyl-CoA dehydrogenase long chain expression is associated with esophageal squamous cell carcinoma progression and poor prognosis. Onco Targets Ther. 2018;11:7643 $\square 7653$. doi:10.2147/OTT.S171963

300. Zou Q, Yang ZL, Yuan Y, Li JH, Liang LF, Zeng GX, Chen SL. Clinicopathological features and CCT2 and PDIA2 expression in gallbladder squamous/adenosquamous carcinoma and gallbladder adenocarcinoma. World J Surg Oncol. 2013;11:143. doi:10.1186/1477-7819-11-143

301. Giovannetti E, Wang Q, Avan A, Funel N, Lagerweij T, Lee JH, Caretti V, van der Velde A, Boggi U, Wang Y, et al. Role of CYB5A in pancreatic cancer prognosis and autophagy modulation. J Natl Cancer Inst. 2014;106(1):djt346. doi:10.1093/jnci/djt346

302. da Silveira Mitteldorf CA, de Sousa-Canavez JM, Leite KR, Massumoto C, Camara-Lopes LH. FN1, GALE, MET, and QPCT overexpression in papillary thyroid carcinoma: molecular analysis using frozen tissue and routine fine-needle aspiration biopsy samples. Diagn Cytopathol. 2011;39(8):556 $\square$ 561. doi:10.1002/dc.21423

303. Liu XP, Yin XH, Meng XY, Yan XH, Cao Y, Zeng XT, Wang XH. DHCR24 predicts poor clinicopathological features of patients with bladder cancer: A STROBE-compliant study. Medicine (Baltimore). 2018;97(39):e11830. doi:10.1097/MD.0000000000011830

304. Maman S, Sagi-Assif O, Yuan W, Ginat R, Meshel T, Zubrilov I, Keisari Y, Lu W, Lu W, Witz IP. The Beta Subunit of Hemoglobin (HBB2/HBB) Suppresses Neuroblastoma Growth and Metastasis. Cancer Res. 2017;77(1):14 $\square$ 26. doi:10.1158/0008-5472.CAN-15-2929

305. Rodriguez-Aguayo C, Bayraktar E, Ivan C, Aslan B, Mai J, He G, Mangala LS, Jiang D, Nagaraja AS, Ozpolat B, et al. PTGER3 induces ovary tumorigenesis and confers resistance to cisplatin therapy through upregulation Ras-MAPK/Erk-ETS1-ELK1/CFTR1 axis. EBioMedicine. 2019;40:290-304. doi:10.1016/j.ebiom.2018.11.045

306. Worst TS, Meyer Y, Gottschalt M, Weis CA, Von Hardenberg J, Frank C, Steidler A, Michel MS, Erben P. RAB27A, RAB27B and VPS36 are downregulated in advanced prostate cancer and show functional relevance in prostate cancer cells. Int J Oncol. 2017;50(3):920 $\square 932$. doi:10.3892/ijo.2017.3872 
307. Fernandez AI, Geng X, Chaldekas K, Harris B, Duttargi A, Berry VL, Berry DL, Mahajan A, Cavalli LR, Győrffy B, et al. The orphan nuclear receptor estrogen-related receptor beta $(\operatorname{ERR} \beta)$ in triple-negative breast cancer. Breast Cancer Res Treat. 2020;179(3):585 6604 . doi:10.1007/s10549-019-05485-5

308. Lu J, Chen Z, Zhao H, Dong H, Zhu L, Zhang Y, Wang J, Zhu H, Cui Q, Qi C, et al. ABAT and ALDH6A1, regulated by transcription factor HNF4A, suppress tumorigenic capability in clear cell renal cell carcinoma. J Transl Med. 2020;18(1):101. doi:10.1186/s12967-020-02268-1

309. Seibert JK, Quagliata L, Quintavalle C, Hammond TG, Terracciano L, Odermatt A. A role for the dehydrogenase DHRS7 (SDR34C1) in prostate cancer. Cancer Med. 2015;4(11):1717 $\square$ 1729. doi:10.1002/cam4.517

310. Wang Y, Li G, Wan F, Dai B, Ye D. Prognostic value of D-lactate dehydrogenase in patients with clear cell renal cell carcinoma. Oncol Lett. 2018;16(1):866 $\square$ 874. doi:10.3892/ol.2018.8782

311. Shimomura H, Sasahira T, Nakashima C, Shimomura-Kurihara M, Kirita T. Downregulation of DHRS9 is associated with poor prognosis in oral squamous cell carcinoma. Pathology. 2018;50(6):642 $\square 647$. doi:10.1016/j.pathol.2018.06.002

312. Xue Y, Wu L, Liu Y, Ma Y, Zhang L, Ma X, Yang Y, Chen J. ENTPD5 induces apoptosis in lung cancer cells via regulating caspase 3 expression. PLoS One. 2015;10(3):e120046. doi:10.1371/journal.pone.0120046

313. Zhang Q, Hong Z, Zhu J, Zeng C, Tang Z, Wang W, Huang H. miR4999-5p Predicts Colorectal Cancer Survival Outcome and Reprograms Glucose Metabolism by Targeting PRKAA2. Onco Targets Ther. 2020;13:1199 $\square$ 1210. doi:10.2147/OTT.S234666

314. Sánchez-Rodríguez R, Torres-Mena JE, Quintanar-Jurado V, Chagoya-Hazas V, del Castillo ER, del Pozo Yauner L, Villa-Treviño S, Pérez-Carreón JI. Ptgr1 expression is regulated by NRF2 in rat hepatocarcinogenesis and promotes cell proliferation and resistance to oxidative stress. Free Radic Biol Med. 2017;102:87 $\square 99$. doi:10.1016/j.freeradbiomed.2016.11.027

315. Hu YH, Ma S, Zhang XN, Zhang ZY, Zhu HF, Ji YH, Li J, Qian XL, Wang YX. Hypermethylation Of ADHFE1 Promotes The Proliferation Of 
Colorectal Cancer Cell Via Modulating Cell Cycle Progression. Onco Targets Ther. 2019;12:8105 $\square 8115$. doi:10.2147/OTT.S223423

316. Yamaguchi M, Osuka S, Weitzmann MN, Shoji M, Murata T. Increased regucalcin gene expression extends survival in breast cancer patients: Overexpression of regucalcin suppresses the proliferation and metastatic bone activity in MDA-MB-231 human breast cancer cells in vitro. Int J Oncol. 2016;49(2):812 $\square$ 822. doi:10.3892/ijo.2016.3538

317. Zhu L, Xing S, Zhang L, Yu JM, Lin C, Yang WJ. Involvement of Polo-like kinase 1 (Plk1) in quiescence regulation of cancer stem-like cells of the gastric cancer cell lines. Oncotarget. 2017;8(23):37633 $\square 37645$. doi:10.18632/oncotarget.16839

318. Pandi NS, Manimuthu M, Harunipriya P, Murugesan M, Asha GV, Rajendran S. In silico analysis of expression pattern of a Wnt/ $\beta$-catenin responsive gene ANLN in gastric cancer. Gene. 2014;545(1):23 $\square 29$. doi:10.1016/j.gene.2014.05.013

319. Zhang X, Wang W, Li P, Wang X, Ni K. High TREM2 expression correlates with poor prognosis in gastric cancer. Hum Pathol. 2018;72:91 $\square$ 99. doi:10.1016/j.humpath.2017.10.026

320. Rabenau KE, O'Toole JM, Bassi R, Kotanides H, Witte L, Ludwig DL, Pereira DS. DEGA/AMIGO-2, a leucine-rich repeat family member, differentially expressed in human gastric adenocarcinoma: effects on ploidy, chromosomal stability, cell adhesion/migration and tumorigenicity. Oncogene. 2004;23(29):5056 $\square$ 5067. doi:10.1038/sj.onc.1207681

321. Kaya S, Gumus M, Gurbuz Y, Cabuk D, Acikgoz O, Temiz S, Uygun $\mathrm{K}$. The prognostic value of $\beta$-catenin and LEF-1 expression in patients with operable gastric carcinoma. Am J Transl Res. 2016;8(2):1228 $\square 1236$.

322. Kang H, An HJ, Song JY, Kim TH, Heo JH, Ahn DH, Kim G. Notch3 and Jagged2 contribute to gastric cancer development and to glandular differentiation associated with MUC2 and MUC5AC expression. Histopathology. 2012;61(4):576 $\quad$ doi:10.1111/j.13652559.2012.04274.x

323. He XY, Zhao J, Chen ZQ, Jin R, Liu CY. High Expression of Retinoic Acid Induced 14 (RAI14) in Gastric Cancer and Its Prognostic Value. Med Sci Monit. 2018;24:2244ø2251. doi:10.12659/msm.910133 
324. Sun WJ, Hu DH, Wu H, Xiao H, Lu MD, Guo WJ, Huang H, Yu YJ, $\mathrm{Hu}$ TY, Zheng ZQ. Expression of AQP1 Was Associated with Apoptosis and Survival of Patients in Gastric Adenocarcinoma. Dig Surg. 2016;33(3):190 $\square$ 196. doi:10.1159/000443843

325. Kato F, Wada N, Hayashida T, Fukuda K, Nakamura R, Takahashi T,

Kawakubo H, Takeuchi H, Kitagawa Y. Experimental and clinicopathological analysis of HOXB9 in gastric cancer. Oncol Lett. 2019;17(3):3097ø3102. doi:10.3892/ol.2019.10008

326. Yang JY, Li D, Zhang Y, Guan BX, Gao P, Zhou XC, Zhou CJ. The Expression of MCM7 is a Useful Biomarker in the Early Diagnostic of Gastric Cancer. Pathol Oncol Res. 2018;24(2):367 $\square 372$. doi:10.1007/s12253-017-0251-1

327. Liu M, Li JS, Tian DP, Huang B, Rosqvist S, Su M. MCM2 expression levels predict diagnosis and prognosis in gastric cardiac cancer. Histol Histopathol. 2013;28(4):481 $\square$ 492. doi:10.14670/HH-28.481

328. Zhao B, Zhang J, Chen X, Xu H, Huang B. Mir-26b inhibits growth and resistance to paclitaxel chemotherapy by silencing the CDC6 gene in gastric cancer. Arch Med Sci. 2019;15(2):498 $\square 503$. doi:10.5114/aoms.2018.73315

329. Zhu Z, Yu Z, Rong Z, Luo Z, Zhang J, Qiu Z, Huang C. The novel GINS4 axis promotes gastric cancer growth and progression by activating Rac1 and CDC42. Theranostics. 2019;9(26):8294 $\square 8311$. doi:10.7150/thno.36256

330. Ma H, Chen X, Hu H, Li B, Ying X, Zhou C, Zhong J, Zhao G, Duan S. Hypermethylation of MDFI promoter with NSCLC is specific for females, non-smokers and people younger than 65. Oncol Lett. 2018;15(6):9017 $\square$ 9024. doi:10.3892/ol.2018.8535

331. Kuo KK, Jian SF, Li YJ, Wan SW, Weng CC, Fang K, Wu DC, Cheng KH. Epigenetic inactivation of transforming growth factor- $\beta 1$ target gene HEYL, a novel tumor suppressor, is involved in the P53-induced apoptotic pathway in hepatocellular carcinoma. Hepatol Res. 2015;45(7):782 $\square 793$. doi:10.1111/hepr.12414

332. Yuan Z, Mehta HJ, Mohammed K, Nasreen N, Roman R, Brantly M, Sadikot RT. TREM-1 is induced in tumor associated macrophages by cyclo- 
oxygenase pathway in human non-small cell lung cancer. PLoS One. 2014;9(5):e94241. doi:10.1371/journal.pone.0094241

333. Chung FF, Mai CW, Ng PY, Leong CO. Cytochrome P450 2W1 (CYP2W1) in Colorectal Cancers. Curr Cancer Drug Targets. 2016;16(1):71ロ78. doi:10.2174/1568009616888151112095948

334. Feigin ME, Xue B, Hammell MC, Muthuswamy SK. G-proteincoupled receptor GPR161 is overexpressed in breast cancer and is a promoter of cell proliferation and invasion. Proc Natl Acad Sci U S A. 2014;111(11):4191 $\square$ 4196. doi:10.1073/pnas.1320239111

335. Lawson CD, Der CJ. Filling GAPs in our knowledge: ARHGAP11A and RACGAP1 act as oncogenes in basal-like breast cancers. Small GTPases. 2018;9(4):290 $\square$ 296. doi:10.1080/21541248.2016.1220350

336. Tolkach Y, Ellinger J, Kremer A, Esser L, Müller SC, Stephan C, Jung K, Toma M, Kristiansen G, Hauser S. Apelin and apelin receptor expression in renal cell carcinoma. Br J Cancer. 2019;120(6):633 $\square 639$. doi:10.1038/s41416-019-0396-7

337. Zheng S, Lv P, Su J, Miao K, Xu H, Li M. Overexpression of CBX2 in breast cancer promotes tumor progression through the PI3K/AKT signaling pathway. Am J Transl Res. 2019;11(3):1668 $\square 1682$.

338. Chen X, Xiong D, Ye L, Wang K, Huang L, Mei S, Wu J, Chen S, Lai $\mathrm{X}$, Zheng L, et al. Up-regulated lncRNA XIST contributes to progression of cervical cancer via regulating miR-140-5p and ORC1. Cancer Cell Int. 2019;19:45. doi:10.1186/s12935-019-0744-y

339. Mahadevappa R, Neves H, Yuen SM, Jameel M, Bai Y, Yuen HF, Zhang SD, Zhu Y, Lin Y, Kwok HF. Mahadevappa R, Neves H, Yuen SM, et al. DNA Replication Licensing Protein MCM10 Promotes Tumor Progression and Is a Novel Prognostic Biomarker and Potential Therapeutic Target in Breast Cancer. Cancers (Basel). 2018;10(9):282. doi:10.3390/cancers10090282

340. Yang L, Xu JF, Kang Q, Li AQ, Jin P, Wang X, He YQ, Li N, Cheng T, Sheng JQ. Predictive Value of Stemness Factor Sox2 in Gastric Cancer Is Associated with Tumor Location and Stage. PLoS One. 2017;12(1):e0169124. doi:10.1371/journal.pone.0169124

341. Yang S, Lu M, Chen Y, Meng D, Sun R, Yun D, Zhao Z, Lu D, Li Y. Overexpression of eukaryotic elongation factor 1 alpha-2 is associated with 
poorer prognosis in patients with gastric cancer. J Cancer Res Clin Oncol. 2015;141(7):1265 $\square$ 1275. doi:10.1007/s00432-014-1897-7

342. Shimoyama S, Kaminishi M. Angiogenin in sera as an independent prognostic factor in gastric cancer. $\mathrm{J}$ Cancer Res Clin Oncol. 2003;129(4):239 $\square$ 244. doi:10.1007/s00432-003-0422-1

343. Zhang B, Bie Q, Wu P, Zhang J, You B, Shi H, Qian H, Xu W. PGD2/PTGDR2 Signaling Restricts the Self-Renewal and Tumorigenesis of Gastric Cancer. Stem Cells. 2018;36(7):990 $\square$ 1003. doi:10.1002/stem.2821

344. Xu J, Gong L, Qian Z, Song G, Liu J. ERBB4 promotes the proliferation of gastric cancer cells via the PI3K/Akt signaling pathway. Oncol Rep. 2018;39(6):2892 $\square 2898$. doi:10.3892/or.2018.6343

345. Abbott GW, Roepke TK. KCNE2 and gastric cancer: bench to bedside. Oncotarget. 2016;7(14):17286 $\square 17287$. doi:10.18632/oncotarget.7921

346. Kato Y, Yashiro M, Noda S, Kashiwagi S, Matsuoka J, Fuyuhiro Y, Doi Y, Hirakawa K. Expression of a hypoxia-associated protein, carbonic anhydrase-9, correlates with malignant phenotypes of gastric carcinoma. Digestion. 2010;82(4):246 $\square 251$. doi:10.1159/000297208

347. Qiao L, Feng Y. Genetic variations of prostate stem cell antigen (PSCA) contribute to the risk of gastric cancer for Eastern Asians: a metaanalysis based on 16792 individuals. Gene. 2012;493(1):83 $\square 91$. doi:10.1016/j.gene.2011.11.017

348. Qi ZH, Xu HX, Zhang SR, Xu JZ, Li S, Gao HL, Jin W, Wang WQ, Wu CT, Ni QX, et al. RIPK4/PEBP1 axis promotes pancreatic cancer cell migration and invasion by activating RAF1/MEK/ERK signaling. Int $\mathrm{J}$ Oncol. 2018;52(4):1105 $\square$ 1116. doi:10.3892/ijo.2018.4269

349. Li Z, Mou H, Wang T, Xue J, Deng B, Qian L, Zhou Y, Gong W, Wang JM, Wu G, et al. A non-secretory form of FAM3B promotes invasion and metastasis of human colon cancer cells by upregulating Slug expression. Cancer Lett. 2013;328(2):278 $\square 284$. doi:10.1016/j.canlet.2012.09.026

350. Yang H, Zhang H, Ge S, Ning T, Bai M, Li J, Li S, Sun W, Deng T, Zhang L, et al. Exosome-Derived miR-130a Activates Angiogenesis in Gastric Cancer by Targeting C-MYB in Vascular Endothelial Cells. Mol Ther. 2018;26(10):2466 $\square 2475$. doi:10.1016/j.ymthe.2018.07.023 
351. Pan L, Liang W, Gu J, Zang X, Huang Z, Shi H, Chen J, Fu M, Zhang $\mathrm{P}$, Xiao X, et al. Long noncoding RNA DANCR is activated by SALL4 and promotes the proliferation and invasion of gastric cancer cells. Oncotarget. 2017;9(2):1915 $\square$ 1930. doi:10.18632/oncotarget.23019

352. Tsutsumi K, Sato N, Cui L, Mizumoto K, Sadakari Y, Fujita H, Ohuchida K, Ohtsuka T, Takahata S, Tanaka M. Expression of claudin-4 (CLDN4) mRNA in intraductal papillary mucinous neoplasms of the pancreas. Mod $\quad$ Pathol. 2011;24(4):533 $\square 541$. doi:10.1038/modpathol.2010.218

353. Liu H, Du F, Sun L, Wu Q, Wu J, Tong M, Wang X, Wang Q, Cao T, Gao X, et al. GATA6 suppresses migration and metastasis by regulating the miR-520b/CREB1 axis in gastric cancer. Cell Death Dis. 2019;10(2):35. doi:10.1038/s41419-018-1270-x

354. Li X, Li Z, Liu Z, Xiao J, Yu S, Song Y. Long non-coding RNA DLEU1 predicts poor prognosis of gastric cancer and contributes to cell proliferation by epigenetically suppressing KLF2. Cancer Gene Ther. 2018;25(3-4):58 $\square 67$. doi:10.1038/s41417-017-0007-9

355. Zhang R, Zhu JC, Hu H, Lin QY, Shao W, Ji TH. MicroRNA-140-5p suppresses invasion and proliferation of glioma cells by targeting glutamateammonia ligase (GLUL). Neoplasma. 2020;67(2):371 $\square 378$. doi:10.4149/neo_2020_190514N432

356. Araújo TM, Seabra AD, Lima EM, Assumpção PP, Montenegro RC, Demachki S, Burbano RM, Khayat AS. Recurrent amplification of RTEL1 and ABCA13 and its synergistic effect associated with clinicopathological data of gastric adenocarcinoma. Mol Cytogenet. 2016;9:52. doi:10.1186/s13039-016-0260-x

357. Hour TC, Kuo YZ, Liu GY, Kang WY, Huang CY, Tsai YC, Wu WJ, Huang SP, Pu YS. ownregulation of ABCD1 in human renal cell carcinoma. Int J Biol Markers. 2009;24(3):171 $\square$ 178. doi:10.5301/jbm.2009.3280

358. Liang Y, Luo H, Zhang H, Dong Y, Bao Y. Oncogene Delta/NotchLike EGF-Related Receptor Promotes Cell Proliferation, Invasion, and Migration in Hepatocellular Carcinoma and Predicts a Poor Prognosis. 
Cancer Biother $\quad$ Radiopharm. 2018;33(9):380 $\quad 386$. doi:10.1089/cbr.2018.2460

359. Wang P, Zhuang C, Huang D, Xu K. Downregulation of miR-377 contributes to IRX3 deregulation in hepatocellular carcinoma. Oncol Rep. 2016;36(1):247 $\square$ 252. doi:10.3892/or.2016.4815

360. Mello AA, Leal MF, Rey JA, Pinto GR, Lamarão LM, Montenegro RC, Alves AP, Assumpcao PP, do Nascimento Borges B, Smith MC, et al. Deregulated Expression of SRC, LYN and CKB Kinases by DNA Methylation and Its Potential Role in Gastric Cancer Invasiveness and Metastasis. PLoS One. 2015;10(10):e0140492. doi:10.1371/journal.pone.0140492

361. Dabanaka K, Chung S, Nakagawa H, Nakamura Y, Okabayashi T, Sugimoto T, Hanazaki K, Furihata M. PKIB expression strongly correlated with phosphorylated Akt expression in breast cancers and also with triplenegative breast cancer subtype. Med Mol Morphol. 2012;45(4):229 233. doi:10.1007/s00795-011-0565-0

\section{Tables}

Table 1. Primers used for quantitative PCR

\begin{tabular}{ccc}
\hline & Primer sequence $\mathbf{( 5} \rightarrow \mathbf{3}^{\prime} \mathbf{)}$ & \\
\hline Forward & Forward & Forward \\
FN1 & CGGTGGCTGTCAGTCAAAG & AAACCTCGGCTTCCTCCATAA \\
PLK1 & AAAGAGATCCCGGAGGTCCTA & GGCTGCGGTGAATGGATATTTC \\
ANLN & TGCCAGGCGAGAGAATCTTC & CGCTTAGCATGAGTCATAGACCT \\
MCM7 & CCTACCAGCCGATCCAGTCT & CCTCCTGAGCGGTTGGTTT \\
MCM2 & ATGGCGGAATCATCGGAATCC & GGTGAGGGCATCAGTACGC \\
EEF1A2 & GAAGACCCACATCAACATCGT & CTCCGCATTTGTAGATGAGGTG \\
PTGER3 & CGCCTCAACCACTCCTACAC & GACACCGATCCGCAATCCTC \\
CKB & GCTGCGACTTCAGAAGCGA & GGCATGAGGTCGTCGATGG \\
ERBB4 & GTCCAGCCCAGCGATTCTC & AGAGCCACTAACACGTAGCCT \\
PRKAA2 & GTGAAGATCGGACACTACGTG & CTGCCACTTTATGGCCTGTTA \\
\hline
\end{tabular}

Table 2 The statistical metrics for key differentially expressed genes (DEGs)

\begin{tabular}{ccccccc}
\hline Gene Symbol & logFC & pValue & adj.P.Val & tvalue & Regulation & Gene Name \\
\hline COL4A1 & 2.972614 & $1.62 \mathrm{E}-19$ & $7.66 \mathrm{E}-16$ & 10.92342 & Up & collagen type IV alpha 1 chain \\
INHBA & 4.080822 & $1.08 \mathrm{E}-18$ & $3.39 \mathrm{E}-15$ & 10.57369 & $\mathrm{Up}$ & inhibin subunit beta A
\end{tabular}




\begin{tabular}{|c|c|c|c|c|c|c|}
\hline $\mathrm{RCC} 2$ & 1.607652 & $1.15 \mathrm{E}-18$ & $3.39 \mathrm{E}-15$ & 10.56222 & Up & regulator of chromosome condensation 2 \\
\hline THY1 & 3.439673 & $7.51 \mathrm{E}-18$ & $1.37 \mathrm{E}-14$ & 10.21558 & Up & Thy- 1 cell surface antigen \\
\hline MSR1 & 2.674374 & $9.57 \mathrm{E}-18$ & $1.62 \mathrm{E}-14$ & 10.17093 & Up & macrophage scavenger receptor 1 \\
\hline FAP & 4.024768 & $1.6 \mathrm{E}-17$ & $2.36 \mathrm{E}-14$ & 10.07644 & Up & fibroblast activation protein alpha \\
\hline SULF1 & 4.025951 & $2.37 \mathrm{E}-17$ & $3.12 \mathrm{E}-14$ & 10.00358 & Up & sulfatase 1 \\
\hline SERPINH1 & 2.149675 & $4.17 \mathrm{E}-17$ & $4.93 \mathrm{E}-14$ & 9.899306 & Up & serpin family $\mathrm{H}$ member 1 \\
\hline E2F3 & 1.634912 & $1.01 \mathrm{E}-16$ & $1.09 \mathrm{E}-13$ & 9.734805 & Up & $\begin{array}{c}\text { E2F transcription factor } 3 \\
\text { GLYCOSYLTRANSFERASE 25 FAMULY }\end{array}$ \\
\hline GLT25D1 & 1.642413 & $2.15 \mathrm{E}-16$ & $1.95 \mathrm{E}-13$ & 9.596128 & Up & MEMBER 1 \\
\hline BGN & 4.165579 & $2.62 \mathrm{E}-16$ & $2.3 \mathrm{E}-13$ & 9.55921 & Up & biglycan \\
\hline WISP1 & 3.125136 & $3.3 \mathrm{E}-16$ & $2.6 \mathrm{E}-13$ & 9.516536 & Up & Wnt1-inducible signaling pathway protein-1 \\
\hline TCOF1 & 1.579282 & $4.8 \mathrm{E}-16$ & $3.44 \mathrm{E}-13$ & 9.44697 & Up & treacle ribosome biogenesis factor 1 \\
\hline NID2 & 2.481827 & $5.63 \mathrm{E}-16$ & $3.7 \mathrm{E}-13$ & 9.417359 & Up & nidogen 2 \\
\hline $\mathrm{CAD}$ & 1.957354 & $8.28 \mathrm{E}-16$ & $4.9 \mathrm{E}-13$ & 9.345783 & Up & transcarbamylase, and dihydroorotase \\
\hline ADCY3 & 1.8303 & $1.1 \mathrm{E}-15$ & $6.21 \mathrm{E}-13$ & 9.292654 & Up & adenylatecyclase 3 \\
\hline ITGAX & 2.919285 & $1.3 \mathrm{E}-15$ & $7.09 \mathrm{E}-13$ & 9.26149 & Up & integrin subunit alpha $X$ \\
\hline ADAMTS12 & 3.296182 & $1.38 \mathrm{E}-15$ & $7.12 \mathrm{E}-13$ & 9.25041 & Up & $\begin{array}{l}\text { type } 1 \text { motif } 12 \\
\text { transient receptor potential cation channel }\end{array}$ \\
\hline TRPM2 & 1.961827 & $1.62 \mathrm{E}-15$ & $8 \mathrm{E}-13$ & 9.220805 & Up & subfamily M member 2 \\
\hline COL8A1 & 4.371259 & $2.07 \mathrm{E}-15$ & $9.61 \mathrm{E}-13$ & 9.175361 & Up & collagen type VIII alpha 1 chain \\
\hline TREM2 & 2.785416 & $2.15 \mathrm{E}-15$ & $9.8 \mathrm{E}-13$ & 9.168072 & Up & $\begin{array}{l}\text { triggering receptor expressed on myeloid cells } 2 \\
\text { methylenetetrahydrofolate dehydrogenase (NADP+ }\end{array}$ \\
\hline MTHFD1L & 2.041684 & $2.32 \mathrm{E}-15$ & $1.02 \mathrm{E}-12$ & 9.154495 & Up & dependent) 1 like \\
\hline TEAD4 & 1.8995 & $3.74 \mathrm{E}-15$ & $1.53 \mathrm{E}-12$ & 9.065089 & Up & TEA domain transcription factor 4 \\
\hline LOC541471 & 1.678209 & $7.14 \mathrm{E}-15$ & $2.68 \mathrm{E}-12$ & 8.944444 & Up & \#N/A \\
\hline COL4A2 & 2.519381 & $7.69 \mathrm{E}-15$ & $2.84 \mathrm{E}-12$ & 8.930613 & Up & collagen type IV alpha 2 chain \\
\hline SDS & 2.945396 & $9.34 \mathrm{E}-15$ & $3.4 \mathrm{E}-12$ & 8.894271 & Up & serine dehydratase \\
\hline BMP1 & 2.177414 & $1.56 \mathrm{E}-14$ & $5.06 \mathrm{E}-12$ & 8.798462 & Up & bone morphogenetic protein 1 \\
\hline SPARC & 2.574807 & $1.56 \mathrm{E}-14$ & $5.06 \mathrm{E}-12$ & 8.798331 & Up & secreted protein acidic and cysteine rich \\
\hline NOP2 & 1.613861 & $1.9 \mathrm{E}-14$ & $6.01 \mathrm{E}-12$ & 8.760938 & Up & NOP2 nucleolar protein \\
\hline GPNMB & 2.825201 & $2.18 \mathrm{E}-14$ & $6.62 \mathrm{E}-12$ & 8.735456 & Up & glycoprotein nmb \\
\hline RRP12 & 1.670106 & $2.22 \mathrm{E}-14$ & $6.67 \mathrm{E}-12$ & 8.73165 & Up & ribosomal RNA processing 12 homolog \\
\hline THBS2 & 4.303173 & $2.56 \mathrm{E}-14$ & $7.57 \mathrm{E}-12$ & 8.705365 & Up & thrombospondin 2 \\
\hline COL18A1 & 2.437266 & $4.31 \mathrm{E}-14$ & $1.2 \mathrm{E}-11$ & 8.607211 & Up & collagen type XVIII alpha 1 chain \\
\hline PLXNA1 & 1.662541 & $4.7 \mathrm{E}-14$ & $1.29 \mathrm{E}-11$ & 8.591156 & Up & plexin A1 \\
\hline RELT & 1.775325 & $4.93 \mathrm{E}-14$ & $1.3 \mathrm{E}-11$ & 8.582095 & Up & RELT TNF receptor \\
\hline COL5A2 & 2.509222 & $6.01 \mathrm{E}-14$ & $1.51 \mathrm{E}-11$ & 8.544741 & Up & collagen type $\mathrm{V}$ alpha 2 chain \\
\hline COL6A3 & 3.261072 & $6.35 \mathrm{E}-14$ & $1.57 \mathrm{E}-11$ & 8.534447 & Up & collagen type VI alpha 3 chain \\
\hline PRRX1 & 3.293988 & $9.59 \mathrm{E}-14$ & $2.2 \mathrm{E}-11$ & 8.456677 & Up & paired related homeobox 1 \\
\hline HAVCR2 & 1.895769 & $1.1 \mathrm{E}-13$ & $2.42 \mathrm{E}-11$ & 8.43141 & Up & hepatitis A virus cellular receptor 2 \\
\hline ANGPT2 & 1.886597 & $1.16 \mathrm{E}-13$ & $2.55 \mathrm{E}-11$ & 8.420387 & Up & angiopoietin 2 \\
\hline CEP170 & 1.820113 & $1.23 \mathrm{E}-13$ & $2.64 \mathrm{E}-11$ & 8.409774 & Up & $\begin{array}{l}\text { centrosomal protein } 170 \\
\text { ADAM metallopeptidase with thrombospondin }\end{array}$ \\
\hline ADAMTS2 & 3.15333 & $1.54 \mathrm{E}-13$ & $3.22 \mathrm{E}-11$ & 8.367548 & Up & type 1 motif 2 \\
\hline COL12A1 & 2.963842 & $1.61 \mathrm{E}-13$ & $3.34 \mathrm{E}-11$ & 8.358832 & Up & collagen type XII alpha 1 chain \\
\hline
\end{tabular}




\begin{tabular}{|c|c|c|c|c|c|c|}
\hline MFAP2 & 2.775014 & $1.99 \mathrm{E}-13$ & $3.99 \mathrm{E}-11$ & 8.318485 & Up & microfibril associated protein 2 \\
\hline MMP14 & 1.80734 & $3 \mathrm{E}-13$ & $5.77 \mathrm{E}-11$ & 8.240846 & Up & matrix metallopeptidase 14 \\
\hline FOXK1 & 1.63315 & $3.26 \mathrm{E}-13$ & $6.08 \mathrm{E}-11$ & 8.224703 & Up & forkhead box K1 \\
\hline PVT1 & 2.137405 & $3.33 \mathrm{E}-13$ & $6.12 \mathrm{E}-11$ & 8.220692 & Up & Pvt1 oncogene \\
\hline LEPRE1 & 1.683065 & $3.53 \mathrm{E}-13$ & $6.33 \mathrm{E}-11$ & 8.209775 & Up & Leucine- And Proline-Enriched Proteoglycan 1 \\
\hline PLA2G7 & 2.335604 & $3.87 \mathrm{E}-13$ & $6.78 \mathrm{E}-11$ & 8.192344 & Up & phospholipase A2 group VII \\
\hline CTHRC1 & 2.993366 & $4.44 \mathrm{E}-13$ & 7.73E-11 & 8.166018 & Up & collagen triple helix repeat containing 1 \\
\hline TIMP1 & 2.769289 & $4.77 \mathrm{E}-13$ & $8.01 \mathrm{E}-11$ & 8.152381 & Up & TIMP metallopeptidase inhibitor 1 \\
\hline PDGFRB & 2.683245 & $6.53 \mathrm{E}-13$ & $1.01 \mathrm{E}-10$ & 8.092516 & Up & platelet derived growth factor receptor beta \\
\hline LILRB4 & 2.318613 & $7.91 \mathrm{E}-13$ & $1.18 \mathrm{E}-10$ & 8.055983 & Up & leukocyte immunoglobulin like receptor B4 \\
\hline $\begin{array}{c}\text { TTYH3 } \\
\text { LOC } 10050570\end{array}$ & 2.15944 & $1.08 \mathrm{E}-12$ & $1.53 \mathrm{E}-10$ & 7.996266 & $\mathrm{Up}$ & tweety family member 3 \\
\hline 2 & 1.823494 & $1.11 \mathrm{E}-12$ & $1.56 \mathrm{E}-10$ & 7.992044 & Up & \#N/A \\
\hline LPCAT1 & 1.603274 & $1.19 \mathrm{E}-12$ & $1.67 \mathrm{E}-10$ & 7.9781 & Up & lysophosphatidylcholineacyltransferase 1 \\
\hline KIAA1199 & 3.7798 & $1.2 \mathrm{E}-12$ & $1.67 \mathrm{E}-10$ & 7.976353 & Up & $\begin{array}{l}\text { Hyaluronan-Binding Protein } \\
\text { nucleotide binding oligomerization domain }\end{array}$ \\
\hline NOD1 & 1.812531 & $1.28 \mathrm{E}-12$ & $1.77 \mathrm{E}-10$ & 7.964454 & Up & containing 1 \\
\hline COL1A2 & 3.011069 & $1.53 \mathrm{E}-12$ & $2.05 \mathrm{E}-10$ & 7.930162 & $\mathrm{Up}$ & collagen type I alpha 2 chain \\
\hline KAL1 & 2.529049 & $1.56 \mathrm{E}-12$ & $2.08 \mathrm{E}-10$ & 7.926407 & Up & Kallmann syndrome 1 \\
\hline PGF & 1.827148 & $1.9 \mathrm{E}-12$ & $2.44 \mathrm{E}-10$ & 7.888251 & Up & placental growth factor \\
\hline CTSL1 & 1.924328 & $2.02 \mathrm{E}-12$ & $2.57 \mathrm{E}-10$ & 7.876392 & Up & Cathepsin L1 \\
\hline NOTCH1 & 2.04241 & $2.11 \mathrm{E}-12$ & $2.65 \mathrm{E}-10$ & 7.867689 & Up & notch receptor 1 \\
\hline MYBBP1A & 1.56545 & $2.92 \mathrm{E}-12$ & $3.55 \mathrm{E}-10$ & 7.805317 & $\mathrm{Up}$ & MYB binding protein 1a \\
\hline LIF & 2.628837 & $3.26 \mathrm{E}-12$ & $3.9 \mathrm{E}-10$ & 7.784528 & Up & LIF interleukin 6 family cytokine \\
\hline MTBP & 1.566688 & $3.43 \mathrm{E}-12$ & $4.08 \mathrm{E}-10$ & 7.774674 & $\mathrm{Up}$ & MDM2 binding protein \\
\hline PODXL & 1.678369 & $3.49 \mathrm{E}-12$ & $4.14 \mathrm{E}-10$ & 7.771017 & Up & podocalyxin like \\
\hline FCGR2A & 2.042815 & $4.77 \mathrm{E}-12$ & $5.43 \mathrm{E}-10$ & 7.711092 & Up & $\mathrm{Fc}$ fragment of IgG receptor IIa \\
\hline ASPN & 3.192313 & $5.69 \mathrm{E}-12$ & $6.33 \mathrm{E}-10$ & 7.67682 & Up & asporin \\
\hline MEST & 2.033002 & $5.91 \mathrm{E}-12$ & $6.5 \mathrm{E}-10$ & 7.669643 & Up & mesoderm specific transcript \\
\hline IFITM3 & 1.811626 & $6.53 \mathrm{E}-12$ & $7.06 \mathrm{E}-10$ & 7.650202 & Up & interferon induced transmembrane protein 3 \\
\hline VASH1 & 1.732625 & $6.94 \mathrm{E}-12$ & $7.36 \mathrm{E}-10$ & 7.638494 & Up & $\begin{array}{l}\text { vasohibin } 1 \\
\text { splA/ryanodine receptor domain and SOCS box }\end{array}$ \\
\hline SPSB1 & 1.557471 & $8.5 \mathrm{E}-12$ & $8.63 \mathrm{E}-10$ & 7.599137 & Up & containing 1 \\
\hline RAB31 & 1.850995 & $9.07 \mathrm{E}-12$ & $9.06 \mathrm{E}-10$ & 7.586573 & $\mathrm{Up}$ & RAB31, member RAS oncogene family \\
\hline COL1A1 & 3.64102 & $9.22 \mathrm{E}-12$ & $9.17 \mathrm{E}-10$ & 7.5834 & Up & collagen type I alpha 1 chain \\
\hline KNTC1 & 1.565897 & $1.22 \mathrm{E}-11$ & $1.16 \mathrm{E}-09$ & 7.529552 & Up & kinetochore associated 1 \\
\hline SLC39A10 & 1.680223 & $1.42 \mathrm{E}-11$ & $1.32 \mathrm{E}-09$ & 7.498991 & Up & solute carrier family 39 member 10 \\
\hline ACTN1 & 1.677965 & $1.47 \mathrm{E}-11$ & $1.35 \mathrm{E}-09$ & 7.492714 & Up & actinin alpha 1 \\
\hline TDRD6 & 1.891436 & $1.78 \mathrm{E}-11$ & $1.61 \mathrm{E}-09$ & 7.454971 & Up & tudor domain containing 6 \\
\hline COL5A3 & 2.202227 & $2.01 \mathrm{E}-11$ & $1.77 \mathrm{E}-09$ & 7.431748 & Up & collagen type $\mathrm{V}$ alpha 3 chain \\
\hline SPHK1 & 2.448979 & $2.09 \mathrm{E}-11$ & $1.83 \mathrm{E}-09$ & 7.423857 & Up & sphingosine kinase 1 \\
\hline C5AR1 & 2.091061 & $2.32 \mathrm{E}-11$ & $2 \mathrm{E}-09$ & 7.403032 & $\mathrm{Up}$ & complement $\mathrm{C} 5$ a receptor 1 \\
\hline CTSB & 1.825225 & $2.34 \mathrm{E}-11$ & 2.01E-09 & 7.401651 & Up & cathepsin B \\
\hline SNX10 & 2.172538 & $2.4 \mathrm{E}-11$ & 2.04E-09 & 7.397183 & Up & sorting nexin 10 \\
\hline CLEC7A & 1.80967 & $2.58 \mathrm{E}-11$ & 2.17E-09 & 7.382581 & Up & C-type lectin domain containing 7A \\
\hline
\end{tabular}




\begin{tabular}{|c|c|c|c|c|c|c|}
\hline NFAM1 & 1.853487 & 2.63E-11 & $2.2 \mathrm{E}-09$ & 7.378992 & Up & NFAT activating protein with ITAM motif 1 \\
\hline ABCA1 & 1.719536 & $2.79 \mathrm{E}-11$ & $2.29 \mathrm{E}-09$ & 7.367414 & $\mathrm{Up}$ & ATP binding cassette subfamily A member 1 \\
\hline EMILIN2 & 1.553408 & $3.15 \mathrm{E}-11$ & 2.52E-09 & 7.343301 & Up & elastin microfibrilinterfacer 2 \\
\hline WDR62 & 1.957436 & $3.83 \mathrm{E}-11$ & $2.98 \mathrm{E}-09$ & 7.304983 & Up & WD repeat domain 62 \\
\hline RAI14 & 1.601279 & 4.4E-11 & $3.32 \mathrm{E}-09$ & 7.277967 & $\mathrm{Up}$ & $\begin{array}{l}\text { retinoic acid induced } 14 \\
\text { piezo type mechanosensitive ion channel }\end{array}$ \\
\hline PIEZO1 & 1.74628 & $4.6 \mathrm{E}-11$ & $3.41 \mathrm{E}-09$ & 7.269156 & Up & component 1 \\
\hline SERPINE1 & 2.947958 & 4.94E-11 & 3.61E-09 & 7.254962 & $\mathrm{Up}$ & serpin family E member 1 \\
\hline BMP8A & 2.229521 & $5.55 \mathrm{E}-11$ & 3.95E-09 & 7.232267 & Up & bone morphogenetic protein $8 \mathrm{a}$ \\
\hline NOTCH3 & 2.452432 & $5.96 \mathrm{E}-11$ & 4.21E-09 & 7.21815 & $\mathrm{Up}$ & notch receptor 3 \\
\hline NCF2 & 1.870599 & $6.03 \mathrm{E}-11$ & 4.23E-09 & 7.215631 & Up & neutrophil cytosolic factor 2 \\
\hline TGFBI & 1.984846 & $6.52 \mathrm{E}-11$ & 4.55E-09 & 7.200364 & Up & transforming growth factor beta induced \\
\hline CD300LF & 1.757513 & $6.72 \mathrm{E}-11$ & 4.63E-09 & 7.194229 & Up & CD300 molecule like family member f \\
\hline PRKDC & 1.608728 & 7.13E-11 & 4.81E-09 & 7.182665 & Up & protein kinase, DNA-activated, catalytic subunit \\
\hline DUSP10 & 1.667554 & 7.38E-11 & 4.91E-09 & 7.175931 & Up & dual specificity phosphatase 10 \\
\hline IFFO2 & 1.573573 & $7.81 \mathrm{E}-11$ & 5.15E-09 & 7.164643 & Up & intermediate filament family orphan 2 \\
\hline FSTL1 & 2.16055 & 7.95E-11 & 5.23E-09 & 7.161207 & Up & follistatin like 1 \\
\hline ST3GAL2 & 1.575122 & $8.61 \mathrm{E}-11$ & $5.62 \mathrm{E}-09$ & 7.145338 & Up & ST3 beta-galactoside alpha-2,3-sialyltransferase 2 \\
\hline TRIO & 1.628151 & $8.67 \mathrm{E}-11$ & 5.64E-09 & 7.143936 & Up & trio Rho guanine nucleotide exchange factor \\
\hline $\mathrm{F} 2 \mathrm{R}$ & 2.096849 & $9.01 \mathrm{E}-11$ & 5.81E-09 & 7.136385 & Up & coagulation factor II thrombin receptor \\
\hline PLXNC1 & 1.778859 & $9.55 \mathrm{E}-11$ & $6.11 \mathrm{E}-09$ & 7.124841 & Up & plexin $\mathrm{C} 1$ \\
\hline HAPLN3 & 2.194557 & $9.62 \mathrm{E}-11$ & $6.14 \mathrm{E}-09$ & 7.123387 & Up & hyaluronan and proteoglycan link protein 3 \\
\hline FN1 & 3.278172 & $9.82 \mathrm{E}-11$ & $6.25 \mathrm{E}-09$ & 7.119179 & Up & fibronectin 1 \\
\hline $\mathrm{RCN} 3$ & 2.200572 & $9.88 \mathrm{E}-11$ & $6.26 \mathrm{E}-09$ & 7.118011 & Up & reticulocalbin 3 \\
\hline ATAD5 & 1.68341 & $1.05 \mathrm{E}-10$ & $6.6 \mathrm{E}-09$ & 7.105167 & Up & $\begin{array}{l}\text { ATPase family AAA domain containing } 5 \\
\text { minichromosome maintenance complex component }\end{array}$ \\
\hline MCM7 & 1.670101 & $1.3 \mathrm{E}-10$ & 7.87E-09 & 7.063095 & Up & 7 \\
\hline IER5L & 1.897802 & $1.34 \mathrm{E}-10$ & 7.95E-09 & 7.058115 & Up & immediate early response 5 like \\
\hline DOCK4 & 1.670651 & $1.34 \mathrm{E}-10$ & 7.95E-09 & 7.057479 & Up & dedicator of cytokinesis 4 \\
\hline BOP1 & 1.707862 & $1.4 \mathrm{E}-10$ & $8.24 \mathrm{E}-09$ & 7.048991 & Up & BOP1 ribosomal biogenesis factor \\
\hline MDFI & 1.827513 & $1.46 \mathrm{E}-10$ & 8.57E-09 & 7.040197 & Up & MyoD family inhibitor \\
\hline EPHB2 & 3.171361 & $1.63 \mathrm{E}-10$ & $9.34 \mathrm{E}-09$ & 7.018777 & Up & $\mathrm{EPH}$ receptor $\mathrm{B} 2$ \\
\hline GAL3ST4 & 1.84346 & $1.63 \mathrm{E}-10$ & $9.35 \mathrm{E}-09$ & 7.018003 & Up & galactose-3-O-sulfotransferase 4 \\
\hline RHBDF2 & 1.570682 & $1.8 \mathrm{E}-10$ & $1.01 \mathrm{E}-08$ & 6.998712 & Up & $\begin{array}{l}\text { rhomboid } 5 \text { homolog } 2 \\
\text { potassium voltage-gated channel subfamily A }\end{array}$ \\
\hline KCNAB2 & 1.645556 & $1.93 \mathrm{E}-10$ & $1.06 \mathrm{E}-08$ & 6.98504 & Up & regulatory beta subunit 2 \\
\hline CLDN7 & 3.228188 & $1.99 \mathrm{E}-10$ & $1.09 \mathrm{E}-08$ & 6.979206 & Up & $\begin{array}{c}\text { claudin } 7 \\
\text { prostate transmembrane protein, androgen induced }\end{array}$ \\
\hline PMEPA1 & 2.347479 & $2.02 \mathrm{E}-10$ & $1.1 \mathrm{E}-08$ & 6.975423 & Up & 1 \\
\hline ILDR1 & 1.930265 & $2.03 \mathrm{E}-10$ & 1.1E-08 & 6.975195 & Up & immunoglobulin like domain containing receptor 1 \\
\hline RFTN1 & 1.824451 & $2.07 \mathrm{E}-10$ & $1.11 \mathrm{E}-08$ & 6.971295 & Up & raftlin, lipid raft linker 1 \\
\hline ENC1 & 1.605404 & $2.1 \mathrm{E}-10$ & $1.12 \mathrm{E}-08$ & 6.968068 & Up & $\begin{array}{l}\text { ectodermal-neural cortex } 1 \\
\text { FCH and mu domain containing endocytic adaptor }\end{array}$ \\
\hline FCHO1 & 1.699355 & $2.22 \mathrm{E}-10$ & $1.18 \mathrm{E}-08$ & 6.956621 & Up & 1 \\
\hline ENTPD1 & 1.602404 & $2.33 \mathrm{E}-10$ & $1.23 \mathrm{E}-08$ & 6.946888 & Up & ectonucleoside triphosphate diphosphohydrolase 1 \\
\hline SFRP4 & 4.658162 & $2.47 \mathrm{E}-10$ & $1.28 \mathrm{E}-08$ & 6.935666 & Up & secreted frizzled related protein 4 \\
\hline SEMA6B & 1.802608 & $2.5 \mathrm{E}-10$ & $1.3 \mathrm{E}-08$ & 6.932809 & Up & semaphorin 6B \\
\hline
\end{tabular}




\begin{tabular}{|c|c|c|c|c|c|c|}
\hline FGD6 & 1.724331 & $2.62 \mathrm{E}-10$ & $1.34 \mathrm{E}-08$ & 6.923574 & $\mathrm{Up}$ & $\begin{array}{l}\text { FYVE, RhoGEF and PH domain containing } 6 \\
\text { leucine rich repeat and fibronectin type III domain }\end{array}$ \\
\hline LRFN4 & 1.744418 & $2.94 \mathrm{E}-10$ & $1.47 \mathrm{E}-08$ & 6.90061 & $\mathrm{Up}$ & containing 4 \\
\hline LRP8 & 2.29507 & $3.15 \mathrm{E}-10$ & $1.55 \mathrm{E}-08$ & 6.886442 & $\mathrm{Up}$ & LDL receptor related protein 8 \\
\hline ESM1 & 2.497572 & $3.45 \mathrm{E}-10$ & $1.68 \mathrm{E}-08$ & 6.868734 & Up & endothelial cell specific molecule 1 \\
\hline LAPTM5 & 1.683259 & $3.6 \mathrm{E}-10$ & $1.74 \mathrm{E}-08$ & 6.859677 & $\mathrm{Up}$ & lysosomal protein transmembrane 5 \\
\hline ABCD1 & 1.57295 & $3.84 \mathrm{E}-10$ & $1.83 \mathrm{E}-08$ & 6.847189 & $\mathrm{Up}$ & ATP binding cassette subfamily D member 1 \\
\hline CLDN1 & 3.716278 & $4.19 \mathrm{E}-10$ & $1.97 \mathrm{E}-08$ & 6.829177 & $\mathrm{Up}$ & claudin 1 \\
\hline P4HA3 & 1.997044 & 4.63E-10 & 2.12E-08 & 6.809425 & $\mathrm{Up}$ & prolyl 4-hydroxylase subunit alpha 3 \\
\hline RAD54L & 1.729109 & $4.79 \mathrm{E}-10$ & $2.18 \mathrm{E}-08$ & 6.802366 & Up & RAD54 like \\
\hline CDH11 & 2.246797 & $4.9 \mathrm{E}-10$ & $2.22 \mathrm{E}-08$ & 6.797743 & $\mathrm{Up}$ & cadherin 11 \\
\hline CENPF & 2.020875 & $4.95 \mathrm{E}-10$ & $2.24 \mathrm{E}-08$ & 6.795601 & Up & centromere protein $\mathrm{F}$ \\
\hline CCR1 & 1.679479 & $5.01 \mathrm{E}-10$ & $2.26 \mathrm{E}-08$ & 6.793304 & Up & C-C motif chemokine receptor 1 \\
\hline $\mathrm{CDH} 13$ & 1.816279 & $5.19 \mathrm{E}-10$ & $2.32 \mathrm{E}-08$ & 6.786121 & Up & cadherin 13 \\
\hline SPON2 & 2.178941 & $5.21 \mathrm{E}-10$ & $2.32 \mathrm{E}-08$ & 6.785554 & $\mathrm{Up}$ & spondin 2 \\
\hline KIF18B & 1.857397 & $5.6 \mathrm{E}-10$ & $2.43 \mathrm{E}-08$ & 6.770716 & Up & kinesin family member $18 \mathrm{~B}$ \\
\hline CHN1 & 1.770805 & $6.24 \mathrm{E}-10$ & $2.65 \mathrm{E}-08$ & 6.749164 & Up & chimerin 1 \\
\hline PKMYT1 & 1.848328 & $6.3 \mathrm{E}-10$ & $2.67 \mathrm{E}-08$ & 6.747231 & $\mathrm{Up}$ & tyrosine/threonine 1 \\
\hline KIF23 & 1.815158 & $6.4 \mathrm{E}-10$ & $2.7 \mathrm{E}-08$ & 6.744026 & Up & kinesin family member 23 \\
\hline GPR176 & 1.72814 & $6.48 \mathrm{E}-10$ & $2.72 \mathrm{E}-08$ & 6.741355 & Up & G protein-coupled receptor 176 \\
\hline KIAA1524 & 1.707069 & $6.81 \mathrm{E}-10$ & $2.83 \mathrm{E}-08$ & 6.731287 & $\mathrm{Up}$ & cancerous inhibitor of PP2A \\
\hline TRIP13 & 1.765499 & $7.2 \mathrm{E}-10$ & $2.95 \mathrm{E}-08$ & 6.720174 & Up & thyroid hormone receptor interactor 13 \\
\hline FNDC1 & 4.01704 & $7.25 \mathrm{E}-10$ & $2.96 \mathrm{E}-08$ & 6.718633 & $\mathrm{Up}$ & fibronectin type III domain containing 1 \\
\hline FMNL3 & 1.625477 & 7.67E-10 & $3.11 \mathrm{E}-08$ & 6.707091 & Up & formin like 3 \\
\hline FANCD2 & 1.56858 & 7.7E-10 & $3.11 \mathrm{E}-08$ & 6.706407 & $\mathrm{Up}$ & FA complementation group D2 \\
\hline PLBD2 & 1.57102 & $7.73 \mathrm{E}-10$ & $3.12 \mathrm{E}-08$ & 6.705521 & $\mathrm{Up}$ & phospholipase B domain containing 2 \\
\hline SULF2 & 1.885993 & $8.06 \mathrm{E}-10$ & $3.22 \mathrm{E}-08$ & 6.697174 & $\mathrm{Up}$ & sulfatase 2 \\
\hline SPP1 & 4.420367 & $8.14 \mathrm{E}-10$ & $3.25 \mathrm{E}-08$ & 6.695265 & Up & secreted phosphoprotein 1 \\
\hline DYSF & 1.749917 & $8.65 \mathrm{E}-10$ & $3.41 \mathrm{E}-08$ & 6.682716 & $\mathrm{Up}$ & dysferlin \\
\hline THBS1 & 2.403719 & $8.93 \mathrm{E}-10$ & $3.48 \mathrm{E}-08$ & 6.676436 & $\mathrm{Up}$ & thrombospondin 1 \\
\hline OLFML2B & 2.620057 & $8.99 \mathrm{E}-10$ & $3.49 \mathrm{E}-08$ & 6.675031 & $\mathrm{Up}$ & olfactomedin like 2B \\
\hline SLC43A3 & 1.772551 & $9.03 \mathrm{E}-10$ & $3.49 \mathrm{E}-08$ & 6.674004 & Up & solute carrier family 43 member 3 \\
\hline ATAD2 & 1.726658 & $9.09 \mathrm{E}-10$ & $3.51 \mathrm{E}-08$ & 6.672638 & $\mathrm{Up}$ & ATPase family AAA domain containing 2 \\
\hline UPP1 & 1.604403 & $9.23 \mathrm{E}-10$ & $3.55 \mathrm{E}-08$ & 6.669603 & $\mathrm{Up}$ & uridinephosphorylase 1 \\
\hline XRCC2 & 1.560921 & $9.32 \mathrm{E}-10$ & $3.58 \mathrm{E}-08$ & 6.667543 & Up & $\mathrm{X}$-ray repair cross complementing 2 \\
\hline KIF14 & 1.850539 & $9.89 \mathrm{E}-10$ & $3.78 \mathrm{E}-08$ & 6.655614 & $\mathrm{Up}$ & kinesin family member 14 \\
\hline $\begin{array}{l}\text { COL3A1 } \\
\text { CSGALNACT }\end{array}$ & 2.576945 & 1E-09 & $3.82 \mathrm{E}-08$ & 6.653135 & $\mathrm{Up}$ & $\begin{array}{l}\text { collagen type III alpha } 1 \text { chain } \\
\text { chondroitin sulfate } \mathrm{N}-\end{array}$ \\
\hline 2 & 1.571169 & $1.01 \mathrm{E}-09$ & $3.85 \mathrm{E}-08$ & 6.651072 & $\mathrm{Up}$ & acetylgalactosaminyltransferase 2 \\
\hline IGFBP7 & 2.014261 & $1.03 \mathrm{E}-09$ & $3.91 \mathrm{E}-08$ & 6.647011 & $\mathrm{Up}$ & insulin like growth factor binding protein 7 \\
\hline ARMC9 & 1.606979 & $1.12 \mathrm{E}-09$ & 4.17E-08 & 6.630646 & $\mathrm{Up}$ & armadillo repeat containing 9 \\
\hline CDC25B & 1.734181 & $1.14 \mathrm{E}-09$ & 4.24E-08 & 6.625943 & $\mathrm{Up}$ & cell division cycle $25 \mathrm{~B}$ \\
\hline GNB4 & 1.564483 & $1.16 \mathrm{E}-09$ & $4.29 \mathrm{E}-08$ & 6.622715 & $\mathrm{Up}$ & G protein subunit beta 4 \\
\hline FCGR3A & 2.185483 & $1.2 \mathrm{E}-09$ & $4.39 \mathrm{E}-08$ & 6.615553 & Up & $\mathrm{Fc}$ fragment of $\mathrm{IgG}$ receptor IIIa \\
\hline
\end{tabular}




\begin{tabular}{|c|c|c|c|c|c|c|}
\hline ARHGAP39 & 1.765533 & $1.22 \mathrm{E}-09$ & 4.44E-08 & 6.612702 & Up & Rho GTPase activating protein 39 \\
\hline SH3PXD2B & 1.878221 & $1.28 \mathrm{E}-09$ & 4.62E-08 & 6.602918 & Up & SH3 and PX domains $2 \mathrm{~B}$ \\
\hline BUB1B & 1.722101 & $1.35 \mathrm{E}-09$ & 4.82E-08 & 6.592167 & Up & BUB1 mitotic checkpoint serine/threonine kinase B \\
\hline ACAN & 2.742413 & $1.41 \mathrm{E}-09$ & 4.98E-08 & 6.582618 & Up & aggrecan \\
\hline MARVELD1 & 1.670593 & $1.52 \mathrm{E}-09$ & $5.28 \mathrm{E}-08$ & 6.567303 & Up & MARVEL domain containing 1 \\
\hline SLC1A3 & 2.022669 & $1.61 \mathrm{E}-09$ & $5.55 \mathrm{E}-08$ & 6.556542 & Up & solute carrier family 1 member 3 \\
\hline PIK3AP1 & 1.62924 & $1.65 \mathrm{E}-09$ & 5.67E-08 & 6.550842 & Up & phosphoinositide-3-kinase adaptor protein 1 \\
\hline CKAP2 & 1.553455 & $1.68 \mathrm{E}-09$ & 5.74E-08 & 6.547273 & Up & cytoskeleton associated protein 2 \\
\hline SLC37A2 & 1.734597 & $1.8 \mathrm{E}-09$ & $6.06 \mathrm{E}-08$ & 6.532982 & Up & solute carrier family 37 member 2 \\
\hline PDPN & 2.041864 & $1.84 \mathrm{E}-09$ & $6.15 \mathrm{E}-08$ & 6.528961 & Up & podoplanin \\
\hline ADAM12 & 2.395205 & $1.91 \mathrm{E}-09$ & $6.31 \mathrm{E}-08$ & 6.520854 & $\mathrm{Up}$ & ADAM metallopeptidase domain 12 \\
\hline C1QTNF6 & 1.701272 & $1.97 \mathrm{E}-09$ & $6.49 \mathrm{E}-08$ & 6.514985 & Up & $\mathrm{C} 1 \mathrm{q}$ and $\mathrm{TNF}$ related 6 \\
\hline COL7A1 & 2.892737 & $2.19 \mathrm{E}-09$ & 7.09E-08 & 6.493046 & Up & collagen type VII alpha 1 chain \\
\hline $\mathrm{CCNF}$ & 1.591779 & $2.19 \mathrm{E}-09$ & 7.09E-08 & 6.492753 & Up & cyclin $\mathrm{F}$ \\
\hline CLSPN & 1.754245 & $2.23 \mathrm{E}-09$ & $7.2 \mathrm{E}-08$ & 6.48898 & $\mathrm{Up}$ & claspin \\
\hline ATP11A & 1.733479 & 2.33E-09 & 7.44E-08 & 6.480717 & Up & ATPase phospholipid transporting 11A \\
\hline CHTF18 & 1.562715 & 2.37E-09 & 7.55E-08 & 6.477173 & Up & chromosome transmission fidelity factor 18 \\
\hline LCP2 & 1.563638 & $2.37 \mathrm{E}-09$ & 7.55E-08 & 6.476875 & Up & $\begin{array}{l}\text { lymphocyte cytosolic protein } 2 \\
\text { hes related family bHLH transcription factor with }\end{array}$ \\
\hline HEYL & 2.589415 & $2.47 \mathrm{E}-09$ & $7.8 \mathrm{E}-08$ & 6.467962 & Up & YRPW motif like \\
\hline NNMT & 2.291847 & 2.77E-09 & $8.65 \mathrm{E}-08$ & 6.44469 & Up & nicotinamide N-methyltransferase \\
\hline IGSF6 & 1.701301 & $2.79 \mathrm{E}-09$ & 8.69E-08 & 6.443287 & Up & immunoglobulin superfamily member 6 \\
\hline BUB1 & 1.787001 & $2.83 \mathrm{E}-09$ & $8.8 \mathrm{E}-08$ & 6.439972 & Up & BUB1 mitotic checkpoint serine/threonine kinase \\
\hline RECQL4 & 1.873814 & 3.36E-09 & $1.01 \mathrm{E}-07$ & 6.404925 & Up & RecQ like helicase 4 \\
\hline $\begin{array}{c}\text { C11 orf } 82 \\
\text { LOC } 10028863\end{array}$ & 1.643213 & 3.61E-09 & $1.08 \mathrm{E}-07$ & 6.390004 & Up & Chromosome 11 Open Reading Frame 82 \\
\hline 7 & 1.570791 & $3.74 \mathrm{E}-09$ & $1.12 \mathrm{E}-07$ & 6.382551 & Up & OTU deubiquitinase 7A pseudogene \\
\hline $\mathrm{NCAPH}$ & 1.598637 & $4.26 \mathrm{E}-09$ & $1.24 \mathrm{E}-07$ & 6.355631 & Up & non-SMC condensin I complex subunit $\mathrm{H}$ \\
\hline OSMR & 1.821329 & $4.29 \mathrm{E}-09$ & $1.25 \mathrm{E}-07$ & 6.354286 & Up & oncostatin $\mathrm{M}$ receptor \\
\hline LZTS1 & 2.266255 & 4.34E-09 & $1.26 \mathrm{E}-07$ & 6.351682 & Up & leucine zipper tumor suppressor 1 \\
\hline KIAA1274 & 1.713015 & 4.46E-09 & $1.29 \mathrm{E}-07$ & 6.345972 & Up & Phosphatase Domain Containing Paladin 1 \\
\hline SLC11A1 & 2.285848 & $4.51 \mathrm{E}-09$ & $1.3 \mathrm{E}-07$ & 6.343859 & Up & solute carrier family 11 member 1 \\
\hline STIL & 1.715736 & $4.68 \mathrm{E}-09$ & $1.34 \mathrm{E}-07$ & 6.336072 & Up & STIL centriolar assembly protein \\
\hline C15orf42 & 1.947609 & 4.82E-09 & $1.37 \mathrm{E}-07$ & 6.329813 & Up & chromosome 15 open reading frame 42 \\
\hline KIF4A & 1.725143 & $4.88 \mathrm{E}-09$ & $1.39 \mathrm{E}-07$ & 6.327425 & Up & kinesin family member $4 \mathrm{~A}$ \\
\hline GPR161 & 1.690141 & 4.94E-09 & $1.4 \mathrm{E}-07$ & 6.324796 & Up & G protein-coupled receptor 161 \\
\hline $\mathrm{P} 2 \mathrm{RX} 7$ & 1.582058 & $5.01 \mathrm{E}-09$ & $1.41 \mathrm{E}-07$ & 6.321892 & Up & purinergic receptor $\mathrm{P} 2 \mathrm{X} 7$ \\
\hline CDCA5 & 1.864053 & $5.03 \mathrm{E}-09$ & $1.41 \mathrm{E}-07$ & 6.321119 & Up & cell division cycle associated 5 \\
\hline CLEC5A & 1.99045 & $5.18 \mathrm{E}-09$ & $1.45 \mathrm{E}-07$ & 6.315142 & Up & C-type lectin domain containing $5 \mathrm{~A}$ \\
\hline KIF26B & 2.186482 & 5.3E-09 & $1.48 \mathrm{E}-07$ & 6.310447 & Up & kinesin family member $26 \mathrm{~B}$ \\
\hline TFEC & 1.566971 & $5.52 \mathrm{E}-09$ & $1.53 \mathrm{E}-07$ & 6.301734 & Up & transcription factor EC \\
\hline EXO1 & 1.67768 & $5.78 \mathrm{E}-09$ & $1.58 \mathrm{E}-07$ & 6.29207 & Up & exonuclease 1 \\
\hline TUBB3 & 2.236373 & $5.92 \mathrm{E}-09$ & $1.61 \mathrm{E}-07$ & 6.287251 & Up & tubulin beta 3 class III \\
\hline CASC5 & 1.652782 & $6.12 \mathrm{E}-09$ & $1.65 \mathrm{E}-07$ & 6.280163 & Up & kinetochore scaffold 1 \\
\hline
\end{tabular}




\begin{tabular}{|c|c|c|c|c|c|c|}
\hline TPX2 & 1.930431 & $6.29 \mathrm{E}-09$ & $1.69 \mathrm{E}-07$ & 6.274712 & $\mathrm{Up}$ & TPX2 microtubule nucleation factor \\
\hline POLQ & 1.819336 & $6.84 \mathrm{E}-09$ & $1.81 \mathrm{E}-07$ & 6.257122 & $\mathrm{Up}$ & DNA polymerase theta \\
\hline RGS1 & 2.049497 & 7.19E-09 & $1.87 \mathrm{E}-07$ & 6.246677 & $\mathrm{Up}$ & regulator of $\mathrm{G}$ protein signaling 1 \\
\hline EDNRA & 1.856733 & 7.22E-09 & $1.88 \mathrm{E}-07$ & 6.245851 & $\mathrm{Up}$ & endothelin receptor type A \\
\hline ITGA5 & 1.716856 & 7.64E-09 & $1.97 \mathrm{E}-07$ & 6.233848 & $\mathrm{Up}$ & integrin subunit alpha 5 \\
\hline PRR5L & 1.676315 & 7.72E-09 & $1.98 \mathrm{E}-07$ & 6.231668 & Up & proline rich 5 like \\
\hline PLXDC2 & 2.054708 & 7.76E-09 & $1.98 \mathrm{E}-07$ & 6.230814 & $\mathrm{Up}$ & plexin domain containing 2 \\
\hline FAM26E & 1.758127 & $8.22 \mathrm{E}-09$ & $2.07 \mathrm{E}-07$ & 6.21852 & Up & Calcium Homeostasis Modulator Family Member 5 \\
\hline KIF20A & 1.597958 & $8.41 \mathrm{E}-09$ & $2.11 \mathrm{E}-07$ & 6.213917 & $\mathrm{Up}$ & kinesin family member $20 \mathrm{~A}$ \\
\hline PLAU & 1.923316 & 8.99E-09 & $2.24 \mathrm{E}-07$ & 6.199773 & $\mathrm{Up}$ & plasminogen activator, urokinase \\
\hline KIRREL & 1.859596 & $9.32 \mathrm{E}-09$ & $2.32 \mathrm{E}-07$ & 6.192213 & Up & Kirre Like Nephrin Family Adhesion Molecule 1 \\
\hline KIF21B & 1.572691 & $9.79 \mathrm{E}-09$ & $2.41 \mathrm{E}-07$ & 6.181902 & Up & kinesin family member $21 \mathrm{~B}$ \\
\hline FKBP10 & 2.18757 & $1 \mathrm{E}-08$ & $2.45 \mathrm{E}-07$ & 6.17754 & Up & FKBP prolylisomerase 10 \\
\hline RTKN2 & 1.676019 & $1.05 \mathrm{E}-08$ & $2.55 \mathrm{E}-07$ & 6.16672 & $\mathrm{Up}$ & rhotekin 2 \\
\hline MRC2 & 2.049876 & $1.15 \mathrm{E}-08$ & $2.76 \mathrm{E}-07$ & 6.147734 & $\mathrm{Up}$ & mannose receptor $\mathrm{C}$ type 2 \\
\hline PVRL1 & 1.725234 & $1.16 \mathrm{E}-08$ & $2.76 \mathrm{E}-07$ & 6.146977 & $\mathrm{Up}$ & Poliovirus receptor-related 1 \\
\hline LEF1 & 1.927508 & $1.22 \mathrm{E}-08$ & $2.88 \mathrm{E}-07$ & 6.13553 & $\mathrm{Up}$ & lymphoid enhancer binding factor 1 \\
\hline LILRB3 & 1.673521 & $1.24 \mathrm{E}-08$ & $2.92 \mathrm{E}-07$ & 6.13191 & Up & $\begin{array}{l}\text { leukocyte immunoglobulin like receptor B3 } \\
\text { EGF-like module-containing mucin-like hormone }\end{array}$ \\
\hline EMR2 & 1.578167 & $1.28 \mathrm{E}-08$ & $2.99 \mathrm{E}-07$ & 6.125181 & $\mathrm{Up}$ & receptor-like 2 \\
\hline COL15A1 & 1.883791 & $1.35 \mathrm{E}-08$ & $3.13 \mathrm{E}-07$ & 6.114452 & $\mathrm{Up}$ & $\begin{array}{l}\text { collagen type } \mathrm{XV} \text { alpha } 1 \text { chain } \\
\text { pleckstrin homology and RhoGEF domain }\end{array}$ \\
\hline PLEKHG2 & 1.80988 & $1.35 \mathrm{E}-08$ & $3.13 \mathrm{E}-07$ & 6.113741 & $\mathrm{Up}$ & containing G2 \\
\hline PDLIM7 & 1.740568 & $1.38 \mathrm{E}-08$ & $3.18 \mathrm{E}-07$ & 6.109095 & $\mathrm{Up}$ & PDZ and LIM domain 7 \\
\hline HTRA3 & 2.032862 & $1.4 \mathrm{E}-08$ & $3.21 \mathrm{E}-07$ & 6.10624 & $\mathrm{Up}$ & HtrA serine peptidase 3 \\
\hline COL5A1 & 2.251397 & $1.41 \mathrm{E}-08$ & $3.21 \mathrm{E}-07$ & 6.105813 & $\mathrm{Up}$ & collagen type $\mathrm{V}$ alpha 1 chain \\
\hline FSCN1 & 1.859536 & $1.6 \mathrm{E}-08$ & $3.58 \mathrm{E}-07$ & 6.078685 & $\mathrm{Up}$ & fascin actin-bundling protein 1 \\
\hline $\mathrm{CPZ}$ & 2.709031 & $1.6 \mathrm{E}-08$ & $3.58 \mathrm{E}-07$ & 6.078232 & Up & carboxypeptidase $\mathrm{Z}$ \\
\hline PILRA & 1.639131 & $1.64 \mathrm{E}-08$ & $3.66 \mathrm{E}-07$ & 6.072697 & $\mathrm{Up}$ & paired immunoglobin like type 2 receptor alpha \\
\hline NOX4 & 2.17837 & $1.68 \mathrm{E}-08$ & $3.74 \mathrm{E}-07$ & 6.067524 & $\mathrm{Up}$ & NADPH oxidase 4 \\
\hline COL10A1 & 3.294663 & $1.69 \mathrm{E}-08$ & $3.74 \mathrm{E}-07$ & 6.066712 & $\mathrm{Up}$ & collagen type $X$ alpha 1 chain \\
\hline CDCA7 & 1.873706 & $1.7 \mathrm{E}-08$ & $3.74 \mathrm{E}-07$ & 6.066149 & Up & cell division cycle associated 7 \\
\hline GUCY1B3 & 1.714941 & $1.75 \mathrm{E}-08$ & $3.84 \mathrm{E}-07$ & 6.058799 & Up & Guanylatecyclase soluble subunit beta- 1 \\
\hline FCGR1A & 1.550648 & $1.8 \mathrm{E}-08$ & $3.92 \mathrm{E}-07$ & 6.053685 & $\mathrm{Up}$ & $\begin{array}{l}\mathrm{Fc} \text { fragment of IgG receptor Ia } \\
\text { cysteine rich secretory protein LCCL domain }\end{array}$ \\
\hline CRISPLD1 & 2.840034 & $1.87 \mathrm{E}-08$ & $4.06 \mathrm{E}-07$ & 6.045375 & $\mathrm{Up}$ & containing 1 \\
\hline PGM2L1 & 1.604202 & $1.89 \mathrm{E}-08$ & $4.08 \mathrm{E}-07$ & 6.043469 & $\mathrm{Up}$ & phosphoglucomutase 2 like 1 \\
\hline HJURP & 1.660521 & $1.9 \mathrm{E}-08$ & 4.09E-07 & 6.042214 & $\mathrm{Up}$ & $\begin{array}{l}\text { Holliday junction recognition protein } \\
\text { minichromosome maintenance complex component }\end{array}$ \\
\hline MCM2 & 1.610827 & $1.9 \mathrm{E}-08$ & 4.1E-07 & 6.041763 & Up & 2 \\
\hline EPPK1 & 2.121199 & $1.97 \mathrm{E}-08$ & $4.21 \mathrm{E}-07$ & 6.034651 & $\mathrm{Up}$ & epiplakin 1 \\
\hline LRRC32 & 2.114457 & $1.98 \mathrm{E}-08$ & 4.23E-07 & 6.03315 & $\mathrm{Up}$ & leucine rich repeat containing 32 \\
\hline GINS4 & 1.554033 & $2.01 \mathrm{E}-08$ & $4.28 \mathrm{E}-07$ & 6.030407 & Up & GINS complex subunit 4 \\
\hline $\mathrm{CD} 84$ & 1.610976 & $2.02 \mathrm{E}-08$ & 4.3E-07 & 6.029305 & $\mathrm{Up}$ & CD84 molecule \\
\hline VCAN & 2.144966 & $2.03 \mathrm{E}-08$ & 4.33E-07 & 6.027469 & $\mathrm{Up}$ & versican \\
\hline ARHGAP11A & 1.630033 & $2.09 \mathrm{E}-08$ & 4.44E-07 & 6.021732 & $\mathrm{Up}$ & Rho GTPase activating protein $11 \mathrm{~A}$ \\
\hline
\end{tabular}




\begin{tabular}{|c|c|c|c|c|c|c|}
\hline SLC2A3 & 1.845064 & $2.14 \mathrm{E}-08$ & 4.52E-07 & 6.016445 & Up & solute carrier family 2 member 3 \\
\hline FOXM1 & 1.797631 & $2.19 \mathrm{E}-08$ & 4.6E-07 & 6.012159 & Up & forkhead box M1 \\
\hline ORC1 & 1.553737 & 2.2E-08 & 4.62E-07 & 6.010844 & Up & origin recognition complex subunit 1 \\
\hline TNFAIP2 & 1.893301 & $2.33 \mathrm{E}-08$ & 4.84E-07 & 5.998857 & Up & $\begin{array}{c}\text { TNF alpha induced protein } 2 \\
\text { ADAM metallopeptidase with thrombospondin }\end{array}$ \\
\hline ADAMTS4 & 1.862137 & $2.39 \mathrm{E}-08$ & 4.93E-07 & 5.993264 & Up & type 1 motif 4 \\
\hline SERPINB9 & 1.76002 & $2.45 \mathrm{E}-08$ & $5.01 \mathrm{E}-07$ & 5.9883 & Up & serpin family B member 9 \\
\hline OLR1 & 2.216021 & $2.64 \mathrm{E}-08$ & $5.36 \mathrm{E}-07$ & 5.972109 & Up & oxidized low density lipoprotein receptor 1 \\
\hline FSTL3 & 1.861555 & $2.7 \mathrm{E}-08$ & $5.45 \mathrm{E}-07$ & 5.966959 & Up & follistatin like 3 \\
\hline LOXL2 & 1.628413 & $2.84 \mathrm{E}-08$ & $5.66 \mathrm{E}-07$ & 5.956474 & Up & lysyl oxidase like 2 \\
\hline $\mathrm{KIF} 2 \mathrm{C}$ & 1.696056 & $2.86 \mathrm{E}-08$ & $5.7 \mathrm{E}-07$ & 5.954899 & Up & kinesin family member $2 \mathrm{C}$ \\
\hline FOXS1 & 1.848254 & $3 \mathrm{E}-08$ & 5.91E-07 & 5.944636 & Up & forkhead box S1 \\
\hline ANKRD13B & 1.557613 & $3.1 \mathrm{E}-08$ & $6.08 \mathrm{E}-07$ & 5.937383 & Up & ankyrin repeat domain 13B \\
\hline GUCY1A3 & 2.333005 & $3.12 \mathrm{E}-08$ & $6.1 \mathrm{E}-07$ & 5.936473 & Up & $\begin{array}{l}\text { Guanylatecyclase soluble subunit alpha-3 } \\
\text { Sterile alpha motif and leucine zipper containing }\end{array}$ \\
\hline ZAK & 1.552581 & $3.16 \mathrm{E}-08$ & $6.15 \mathrm{E}-07$ & 5.933546 & Up & kinase AZK \\
\hline ITGA11 & 2.068155 & $3.25 \mathrm{E}-08$ & $6.3 \mathrm{E}-07$ & 5.927286 & Up & integrin subunit alpha 11 \\
\hline ICAM1 & 1.944005 & $3.74 \mathrm{E}-08$ & 7.03E-07 & 5.897156 & Up & intercellular adhesion molecule 1 \\
\hline PXDN & 1.618901 & $4.16 \mathrm{E}-08$ & 7.66E-07 & 5.874542 & Up & peroxidasin \\
\hline ODF2L & 1.618387 & $4.25 \mathrm{E}-08$ & $7.8 \mathrm{E}-07$ & 5.869993 & Up & outer dense fiber of sperm tails 2 like \\
\hline ASPM & 1.759881 & $4.28 \mathrm{E}-08$ & 7.83E-07 & 5.868482 & Up & $\begin{array}{l}\text { abnormal spindle microtubule assembly } \\
\text { GTP binding protein overexpressed in skeletal }\end{array}$ \\
\hline GEM & 1.935598 & $4.58 \mathrm{E}-08$ & $8.31 \mathrm{E}-07$ & 5.853538 & Up & muscle \\
\hline GPX8 & 1.574781 & $4.62 \mathrm{E}-08$ & $8.36 \mathrm{E}-07$ & 5.852054 & Up & glutathione peroxidase 8 (putative) \\
\hline APOC1 & 2.532428 & $4.78 \mathrm{E}-08$ & 8.6E-07 & 5.844346 & Up & apolipoprotein $\mathrm{C} 1$ \\
\hline CSF3R & 2.319103 & $5.28 \mathrm{E}-08$ & $9.29 \mathrm{E}-07$ & 5.823068 & Up & colony stimulating factor 3 receptor \\
\hline TMEM158 & 1.64545 & $5.67 \mathrm{E}-08$ & $9.86 \mathrm{E}-07$ & 5.807673 & Up & transmembrane protein 158 (gene/pseudogene) \\
\hline ZNF469 & 2.064601 & $5.91 \mathrm{E}-08$ & $1.02 \mathrm{E}-06$ & 5.798504 & Up & zinc finger protein 469 \\
\hline PLXDC1 & 1.737904 & $6.08 \mathrm{E}-08$ & $1.05 \mathrm{E}-06$ & 5.79242 & Up & plexin domain containing 1 \\
\hline PIK3R5 & 1.553293 & $6.25 \mathrm{E}-08$ & 1.07E-06 & 5.78673 & Up & phosphoinositide-3-kinase regulatory subunit 5 \\
\hline DGKH & 1.612376 & $6.55 \mathrm{E}-08$ & $1.12 \mathrm{E}-06$ & 5.77644 & Up & diacylglycerol kinase eta \\
\hline FADS2 & 1.657975 & 7.05E-08 & $1.18 \mathrm{E}-06$ & 5.760527 & Up & fatty acid desaturase 2 \\
\hline FGR & 1.579559 & $7.16 \mathrm{E}-08$ & $1.2 \mathrm{E}-06$ & 5.757077 & Up & FGR proto-oncogene, Src family tyrosine kinase \\
\hline LIPG & 2.049762 & $7.36 \mathrm{E}-08$ & $1.23 \mathrm{E}-06$ & 5.751138 & Up & lipase G, endothelial type \\
\hline SERPINE2 & 2.202612 & 7.53E-08 & $1.25 \mathrm{E}-06$ & 5.74608 & Up & serpin family E member 2 \\
\hline MMP11 & 2.952133 & 7.63E-08 & $1.26 \mathrm{E}-06$ & 5.743236 & Up & $\begin{array}{l}\text { matrix metallopeptidase } 11 \\
\text { minichromosome maintenance } 10 \text { replication }\end{array}$ \\
\hline MCM10 & 1.774936 & 7.71E-08 & $1.27 \mathrm{E}-06$ & 5.741063 & Up & initiation factor \\
\hline APOE & 2.254187 & 7.79E-08 & $1.28 \mathrm{E}-06$ & 5.738793 & Up & apolipoprotein E \\
\hline NEK2 & 1.692854 & $7.85 \mathrm{E}-08$ & $1.29 \mathrm{E}-06$ & 5.737093 & Up & NIMA related kinase 2 \\
\hline CDCA2 & 1.668033 & $8.29 \mathrm{E}-08$ & $1.35 \mathrm{E}-06$ & 5.725122 & Up & cell division cycle associated 2 \\
\hline IQGAP3 & 1.733444 & $8.51 \mathrm{E}-08$ & $1.38 \mathrm{E}-06$ & 5.719417 & Up & IQ motif containing GTPase activating protein 3 \\
\hline CALD1 & 1.71965 & $8.94 \mathrm{E}-08$ & $1.44 \mathrm{E}-06$ & 5.708809 & Up & caldesmon 1 \\
\hline $\mathrm{CBX} 2$ & 1.867374 & $1.01 \mathrm{E}-07$ & $1.6 \mathrm{E}-06$ & 5.683057 & Up & chromobox 2 \\
\hline FAR2 & 1.571986 & $1.04 \mathrm{E}-07$ & 1.64E-06 & 5.674834 & Up & fatty acyl-CoA reductase 2 \\
\hline NTM & 1.953707 & $1.05 \mathrm{E}-07$ & $1.64 \mathrm{E}-06$ & 5.674553 & Up & neurotrimin \\
\hline
\end{tabular}




\begin{tabular}{|c|c|c|c|c|c|c|}
\hline AMIGO2 & 1.75988 & $1.16 \mathrm{E}-07$ & $1.78 \mathrm{E}-06$ & 5.65216 & Up & adhesion molecule with Ig like domain 2 \\
\hline WNT2 & 2.404356 & $1.2 \mathrm{E}-07$ & $1.84 \mathrm{E}-06$ & 5.644602 & Up & $\begin{array}{l}\text { Wnt family member } 2 \\
\text { glutamate ionotropic receptor NMDA type subunit }\end{array}$ \\
\hline GRIN2D & 2.307741 & $1.27 \mathrm{E}-07$ & $1.93 \mathrm{E}-06$ & 5.63168 & Up & $2 \mathrm{D}$ \\
\hline MKI67 & 1.710561 & $1.32 \mathrm{E}-07$ & $1.99 \mathrm{E}-06$ & 5.623865 & Up & marker of proliferation Ki-67 \\
\hline LINC00340 & 1.704574 & $1.37 \mathrm{E}-07$ & $2.06 \mathrm{E}-06$ & 5.614696 & Up & \#N/A \\
\hline ETV4 & 2.243602 & $1.39 \mathrm{E}-07$ & $2.08 \mathrm{E}-06$ & 5.611977 & Up & ETS variant transcription factor 4 \\
\hline AJUBA & 1.785348 & $1.51 \mathrm{E}-07$ & $2.22 \mathrm{E}-06$ & 5.593443 & Up & ajuba LIM protein \\
\hline ANLN & 1.750152 & $1.58 \mathrm{E}-07$ & $2.31 \mathrm{E}-06$ & 5.584125 & Up & anillin actin binding protein \\
\hline PARVG & 1.560826 & $1.64 \mathrm{E}-07$ & $2.38 \mathrm{E}-06$ & 5.575666 & Up & parvin gamma \\
\hline ADAMTS14 & 2.019487 & $1.66 \mathrm{E}-07$ & $2.41 \mathrm{E}-06$ & 5.573088 & Up & type 1 motif 14 \\
\hline PLK1 & 1.552472 & $1.72 \mathrm{E}-07$ & $2.47 \mathrm{E}-06$ & 5.564603 & Up & polo like kinase 1 \\
\hline PLEK & 1.606253 & $1.74 \mathrm{E}-07$ & $2.5 \mathrm{E}-06$ & 5.562167 & Up & pleckstrin \\
\hline LUM & 2.195011 & $1.98 \mathrm{E}-07$ & $2.78 \mathrm{E}-06$ & 5.533808 & Up & lumican \\
\hline SRPX2 & 1.666163 & $2.03 \mathrm{E}-07$ & $2.83 \mathrm{E}-06$ & 5.528704 & Up & sushi repeat containing protein $\mathrm{X}$-linked 2 \\
\hline ONECUT2 & 3.067256 & $2.04 \mathrm{E}-07$ & $2.84 \mathrm{E}-06$ & 5.527044 & Up & one cut homeobox 2 \\
\hline $\mathrm{BICC1}$ & 2.129691 & $2.11 \mathrm{E}-07$ & $2.91 \mathrm{E}-06$ & 5.520162 & Up & BicC family RNA binding protein 1 \\
\hline KLHL29 & 1.658014 & $2.13 \mathrm{E}-07$ & $2.94 \mathrm{E}-06$ & 5.517367 & Up & kelch like family member 29 \\
\hline H19 & 3.375443 & $2.25 \mathrm{E}-07$ & 3.07E-06 & 5.505067 & Up & H19 imprinted maternally expressed transcript \\
\hline TGM2 & 2.005721 & $2.28 \mathrm{E}-07$ & $3.1 \mathrm{E}-06$ & 5.502485 & Up & transglutaminase 2 \\
\hline FCER1G & 1.567203 & $2.36 \mathrm{E}-07$ & $3.19 \mathrm{E}-06$ & 5.494477 & Up & $\mathrm{Fc}$ fragment of IgE receptor Ig \\
\hline ZNF462 & 1.8336 & $2.43 \mathrm{E}-07$ & $3.26 \mathrm{E}-06$ & 5.488355 & Up & zinc finger protein 462 \\
\hline CLSTN3 & 1.589208 & $2.66 \mathrm{E}-07$ & $3.53 \mathrm{E}-06$ & 5.467758 & Up & calsyntenin 3 \\
\hline CD248 & 1.816546 & 2.7E-07 & $3.57 \mathrm{E}-06$ & 5.464493 & Up & CD248 molecule \\
\hline NT5DC3 & 1.656425 & $2.79 \mathrm{E}-07$ & 3.67E-06 & 5.457673 & Up & $\begin{array}{l}\text { 5'-nucleotidase domain containing } 3 \\
\text { glycerophosphodiesterphosphodiesterase domain }\end{array}$ \\
\hline GDPD5 & 1.706172 & $2.79 \mathrm{E}-07$ & $3.67 \mathrm{E}-06$ & 5.457168 & Up & containing 5 \\
\hline FBN1 & 2.205815 & $2.84 \mathrm{E}-07$ & $3.72 \mathrm{E}-06$ & 5.453361 & Up & fibrillin 1 \\
\hline ATP10A & 1.594819 & $2.85 \mathrm{E}-07$ & $3.73 \mathrm{E}-06$ & 5.452813 & Up & ATPase phospholipid transporting 10A (putative) \\
\hline STC2 & 1.637092 & $2.87 \mathrm{E}-07$ & $3.75 \mathrm{E}-06$ & 5.451086 & Up & stanniocalcin 2 \\
\hline OSR2 & 1.919816 & $2.91 \mathrm{E}-07$ & $3.81 \mathrm{E}-06$ & 5.447658 & Up & odd-skipped related transciption factor 2 \\
\hline ANGPTL2 & 1.741942 & $2.93 \mathrm{E}-07$ & $3.82 \mathrm{E}-06$ & 5.446431 & Up & angiopoietin like 2 \\
\hline LY6E & 1.958299 & $3.06 \mathrm{E}-07$ & $3.97 \mathrm{E}-06$ & 5.436569 & Up & lymphocyte antigen 6 family member $\mathrm{E}$ \\
\hline CPXM1 & 2.38795 & $3.15 \mathrm{E}-07$ & 4.07E-06 & 5.430499 & Up & $\begin{array}{l}\text { carboxypeptidase X, M14 family member } 1 \\
\text { SPARC (osteonectin), cwcv and kazal like domains }\end{array}$ \\
\hline SPOCK1 & 2.423261 & $3.27 \mathrm{E}-07$ & 4.2E-06 & 5.421649 & Up & proteoglycan 1 \\
\hline TOP2A & 1.727058 & $3.36 \mathrm{E}-07$ & $4.28 \mathrm{E}-06$ & 5.415637 & Up & DNA topoisomerase II alpha \\
\hline ESPL1 & 1.596797 & $3.77 \mathrm{E}-07$ & $4.71 \mathrm{E}-06$ & 5.390156 & Up & extra spindle pole bodies like 1 , separase \\
\hline LPPR4 & 1.994093 & $3.83 \mathrm{E}-07$ & 4.79E-06 & 5.3865 & Up & Lipid phosphate phosphatase-related protein type 4 . \\
\hline CDC6 & 1.641411 & $3.88 \mathrm{E}-07$ & $4.84 \mathrm{E}-06$ & 5.383599 & Up & cell division cycle 6 \\
\hline MXRA5 & 1.903509 & $4 \mathrm{E}-07$ & $4.95 \mathrm{E}-06$ & 5.376656 & Up & matrix remodeling associated 5 \\
\hline KIAA1755 & 1.931666 & $4.06 \mathrm{E}-07$ & $5.02 \mathrm{E}-06$ & 5.373205 & Up & $\begin{array}{c}\text { KIAA1755 } \\
\text { immunoglobulin superfamily containing leucine }\end{array}$ \\
\hline ISLR & 2.226024 & 4.45E-07 & $5.44 \mathrm{E}-06$ & 5.352365 & Up & rich repeat \\
\hline RARRES1 & 2.14138 & $4.53 \mathrm{E}-07$ & $5.5 \mathrm{E}-06$ & 5.348611 & Up & retinoic acid receptor responder 1 \\
\hline CTSK & 2.028253 & $4.61 \mathrm{E}-07$ & $5.58 \mathrm{E}-06$ & 5.344477 & Up & cathepsin K \\
\hline
\end{tabular}




\begin{tabular}{|c|c|c|c|c|c|c|}
\hline ANTXR1 & 1.960624 & $5.03 \mathrm{E}-07$ & $6 \mathrm{E}-06$ & 5.324851 & Up & $\begin{array}{l}\text { ANTXR cell adhesion molecule } 1 \\
\text { insulin like growth factor } 2 \text { mRNA binding protein }\end{array}$ \\
\hline IGF2BP3 & 3.023841 & $5.23 \mathrm{E}-07$ & $6.19 \mathrm{E}-06$ & 5.315889 & Up & 3 \\
\hline IL2RA & 1.561204 & $5.27 \mathrm{E}-07$ & $6.22 \mathrm{E}-06$ & 5.314141 & Up & interleukin 2 receptor subunit alpha \\
\hline FAM83D & 1.667622 & $5.3 \mathrm{E}-07$ & $6.25 \mathrm{E}-06$ & 5.313207 & Up & family with sequence similarity 83 member D \\
\hline BCAT1 & 1.669577 & $5.96 \mathrm{E}-07$ & $6.91 \mathrm{E}-06$ & 5.286322 & Up & branched chain amino acid transaminase 1 \\
\hline MYBL2 & 1.852727 & $6.84 \mathrm{E}-07$ & $7.75 \mathrm{E}-06$ & 5.25504 & Up & MYB proto-oncogene like 2 \\
\hline SCARF2 & 1.773794 & $6.97 \mathrm{E}-07$ & 7.87E-06 & 5.250857 & Up & scavenger receptor class F member 2 \\
\hline AEBP1 & 2.090302 & 7.63E-07 & $8.51 \mathrm{E}-06$ & 5.229903 & Up & AE binding protein 1 \\
\hline ECT2 & 1.654658 & $8.21 \mathrm{E}-07$ & $9.05 \mathrm{E}-06$ & 5.213145 & Up & epithelial cell transforming 2 \\
\hline CLDN4 & 2.507943 & 8.77E-07 & $9.58 \mathrm{E}-06$ & 5.198137 & Up & claudin 4 \\
\hline DKK2 & 1.649707 & $8.98 \mathrm{E}-07$ & $9.78 \mathrm{E}-06$ & 5.19271 & Up & dickkopf WNT signaling pathway inhibitor 2 \\
\hline CD109 & 1.660368 & $9.34 \mathrm{E}-07$ & $1.01 \mathrm{E}-05$ & 5.18369 & Up & CD109 molecule \\
\hline HIST3H2BB & 1.769554 & $9.72 \mathrm{E}-07$ & $1.05 \mathrm{E}-05$ & 5.174465 & Up & Histone $\mathrm{H} 2 \mathrm{~B}$ type 3 -B \\
\hline LGI2 & 2.200628 & $9.77 \mathrm{E}-07$ & $1.05 \mathrm{E}-05$ & 5.173415 & Up & leucine rich repeat LGI family member 2 \\
\hline NEIL2 & 1.604316 & $1.04 \mathrm{E}-06$ & $1.11 \mathrm{E}-05$ & 5.15844 & Up & nei like DNA glycosylase 2 \\
\hline EGR2 & 1.661751 & $1.14 \mathrm{E}-06$ & $1.2 \mathrm{E}-05$ & 5.13733 & Up & $\begin{array}{l}\text { early growth response } 2 \\
\text { ADAM metallopeptidase with thrombospondin }\end{array}$ \\
\hline ADAMTS9 & 1.572869 & $1.31 \mathrm{E}-06$ & $1.35 \mathrm{E}-05$ & 5.106375 & Up & type 1 motif 9 \\
\hline COL11A1 & 3.770104 & $1.39 \mathrm{E}-06$ & $1.42 \mathrm{E}-05$ & 5.091092 & Up & collagen type XI alpha 1 chain \\
\hline ITGB8 & 1.76404 & $1.4 \mathrm{E}-06$ & $1.43 \mathrm{E}-05$ & 5.090304 & Up & integrin subunit beta 8 \\
\hline ZNF703 & 2.008932 & $1.52 \mathrm{E}-06$ & $1.52 \mathrm{E}-05$ & 5.070981 & Up & zinc finger protein 703 \\
\hline PDE3A & 1.945529 & $1.68 \mathrm{E}-06$ & $1.65 \mathrm{E}-05$ & 5.047789 & Up & phosphodiesterase $3 \mathrm{~A}$ \\
\hline TNFRSF11B & 2.312306 & $1.69 \mathrm{E}-06$ & $1.66 \mathrm{E}-05$ & 5.046034 & Up & TNF receptor superfamily member $11 \mathrm{~b}$ \\
\hline CHRDL2 & 2.572031 & $1.76 \mathrm{E}-06$ & $1.71 \mathrm{E}-05$ & 5.037378 & Up & chordin like 2 \\
\hline STRA6 & 2.132464 & $1.76 \mathrm{E}-06$ & $1.72 \mathrm{E}-05$ & 5.036683 & Up & stimulated by retinoic acid 6 \\
\hline MFI2 & 2.253506 & $1.84 \mathrm{E}-06$ & $1.78 \mathrm{E}-05$ & 5.027016 & Up & Melanotransferrin \\
\hline F2RL2 & 2.038989 & $2.14 \mathrm{E}-06$ & $2.02 \mathrm{E}-05$ & 4.991024 & Up & coagulation factor II thrombin receptor like 2 \\
\hline TYMP & 1.570039 & $2.18 \mathrm{E}-06$ & $2.05 \mathrm{E}-05$ & 4.98695 & Up & thymidine phosphorylase \\
\hline HTRA1 & 1.605928 & $2.26 \mathrm{E}-06$ & $2.12 \mathrm{E}-05$ & 4.97802 & Up & HtrA serine peptidase 1 \\
\hline GGT5 & 1.784196 & $2.62 \mathrm{E}-06$ & $2.41 \mathrm{E}-05$ & 4.943505 & Up & gamma-glutamyltransferase 5 \\
\hline LAMA5 & 1.740776 & $2.65 \mathrm{E}-06$ & $2.44 \mathrm{E}-05$ & 4.940342 & Up & laminin subunit alpha 5 \\
\hline GFPT2 & 1.838625 & $2.95 \mathrm{E}-06$ & 2.67E-05 & 4.91535 & Up & glutamine-fructose-6-phosphate transaminase 2 \\
\hline PKDCC & 2.156848 & $2.95 \mathrm{E}-06$ & $2.67 \mathrm{E}-05$ & 4.915316 & Up & protein kinase domain containing, cytoplasmic \\
\hline MAP1A & 1.891892 & $3.23 \mathrm{E}-06$ & $2.88 \mathrm{E}-05$ & 4.893781 & Up & microtubule associated protein $1 \mathrm{~A}$ \\
\hline MYH10 & 1.618718 & $3.4 \mathrm{E}-06$ & $3.01 \mathrm{E}-05$ & 4.881443 & Up & myosin heavy chain 10 \\
\hline MMP16 & 1.693752 & 3.4E-06 & 3.01E-05 & 4.88143 & Up & $\begin{array}{l}\text { matrix metallopeptidase } 16 \\
\text { latent transforming growth factor beta binding }\end{array}$ \\
\hline LTBP2 & 2.006391 & $3.41 \mathrm{E}-06$ & $3.01 \mathrm{E}-05$ & 4.880896 & Up & protein 2 \\
\hline TREM1 & 1.925025 & $3.51 \mathrm{E}-06$ & $3.08 \mathrm{E}-05$ & 4.873843 & Up & triggering receptor expressed on myeloid cells 1 \\
\hline CCL3 & 1.680971 & $3.82 \mathrm{E}-06$ & $3.3 \mathrm{E}-05$ & 4.853691 & Up & $\mathrm{C}-\mathrm{C}$ motif chemokine ligand 3 \\
\hline $\mathrm{DIO} 2$ & 2.219681 & $3.87 \mathrm{E}-06$ & $3.34 \mathrm{E}-05$ & 4.851101 & Up & iodothyroninedeiodinase 2 \\
\hline CST1 & 3.432026 & $3.9 \mathrm{E}-06$ & $3.36 \mathrm{E}-05$ & 4.848715 & Up & cystatin $\mathrm{SN}$ \\
\hline UBE2C & 1.564194 & $3.93 \mathrm{E}-06$ & $3.38 \mathrm{E}-05$ & 4.847262 & Up & ubiquitin conjugating enzyme $\mathrm{E} 2 \mathrm{C}$ \\
\hline NCR3LG1 & 1.774407 & 3.97E-06 & $3.41 \mathrm{E}-05$ & 4.844728 & Up & natural killer cell cytotoxicity receptor 3 ligand 1 \\
\hline
\end{tabular}




\begin{tabular}{|c|c|c|c|c|c|c|}
\hline AQP1 & 1.912101 & 4.25E-06 & $3.6 \mathrm{E}-05$ & 4.828269 & Up & aquaporin 1 (Colton blood group) \\
\hline CELSR3 & 1.893472 & $4.52 \mathrm{E}-06$ & $3.78 \mathrm{E}-05$ & 4.813793 & Up & cadherin EGF LAG seven-pass G-type receptor 3 \\
\hline PTPRO & 1.641236 & $4.56 \mathrm{E}-06$ & $3.81 \mathrm{E}-05$ & 4.81153 & Up & protein tyrosine phosphatase receptor type $\mathrm{O}$ \\
\hline PADI2 & 1.837363 & $4.68 \mathrm{E}-06$ & $3.9 \mathrm{E}-05$ & 4.805194 & Up & peptidyl arginine deiminase 2 \\
\hline SELL & 1.712176 & 4.86E-06 & 4.02E-05 & 4.796038 & Up & selectin L \\
\hline DPYSL3 & 1.965102 & 4.94E-06 & $4.08 \mathrm{E}-05$ & 4.792282 & Up & dihydropyrimidinase like 3 \\
\hline HIST1H3G & 1.577336 & $5.35 \mathrm{E}-06$ & 4.36E-05 & 4.773012 & Up & histone cluster $1 \mathrm{H} 3$ family member $\mathrm{g}$ \\
\hline FPR1 & 1.68925 & $5.41 \mathrm{E}-06$ & 4.4E-05 & 4.770541 & Up & formyl peptide receptor 1 \\
\hline C13orf33 & 1.748636 & $6.21 \mathrm{E}-06$ & 4.95E-05 & 4.737008 & Up & $\begin{array}{l}\text { Mesenteric Estrogen Dependent Adipogenesis } \\
\text { family with sequence similarity } 19 \text { (chemokine (C- }\end{array}$ \\
\hline FAM19A5 & 1.647679 & $6.4 \mathrm{E}-06$ & $5.08 \mathrm{E}-05$ & 4.729791 & Up & C motif)-like), member A5 \\
\hline PCOLCE & 1.782918 & $6.69 \mathrm{E}-06$ & $5.27 \mathrm{E}-05$ & 4.71896 & Up & procollagen C-endopeptidase enhancer \\
\hline ATHL1 & 1.857749 & 7.96E-06 & $6.11 \mathrm{E}-05$ & 4.676623 & Up & Acid trehalase-like protein 1. \\
\hline $\mathrm{C} 1 \mathrm{R}$ & 1.668333 & 8.01E-06 & $6.13 \mathrm{E}-05$ & 4.675179 & Up & complement $\mathrm{C} 1 \mathrm{r}$ \\
\hline DNM3OS & 1.810025 & $8.44 \mathrm{E}-06$ & $6.4 \mathrm{E}-05$ & 4.662446 & Up & $\begin{array}{l}\text { DNM3 opposite strand/antisense RNA } \\
\text { pleckstrin homology and RhoGEF domain }\end{array}$ \\
\hline PLEKHG4 & 1.678447 & $9.06 \mathrm{E}-06$ & $6.8 \mathrm{E}-05$ & 4.645179 & Up & containing G4 \\
\hline MYB & 1.976157 & $9.2 \mathrm{E}-06$ & $6.89 \mathrm{E}-05$ & 4.641278 & Up & MYB proto-oncogene, transcription factor \\
\hline MAPK15 & 1.566636 & $9.35 \mathrm{E}-06$ & $6.98 \mathrm{E}-05$ & 4.637383 & Up & mitogen-activated protein kinase 15 \\
\hline THBS4 & 4.239608 & $9.36 \mathrm{E}-06$ & $6.99 \mathrm{E}-05$ & 4.637157 & Up & thrombospondin 4 \\
\hline CACNA1E & 1.952079 & $1.03 \mathrm{E}-05$ & 7.57E-05 & 4.613471 & Up & calcium voltage-gated channel subunit alpha1 E \\
\hline IFITM1 & 1.68165 & $1.05 \mathrm{E}-05$ & $7.66 \mathrm{E}-05$ & 4.609872 & Up & interferon induced transmembrane protein 1 \\
\hline FOXC1 & 1.657759 & $1.31 \mathrm{E}-05$ & $9.29 \mathrm{E}-05$ & 4.554126 & Up & forkhead box C1 \\
\hline SALL4 & 2.027354 & $1.36 \mathrm{E}-05$ & $9.55 \mathrm{E}-05$ & 4.545063 & Up & spalt like transcription factor 4 \\
\hline GREM1 & 2.236937 & $1.41 \mathrm{E}-05$ & $9.86 \mathrm{E}-05$ & 4.535872 & Up & gremlin 1, DAN family BMP antagonist \\
\hline MXRA8 & 1.673416 & $1.53 \mathrm{E}-05$ & 0.000106 & 4.51605 & Up & matrix remodeling associated 8 \\
\hline LINC00578 & 1.578457 & $1.54 \mathrm{E}-05$ & 0.000107 & 4.513109 & Up & long intergenic non-protein coding RNA 578 \\
\hline TNFAIP6 & 1.55874 & $1.55 \mathrm{E}-05$ & 0.000107 & 4.512004 & Up & TNF alpha induced protein 6 \\
\hline GAS7 & 1.642789 & $1.63 \mathrm{E}-05$ & 0.000112 & 4.499178 & Up & growth arrest specific 7 \\
\hline OSM & 2.089218 & $1.64 \mathrm{E}-05$ & 0.000112 & 4.498105 & Up & oncostatin $\mathrm{M}$ \\
\hline PTGS2 & 2.220566 & $1.74 \mathrm{E}-05$ & 0.000118 & 4.483727 & Up & prostaglandin-endoperoxide synthase 2 \\
\hline GLI2 & 1.767141 & $1.75 \mathrm{E}-05$ & 0.000118 & 4.481492 & Up & GLI family zinc finger 2 \\
\hline CCND2 & 1.851117 & $1.82 \mathrm{E}-05$ & 0.000122 & 4.472625 & Up & cyclin D2 \\
\hline AHNAK2 & 2.276015 & $1.94 \mathrm{E}-05$ & 0.000129 & 4.456469 & Up & AHNAK nucleoprotein 2 \\
\hline MEX3A & 1.55585 & $1.96 \mathrm{E}-05$ & 0.000131 & 4.453107 & Up & mex-3 RNA binding family member A \\
\hline ITGBL1 & 2.678016 & $1.99 \mathrm{E}-05$ & 0.000132 & 4.449749 & Up & integrin subunit beta like 1 \\
\hline FBXO32 & 1.658792 & $2.3 \mathrm{E}-05$ & 0.000149 & 4.413422 & Up & F-box protein 32 \\
\hline SELE & 2.552922 & $2.36 \mathrm{E}-05$ & 0.000153 & 4.40637 & Up & selectin E \\
\hline $\mathrm{C} 3$ & 2.416315 & $2.47 \mathrm{E}-05$ & 0.000158 & 4.39516 & Up & complement C3 \\
\hline GBP5 & 1.887503 & $2.54 \mathrm{E}-05$ & 0.000162 & 4.387905 & $\mathrm{Up}$ & guanylate binding protein 5 \\
\hline ALDH1A3 & 1.747154 & $2.69 \mathrm{E}-05$ & 0.000171 & 4.373742 & Up & aldehyde dehydrogenase 1 family member A3 \\
\hline HOXA10 & 1.767013 & $2.96 \mathrm{E}-05$ & 0.000185 & 4.349093 & Up & homeobox A10 \\
\hline DNM1 & 1.641482 & $2.99 \mathrm{E}-05$ & 0.000186 & 4.346055 & Up & dynamin 1 \\
\hline CHI3L1 & 2.692343 & $3 \mathrm{E}-05$ & 0.000187 & 4.345501 & $\mathrm{Up}$ & chitinase 3 like 1 \\
\hline
\end{tabular}




\begin{tabular}{|c|c|c|c|c|c|c|}
\hline KRT80 & 1.999185 & 3.3E-05 & 0.000203 & 4.320945 & $\mathrm{Up}$ & keratin 80 \\
\hline SLC28A3 & 2.007432 & $3.61 \mathrm{E}-05$ & 0.000218 & 4.298069 & $\mathrm{Up}$ & solute carrier family 28 member 3 \\
\hline VGLL3 & 1.741023 & $3.72 \mathrm{E}-05$ & 0.000224 & 4.290212 & $\mathrm{Up}$ & vestigial like family member 3 \\
\hline СРXM2 & 1.872947 & $3.84 \mathrm{E}-05$ & 0.00023 & 4.282207 & $\mathrm{Up}$ & carboxypeptidase X, M14 family member 2 \\
\hline BCL2A1 & 1.656709 & $3.86 \mathrm{E}-05$ & 0.000231 & 4.280957 & $\mathrm{Up}$ & BCL2 related protein A1 \\
\hline PI15 & 2.584688 & $4.22 \mathrm{E}-05$ & 0.000249 & 4.257782 & Up & peptidase inhibitor 15 \\
\hline IGSF9B & 1.553308 & $4.68 \mathrm{E}-05$ & 0.000271 & 4.231241 & $\mathrm{Up}$ & immunoglobulin superfamily member 9B \\
\hline LOC154860 & 1.590749 & 4.69E-05 & 0.000271 & 4.230639 & $\mathrm{Up}$ & \#N/A \\
\hline $\mathrm{HMCN} 1$ & 2.380264 & $5.36 \mathrm{E}-05$ & 0.000305 & 4.195435 & Up & hemicentin 1 \\
\hline SLC24A3 & 1.603357 & $5.51 \mathrm{E}-05$ & 0.000313 & 4.18864 & $\mathrm{Up}$ & solute carrier family 24 member 3 \\
\hline CXCL1 & 2.294197 & $5.51 \mathrm{E}-05$ & 0.000313 & 4.188195 & Up & $\mathrm{C}-\mathrm{X}-\mathrm{C}$ motif chemokine ligand 1 \\
\hline ODZ4 & 1.748243 & $5.53 \mathrm{E}-05$ & 0.000314 & 4.187256 & Up & $\begin{array}{c}\text { Teneurin-4 } \\
\text { calcium/calmodulin dependent protein kinase II }\end{array}$ \\
\hline CAMK2N1 & 1.634814 & $5.66 \mathrm{E}-05$ & 0.00032 & 4.181603 & $\mathrm{Up}$ & inhibitor 1 \\
\hline AGT & 2.291038 & $6.55 \mathrm{E}-05$ & 0.000361 & 4.142954 & Up & angiotensinogen \\
\hline IL8 & 2.999956 & $6.88 \mathrm{E}-05$ & 0.000377 & 4.129921 & $\mathrm{Up}$ & interleukin 8 \\
\hline HOXB9 & 1.958455 & $7.39 \mathrm{E}-05$ & 0.000401 & 4.111134 & $\mathrm{Up}$ & homeobox B9 \\
\hline APLN & 1.555857 & $9.33 \mathrm{E}-05$ & 0.000489 & 4.049282 & $\mathrm{Up}$ & apelin \\
\hline EPHB1 & 1.685685 & 0.000107 & 0.000549 & 4.013409 & $\mathrm{Up}$ & EPH receptor B1 \\
\hline AQP9 & 1.933182 & 0.000117 & 0.000597 & 3.987386 & $\mathrm{Up}$ & aquaporin 9 \\
\hline HEPH & 2.011133 & 0.000119 & 0.000602 & 3.984451 & $\mathrm{Up}$ & hephaestin \\
\hline NEB & 2.076932 & 0.00012 & 0.000608 & 3.981512 & Up & nebulin \\
\hline KRT17 & 2.919829 & 0.000124 & 0.000626 & 3.972853 & $\mathrm{Up}$ & keratin 17 \\
\hline VIL1 & 2.131168 & 0.000133 & 0.000666 & 3.953475 & $\mathrm{Up}$ & villin 1 \\
\hline MLK7-AS1 & 1.815952 & 0.000134 & 0.000671 & 3.951002 & $\mathrm{Up}$ & MLK7 antisense RNA 1 \\
\hline HOXA13 & 2.203005 & 0.00014 & 0.000692 & 3.940298 & $\mathrm{Up}$ & homeobox A13 \\
\hline MIR100HG & 1.672169 & 0.000143 & 0.000704 & 3.934599 & Up & mir-100-let-7a-2-mir-125b-1 cluster host gene \\
\hline C2orf89 & 1.980425 & 0.000151 & 0.00074 & 3.918988 & $\mathrm{Up}$ & chromosome 2 open reading frame 89 \\
\hline $\mathrm{CDX} 2$ & 2.101672 & 0.000161 & 0.000781 & 3.901649 & $\mathrm{Up}$ & caudal type homeobox 2 \\
\hline $\mathrm{TNC}$ & 1.759858 & 0.000166 & 0.0008 & 3.893609 & Up & tenascin $\mathrm{C}$ \\
\hline COL16A1 & 1.675579 & 0.000175 & 0.000841 & 3.878528 & $\mathrm{Up}$ & collagen type XVI alpha 1 chain \\
\hline NRK & 2.007124 & 0.000195 & 0.000922 & 3.848801 & Up & Nik related kinase \\
\hline HKDC1 & 2.071149 & 0.000266 & 0.001194 & 3.762683 & $\mathrm{Up}$ & hexokinase domain containing 1 \\
\hline GDF15 & 1.618022 & 0.000285 & 0.001269 & 3.742307 & Up & growth differentiation factor 15 \\
\hline MMP3 & 2.913904 & 0.000337 & 0.001464 & 3.695627 & $\mathrm{Up}$ & matrix metallopeptidase 3 \\
\hline $\begin{array}{c}\text { MYOM3 } \\
\text { LOC10012469 }\end{array}$ & 1.83562 & 0.000337 & 0.001466 & 3.6951 & Up & myomesin 3 \\
\hline 2 & 2.216207 & 0.000349 & 0.001509 & 3.685408 & Up & \#N/A \\
\hline IFI44L & 1.587711 & 0.000365 & 0.00157 & 3.672376 & $\mathrm{Up}$ & interferon induced protein 44 like \\
\hline PLEKHS1 & 2.099427 & 0.000395 & 0.001677 & 3.65015 & Up & pleckstrin homology domain containing S1 \\
\hline $\mathrm{CDH} 3$ & 1.714521 & 0.000401 & 0.001699 & 3.645624 & Up & cadherin 3 \\
\hline ELN & 2.002142 & 0.000425 & 0.001782 & 3.629115 & $\mathrm{Up}$ & elastin \\
\hline COMP & 1.742429 & 0.000454 & 0.001884 & 3.610079 & Up & cartilage oligomeric matrix protein \\
\hline MMP9 & 1.99775 & 0.000464 & 0.00192 & 3.603783 & $\mathrm{Up}$ & matrix metallopeptidase 9 \\
\hline
\end{tabular}




\begin{tabular}{|c|c|c|c|c|c|c|}
\hline CLDN3 & 2.474438 & 0.000465 & 0.001923 & 3.602954 & Up & claudin 3 \\
\hline CRABP2 & 1.566544 & 0.000495 & 0.002026 & 3.584792 & Up & cellular retinoic acid binding protein 2 \\
\hline ABCA13 & 1.592582 & 0.000498 & 0.002036 & 3.583143 & $\mathrm{Up}$ & ATP binding cassette subfamily A member 13 \\
\hline LINC00478 & 1.585816 & 0.000504 & 0.002054 & 3.579916 & Up & \#N/A \\
\hline IL6 & 1.683392 & 0.000519 & 0.002112 & 3.571026 & Up & interleukin 6 \\
\hline CXCL6 & 1.96745 & 0.000709 & 0.002755 & 3.479615 & Up & $\mathrm{C}-\mathrm{X}-\mathrm{C}$ motif chemokine ligand 6 \\
\hline LOC93432 & 1.946221 & 0.000758 & 0.002913 & 3.459718 & Up & \#N/A \\
\hline LGR5 & 1.783554 & 0.000797 & 0.003041 & 3.444591 & Up & receptor 5 \\
\hline FLRT2 & 1.639972 & 0.000883 & 0.00331 & 3.414201 & Up & fibronectinleucine rich transmembrane protein 2 \\
\hline STK31 & 1.593465 & 0.000899 & 0.003358 & 3.408694 & Up & serine/threonine kinase 31 \\
\hline $\mathrm{C} 2 \mathrm{CD} 4 \mathrm{~A}$ & 1.641563 & 0.001085 & 0.003936 & 3.351939 & $\mathrm{Up}$ & $\mathrm{C} 2$ calcium dependent domain containing $4 \mathrm{~A}$ \\
\hline SFRP2 & 2.377128 & 0.001102 & 0.003989 & 3.347103 & Up & secreted frizzled related protein 2 \\
\hline TRIM29 & 2.175502 & 0.001163 & 0.00418 & 3.330604 & Up & tripartite motif containing 29 \\
\hline EPHA3 & 1.60529 & 0.001288 & 0.004552 & 3.299431 & Up & EPH receptor A3 \\
\hline OMD & 1.604119 & 0.001325 & 0.004665 & 3.290695 & Up & osteomodulin \\
\hline CXCL9 & 1.737291 & 0.001451 & 0.00504 & 3.262741 & Up & C-X-C motif chemokine ligand 9 \\
\hline CLDN2 & 2.328 & 0.001468 & 0.005088 & 3.259026 & Up & claudin 2 \\
\hline IL11 & 1.74806 & 0.001484 & 0.005136 & 3.255678 & Up & interleukin 11 \\
\hline ROBO2 & 1.597553 & 0.001824 & 0.006131 & 3.191206 & Up & roundabout guidance receptor 2 \\
\hline MYO7B & 2.265256 & 0.002115 & 0.006956 & 3.144449 & Up & myosin VIIB \\
\hline BOC & 1.564592 & 0.002391 & 0.007737 & 3.105276 & Up & BOC cell adhesion associated, oncogene regulated \\
\hline CCDC80 & 1.737263 & 0.002517 & 0.008086 & 3.088781 & Up & coiled-coil domain containing 80 \\
\hline ANXA13 & 2.127525 & 0.002728 & 0.008669 & 3.062776 & Up & annexin A13 \\
\hline MGP & 1.760338 & 0.002932 & 0.009217 & 3.039314 & Up & matrix Gla protein \\
\hline CYP2B6 & 1.577043 & 0.003615 & 0.011048 & 2.970589 & Up & cytochrome P450 family 2 subfamily B member 6 \\
\hline SLC39A5 & 1.929535 & 0.003709 & 0.011286 & 2.962123 & Up & solute carrier family 39 member 5 \\
\hline SERPINB5 & 2.091229 & 0.003875 & 0.011718 & 2.947537 & Up & serpin family B member 5 \\
\hline CYP2W1 & 1.750607 & 0.004086 & 0.012245 & 2.929892 & Up & cytochrome $\mathrm{P} 450$ family 2 subfamily $\mathrm{W}$ member 1 \\
\hline MMP1 & 1.872645 & 0.004143 & 0.012387 & 2.925223 & Up & $\begin{array}{c}\text { matrix metallopeptidase } 1 \\
\text { protein phosphatase } 1 \text { regulatory inhibitor subunit }\end{array}$ \\
\hline PPP1R1B & 2.052602 & 0.004324 & 0.012839 & 2.910954 & Up & $1 \mathrm{~B}$ \\
\hline CCL18 & 1.586798 & 0.004432 & 0.013114 & 2.902656 & Up & C-C motif chemokine ligand 18 \\
\hline CLRN3 & 1.612409 & 0.00469 & 0.013758 & 2.883553 & Up & clarin 3 \\
\hline KLK6 & 1.688522 & 0.004878 & 0.014216 & 2.87025 & Up & kallikrein related peptidase 6 \\
\hline CDH17 & 2.620031 & 0.005285 & 0.015217 & 2.842959 & Up & cadherin 17 \\
\hline IDO1 & 1.779523 & 0.007847 & 0.021186 & 2.705718 & Up & indoleamine 2,3-dioxygenase 1 \\
\hline FCGR3B & 1.579377 & 0.009356 & 0.024675 & 2.643002 & Up & Fc fragment of IgG receptor IIIb \\
\hline WDR72 & 1.857672 & 0.010012 & 0.026125 & 2.618572 & Up & WD repeat domain 72 \\
\hline MMP7 & 2.195172 & 0.0136 & 0.033814 & 2.506018 & Up & matrix metallopeptidase 7 \\
\hline MSLN & 2.009849 & 0.014377 & 0.035418 & 2.485225 & Up & mesothelin \\
\hline MUC16 & 1.592157 & 0.01469 & 0.036076 & 2.477136 & Up & mucin 16 , cell surface associated \\
\hline TNS4 & 1.670843 & 0.01559 & 0.03795 & 2.454666 & Up & tensin 4 \\
\hline CPS1 & 2.230898 & 0.020655 & 0.048108 & 2.346431 & Up & carbamoyl-phosphate synthase 1 \\
\hline
\end{tabular}




\begin{tabular}{|c|c|c|c|c|c|c|}
\hline GUCA2B & -2.7219 & 3.07E-22 & 7.27E-18 & -12.0832 & Down & guanylatecyclase activator $2 \mathrm{~B}$ \\
\hline LINC00332 & -1.1776 & $3.45 \mathrm{E}-21$ & 4.09E-17 & -11.6342 & Down & long intergenic non-protein coding RNA 332 \\
\hline C14orf180 & -1.50929 & $1.52 \mathrm{E}-19$ & $7.66 \mathrm{E}-16$ & -10.9349 & Down & $\begin{array}{l}\text { chromosome } 14 \text { open reading frame } 180 \\
\text { alcohol dehydrogenase } 7 \text { (class IV), mu or sigma }\end{array}$ \\
\hline $\mathrm{ADH} 7$ & -3.79214 & $1.93 \mathrm{E}-18$ & $5.08 \mathrm{E}-15$ & -10.4663 & Down & polypeptide \\
\hline ATP4A & -7.94795 & 5.13E-18 & $1.22 \mathrm{E}-14$ & -10.2859 & Down & ATPase $\mathrm{H}+/ \mathrm{K}+$ transporting subunit alpha \\
\hline CWH43 & -3.38545 & $5.94 \mathrm{E}-18$ & $1.28 \mathrm{E}-14$ & -10.2588 & Down & cell wall biogenesis $43 \mathrm{C}$-terminal homolog \\
\hline MAL & -3.08582 & $1.16 \mathrm{E}-17$ & $1.83 \mathrm{E}-14$ & -10.1352 & Down & mal, $\mathrm{T}$ cell differentiation protein \\
\hline АТP4B & -7.22434 & $1.86 \mathrm{E}-17$ & $2.59 \mathrm{E}-14$ & -10.0482 & Down & ATPase $\mathrm{H}+/ \mathrm{K}+$ transporting subunit beta \\
\hline CHIA & -4.12203 & $2.65 \mathrm{E}-17$ & $3.3 \mathrm{E}-14$ & -9.9833 & Down & chitinase acidic \\
\hline HTR1E & -1.16176 & $6.6 \mathrm{E}-17$ & 7.44E-14 & -9.81443 & Down & 5-hydroxytryptamine receptor $1 \mathrm{E}$ \\
\hline CCKAR & -3.34303 & $1.72 \mathrm{E}-16$ & $1.7 \mathrm{E}-13$ & -9.63723 & Down & cholecystokinin A receptor \\
\hline LGALS9B & -3.08644 & $2.73 \mathrm{E}-16$ & $2.31 \mathrm{E}-13$ & -9.55146 & Down & galectin 9B \\
\hline PDILT & -3.17607 & $2.88 \mathrm{E}-16$ & $2.35 \mathrm{E}-13$ & -9.54145 & Down & protein disulfideisomerase like, testis expressed \\
\hline SLC5A5 & -6.1349 & $3.51 \mathrm{E}-16$ & $2.66 \mathrm{E}-13$ & -9.50499 & Down & solute carrier family 5 member 5 \\
\hline PGA5 & -8.20606 & $3.6 \mathrm{E}-16$ & $2.66 \mathrm{E}-13$ & -9.50047 & Down & pepsinogen A5 \\
\hline GUCA1C & -1.35912 & 5.33E-16 & 3.7E-13 & -9.42767 & Down & $\begin{array}{c}\text { guanylatecyclase activator 1C } \\
\text { glutamate ionotropic receptor AMPA type subunit }\end{array}$ \\
\hline GRIA4 & -2.69276 & $5.51 \mathrm{E}-16$ & $3.7 \mathrm{E}-13$ & -9.42125 & Down & 4 \\
\hline RDH12 & -2.86156 & $6.36 \mathrm{E}-16$ & $3.86 \mathrm{E}-13$ & -9.39465 & Down & retinol dehydrogenase 12 \\
\hline PSAPL1 & -5.56816 & $1.05 \mathrm{E}-15$ & $6.07 \mathrm{E}-13$ & -9.30131 & Down & prosaposin like 1 (gene/pseudogene) \\
\hline VSTM2A & -1.5564 & $1.83 \mathrm{E}-15$ & $8.84 \mathrm{E}-13$ & -9.19831 & Down & $\begin{array}{l}\text { V-set and transmembrane domain containing } 2 \mathrm{~A} \\
\text { Alanine--glyoxylate aminotransferase } 2 \text {-like } 1\end{array}$ \\
\hline AGXT2L1 & -3.07655 & $1.99 \mathrm{E}-15$ & $9.41 \mathrm{E}-13$ & -9.1829 & Down & isoform 1 \\
\hline ASB 11 & -2.7366 & $2.34 \mathrm{E}-15$ & $1.02 \mathrm{E}-12$ & -9.15274 & Down & ankyrin repeat and SOCS box containing 11 \\
\hline GNMT & -1.40388 & $2.58 \mathrm{E}-15$ & $1.11 \mathrm{E}-12$ & -9.1341 & Down & glycine N-methyltransferase \\
\hline CCKBR & -3.28447 & $2.62 \mathrm{E}-15$ & $1.11 \mathrm{E}-12$ & -9.13137 & Down & cholecystokinin B receptor \\
\hline DCAF12L1 & -1.38042 & $2.95 \mathrm{E}-15$ & $1.22 \mathrm{E}-12$ & -9.10962 & Down & DDB1 and CUL4 associated factor 12 like 1 \\
\hline GSTA3 & -1.58126 & $4.2 \mathrm{E}-15$ & $1.69 \mathrm{E}-12$ & -9.04349 & Down & glutathione S-transferase alpha 3 \\
\hline SCNN1B & -3.05194 & $4.76 \mathrm{E}-15$ & $1.88 \mathrm{E}-12$ & -9.02024 & Down & sodium channel epithelial 1 beta subunit \\
\hline AQP4 & -4.31119 & $1.45 \mathrm{E}-14$ & 4.84E-12 & -8.81159 & Down & aquaporin 4 \\
\hline TMED6 & -2.62873 & $1.93 \mathrm{E}-14$ & $6.02 \mathrm{E}-12$ & -8.75803 & Down & transmembrane p24 trafficking protein 6 \\
\hline FAM135B & -1.56176 & $2.74 \mathrm{E}-14$ & $8 \mathrm{E}-12$ & -8.69261 & Down & family with sequence similarity 135 member B \\
\hline GIF & -7.35545 & $4.9 \mathrm{E}-14$ & $1.3 \mathrm{E}-11$ & -8.58318 & Down & gastric intrinsic factor \\
\hline DNER & -3.2273 & $5.79 \mathrm{E}-14$ & $1.47 \mathrm{E}-11$ & -8.55171 & Down & delta/notch like EGF repeat containing \\
\hline GKN2 & -8.97895 & $6.38 \mathrm{E}-14$ & $1.57 \mathrm{E}-11$ & -8.53346 & Down & gastrokine 2 \\
\hline ESRRG & -4.70155 & 7.39E-14 & $1.77 \mathrm{E}-11$ & -8.50569 & Down & estrogen related receptor gamma \\
\hline B3GAT1 & -2.2731 & 7.93E-14 & $1.88 \mathrm{E}-11$ & -8.4924 & Down & beta-1,3-glucuronyltransferase 1 \\
\hline DNMBP-AS1 & -1.61328 & $8.08 \mathrm{E}-14$ & $1.9 \mathrm{E}-11$ & -8.48885 & Down & DNMBP antisense RNA 1 \\
\hline GKN1 & -10.7882 & $1.07 \mathrm{E}-13$ & $2.4 \mathrm{E}-11$ & -8.43508 & Down & gastrokine 1 \\
\hline TRIM50 & -3.04881 & $1.21 \mathrm{E}-13$ & $2.63 \mathrm{E}-11$ & -8.41231 & Down & tripartite motif containing 50 \\
\hline LGALS9C & -3.4389 & $1.35 \mathrm{E}-13$ & $2.87 \mathrm{E}-11$ & -8.39232 & Down & galectin 9C \\
\hline PGA4 & -1.61309 & $1.39 \mathrm{E}-13$ & $2.93 \mathrm{E}-11$ & -8.38695 & Down & pepsinogen A4 \\
\hline UNC5D & -1.19374 & $1.76 \mathrm{E}-13$ & $3.62 \mathrm{E}-11$ & -8.34178 & Down & $\begin{array}{c}\text { unc-5 netrin receptor D } \\
\text { potassium voltage-gated channel subfamily } \mathrm{E}\end{array}$ \\
\hline KCNE2 & -4.98462 & $1.8 \mathrm{E}-13$ & $3.65 \mathrm{E}-11$ & -8.33726 & Down & regulatory subunit 2 \\
\hline
\end{tabular}




\begin{tabular}{|c|c|c|c|c|c|c|}
\hline LOC388387 & -1.73995 & $2.33 \mathrm{E}-13$ & $4.56 \mathrm{E}-11$ & -8.28855 & Down & \#N/A \\
\hline LOC728606 & -2.5326 & $2.47 \mathrm{E}-13$ & $4.79 \mathrm{E}-11$ & -8.27777 & Down & \#N/A \\
\hline SIGLEC11 & -2.42008 & $4.48 \mathrm{E}-13$ & $7.74 \mathrm{E}-11$ & -8.16441 & Down & sialic acid binding Ig like lectin 11 \\
\hline SCGB2A1 & -2.78376 & $4.99 \mathrm{E}-13$ & $8.26 \mathrm{E}-11$ & -8.14398 & Down & secretoglobin family $2 \mathrm{~A}$ member 1 \\
\hline CKM & -2.63883 & $6.25 \mathrm{E}-13$ & $9.79 \mathrm{E}-11$ & -8.10113 & Down & $\begin{array}{l}\text { creatine kinase, M-type } \\
\text { flavin containing dimethylanilinemonoxygenase } 6\end{array}$ \\
\hline FMO6P & -1.85337 & $6.53 \mathrm{E}-13$ & $1.01 \mathrm{E}-10$ & -8.09258 & Down & pseudogene \\
\hline LOC150622 & -2.27665 & $6.82 \mathrm{E}-13$ & $1.05 \mathrm{E}-10$ & -8.08429 & Down & \#N/A \\
\hline CPA2 & -4.84591 & $1.04 \mathrm{E}-12$ & $1.48 \mathrm{E}-10$ & -8.00357 & Down & carboxypeptidase A2 \\
\hline EEF1A2 & -2.65996 & $1.41 \mathrm{E}-12$ & $1.92 \mathrm{E}-10$ & -7.94605 & Down & eukaryotic translation elongation factor 1 alpha 2 \\
\hline LIPF & -10.3248 & $1.76 \mathrm{E}-12$ & $2.3 \mathrm{E}-10$ & -7.9034 & Down & lipase F, gastric type \\
\hline SPINK13 & -1.45446 & $2.63 \mathrm{E}-12$ & $3.23 \mathrm{E}-10$ & -7.82546 & Down & serine peptidase inhibitor, Kazal type 13 (putative) \\
\hline HRASLS2 & -4.085 & $2.87 \mathrm{E}-12$ & $3.51 \mathrm{E}-10$ & -7.80865 & Down & HRAS-like suppressor 2 \\
\hline GCNT4 & -3.44785 & $3.16 \mathrm{E}-12$ & $3.8 \mathrm{E}-10$ & -7.79046 & Down & glucosaminyl (N-acetyl) transferase 4 \\
\hline CLCNKA & -1.66591 & $6.62 \mathrm{E}-12$ & 7.13E-10 & -7.64752 & Down & chloride voltage-gated channel Ka \\
\hline ESRRB & -1.73267 & $6.74 \mathrm{E}-12$ & $7.22 \mathrm{E}-10$ & -7.64407 & Down & estrogen related receptor beta \\
\hline CNTN3 & -1.44241 & $7.14 \mathrm{E}-12$ & $7.52 \mathrm{E}-10$ & -7.63278 & Down & $\begin{array}{c}\text { contactin } 3 \\
\text { notassium inwardly rectifving channel subfamily }\end{array}$ \\
\hline KCNJ16 & -4.09464 & $9.01 \mathrm{E}-12$ & $9.04 \mathrm{E}-10$ & -7.58774 & Down & member 16 \\
\hline SOSTDC1 & -4.29253 & $1.24 \mathrm{E}-11$ & 1.17E-09 & -7.5263 & Down & $\begin{array}{c}\text { sclerostin domain containing } 1 \\
\text { SH3 domain containing GRB2 like 2, endophilin }\end{array}$ \\
\hline SH3GL2 & -2.06709 & $1.38 \mathrm{E}-11$ & $1.29 \mathrm{E}-09$ & -7.50487 & Down & A1 \\
\hline FLJ42875 & -2.84725 & $1.83 \mathrm{E}-11$ & $1.64 \mathrm{E}-09$ & -7.44946 & Down & \#N/A \\
\hline IRX3 & -1.97395 & $2.07 \mathrm{E}-11$ & $1.82 \mathrm{E}-09$ & -7.42543 & Down & iroquoishomeobox 3 \\
\hline ASAH2 & -2.33127 & $3.38 \mathrm{E}-11$ & $2.68 \mathrm{E}-09$ & -7.32979 & Down & $\mathrm{N}$-acylsphingosineamidohydrolase 2 \\
\hline SCNN1G & -2.51233 & $3.97 \mathrm{E}-11$ & 3.07E-09 & -7.29803 & Down & sodium channel epithelial 1 gamma subunit \\
\hline PGA3 & -8.64003 & $4.08 \mathrm{E}-11$ & 3.13E-09 & -7.29249 & Down & pepsinogen A3 \\
\hline ACADL & -1.50519 & $5.1 \mathrm{E}-11$ & $3.69 \mathrm{E}-09$ & -7.24896 & Down & acyl-CoA dehydrogenase long chain \\
\hline ACER2 & -2.90333 & $6.04 \mathrm{E}-11$ & 4.23E-09 & -7.21546 & Down & alkaline ceramidase 2 \\
\hline RNASE1 & -2.94249 & $8.7 \mathrm{E}-11$ & $5.64 \mathrm{E}-09$ & -7.14325 & Down & ribonuclease A family member 1, pancreatic \\
\hline SLC7A8 & -1.66853 & $1.08 \mathrm{E}-10$ & $6.71 \mathrm{E}-09$ & -7.10037 & Down & solute carrier family 7 member 8 \\
\hline PM20D1 & -1.32165 & $1.63 \mathrm{E}-10$ & $9.34 \mathrm{E}-09$ & -7.01865 & Down & peptidase M20 domain containing 1 \\
\hline C17orf110 & -2.46061 & $1.77 \mathrm{E}-10$ & $9.98 \mathrm{E}-09$ & -7.00211 & Down & Small Integral Membrane Protein 6 \\
\hline NRG4 & -2.30508 & $1.78 \mathrm{E}-10$ & $9.99 \mathrm{E}-09$ & -7.00084 & Down & neuregulin 4 \\
\hline AQP10 & -1.46396 & $1.87 \mathrm{E}-10$ & $1.04 \mathrm{E}-08$ & -6.99086 & Down & aquaporin 10 \\
\hline DMRTA1 & -2.06762 & $2.03 \mathrm{E}-10$ & $1.1 \mathrm{E}-08$ & -6.97447 & Down & DMRT like family A1 \\
\hline APLP1 & -2.38614 & $2.31 \mathrm{E}-10$ & $1.22 \mathrm{E}-08$ & -6.94873 & Down & amyloid beta precursor like protein 1 \\
\hline SULT2A1 & -3.326 & $2.72 \mathrm{E}-10$ & $1.38 \mathrm{E}-08$ & -6.91584 & Down & sulfotransferase family $2 \mathrm{~A}$ member 1 \\
\hline PXMP2 & -1.58853 & $3.07 \mathrm{E}-10$ & $1.52 \mathrm{E}-08$ & -6.89205 & Down & peroxisomal membrane protein 2 \\
\hline SLC26A7 & -2.5464 & $3.37 \mathrm{E}-10$ & $1.64 \mathrm{E}-08$ & -6.87293 & Down & solute carrier family 26 member 7 \\
\hline SLC9A4 & -4.74981 & $4.57 \mathrm{E}-10$ & $2.11 \mathrm{E}-08$ & -6.81174 & Down & solute carrier family 9 member A4 \\
\hline NKX6-2 & -2.77989 & $5.24 \mathrm{E}-10$ & $2.32 \mathrm{E}-08$ & -6.78422 & Down & NK6 homeobox 2 \\
\hline RAB27A & -1.63418 & $6.75 \mathrm{E}-10$ & $2.81 \mathrm{E}-08$ & -6.733 & Down & $\begin{array}{l}\text { RAB27A, member RAS oncogene family } \\
\text { reprimo, TP53 dependent G2 arrest mediator }\end{array}$ \\
\hline RPRM & -1.3426 & $8.16 \mathrm{E}-10$ & $3.25 \mathrm{E}-08$ & -6.69476 & Down & homolog \\
\hline DPCR1 & -3.89479 & 8.97E-10 & 3.49E-08 & -6.67532 & Down & \#N/A \\
\hline
\end{tabular}




\begin{tabular}{|c|c|c|c|c|c|c|}
\hline AMTN & -1.80401 & $1.04 \mathrm{E}-09$ & $3.94 \mathrm{E}-08$ & -6.64447 & Down & amelotin \\
\hline LDHD & -2.31421 & $1.12 \mathrm{E}-09$ & $4.18 \mathrm{E}-08$ & -6.62935 & Down & lactate dehydrogenase $\mathrm{D}$ \\
\hline SOX 21 & -3.76428 & $1.18 \mathrm{E}-09$ & $4.34 \mathrm{E}-08$ & -6.61935 & Down & SRY-box transcription factor 21 \\
\hline MFSD4 & -3.84008 & $1.36 \mathrm{E}-09$ & $4.84 \mathrm{E}-08$ & -6.59049 & Down & \#N/A \\
\hline FBP2 & -2.70325 & $1.38 \mathrm{E}-09$ & $4.89 \mathrm{E}-08$ & -6.58779 & Down & fructose-bisphosphatase 2 \\
\hline ENHO & -1.15412 & $1.41 \mathrm{E}-09$ & $4.98 \mathrm{E}-08$ & -6.5826 & Down & energy homeostasis associated \\
\hline SNORD116-8 & -1.88842 & $1.52 \mathrm{E}-09$ & $5.28 \mathrm{E}-08$ & -6.56728 & Down & small nucleolar RNA, C/D box 116-8 \\
\hline SPTSSB & -3.57356 & $1.65 \mathrm{E}-09$ & $5.67 \mathrm{E}-08$ & -6.55066 & Down & serine palmitoyltransferase small subunit B \\
\hline RANBP3L & -1.26145 & $1.67 \mathrm{E}-09$ & $5.7 \mathrm{E}-08$ & -6.54868 & Down & RAN binding protein 3 like \\
\hline COL2A1 & -2.95189 & $1.84 \mathrm{E}-09$ & $6.15 \mathrm{E}-08$ & -6.52898 & Down & collagen type II alpha 1 chain \\
\hline LINC00520 & -1.52475 & $1.85 \mathrm{E}-09$ & $6.17 \mathrm{E}-08$ & -6.52761 & Down & long intergenic non-protein coding RNA 520 \\
\hline MAP7D2 & -3.20063 & $1.85 \mathrm{E}-09$ & $6.18 \mathrm{E}-08$ & -6.52716 & Down & MAP7 domain containing 2 \\
\hline REP15 & -3.34177 & $1.99 \mathrm{E}-09$ & $6.54 \mathrm{E}-08$ & -6.51265 & Down & RAB 15 effector protein \\
\hline SNORD116-22 & -1.53513 & 3.37E-09 & $1.01 \mathrm{E}-07$ & -6.40446 & Down & small nucleolar RNA, C/D box 116-22 \\
\hline FBXL13 & -1.51457 & 4.12E-09 & $1.21 \mathrm{E}-07$ & -6.36247 & Down & F-box and leucine rich repeat protein 13 \\
\hline SST & -3.53196 & 4.21E-09 & $1.23 \mathrm{E}-07$ & -6.35817 & Down & somatostatin \\
\hline SSTR1 & -2.89045 & 4.95E-09 & $1.4 \mathrm{E}-07$ & -6.32433 & Down & somatostatin receptor 1 \\
\hline CYSTM1 & -2.62765 & 4.97E-09 & $1.41 \mathrm{E}-07$ & -6.32349 & Down & cysteine rich transmembrane module containing 1 \\
\hline SNORD116-24 & -1.92841 & $5.04 \mathrm{E}-09$ & $1.41 \mathrm{E}-07$ & -6.3207 & Down & small nucleolar RNA, C/D box 116-24 \\
\hline UBE2QL1 & -1.33169 & $6.9 \mathrm{E}-09$ & $1.82 \mathrm{E}-07$ & -6.25529 & Down & ubiquitin conjugating enzyme E2 Q family like 1 \\
\hline SLC26A9 & -3.70909 & 7.03E-09 & $1.84 \mathrm{E}-07$ & -6.2514 & Down & solute carrier family 26 member 9 \\
\hline AKR1B15 & -1.68777 & $7.81 \mathrm{E}-09$ & $2 \mathrm{E}-07$ & -6.2293 & Down & aldo-ketoreductase family 1 member B 15 \\
\hline C16orf89 & -3.15116 & $8.26 \mathrm{E}-09$ & $2.08 \mathrm{E}-07$ & -6.21756 & Down & chromosome 16 open reading frame 89 \\
\hline DHRS7 & -1.25342 & 8.5E-09 & 2.13E-07 & -6.21152 & Down & dehydrogenase/reductase 7 \\
\hline GHRL & -2.81942 & $1.04 \mathrm{E}-08$ & $2.53 \mathrm{E}-07$ & -6.16876 & Down & ghrelin and obestatinprepropeptide \\
\hline MYOC & -2.36235 & $1.1 \mathrm{E}-08$ & $2.65 \mathrm{E}-07$ & -6.15769 & Down & myocilin \\
\hline PLIN5 & -1.63943 & $1.1 \mathrm{E}-08$ & $2.65 \mathrm{E}-07$ & -6.15738 & Down & perilipin 5 \\
\hline TFF1 & -5.96452 & $1.28 \mathrm{E}-08$ & 2.99E-07 & -6.12626 & Down & trefoil factor 1 \\
\hline SNORD116-15 & -1.81246 & $1.32 \mathrm{E}-08$ & 3.06E-07 & -6.11943 & Down & small nucleolar RNA, C/D box 116-15 \\
\hline CLIC6 & -3.00234 & $1.38 \mathrm{E}-08$ & $3.18 \mathrm{E}-07$ & -6.11 & Down & chloride intracellular channel 6 \\
\hline GPX3 & -1.53402 & $1.39 \mathrm{E}-08$ & $3.19 \mathrm{E}-07$ & -6.10797 & Down & glutathione peroxidase 3 \\
\hline SNORD116-1 & -1.23006 & $1.41 \mathrm{E}-08$ & $3.21 \mathrm{E}-07$ & -6.1057 & Down & small nucleolar RNA, C/D box 116-1 \\
\hline C17orf109 & -1.78583 & $1.55 \mathrm{E}-08$ & $3.48 \mathrm{E}-07$ & -6.08492 & Down & Small Integral Membrane Protein 5) \\
\hline SNORD116-16 & -1.85033 & $1.63 \mathrm{E}-08$ & $3.65 \mathrm{E}-07$ & -6.07383 & Down & small nucleolar RNA, C/D box 116-16 \\
\hline DDX60 & -1.90016 & 1.7E-08 & $3.75 \mathrm{E}-07$ & -6.06529 & Down & DExD/H-box helicase 60 \\
\hline AKR1C1 & -2.71499 & $1.87 \mathrm{E}-08$ & $4.06 \mathrm{E}-07$ & -6.04482 & Down & aldo-ketoreductase family 1 member $\mathrm{C} 1$ \\
\hline CHGA & -4.92682 & $1.95 \mathrm{E}-08$ & $4.18 \mathrm{E}-07$ & -6.03667 & Down & chromogranin A \\
\hline ATP13A5 & -1.21452 & $1.95 \mathrm{E}-08$ & 4.18E-07 & -6.03656 & Down & ATPase 13 A5 \\
\hline CKB & -2.96435 & $2.2 \mathrm{E}-08$ & $4.62 \mathrm{E}-07$ & -6.01088 & Down & creatine kinase B \\
\hline GPER & -1.80627 & $2.36 \mathrm{E}-08$ & $4.89 \mathrm{E}-07$ & -5.99599 & Down & G protein-coupled estrogen receptor 1 \\
\hline SNORD8 & -1.80282 & 3.07E-08 & $6.02 \mathrm{E}-07$ & -5.93999 & Down & small nucleolar RNA, C/D box 8 \\
\hline CADM2 & -1.89173 & $3.26 \mathrm{E}-08$ & $6.3 \mathrm{E}-07$ & -5.92695 & Down & cell adhesion molecule 2 \\
\hline ZNF385B & -1.78893 & $3.57 \mathrm{E}-08$ & $6.78 \mathrm{E}-07$ & -5.90705 & Down & zinc finger protein $385 \mathrm{~B}$ \\
\hline
\end{tabular}




\begin{tabular}{|c|c|c|c|c|c|c|}
\hline ACSM1 & -1.46055 & 3.7E-08 & $6.96 \mathrm{E}-07$ & -5.89993 & Down & $\begin{array}{l}\text { acyl-CoA synthetase medium chain family member } \\
1\end{array}$ \\
\hline TFF2 & -6.44232 & $3.72 \mathrm{E}-08$ & 7E-07 & -5.89859 & Down & trefoil factor 2 \\
\hline CSTA & -1.86609 & $4.26 \mathrm{E}-08$ & $7.81 \mathrm{E}-07$ & -5.86943 & Down & cystatin A \\
\hline PTGDR2 & -1.81674 & 4.69E-08 & $8.46 \mathrm{E}-07$ & -5.84879 & Down & $\begin{array}{c}\text { prostaglandin D2 receptor } 2 \\
\text { anolinoprotein } \mathrm{B} \text { m }\end{array}$ \\
\hline APOBEC2 & -1.56849 & $4.86 \mathrm{E}-08$ & 8.7E-07 & -5.84084 & Down & $\begin{array}{l}\text { subunit } 2 \\
\text { G protein-coupled receptor class } \mathrm{C} \text { group } 5\end{array}$ \\
\hline GPRC5C & -1.81291 & $5.23 \mathrm{E}-08$ & $9.22 \mathrm{E}-07$ & -5.82526 & Down & member $\mathrm{C}$ \\
\hline MT1M & -2.74482 & $5.39 \mathrm{E}-08$ & $9.43 \mathrm{E}-07$ & -5.8186 & Down & metallothionein $1 \mathrm{M}$ \\
\hline ALDH6A1 & -1.28921 & $5.45 \mathrm{E}-08$ & $9.53 \mathrm{E}-07$ & -5.81603 & Down & aldehyde dehydrogenase 6 family member A1 \\
\hline PDGFD & -1.8933 & $6.04 \mathrm{E}-08$ & $1.04 \mathrm{E}-06$ & -5.79406 & Down & platelet derived growth factor $\mathrm{D}$ \\
\hline FUT9 & -4.25189 & $6.29 \mathrm{E}-08$ & $1.08 \mathrm{E}-06$ & -5.78508 & Down & fucosyltransferase 9 \\
\hline AKR7A3 & -2.97814 & $6.47 \mathrm{E}-08$ & $1.11 \mathrm{E}-06$ & -5.77892 & Down & aldo-ketoreductase family 7 member A3 \\
\hline GATA5 & -2.62837 & $6.7 \mathrm{E}-08$ & $1.14 \mathrm{E}-06$ & -5.77143 & Down & GATA binding protein 5 \\
\hline PSCA & -5.92828 & $6.79 \mathrm{E}-08$ & $1.15 \mathrm{E}-06$ & -5.76865 & Down & prostate stem cell antigen \\
\hline SYT16 & -1.31438 & $7.05 \mathrm{E}-08$ & $1.19 \mathrm{E}-06$ & -5.76027 & Down & synaptotagmin 16 \\
\hline FRMD1 & -2.30851 & 7.11E-08 & $1.19 \mathrm{E}-06$ & -5.75872 & Down & FERM domain containing 1 \\
\hline HPGD & -3.26128 & 7.9E-08 & $1.3 \mathrm{E}-06$ & -5.7357 & Down & 15-hydroxyprostaglandin dehydrogenase \\
\hline $\begin{array}{c}\text { ERO1LB } \\
\text { LOC10028925 }\end{array}$ & -1.53891 & $8.63 \mathrm{E}-08$ & $1.4 \mathrm{E}-06$ & -5.71649 & Down & endoplasmic reticulum oxidoreductase 1 beta \\
\hline 5 & -2.65977 & $9.04 \mathrm{E}-08$ & $1.45 \mathrm{E}-06$ & -5.70623 & Down & \#N/A \\
\hline B4GALNT3 & -2.22696 & $1.02 \mathrm{E}-07$ & $1.61 \mathrm{E}-06$ & -5.68052 & Down & beta-1,4-N-acetyl-galactosaminyltransferase 3 \\
\hline AKR1C2 & -3.36163 & $1.08 \mathrm{E}-07$ & $1.68 \mathrm{E}-06$ & -5.66757 & Down & aldo-ketoreductase family 1 member $\mathrm{C} 2$ \\
\hline TMEM220 & -1.43809 & $1.14 \mathrm{E}-07$ & $1.76 \mathrm{E}-06$ & -5.65605 & Down & transmembrane protein 220 \\
\hline PDIA2 & -3.22693 & $1.22 \mathrm{E}-07$ & $1.87 \mathrm{E}-06$ & -5.64051 & Down & protein disulfideisomerase family A member 2 \\
\hline GLUL & -1.47258 & $1.39 \mathrm{E}-07$ & $2.09 \mathrm{E}-06$ & -5.61142 & Down & glutamate-ammonia ligase \\
\hline SLC2A12 & -2.17534 & $1.41 \mathrm{E}-07$ & $2.1 \mathrm{E}-06$ & -5.60948 & Down & solute carrier family 2 member 12 \\
\hline CXCL17 & -4.34036 & $1.48 \mathrm{E}-07$ & $2.19 \mathrm{E}-06$ & -5.5984 & Down & $\mathrm{C}-\mathrm{X}-\mathrm{C}$ motif chemokine ligand 17 \\
\hline HOMER2 & -2.62231 & $1.52 \mathrm{E}-07$ & $2.24 \mathrm{E}-06$ & -5.59209 & Down & $\begin{array}{c}\text { homer scaffold protein } 2 \\
\text { potassium inwardly rectifying channel subfamily } \mathrm{J}\end{array}$ \\
\hline KCNJ15 & -2.71143 & $1.87 \mathrm{E}-07$ & $2.65 \mathrm{E}-06$ & -5.54619 & Down & member 15 \\
\hline SLC25A4 & -1.49727 & $1.89 \mathrm{E}-07$ & $2.67 \mathrm{E}-06$ & -5.54412 & Down & solute carrier family 25 member 4 \\
\hline FA2H & -2.0741 & 2.03E-07 & $2.83 \mathrm{E}-06$ & -5.52818 & Down & fatty acid 2-hydroxylase \\
\hline GC & -2.25418 & $2.12 \mathrm{E}-07$ & 2.93E-06 & -5.51839 & Down & GC vitamin D binding protein \\
\hline AGPAT9 & -1.64544 & $2.19 \mathrm{E}-07$ & 3.01E-06 & -5.511 & Down & 1-acylglycerol-3-phosphate O-acyltransferase 9 \\
\hline CA2 & -4.04359 & $2.22 \mathrm{E}-07$ & 3.03E-06 & -5.50885 & Down & carbonic anhydrase 2 \\
\hline ANGPTL3 & -1.65764 & $2.23 \mathrm{E}-07$ & 3.05E-06 & -5.50692 & Down & angiopoietin like 3 \\
\hline ENAM & -1.42603 & $2.25 \mathrm{E}-07$ & $3.07 \mathrm{E}-06$ & -5.50571 & Down & enamelin \\
\hline CNTD1 & -1.15343 & $2.29 \mathrm{E}-07$ & $3.11 \mathrm{E}-06$ & -5.50141 & Down & cyclin $\mathrm{N}$-terminal domain containing 1 \\
\hline C22orf23 & -1.43003 & $2.32 \mathrm{E}-07$ & $3.14 \mathrm{E}-06$ & -5.49836 & Down & chromosome 22 open reading frame 23 \\
\hline VSIG2 & -3.8996 & $2.36 \mathrm{E}-07$ & $3.19 \mathrm{E}-06$ & -5.49508 & Down & V-set and immunoglobulin domain containing 2 \\
\hline DUSP19 & -1.39174 & $2.52 \mathrm{E}-07$ & 3.37E-06 & -5.47987 & Down & dual specificity phosphatase 19 \\
\hline MYZAP & -1.47779 & $2.64 \mathrm{E}-07$ & $3.51 \mathrm{E}-06$ & -5.4695 & Down & myocardial zonulaadherens protein \\
\hline SLC9A1 & -1.43955 & $2.71 \mathrm{E}-07$ & $3.58 \mathrm{E}-06$ & -5.46391 & Down & solute carrier family 9 member A1 \\
\hline PKIB & -2.38026 & $3.06 \mathrm{E}-07$ & 3.97E-06 & -5.43677 & Down & cAMP-dependent protein kinase inhibitor beta \\
\hline PGC & -7.92429 & 4.4E-07 & $5.39 \mathrm{E}-06$ & -5.35497 & Down & progastricsin \\
\hline
\end{tabular}




\begin{tabular}{|c|c|c|c|c|c|c|}
\hline IGFALS & -1.95174 & 4.6E-07 & $5.57 \mathrm{E}-06$ & -5.34513 & Down & $\begin{array}{l}\text { insulin like growth factor binding protein acid } \\
\text { labile subunit }\end{array}$ \\
\hline ALDH3A1 & -3.4432 & 4.75E-07 & $5.72 \mathrm{E}-06$ & -5.33779 & Down & aldehyde dehydrogenase 3 family member A1 \\
\hline SLC1A2 & -2.13118 & 4.75E-07 & $5.72 \mathrm{E}-06$ & -5.33774 & Down & solute carrier family 1 member 2 \\
\hline MT1G & -3.30769 & $5.35 \mathrm{E}-07$ & $6.29 \mathrm{E}-06$ & -5.31104 & Down & metallothionein $1 \mathrm{G}$ \\
\hline CAPN9 & -3.65078 & $5.41 \mathrm{E}-07$ & $6.36 \mathrm{E}-06$ & -5.30841 & Down & calpain 9 \\
\hline VSIG1 & -4.8252 & $5.42 \mathrm{E}-07$ & $6.36 \mathrm{E}-06$ & -5.3081 & Down & $\begin{array}{l}\text { V-set and immunoglobulin domain containing } 1 \\
\text { phosphatidylinositol specific phospholipase C X }\end{array}$ \\
\hline PLCXD3 & -2.25153 & 5.92E-07 & $6.87 \mathrm{E}-06$ & -5.28771 & Down & domain containing 3 \\
\hline PAIP2B & -2.13484 & $6.15 \mathrm{E}-07$ & 7.08E-06 & -5.27904 & Down & poly(A) binding protein interacting protein $2 \mathrm{~B}$ \\
\hline GPR64 & -1.89215 & $6.26 \mathrm{E}-07$ & 7.18E-06 & -5.27515 & Down & G protein-coupled receptor 64 \\
\hline GPT & -2.15929 & $6.45 \mathrm{E}-07$ & 7.38E-06 & -5.2683 & Down & glutamic--pyruvic transaminase \\
\hline CCBE1 & -1.23235 & $6.52 \mathrm{E}-07$ & 7.44E-06 & -5.26599 & Down & collagen and calcium binding EGF domains 1 \\
\hline RMST & -1.51845 & 7.62E-07 & $8.5 \mathrm{E}-06$ & -5.23044 & Down & rhabdomyosarcoma 2 associated transcript \\
\hline ANG & -1.69955 & 7.93E-07 & $8.79 \mathrm{E}-06$ & -5.22129 & Down & angiogenin \\
\hline AKR1B10 & -4.46934 & 8.3E-07 & $9.13 \mathrm{E}-06$ & -5.21088 & Down & aldo-ketoreductase family 1 member B 10 \\
\hline PLLP & -1.89685 & $8.58 \mathrm{E}-07$ & $9.39 \mathrm{E}-06$ & -5.20326 & Down & plasmolipin \\
\hline BRP44L & -1.19484 & 8.7E-07 & $9.52 \mathrm{E}-06$ & -5.19998 & Down & Mitochondrial Pyruvate Carrier 1) \\
\hline LYPD6B & -2.52357 & $9.89 \mathrm{E}-07$ & $1.06 \mathrm{E}-05$ & -5.17051 & Down & LY6/PLAUR domain containing 6B \\
\hline KLF2 & -1.43192 & $9.96 \mathrm{E}-07$ & $1.07 \mathrm{E}-05$ & -5.16887 & Down & Kruppel like factor 2 \\
\hline IRX5 & -1.3397 & $1 \mathrm{E}-06$ & $1.08 \mathrm{E}-05$ & -5.16708 & Down & $\begin{array}{c}\text { iroquoishomeobox } 5 \\
\text { signal peptide, CUB domain and EGF like domain }\end{array}$ \\
\hline SCUBE2 & -1.67574 & $1.08 \mathrm{E}-06$ & $1.15 \mathrm{E}-05$ & -5.14949 & Down & containing 2 \\
\hline PAPPA2 & -1.61521 & 1.1E-06 & $1.16 \mathrm{E}-05$ & -5.14522 & Down & pappalysin 2 \\
\hline CCDC64 & -1.15111 & $1.13 \mathrm{E}-06$ & $1.19 \mathrm{E}-05$ & -5.13998 & Down & Bicaudal D-related protein 1. \\
\hline FAM177B & -2.74114 & $1.18 \mathrm{E}-06$ & $1.24 \mathrm{E}-05$ & -5.12911 & Down & family with sequence similarity 177 member B \\
\hline TMEM92 & -1.54649 & $1.3 \mathrm{E}-06$ & $1.34 \mathrm{E}-05$ & -5.108 & Down & transmembrane protein 92 \\
\hline GSTA2 & -1.84896 & $1.31 \mathrm{E}-06$ & $1.35 \mathrm{E}-05$ & -5.10531 & Down & glutathione S-transferase alpha 2 \\
\hline ITPKA & -1.60035 & $1.35 \mathrm{E}-06$ & $1.39 \mathrm{E}-05$ & -5.09805 & Down & inositol-trisphosphate 3-kinase A \\
\hline CKMT2 & -1.93321 & $1.4 \mathrm{E}-06$ & $1.43 \mathrm{E}-05$ & -5.08937 & Down & creatine kinase, mitochondrial 2 \\
\hline KLHDC7A & -2.13101 & $1.49 \mathrm{E}-06$ & $1.5 \mathrm{E}-05$ & -5.07556 & Down & kelch domain containing 7A \\
\hline GCKR & -1.62805 & $1.52 \mathrm{E}-06$ & $1.52 \mathrm{E}-05$ & -5.07171 & Down & glucokinase regulator \\
\hline B4GALNT2 & -2.1561 & $1.58 \mathrm{E}-06$ & $1.57 \mathrm{E}-05$ & -5.0616 & Down & beta-1,4-N-acetyl-galactosaminyltransferase 2 \\
\hline $\begin{array}{l}\text { TMEM38A } \\
\text { LOC10050563 }\end{array}$ & -1.51917 & $1.59 \mathrm{E}-06$ & $1.58 \mathrm{E}-05$ & -5.06108 & Down & transmembrane protein $38 \mathrm{~A}$ \\
\hline 3 & -2.28691 & $1.59 \mathrm{E}-06$ & $1.58 \mathrm{E}-05$ & -5.0601 & Down & \#N/A \\
\hline RAB37 & -1.32868 & $1.71 \mathrm{E}-06$ & $1.68 \mathrm{E}-05$ & -5.04304 & Down & RAB37, member RAS oncogene family \\
\hline MT1F & -2.10388 & $1.72 \mathrm{E}-06$ & $1.69 \mathrm{E}-05$ & -5.04199 & Down & metallothionein $1 \mathrm{~F}$ \\
\hline XYLT2 & -1.15806 & $1.79 \mathrm{E}-06$ & $1.75 \mathrm{E}-05$ & -5.03245 & Down & xylosyltransferase 2 \\
\hline TM7SF2 & -1.42717 & $1.8 \mathrm{E}-06$ & $1.75 \mathrm{E}-05$ & -5.03183 & Down & transmembrane 7 superfamily member 2 \\
\hline ADHFE1 & -1.33 & $1.83 \mathrm{E}-06$ & $1.78 \mathrm{E}-05$ & -5.02717 & Down & alcohol dehydrogenase iron containing 1 \\
\hline MUM1L1 & -1.15969 & $1.93 \mathrm{E}-06$ & $1.86 \mathrm{E}-05$ & -5.01471 & Down & melanoma associated antigen (mutated) 1-like 1. \\
\hline LOC284578 & -1.14675 & $2.01 \mathrm{E}-06$ & $1.92 \mathrm{E}-05$ & -5.00557 & Down & \#N/A \\
\hline STYK1 & -1.66182 & 2.04E-06 & $1.93 \mathrm{E}-05$ & -5.00288 & Down & serine/threonine/tyrosine kinase 1 \\
\hline MTRNR2L2 & -1.22402 & $2.14 \mathrm{E}-06$ & $2.02 \mathrm{E}-05$ & -4.9906 & Down & MT-RNR2 like 2 \\
\hline VILL & -2.18985 & $2.3 \mathrm{E}-06$ & $2.15 \mathrm{E}-05$ & -4.97381 & Down & villin like \\
\hline
\end{tabular}




\begin{tabular}{|c|c|c|c|c|c|c|}
\hline SLC28A2 & -3.90596 & $2.71 \mathrm{E}-06$ & $2.48 \mathrm{E}-05$ & -4.9353 & Down & solute carrier family 28 member 2 \\
\hline HYAL1 & -2.01532 & $2.88 \mathrm{E}-06$ & $2.62 \mathrm{E}-05$ & -4.92076 & Down & hyaluronidase 1 \\
\hline EPN3 & -1.96052 & 2.93E-06 & $2.65 \mathrm{E}-05$ & -4.91721 & Down & epsin 3 \\
\hline AADAC & -3.09772 & $3.05 \mathrm{E}-06$ & $2.74 \mathrm{E}-05$ & -4.90747 & Down & arylacetamidedeacetylase \\
\hline SYTL5 & -2.99347 & $3.14 \mathrm{E}-06$ & $2.81 \mathrm{E}-05$ & -4.90027 & Down & synaptotagmin like 5 \\
\hline KLK11 & -2.93302 & $3.15 \mathrm{E}-06$ & $2.82 \mathrm{E}-05$ & -4.89979 & Down & kallikrein related peptidase 11 \\
\hline ALDOC & -1.41944 & $3.27 \mathrm{E}-06$ & $2.92 \mathrm{E}-05$ & -4.89084 & Down & aldolase, fructose-bisphosphate C \\
\hline GALE & -1.36741 & $3.35 \mathrm{E}-06$ & 2.97E-05 & -4.88489 & Down & UDP-galactose-4-epimerase \\
\hline GSTA1 & -3.20281 & $3.51 \mathrm{E}-06$ & $3.08 \mathrm{E}-05$ & -4.87396 & Down & glutathione S-transferase alpha 1 \\
\hline CYP2C8 & -1.2518 & $3.67 \mathrm{E}-06$ & $3.2 \mathrm{E}-05$ & -4.86337 & Down & cytochrome $\mathrm{P} 450$ family 2 subfamily $\mathrm{C}$ member 8 \\
\hline ID1 & -1.62166 & $3.8 \mathrm{E}-06$ & $3.29 \mathrm{E}-05$ & -4.85491 & Down & inhibitor of DNA binding 1, HLH protein \\
\hline GPR155 & -1.87712 & $3.84 \mathrm{E}-06$ & $3.32 \mathrm{E}-05$ & -4.85253 & Down & G protein-coupled receptor 155 \\
\hline BMP5 & -1.58937 & $3.91 \mathrm{E}-06$ & $3.36 \mathrm{E}-05$ & -4.84864 & Down & bone morphogenetic protein 5 \\
\hline CAPN13 & -2.494 & $3.99 \mathrm{E}-06$ & $3.42 \mathrm{E}-05$ & -4.8437 & Down & calpain 13 \\
\hline CA9 & -3.29683 & $4.21 \mathrm{E}-06$ & $3.58 \mathrm{E}-05$ & -4.8304 & Down & carbonic anhydrase 9 \\
\hline SCIN & -2.33185 & $4.39 \mathrm{E}-06$ & $3.7 \mathrm{E}-05$ & -4.82083 & Down & scinderin \\
\hline CYP2C18 & -2.59224 & 4.4E-06 & $3.71 \mathrm{E}-05$ & -4.81989 & Down & $\begin{array}{l}\text { cytochrome P450 family } 2 \text { subfamily } \mathrm{C} \text { member } 18 \\
\text { glucosaminyl (N-acetyl) transferase } 2 \text { (I blood }\end{array}$ \\
\hline GCNT2 & -1.783 & 4.63E-06 & $3.86 \mathrm{E}-05$ & -4.80777 & Down & group) \\
\hline EDARADD & -1.45242 & 4.85E-06 & 4.02E-05 & -4.79673 & Down & EDAR associated death domain \\
\hline ARL14 & -2.41024 & $5 \mathrm{E}-06$ & 4.13E-05 & -4.78926 & Down & ADP ribosylation factor like GTPase 14 \\
\hline TMEM229A & -1.44756 & $5.11 \mathrm{E}-06$ & 4.2E-05 & -4.78411 & Down & transmembrane protein 229A \\
\hline CIDEC & -2.156 & $5.2 \mathrm{E}-06$ & $4.26 \mathrm{E}-05$ & -4.78008 & Down & cell death inducing DFFA like effector c \\
\hline FOLR1 & -2.37016 & $5.65 \mathrm{E}-06$ & 4.57E-05 & -4.75983 & Down & folate receptor alpha \\
\hline ELOVL6 & -1.57779 & $5.98 \mathrm{E}-06$ & $4.8 \mathrm{E}-05$ & -4.74624 & Down & ELOVL fatty acid elongase 6 \\
\hline LIFR & -1.94262 & $7.39 \mathrm{E}-06$ & $5.74 \mathrm{E}-05$ & -4.69476 & Down & LIF receptor subunit alpha \\
\hline IL17REL & -1.47128 & 7.69E-06 & 5.93E-05 & -4.68519 & Down & interleukin 17 receptor $\mathrm{E}$ like \\
\hline C1orf210 & -1.31 & $7.82 \mathrm{E}-06$ & $6.02 \mathrm{E}-05$ & -4.68089 & Down & chromosome 1 open reading frame 210 \\
\hline SERPINA5 & -2.4327 & $7.98 \mathrm{E}-06$ & $6.11 \mathrm{E}-05$ & -4.67622 & Down & serpin family A member 5 \\
\hline $\mathrm{HRH} 2$ & -1.32411 & $7.98 \mathrm{E}-06$ & $6.11 \mathrm{E}-05$ & -4.67605 & Down & histamine receptor $\mathrm{H} 2$ \\
\hline TMEM171 & -1.47378 & 8.03E-06 & $6.14 \mathrm{E}-05$ & -4.67468 & Down & transmembrane protein 171 \\
\hline ADTRP & -2.73817 & $8.32 \mathrm{E}-06$ & $6.33 \mathrm{E}-05$ & -4.66581 & Down & androgen dependent TFPI regulating protein \\
\hline MYRIP & -1.74826 & 8.37E-06 & $6.35 \mathrm{E}-05$ & -4.66452 & Down & myosin VIIA and Rab interacting protein \\
\hline RIPK4 & -1.17687 & $8.61 \mathrm{E}-06$ & $6.52 \mathrm{E}-05$ & -4.65744 & Down & receptor interacting serine/threonine kinase 4 \\
\hline FGA & -3.49325 & $8.91 \mathrm{E}-06$ & $6.71 \mathrm{E}-05$ & -4.64908 & Down & $\begin{array}{l}\text { fibrinogen alpha chain } \\
\text { ectonucleoside triphosphate diphosphohydrolase } 5\end{array}$ \\
\hline ENTPD5 & -1.43795 & $9.1 \mathrm{E}-06$ & $6.83 \mathrm{E}-05$ & -4.64388 & Down & (inactive) \\
\hline AKR1C3 & -2.24251 & $9.8 \mathrm{E}-06$ & $7.26 \mathrm{E}-05$ & -4.62586 & Down & $\begin{array}{l}\text { aldo-ketoreductase family } 1 \text { member } \mathrm{C} 3 \\
\text { ectonucleotidepyrophosphatase/phosphodiesterase }\end{array}$ \\
\hline ENPP5 & -1.60223 & $1.08 \mathrm{E}-05$ & $7.85 \mathrm{E}-05$ & -4.60287 & Down & family member 5 \\
\hline ATP13A4 & -2.2645 & $1.11 \mathrm{E}-05$ & $8.04 \mathrm{E}-05$ & -4.59611 & Down & ATPase 13A4 \\
\hline KLF15 & -1.55586 & $1.13 \mathrm{E}-05$ & $8.19 \mathrm{E}-05$ & -4.59049 & Down & Kruppel like factor 15 \\
\hline FAM3B & -2.88357 & $1.13 \mathrm{E}-05$ & $8.21 \mathrm{E}-05$ & -4.58986 & Down & family with sequence similarity 3 member B \\
\hline SLC9A2 & -2.44331 & $1.21 \mathrm{E}-05$ & 8.67E-05 & -4.57391 & Down & solute carrier family 9 member $\mathrm{A} 2$ \\
\hline BEX5 & -1.19649 & $1.22 \mathrm{E}-05$ & $8.75 \mathrm{E}-05$ & -4.57104 & Down & brain expressed $X$-linked 5 \\
\hline
\end{tabular}




\begin{tabular}{|c|c|c|c|c|c|c|}
\hline OASL & -1.75005 & $1.23 \mathrm{E}-05$ & $8.81 \mathrm{E}-05$ & -4.56899 & Down & 2'-5'-oligoadenylate synthetase like \\
\hline LOC400043 & -1.90787 & $1.3 \mathrm{E}-05$ & $9.25 \mathrm{E}-05$ & -4.55525 & Down & \#N/A \\
\hline C1 orf116 & -1.85534 & $1.33 \mathrm{E}-05$ & $9.41 \mathrm{E}-05$ & -4.54997 & Down & chromosome 1 open reading frame 116 \\
\hline SMPD3 & -1.76857 & $1.35 \mathrm{E}-05$ & $9.5 \mathrm{E}-05$ & -4.54688 & Down & sphingomyelinphosphodiesterase 3 \\
\hline SEC14L5 & -1.15197 & $1.44 \mathrm{E}-05$ & 0.000101 & -4.53027 & Down & SEC14 like lipid binding 5 \\
\hline ME1 & -1.28537 & $1.44 \mathrm{E}-05$ & 0.000101 & -4.53004 & Down & malic enzyme 1 \\
\hline MTRNR2L8 & -1.13079 & $1.55 \mathrm{E}-05$ & 0.000107 & -4.51279 & Down & MT-RNR2 like 8 \\
\hline SNORD116-20 & -1.14964 & $1.55 \mathrm{E}-05$ & 0.000107 & -4.51266 & Down & small nucleolar RNA, C/D box 116-20 \\
\hline FER1L6 & -3.70792 & $1.6 \mathrm{E}-05$ & 0.00011 & -4.50424 & Down & fer-1 like family member 6 \\
\hline NWD1 & -1.62763 & $1.74 \mathrm{E}-05$ & 0.000118 & -4.48368 & Down & NACHT and WD repeat domain containing 1 \\
\hline IL1R2 & -2.15474 & $1.77 \mathrm{E}-05$ & 0.00012 & -4.47909 & Down & interleukin 1 receptor type 2 \\
\hline KLF4 & -1.5749 & $1.87 \mathrm{E}-05$ & 0.000125 & -4.46575 & Down & Kruppel like factor 4 \\
\hline ORM2 & -2.06661 & $1.87 \mathrm{E}-05$ & 0.000125 & -4.46517 & Down & orosomucoid 2 \\
\hline AZGP1 & -2.93525 & $1.99 \mathrm{E}-05$ & 0.000132 & -4.44919 & Down & alpha-2-glycoprotein 1, zinc-binding \\
\hline TMEM151A & -1.17211 & 2.13E-05 & 0.00014 & -4.43233 & Down & transmembrane protein $151 \mathrm{~A}$ \\
\hline ENTPD3 & -1.41639 & $2.14 \mathrm{E}-05$ & 0.00014 & -4.4308 & Down & ectonucleoside triphosphate diphosphohydrolase 3 \\
\hline RNASE4 & -1.49833 & $2.2 \mathrm{E}-05$ & 0.000144 & -4.42433 & Down & ribonuclease A family member 4 \\
\hline RASSF6 & -1.61314 & $2.52 \mathrm{E}-05$ & 0.000161 & -4.39047 & Down & Ras association domain family member 6 \\
\hline ANXA10 & -4.16183 & $2.56 \mathrm{E}-05$ & 0.000163 & -4.38594 & Down & annexin A10 \\
\hline MSMB & -3.75333 & $2.71 \mathrm{E}-05$ & 0.000172 & -4.37138 & Down & microseminoprotein beta \\
\hline CYB5A & -1.14489 & $2.74 \mathrm{E}-05$ & 0.000173 & -4.36861 & Down & cytochrome b5 type A \\
\hline NQO1 & -1.86364 & 2.92E-05 & 0.000183 & -4.35221 & Down & $\mathrm{NAD}(\mathrm{P}) \mathrm{H}$ quinone dehydrogenase 1 \\
\hline FMO5 & -1.74122 & 2.97E-05 & 0.000185 & -4.34798 & Down & flavin containing dimethylanilinemonoxygenase 5 \\
\hline DPT & -2.18519 & $2.99 \mathrm{E}-05$ & 0.000186 & -4.34646 & Down & dermatopontin \\
\hline S100P & -2.79699 & $3.12 \mathrm{E}-05$ & 0.000193 & -4.33526 & Down & S100 calcium binding protein $P$ \\
\hline MIA2 & -1.94287 & 3.25E-05 & 0.0002 & -4.32543 & Down & $\begin{array}{l}\text { MIA SH3 domain ER export factor } 2 \\
\text { UDP-GlcNAc:betaGal beta-1,3-N- }\end{array}$ \\
\hline B3GNT6 & -3.29988 & $3.46 \mathrm{E}-05$ & 0.00021 & -4.30883 & Down & acetylglucosaminyltransferase 6 \\
\hline PAQR8 & -1.33801 & $3.49 \mathrm{E}-05$ & 0.000212 & -4.30662 & Down & progestin and adipoQ receptor family member 8 \\
\hline C1orf130 & -1.78106 & $3.65 \mathrm{E}-05$ & 0.00022 & -4.2952 & Down & chromosome 1 open reading frame 130 \\
\hline PP7080 & -1.68017 & $3.69 \mathrm{E}-05$ & 0.000223 & -4.29224 & Down & uncharacterized LOC25845 \\
\hline SULT1C2 & -2.71188 & $4.53 \mathrm{E}-05$ & 0.000264 & -4.23934 & Down & sulfotransferase family $1 \mathrm{C}$ member 2 \\
\hline TPD52L1 & -1.54408 & $4.53 \mathrm{E}-05$ & 0.000264 & -4.23928 & Down & TPD52 like 1 \\
\hline SULT1B1 & -2.5618 & 4.7E-05 & 0.000272 & -4.22996 & Down & sulfotransferase family 1B member 1 \\
\hline HPN & -2.17976 & $5.18 \mathrm{E}-05$ & 0.000297 & -4.20434 & Down & hepsin \\
\hline KRT20 & -4.19415 & $5.25 \mathrm{E}-05$ & 0.0003 & -4.2009 & Down & keratin 20 \\
\hline ALDH1A1 & -2.19118 & $5.58 \mathrm{E}-05$ & 0.000316 & -4.18529 & Down & aldehyde dehydrogenase 1 family member A1 \\
\hline FER1L6-AS1 & -1.4067 & $5.62 \mathrm{E}-05$ & 0.000318 & -4.18345 & Down & FER1L6 antisense RNA 1 \\
\hline ARHGDIG & -1.37568 & $5.63 \mathrm{E}-05$ & 0.000319 & -4.18263 & Down & Rho GDP dissociation inhibitor gamma \\
\hline TST & -1.30825 & $5.94 \mathrm{E}-05$ & 0.000333 & -4.16892 & Down & thiosulfate sulfurtransferase \\
\hline KIAA0895 & -1.34672 & $5.99 \mathrm{E}-05$ & 0.000336 & -4.16645 & Down & KIAA0895 \\
\hline RPS6KA6 & -1.4841 & $6.19 \mathrm{E}-05$ & 0.000344 & -4.15812 & Down & ribosomal protein S6 kinase A6 \\
\hline CHGB & -2.2368 & $6.5 \mathrm{E}-05$ & 0.000359 & -4.14492 & Down & chromogranin B \\
\hline
\end{tabular}




\begin{tabular}{|c|c|c|c|c|c|c|}
\hline COL4A6 & -1.84882 & $6.59 \mathrm{E}-05$ & 0.000363 & -4.14163 & Down & collagen type IV alpha 6 chain \\
\hline ECHDC3 & -1.70417 & $6.94 \mathrm{E}-05$ & 0.00038 & -4.12764 & Down & enoyl-CoA hydratase domain containing 3 \\
\hline INSIG1 & -1.1514 & $6.98 \mathrm{E}-05$ & 0.000381 & -4.1261 & Down & insulin induced gene 1 \\
\hline EPB41L4B & -1.50303 & $7.46 \mathrm{E}-05$ & 0.000404 & -4.1086 & Down & erythrocyte membrane protein band 4.1 like $4 \mathrm{~B}$ \\
\hline IGJ & -3.06899 & $7.5 \mathrm{E}-05$ & 0.000405 & -4.10734 & Down & $\begin{array}{c}\text { \#N/A } \\
\text { phenazine biosynthesis like protein domain }\end{array}$ \\
\hline PBLD & -1.70062 & 7.53E-05 & 0.000407 & -4.10625 & Down & containing \\
\hline MT1E & -2.0273 & 7.77E-05 & 0.000418 & -4.09782 & Down & metallothionein $1 \mathrm{E}$ \\
\hline LTF & -3.65068 & $7.95 \mathrm{E}-05$ & 0.000427 & -4.09188 & Down & lactotransferrin \\
\hline PALM3 & -1.80821 & $8.06 \mathrm{E}-05$ & 0.000432 & -4.08804 & Down & paralemmin 3 \\
\hline ADAMTS15 & -1.7918 & $8.1 \mathrm{E}-05$ & 0.000433 & -4.08687 & Down & $\begin{array}{l}\text { ADAM metallopeptidase with thrombospondin } \\
\text { type } 1 \text { motif } 15\end{array}$ \\
\hline TMPRSS2 & -1.68379 & $8.75 \mathrm{E}-05$ & 0.000464 & -4.06631 & Down & transmembrane serine protease 2 \\
\hline ARHGEF37 & -1.43569 & $9.08 \mathrm{E}-05$ & 0.000479 & -4.05636 & Down & Rho guanine nucleotide exchange factor 37 \\
\hline PRDM16 & -1.44097 & $9.11 \mathrm{E}-05$ & 0.00048 & -4.05544 & Down & PR/SET domain 16 \\
\hline SNORD22 & -1.19739 & $9.2 \mathrm{E}-05$ & 0.000484 & -4.05279 & Down & small nucleolar RNA, C/D box 22 \\
\hline STX19 & -1.42672 & 0.000101 & 0.000525 & -4.02756 & Down & syntaxin 19 \\
\hline SLC16A7 & -1.5037 & 0.000103 & 0.000533 & -4.02328 & Down & solute carrier family 16 member 7 \\
\hline SELENBP1 & -1.60959 & 0.000106 & 0.000546 & -4.01555 & Down & selenium binding protein 1 \\
\hline FNDC5 & -1.181 & 0.00011 & 0.000564 & -4.00544 & Down & fibronectin type III domain containing 5 \\
\hline TTR & -1.71577 & 0.00011 & 0.000564 & -4.00522 & Down & transthyretin \\
\hline BCAS1 & -2.74005 & 0.00011 & 0.000564 & -4.00512 & Down & breast carcinoma amplified sequence 1 \\
\hline C19orf77 & -2.20692 & 0.000121 & 0.000612 & -3.97948 & Down & \#N/A \\
\hline SERPINA4 & -2.36418 & 0.000124 & 0.000626 & -3.97258 & Down & serpin family A member 4 \\
\hline FSIP2 & -1.98347 & 0.000124 & 0.000627 & -3.97219 & Down & fibrous sheath interacting protein 2 \\
\hline IGSF9 & -1.55798 & 0.000131 & 0.000659 & -3.95695 & Down & immunoglobulin superfamily member 9 \\
\hline CLDN18 & -3.33422 & 0.000136 & 0.000676 & -3.94788 & Down & claudin 18 \\
\hline SUSD4 & -1.40629 & 0.000137 & 0.000683 & -3.94471 & Down & sushi domain containing 4 \\
\hline AMPD1 & -1.20089 & 0.000148 & 0.000725 & -3.92525 & Down & adenosine monophosphate deaminase 1 \\
\hline FOXQ1 & -1.91873 & 0.000149 & 0.000729 & -3.92334 & Down & forkhead box Q1 \\
\hline PTGR1 & -1.14721 & 0.000152 & 0.000746 & -3.91648 & Down & prostaglandin reductase 1 \\
\hline C11orf9 & -1.27328 & 0.000155 & 0.000758 & -3.91106 & Down & Myelin Regulatory Factor; Myelin \\
\hline GPR110 & -2.11364 & 0.000156 & 0.00076 & -3.91058 & Down & G-protein coupled receptor $110 \mathrm{i}$ \\
\hline MT1X & -1.41507 & 0.000158 & 0.000771 & -3.9061 & Down & metallothionein $1 \mathrm{X}$ \\
\hline UPK1B & -2.46209 & 0.000166 & 0.0008 & -3.89367 & Down & uroplakin 1B \\
\hline DHCR24 & -1.30452 & 0.000173 & 0.000831 & -3.88192 & Down & 24-dehydrocholesterol reductase \\
\hline EYA2 & -1.67614 & 0.000177 & 0.000847 & -3.87609 & Down & EYA transcriptional coactivator and phosphatase 2 \\
\hline HAPLN1 & -1.94491 & 0.000182 & 0.000869 & -3.86761 & Down & hyaluronan and proteoglycan link protein 1 \\
\hline PTGER3 & -1.63099 & 0.000187 & 0.000891 & -3.85982 & Down & prostaglandin E receptor 3 \\
\hline PHGR1 & -2.78903 & 0.000195 & 0.000923 & -3.84833 & Down & proline, histidine and glycine rich 1 \\
\hline RIMS4 & -1.15833 & 0.000195 & 0.000924 & -3.8481 & Down & regulating synaptic membrane exocytosis 4 \\
\hline ODAM & -1.80133 & 0.000196 & 0.000925 & -3.8476 & Down & odontogenic, ameloblast associated \\
\hline ALDOB & -3.06807 & 0.0002 & 0.000939 & -3.84236 & Down & aldolase, fructose-bisphosphate B \\
\hline GATA6 & -1.17262 & 0.000204 & 0.000958 & -3.83569 & Down & GATA binding protein 6 \\
\hline
\end{tabular}




\begin{tabular}{|c|c|c|c|c|c|c|}
\hline MUC6 & -3.92776 & 0.000222 & 0.001027 & -3.8129 & Down & mucin 6 , oligomeric mucus/gel-forming \\
\hline SNORA50 & -1.1526 & 0.000226 & 0.001043 & -3.80799 & Down & small nucleolar RNA, H/ACA box 50A \\
\hline PLAC8 & -1.89979 & 0.000228 & 0.001051 & -3.80548 & Down & placenta associated 8 \\
\hline ANO7 & -1.82482 & 0.000231 & 0.001063 & -3.80137 & Down & $\operatorname{anoctamin} 7$ \\
\hline ZBTB7C & -1.92666 & 0.000234 & 0.001072 & -3.79863 & Down & zinc finger and BTB domain containing $7 \mathrm{C}$ \\
\hline RORC & -1.83042 & 0.000236 & 0.001083 & -3.79524 & Down & RAR related orphan receptor $\mathrm{C}$ \\
\hline DUOXA2 & -2.3418 & 0.000241 & 0.001099 & -3.79004 & Down & dual oxidase maturation factor 2 \\
\hline LOC643201 & -1.30305 & 0.000248 & 0.001127 & -3.78209 & Down & centrosomal protein $192 \mathrm{kDa}$ pseudogene \\
\hline CTSE & -3.03202 & 0.00025 & 0.001137 & -3.77916 & Down & cathepsin E \\
\hline GPT2 & -1.25616 & 0.000255 & 0.001154 & -3.77415 & Down & glutamic--pyruvic transaminase 2 \\
\hline SH3BGRL2 & -1.24745 & 0.000258 & 0.001164 & -3.77109 & Down & SH3 domain binding glutamate rich protein like 2 \\
\hline SLC9A3 & -2.3467 & 0.000264 & 0.001191 & -3.76382 & Down & solute carrier family 9 member A3 \\
\hline CCRL1 & -1.28784 & 0.000265 & 0.001192 & -3.76351 & Down & C-C chemokine receptor type $11 \mathrm{i}$ \\
\hline FAM174B & -1.19216 & 0.000269 & 0.001206 & -3.75955 & Down & family with sequence similarity 174 member B \\
\hline FER1L4 & -1.77732 & 0.000271 & 0.001215 & -3.75724 & Down & $\begin{array}{l}\text { fer-1 like family member } 4 \text { (pseudogene) } \\
\text { LEUCINE- AND PROLINE-ENRICHED }\end{array}$ \\
\hline LEPREL1 & -1.43316 & 0.000273 & 0.001224 & -3.75483 & Down & PROTEOGLYCAN 1 \\
\hline PDZD3 & -1.49069 & 0.000279 & 0.001245 & -3.74868 & Down & PDZ domain containing 3 \\
\hline $\mathrm{DSC} 2$ & -1.30164 & 0.000283 & 0.001261 & -3.74465 & Down & desmocollin 2 \\
\hline A4GNT & -2.1448 & 0.000283 & 0.001262 & -3.74437 & Down & alpha-1,4-N-acetylglucosaminyltransferase \\
\hline ВНMT & -1.13063 & 0.00029 & 0.001288 & -3.73761 & Down & betaine--homocysteine S-methyltransferase \\
\hline SGK2 & -1.71285 & 0.000299 & 0.001319 & -3.72954 & Down & serum/glucocorticoid regulated kinase 2 \\
\hline SYTL2 & -1.43896 & 0.000303 & 0.001336 & -3.72537 & Down & synaptotagmin like 2 \\
\hline SNORA3 & -1.194 & 0.00031 & 0.001364 & -3.71893 & Down & mall nucleolar RNA, H/ACA box $3 \mathrm{~A}$ \\
\hline F2RL1 & -1.18109 & 0.000312 & 0.00137 & -3.71764 & Down & $\begin{array}{l}\text { F2R like trypsin receptor } 1 \\
\text { alcohol dehydrogenase } 1 \mathrm{C} \text { (class I), gamma }\end{array}$ \\
\hline $\mathrm{ADH} 1 \mathrm{C}$ & -3.13978 & 0.000315 & 0.001384 & -3.71434 & Down & polypeptide \\
\hline FOXA3 & -1.27364 & 0.000319 & 0.001397 & -3.71123 & Down & forkhead box A3 \\
\hline DUOX2 & -3.13093 & 0.000331 & 0.001442 & -3.70071 & Down & dual oxidase 2 \\
\hline ADAM28 & -1.57232 & 0.000339 & 0.001472 & -3.69348 & Down & ADAM metallopeptidase domain 28 \\
\hline APOC3 & -1.66171 & 0.000357 & 0.001538 & -3.67918 & Down & apolipoprotein $\mathrm{C} 3$ \\
\hline RAP1GAP & -1.95704 & 0.00037 & 0.001589 & -3.66858 & Down & RAP1 GTPase activating protein \\
\hline PTPRZ1 & -1.64025 & 0.000393 & 0.001671 & -3.65134 & Down & protein tyrosine phosphatase receptor type $\mathrm{Z} 1$ \\
\hline SCG3 & -1.34963 & 0.000393 & 0.001672 & -3.65109 & Down & secretogranin III \\
\hline CYP2S1 & -1.41489 & 0.000412 & 0.001738 & -3.63761 & Down & cytochrome $\mathrm{P} 450$ family 2 subfamily $\mathrm{S}$ member 1 \\
\hline CAPN8 & -2.0061 & 0.000422 & 0.001772 & -3.63093 & Down & calpain 8 \\
\hline TCEAL2 & -1.17618 & 0.00043 & 0.001802 & -3.62531 & Down & transcription elongation factor A like 2 \\
\hline SNORA47 & -1.38927 & 0.000439 & 0.00183 & -3.61969 & Down & small nucleolar RNA, H/ACA box 47 \\
\hline SNORA37 & -1.43524 & 0.000462 & 0.001913 & -3.60511 & Down & small nucleolar RNA, H/ACA box 37 \\
\hline RAB27B & -1.65807 & 0.000474 & 0.001953 & -3.59755 & Down & RAB27B, member RAS oncogene family \\
\hline SERPINB7 & -1.42666 & 0.000478 & 0.001967 & -3.59519 & Down & serpin family B member 7 \\
\hline LINC00261 & -2.80671 & 0.00051 & 0.002079 & -3.57612 & Down & long intergenic non-protein coding RNA 261 \\
\hline DUOX1 & -1.35608 & 0.000547 & 0.002208 & -3.55587 & Down & dual oxidase 1 \\
\hline METTL7A & -1.26112 & 0.000558 & 0.002246 & -3.55005 & Down & methyltransferase like 7A \\
\hline
\end{tabular}




\begin{tabular}{|c|c|c|c|c|c|c|}
\hline RIMS1 & -1.58304 & 0.000575 & 0.002308 & -3.5411 & Down & regulating synaptic membrane exocytosis 1 \\
\hline OXCT1 & -1.26717 & 0.000588 & 0.002352 & -3.53471 & Down & 3-oxoacid CoA-transferase 1 \\
\hline TCN1 & -2.79339 & 0.00061 & 0.002423 & -3.52398 & Down & $\begin{array}{c}\text { transcobalamin } 1 \\
\text { potassium voltage-gated channel subfamily } \mathrm{Q}\end{array}$ \\
\hline KCNQ1 & -1.51998 & 0.000631 & 0.002495 & -3.51407 & Down & member 1 \\
\hline FGG & -2.32003 & 0.000661 & 0.002599 & -3.50019 & Down & fibrinogen gamma chain \\
\hline C11 orf92 & -1.84043 & 0.000671 & 0.002633 & -3.49577 & Down & chromosome 11 open reading frame 92 \\
\hline FBP1 & -1.14801 & 0.000688 & 0.002689 & -3.48862 & Down & fructose-bisphosphatase 1 \\
\hline TRNP1 & -1.81251 & 0.000691 & 0.002698 & -3.48731 & Down & TMF1 regulated nuclear protein 1 \\
\hline C6orf58 & -2.90429 & 0.000693 & 0.002704 & -3.48651 & Down & chromosome 6 open reading frame 58 \\
\hline NR0B2 & -1.64026 & 0.000709 & 0.002755 & -3.47946 & Down & nuclear receptor subfamily 0 group B member 2 \\
\hline CYP3A5 & -1.70546 & 0.000712 & 0.002767 & -3.47815 & Down & cytochrome P450 family 3 subfamily A member 5 \\
\hline CLDN23 & -1.34669 & 0.000741 & 0.002862 & -3.46652 & Down & claudin 23 \\
\hline C12orf36 & -1.93304 & 0.000744 & 0.002868 & -3.46536 & Down & Chromosome 12 Open Reading Frame 36 \\
\hline CCL28 & -1.67094 & 0.00075 & 0.002888 & -3.46283 & Down & C-C motif chemokine ligand 28 \\
\hline CYP4F12 & -1.402 & 0.000786 & 0.003005 & -3.44906 & Down & cytochrome P450 family 4 subfamily F member 12 \\
\hline COL6A5 & -1.36147 & 0.000808 & 0.003077 & -3.44061 & Down & collagen type VI alpha 5 chain \\
\hline LOC729966 & -1.77488 & 0.000859 & 0.003239 & -3.4224 & Down & uncharacterized LOC729966 \\
\hline C1orf115 & -1.17373 & 0.000863 & 0.003251 & -3.42107 & Down & $\begin{array}{l}\text { chromosome } 1 \text { open reading frame } 115 \\
\text { phosphatidylinositol-4-phosphate 3-kinase catalytic }\end{array}$ \\
\hline PIK3C2G & -2.69778 & 0.000864 & 0.003254 & -3.42067 & Down & subunit type 2 gamma \\
\hline C4orf19 & -1.25061 & 0.000882 & 0.003308 & -3.4146 & Down & chromosome 4 open reading frame 19 \\
\hline TTC39A & -1.29875 & 0.000889 & 0.003326 & -3.4122 & Down & tetratricopeptide repeat domain 39A \\
\hline HS6ST3 & -1.35206 & 0.000968 & 0.003578 & -3.38646 & Down & heparansulfate 6-O-sulfotransferase 3 \\
\hline GALNT6 & -1.21049 & 0.000971 & 0.003586 & -3.38548 & Down & polypeptide $\mathrm{N}$-acetylgalactosaminyltransferase 6 \\
\hline CYP2C9 & -1.28115 & 0.000978 & 0.003607 & -3.38327 & Down & cytochrome P450 family 2 subfamily $\mathrm{C}$ member 9 \\
\hline CD36 & -1.13239 & 0.001055 & 0.003845 & -3.36046 & Down & CD36 molecule \\
\hline EPS8L1 & -1.2057 & 0.001063 & 0.00387 & -3.35821 & Down & EPS8 like 1 \\
\hline LIPH & -1.57886 & 0.001145 & 0.004123 & -3.33537 & Down & lipase $\mathrm{H}$ \\
\hline SHISA6 & -1.15846 & 0.001155 & 0.004152 & -3.33279 & Down & shisa family member 6 \\
\hline RASEF & -1.29797 & 0.001213 & 0.004327 & -3.31793 & Down & RAS and EF-hand domain containing \\
\hline IRX2 & -1.74965 & 0.00123 & 0.004377 & -3.31355 & Down & iroquoishomeobox 2 \\
\hline PTPRR & -1.41316 & 0.001231 & 0.004379 & -3.31334 & Down & protein tyrosine phosphatase receptor type $\mathrm{R}$ \\
\hline PTPRN2 & -1.56508 & 0.001244 & 0.004415 & -3.3101 & Down & $\begin{array}{l}\text { protein tyrosine phosphatase receptor type } \mathrm{N} 2 \\
\text { apolipoprotein B mRNA editing enzyme catalytic }\end{array}$ \\
\hline APOBEC1 & -1.28203 & 0.00126 & 0.004464 & -3.30616 & Down & subunit 1 \\
\hline ADAMTSL1 & -1.20975 & 0.001286 & 0.004546 & -3.30003 & Down & $\begin{array}{c}\text { ADAMTS like 1 } \\
\text { glycerophosphodiesterphosphodiesterase domain }\end{array}$ \\
\hline GDPD2 & -1.15658 & 0.001354 & 0.004744 & -3.28413 & Down & containing 2 \\
\hline SCGN & -1.29653 & 0.001363 & 0.004774 & -3.28206 & Down & secretagogin, EF-hand calcium binding protein \\
\hline SLC16A9 & -1.48478 & 0.001427 & 0.004971 & -3.26778 & Down & solute carrier family 16 member 9 \\
\hline SEMA3B & -1.1954 & 0.00143 & 0.004979 & -3.2672 & Down & semaphorin 3B \\
\hline HAS3 & -1.47447 & 0.001431 & 0.004982 & -3.2669 & Down & hyaluronan synthase 3 \\
\hline CA4 & -1.14208 & 0.00149 & 0.005155 & -3.25439 & Down & carbonic anhydrase 4 \\
\hline ERBB4 & -1.14567 & 0.001495 & 0.00517 & -3.25341 & Down & erb-b2 receptor tyrosine kinase 4 \\
\hline FOXA2 & -1.37138 & 0.001522 & 0.005254 & -3.2479 & Down & forkhead box A2 \\
\hline
\end{tabular}




\begin{tabular}{|c|c|c|c|c|c|c|}
\hline BTNL8 & -1.63429 & 0.001537 & 0.005301 & -3.24474 & Down & butyrophilin like 8 \\
\hline LRRC66 & -1.59439 & 0.001541 & 0.005312 & -3.24398 & Down & $\begin{array}{c}\text { leucine rich repeat containing } 66 \\
\text { sosondowahankyrin repeat domain family member }\end{array}$ \\
\hline SOWAHA & -1.27464 & 0.001575 & 0.005403 & -3.23724 & Down & A \\
\hline DHRS9 & -1.36517 & 0.001582 & 0.005423 & -3.23592 & Down & dehydrogenase/reductase 9 \\
\hline MRAP2 & -1.44774 & 0.001626 & 0.005553 & -3.22728 & Down & $\begin{array}{c}\text { melanocortin } 2 \text { receptor accessory protein } 2 \\
\text { UDP-GlcNAc:betaGal beta-1,3-N- }\end{array}$ \\
\hline B3GNT7 & -1.4936 & 0.00165 & 0.005622 & -3.22266 & Down & acetylglucosaminyltransferase 7 \\
\hline MT1H & -1.63135 & 0.001743 & 0.005902 & -3.20546 & Down & metallothionein $1 \mathrm{H}$ \\
\hline LOC440335 & -1.24996 & 0.001799 & 0.006059 & -3.19566 & Down & \#N/A \\
\hline TSPAN1 & -2.13042 & 0.00197 & 0.006562 & -3.16689 & Down & tetraspanin 1 \\
\hline CYP2C19 & -1.37071 & 0.00198 & 0.006589 & -3.16533 & Down & cytochrome $\mathrm{P} 450$ family 2 subfamily $\mathrm{C}$ member 19 \\
\hline FCGBP & -3.19545 & 0.002032 & 0.006728 & -3.15716 & Down & $\mathrm{Fc}$ fragment of IgG binding protein \\
\hline NCAM1 & -1.23177 & 0.002096 & 0.006903 & -3.14733 & Down & neural cell adhesion molecule 1 \\
\hline HHLA2 & -1.782 & 0.00214 & 0.007023 & -3.14069 & Down & HERV-H LTR-associating 2 \\
\hline PRIMA1 & -1.13115 & 0.002157 & 0.007072 & -3.13824 & Down & proline rich membrane anchor 1 \\
\hline RGN & -1.21003 & 0.002162 & 0.007086 & -3.13742 & Down & regucalcin \\
\hline UGT1A6 & -1.41003 & 0.002217 & 0.007243 & -3.12945 & Down & UDP glucuronosyltransferase family 1 member A6 \\
\hline TFCP2L1 & -1.4672 & 0.00227 & 0.007397 & -3.12195 & Down & transcription factor $\mathrm{CP} 2$ like 1 \\
\hline FXYD3 & -1.4859 & 0.00227 & 0.007398 & -3.12187 & Down & FXYD domain containing ion transport regulator 3 \\
\hline MIR650 & -2.29328 & 0.002276 & 0.007414 & -3.1211 & Down & microRNA 650 \\
\hline FAM189A2 & -1.27394 & 0.002401 & 0.007765 & -3.10391 & Down & family with sequence similarity 189 member A2 \\
\hline SOX2 & -1.62091 & 0.00252 & 0.008094 & -3.08844 & Down & SRY-box transcription factor 2 \\
\hline ORM1 & -1.4435 & 0.00267 & 0.008505 & -3.06973 & Down & orosomucoid 1 \\
\hline F13A1 & -1.57304 & 0.002836 & 0.008952 & -3.05016 & Down & coagulation factor XIII A chain \\
\hline APOA1 & -1.95002 & 0.003046 & 0.009535 & -3.02696 & Down & apolipoprotein A1 \\
\hline ANKRD22 & -1.13226 & 0.003091 & 0.009655 & -3.02212 & Down & ankyrin repeat domain 22 \\
\hline RHBDL2 & -1.23177 & 0.003283 & 0.01018 & -3.00237 & Down & rhomboid like 2 \\
\hline CLEC3B & -1.21628 & 0.003554 & 0.010891 & -2.9762 & Down & C-type lectin domain family 3 member B \\
\hline SCARA5 & -1.54597 & 0.003923 & 0.011848 & -2.94344 & Down & scavenger receptor class A member 5 \\
\hline GGT6 & -1.7999 & 0.004042 & 0.012143 & -2.93348 & Down & gamma-glutamyltransferase 6 \\
\hline MAMDC2 & -1.26013 & 0.00407 & 0.012211 & -2.93121 & Down & MAM domain containing 2 \\
\hline XK & -1.23683 & 0.004074 & 0.012219 & -2.93089 & Down & $\begin{array}{c}\text { X-linked Kx blood group } \\
\text { glycerophosphodiesterphosphodiesterase domain }\end{array}$ \\
\hline GDPD3 & -1.23128 & 0.004159 & 0.012421 & -2.92401 & Down & containing 3 \\
\hline TMEM100 & -1.13751 & 0.004302 & 0.012787 & -2.91261 & Down & transmembrane protein 100 \\
\hline LEPR & -1.176 & 0.004368 & 0.012955 & -2.90755 & Down & leptin receptor \\
\hline IGFBP2 & -1.6738 & 0.00443 & 0.01311 & -2.90282 & Down & insulin like growth factor binding protein 2 \\
\hline DEFB1 & -1.382 & 0.00448 & 0.013228 & -2.89902 & Down & defensin beta 1 \\
\hline SNORD94 & -1.18429 & 0.004833 & 0.014103 & -2.87341 & Down & small nucleolar RNA, C/D box 94 \\
\hline SLC4A4 & -1.44856 & 0.004885 & 0.014233 & -2.86979 & Down & solute carrier family 4 member 4 \\
\hline CXADR & -1.14718 & 0.004919 & 0.014319 & -2.86739 & Down & CXADR Ig-like cell adhesion molecule \\
\hline TFR2 & -1.22223 & 0.004955 & 0.014407 & -2.86497 & Down & transferrin receptor 2 \\
\hline ANO5 & -1.32076 & 0.004958 & 0.014415 & -2.8647 & Down & anoctamin 5 \\
\hline COL17A1 & -1.95731 & 0.005127 & 0.014843 & -2.85333 & Down & collagen type XVII alpha 1 chain \\
\hline
\end{tabular}




\begin{tabular}{|c|c|c|c|c|c|c|}
\hline GCNT1 & -1.29201 & 0.005264 & 0.01517 & -2.84436 & Down & glucosaminyl (N-acetyl) transferase 1 \\
\hline C6 & -1.22604 & 0.005537 & 0.015827 & -2.82708 & Down & complement C6 \\
\hline C11orf86 & -1.4605 & 0.005632 & 0.016046 & -2.82121 & Down & chromosome 11 open reading frame 86 \\
\hline PROM2 & -1.70208 & 0.005709 & 0.016221 & -2.81653 & Down & prominin 2 \\
\hline BPIFB1 & -2.89391 & 0.00604 & 0.017023 & -2.79712 & Down & BPI fold containing family B member 1 \\
\hline MUC1 & -1.55602 & 0.006157 & 0.017299 & -2.79049 & Down & mucin 1 , cell surface associated \\
\hline HBB & -1.33296 & 0.006208 & 0.017414 & -2.78764 & Down & hemoglobin subunit beta \\
\hline MLPH & -1.50248 & 0.006316 & 0.017668 & -2.7817 & Down & melanophilin \\
\hline $\mathrm{CDH} 2$ & -1.13276 & 0.006463 & 0.018017 & -2.77372 & Down & cadherin 2 \\
\hline SLC15A1 & -1.46194 & 0.006776 & 0.018776 & -2.75724 & Down & solute carrier family 15 member 1 \\
\hline TESC & -1.47782 & 0.007011 & 0.019317 & -2.74531 & Down & tescalcin \\
\hline POU2AF1 & -1.18723 & 0.007045 & 0.019394 & -2.74364 & Down & POU class 2 homeobox associating factor 1 \\
\hline FGB & -1.75768 & 0.007504 & 0.020432 & -2.72147 & Down & $\begin{array}{c}\text { fibrinogen beta chain } \\
\text { UDP glucuronosyltransferase family } 1 \text { member }\end{array}$ \\
\hline UGT1A10 & -1.42624 & 0.007717 & 0.020903 & -2.7116 & Down & $\begin{array}{c}\text { A10 } \\
\text { protein kinase AMP-activated catalytic subunit }\end{array}$ \\
\hline PRKAA2 & -1.2771 & 0.00781 & 0.021113 & -2.70737 & Down & $\begin{array}{l}\text { alpha } 2 \\
\text { SAM pointed domain containing ETS transcription }\end{array}$ \\
\hline SPDEF & -1.53032 & 0.008048 & 0.021653 & -2.69677 & Down & factor \\
\hline HGD & -1.25298 & 0.008766 & 0.023318 & -2.66635 & Down & homogentisate 1,2-dioxygenase \\
\hline PRLR & -1.27219 & 0.008797 & 0.023391 & -2.66507 & Down & $\begin{array}{c}\text { prolactin receptor } \\
\text { gamma-aminobutyric acid type A receptor beta3 }\end{array}$ \\
\hline GABRB3 & -1.47248 & 0.00886 & 0.023541 & -2.66251 & Down & subunit \\
\hline PLIN4 & -1.23827 & 0.00932 & 0.024589 & -2.6444 & Down & perilipin 4 \\
\hline REG3A & -2.83122 & 0.00993 & 0.025962 & -2.62155 & Down & regenerating family member 3 alpha \\
\hline B3GALT5 & -1.68133 & 0.009937 & 0.025979 & -2.62127 & Down & beta-1,3-galactosyltransferase 5 \\
\hline GALNT5 & -1.26116 & 0.010092 & 0.026304 & -2.61569 & Down & polypeptide $\mathrm{N}$-acetylgalactosaminyltransferase 5 \\
\hline APOA4 & -1.79981 & 0.010478 & 0.027174 & -2.60206 & Down & apolipoprotein A4 \\
\hline TM6SF2 & -1.15162 & 0.010774 & 0.027797 & -2.59193 & Down & transmembrane 6 superfamily member 2 \\
\hline CGNL1 & -1.18772 & 0.010931 & 0.028148 & -2.58664 & Down & cingulin like 1 \\
\hline CDHR2 & -1.72899 & 0.011645 & 0.02968 & -2.56348 & Down & cadherin related family member 2 \\
\hline CYP3A4 & -1.40007 & 0.012414 & 0.03131 & -2.53991 & Down & cytochrome P450 family 3 subfamily A member 4 \\
\hline CXCL14 & -1.53213 & 0.01284 & 0.032216 & -2.52742 & Down & $\mathrm{C}-\mathrm{X}-\mathrm{C}$ motif chemokine ligand 14 \\
\hline KIF1A & -1.13421 & 0.013076 & 0.032717 & -2.52066 & Down & kinesin family member $1 \mathrm{~A}$ \\
\hline MUC5B & -2.34029 & 0.013457 & 0.033532 & -2.50997 & Down & mucin 5B, oligomeric mucus/gel-forming \\
\hline PRSS8 & -1.17934 & 0.013595 & 0.033806 & -2.50614 & Down & serine protease 8 \\
\hline AQP5 & -1.73911 & 0.01516 & 0.037052 & -2.46524 & Down & aquaporin 5 \\
\hline FOXA1 & -1.13176 & 0.015252 & 0.037252 & -2.46297 & Down & forkhead box A1 \\
\hline SLPI & -1.50988 & 0.016553 & 0.039947 & -2.43191 & Down & secretory leukocyte peptidase inhibitor \\
\hline CMBL & -1.29617 & 0.016773 & 0.040392 & -2.42687 & Down & carboxymethylenebutenolidase homolog \\
\hline MST1P9 & -1.20601 & 0.017788 & 0.042418 & -2.40436 & Down & \#N/A \\
\hline ST6GALNAC1 & -1.45659 & 0.018428 & 0.043721 & -2.39074 & Down & $\begin{array}{l}\text { ST6 N-acetylgalactosaminide alpha-2,6- } \\
\text { sialyltransferase } 1\end{array}$ \\
\hline KIAA1324 & -1.66186 & 0.019482 & 0.045772 & -2.36921 & Down & KIAA1324 \\
\hline MAOA & -1.2488 & 0.020833 & 0.048467 & -2.34308 & Down & monoamine oxidase A \\
\hline
\end{tabular}


Table 3 The enriched pathway terms of the up regulated differentially expressed genes

\begin{tabular}{|c|c|c|c|c|c|c|c|}
\hline \multicolumn{8}{|c|}{ BIOCYC } \\
\hline Pathway ID & Pathway Name & P-value & $\begin{array}{l}\text { FDR } \\
\text { B\&H }\end{array}$ & $\begin{array}{l}\text { FDR } \\
\text { B\&Y }\end{array}$ & Bonferroni & $\begin{array}{c}\text { Gene } \\
\text { Count }\end{array}$ & Gene \\
\hline 782401 & $\begin{array}{c}\text { pyrimidine } \\
\text { deoxyribonucleosides } \\
\text { degradation }\end{array}$ & $8.43 \mathrm{E}-03$ & $2.69 \mathrm{E}-01$ & $1.00 \mathrm{E}+00$ & $3.46 \mathrm{E}-01$ & 2 & UPP1,TYMP \\
\hline 782385 & $\begin{array}{l}\text { aspirin triggered } \\
\text { resolvin } \mathrm{D} \\
\text { biosynthesis }\end{array}$ & $5.91 \mathrm{E}-02$ & $2.69 \mathrm{E}-01$ & $1.00 \mathrm{E}+00$ & $1.00 \mathrm{E}+00$ & 1 & PTGS2 \\
\hline 142281 & UMP biosynthesis & $5.91 \mathrm{E}-02$ & $2.69 \mathrm{E}-01$ & $1.00 \mathrm{E}+00$ & $1.00 \mathrm{E}+00$ & 1 & CAD \\
\hline 545275 & $\begin{array}{l}\text { chondroitin } \\
\text { biosynthesis }\end{array}$ & 5.91E-02 & $2.69 \mathrm{E}-01$ & $1.00 \mathrm{E}+00$ & $1.00 \mathrm{E}+00$ & 1 & $\mathrm{DIO} 2$ \\
\hline 545371 & MAP kinase cascade & $5.91 \mathrm{E}-02$ & $2.69 \mathrm{E}-01$ & $1.00 \mathrm{E}+00$ & $1.00 \mathrm{E}+00$ & 1 & CSGALNACT2 \\
\hline 545355 & $\begin{array}{l}\text { thyronamine and } \\
\text { iodothyronamine } \\
\text { metabolism }\end{array}$ & $5.91 \mathrm{E}-02$ & $2.69 \mathrm{E}-01$ & $1.00 \mathrm{E}+00$ & $1.00 \mathrm{E}+00$ & 1 & EPHB2 \\
\hline 1271888 & $\begin{array}{l}\text { docosahexaenoate } \\
\text { biosynthesis III } \\
\text { (mammals) }\end{array}$ & $8.72 \mathrm{E}-02$ & $3.25 \mathrm{E}-01$ & $1.00 \mathrm{E}+00$ & $1.00 \mathrm{E}+00$ & 1 & FADS2 \\
\hline 782399 & $\begin{array}{c}\text { UTP and CTP } \\
\text { dephosphorylation II }\end{array}$ & $1.15 \mathrm{E}-01$ & $3.36 \mathrm{E}-01$ & $1.00 \mathrm{E}+00$ & $1.00 \mathrm{E}+00$ & 1 & ENTPD1 \\
\hline 142426 & urea cycle & $1.15 \mathrm{E}-01$ & $3.36 \mathrm{E}-01$ & $1.00 \mathrm{E}+00$ & $1.00 \mathrm{E}+00$ & 1 & CPS1 \\
\hline 142304 & $\begin{array}{l}\text { UDP-N-acetyl-D- } \\
\text { glucosamine } \\
\text { biosynthesis II } \\
\end{array}$ & 1.41E-01 & $3.62 \mathrm{E}-01$ & $1.00 \mathrm{E}+00$ & $1.00 \mathrm{E}+00$ & 1 & GFPT2 \\
\hline \multicolumn{8}{|c|}{ KEGG } \\
\hline 83068 & $\begin{array}{l}\text { ECM-receptor } \\
\text { interaction }\end{array}$ & $2.10 \mathrm{E}-09$ & $5.14 \mathrm{E}-07$ & $3.12 \mathrm{E}-06$ & $5.14 \mathrm{E}-07$ & 16 & $\begin{array}{l}\text { COL1A1,COL1A2,COL4A1, } \\
\text { COL4A2,COL6A3,ITGA11,F } \\
\text { N1,COMP,TNC,SPP1,ITGA5 } \\
\text { ITGB8,LAMA5,THBS1,TH } \\
\text { BS2,THBS4 }\end{array}$ \\
\hline 172847 & $\begin{array}{l}\text { Protein digestion and } \\
\text { absorption }\end{array}$ & $8.70 \mathrm{E}-09$ & $1.06 \mathrm{E}-06$ & $6.45 \mathrm{E}-06$ & $2.12 \mathrm{E}-06$ & 16 & $\begin{array}{l}\text { COL1A1,COL1A2,COL3A1, } \\
\text { COL4A1,COL4A2,COL5A1, } \\
\text { COL5A2,COL6A3,COL7A1, } \\
\text { COL10A1,COL11A1,COL12 } \\
\text { A1,COL15A1,COL5A3,COL } \\
\text { 18A1,ELN }\end{array}$ \\
\hline 692234 & $\begin{array}{l}\text { PI3K-Akt signaling } \\
\text { pathway }\end{array}$ & $1.33 \mathrm{E}-07$ & $1.08 \mathrm{E}-05$ & $6.57 \mathrm{E}-05$ & $3.24 \mathrm{E}-05$ & 30 & $\begin{array}{l}\text { PIK3AP1,PDGFRB,F2R,PGF } \\
\text {,COL1A1,COL1A2,COL4A1, } \\
\text { COL4A2,COL6A3,ITGA11, } \\
\text { ANGPT2,FN1,COMP,TNC,C } \\
\text { SF3R,IL2RA,IL6,MYB,SPP1, } \\
\text { ITGA5,ITGB8,LAMA5,CCN } \\
\text { D2,OSM,THBS1,THBS2,TH } \\
\text { BS4,GNB4,OSMR,PIK3R5 }\end{array}$ \\
\hline 83067 & Focal adhesion & $5.47 \mathrm{E}-07$ & $3.34 \mathrm{E}-05$ & 2.03E-04 & $1.33 \mathrm{E}-04$ & 21 & $\begin{array}{l}\text { PDGFRB,ACTN1,PGF,COL1 } \\
\text { A1,COL1A2,COL4A1,COL4 } \\
\text { A2,COL6A3,ITGA11,FN1,C } \\
\text { OMP,TNC,SPP1,ITGA5,PAR } \\
\text { VG,ITGB8,LAMA5,CCND2, } \\
\text { THBS1,THBS2,THBS4 }\end{array}$ \\
\hline 153910 & Phagosome & $3.59 \mathrm{E}-06$ & $1.75 \mathrm{E}-04$ & $1.07 \mathrm{E}-03$ & 8.77E-04 & 17 & $\begin{array}{l}\text { CLEC7A,TUBB3,FCGR1A,F } \\
\text { CGR2A,FCGR3A,FCGR3B, } \\
\text { COMP,MSR1,NCF2,ITGA5, } \\
\text { MRC2,C1R,C3,OLR1,THBS } \\
\text { 1,THBS2,THBS4 }\end{array}$ \\
\hline 83051 & $\begin{array}{l}\text { Cytokine-cytokine } \\
\text { receptor interaction }\end{array}$ & $3.21 \mathrm{E}-03$ & $5.22 \mathrm{E}-02$ & $3.17 \mathrm{E}-01$ & 7.83E-01 & 17 & $\begin{array}{l}\text { PDGFRB,CXCL9,CCL3,CCR } \\
\text { 1,CCL18,CXCL6,CSF3R,IL2 } \\
\text { RA,IL6,IL11,INHBA,CXCL1 } \\
\text {,TNFRSF11B,LIF,OSM,REL } \\
\text { T,OSMR }\end{array}$ \\
\hline 83069 & $\begin{array}{l}\text { Cell adhesion } \\
\text { molecules (CAMs) }\end{array}$ & $4.24 \mathrm{E}-03$ & $6.47 \mathrm{E}-02$ & $3.93 \mathrm{E}-01$ & $1.00 \mathrm{E}+00$ & 11 & $\begin{array}{l}\text { SELE,SELL,ICAM1,CLDN4, } \\
\text { CLDN3,CLDN7,VCAN,ITG } \\
\text { B8,CLDN2,CLDN1,CDH3 }\end{array}$ \\
\hline 852705 & $\begin{array}{l}\text { MicroRNAs in } \\
\text { cancer }\end{array}$ & $8.74 \mathrm{E}-03$ & $9.70 \mathrm{E}-02$ & $5.89 \mathrm{E}-01$ & $1.00 \mathrm{E}+00$ & 17 & $\begin{array}{l}\text { PDGFRB,SERPINB5,PLAU, } \\
\text { MMP9,MMP16,KIF23,TNC, } \\
\text { FSCN1,CDCA5,ITGA5,PTG }\end{array}$ \\
\hline
\end{tabular}




\begin{tabular}{|c|c|c|c|c|c|c|c|}
\hline \multicolumn{8}{|c|}{ Pathway Interaction Database } \\
\hline 138064 & $\begin{array}{l}\text { Syndecan-4-mediated } \\
\text { signaling events }\end{array}$ & $2.89 \mathrm{E}-05$ & $2.01 \mathrm{E}-03$ & $1.06 \mathrm{E}-02$ & $3.18 \mathrm{E}-03$ & 7 & $\begin{array}{c}\text { ACTN1,MMP9,FN1,TNC,IT } \\
\text { GA5,ADAM12,THBS1 }\end{array}$ \\
\hline 138007 & $\begin{array}{c}\text { PLK1 signaling } \\
\text { events }\end{array}$ & 4.15E-05 & $2.01 \mathrm{E}-03$ & $1.06 \mathrm{E}-02$ & $4.56 \mathrm{E}-03$ & 8 & $\begin{array}{l}\text { PLK1,TPX2,CLSPN,BUB1,B } \\
\text { UB1B,ECT2,KIF20A,CDC25 } \\
\text { B }\end{array}$ \\
\hline 169349 & $\begin{array}{c}\text { Validated } \\
\text { transcriptional targets } \\
\text { of AP1 family } \\
\text { members Fra1 and } \\
\text { Fra2 }\end{array}$ & $5.48 \mathrm{E}-05$ & 2.01E-03 & $1.06 \mathrm{E}-02$ & $6.02 \mathrm{E}-03$ & 7 & $\begin{array}{l}\text { MGP,PLAU,MMP1,MMP9,C } \\
\text { OL1 A2,IL6,LIF }\end{array}$ \\
\hline 137945 & $\begin{array}{l}\text { amb2 Integrin } \\
\text { signaling }\end{array}$ & $5.23 \mathrm{E}-04$ & $1.44 \mathrm{E}-02$ & $7.59 \mathrm{E}-02$ & $5.75 \mathrm{E}-02$ & 7 & $\begin{array}{c}\text { PLAU,FGR,MMP9,FN1,ICA } \\
\text { M1,IL6,THY1 }\end{array}$ \\
\hline 137935 & $\begin{array}{l}\text { FOXM1 transcription } \\
\text { factor network }\end{array}$ & $4.65 \mathrm{E}-03$ & $7.31 \mathrm{E}-02$ & $3.86 \mathrm{E}-01$ & $5.12 \mathrm{E}-01$ & 5 & $\begin{array}{c}\text { CENPF,PLK1,FOXM1,NEK2 } \\
\text {,CDC25B }\end{array}$ \\
\hline 138080 & Aurora B signaling & $5.85 \mathrm{E}-03$ & 8.05E-02 & 4.25E-01 & $6.44 \mathrm{E}-01$ & 5 & $\begin{array}{c}\text { KIF23,BUB1,KIF2C,NCAPH } \\
\text {,KIF20A }\end{array}$ \\
\hline 137934 & $\begin{array}{l}\text { E2F transcription } \\
\text { factor network }\end{array}$ & $2.20 \mathrm{E}-02$ & $1.73 \mathrm{E}-01$ & $9.11 \mathrm{E}-01$ & $1.00 \mathrm{E}+00$ & 6 & $\begin{array}{l}\text { PLAU,MYBL2,E2F3,ORC1, } \\
\text { SERPINE1,CDC6 }\end{array}$ \\
\hline 169345 & $\begin{array}{l}\text { Notch signaling } \\
\text { pathway }\end{array}$ & $2.95 \mathrm{E}-02$ & $1.91 \mathrm{E}-01$ & $1.00 \mathrm{E}+00$ & $1.00 \mathrm{E}+00$ & 5 & $\begin{array}{c}\text { MFAP2,DNM1,NOTCH1,NO } \\
\text { TCH3,ADAM12 }\end{array}$ \\
\hline 137939 & Direct p53 effectors & 4.49E-02 & $2.47 \mathrm{E}-01$ & $1.00 \mathrm{E}+00$ & $1.00 \mathrm{E}+00$ & 8 & $\begin{array}{l}\text { SERPINB5,GDF15,VCAN,S } \\
\text { PP1,BCL2A1,LIF,COL18A1, } \\
\text { SERPINE1 }\end{array}$ \\
\hline 169352 & $\begin{array}{l}\text { Regulation of Wnt- } \\
\text { mediated beta catenin } \\
\text { signaling and target } \\
\text { gene transcription }\end{array}$ & $8.81 \mathrm{E}-02$ & $3.59 \mathrm{E}-01$ & $1.00 \mathrm{E}+00$ & $1.00 \mathrm{E}+00$ & 5 & $\begin{array}{l}\text { MMP9, VCAN,SALL4,CCND } \\
\text { 2,LEF1 }\end{array}$ \\
\hline \multicolumn{8}{|c|}{ REACTOME } \\
\hline 1270244 & $\begin{array}{l}\text { Extracellular matrix } \\
\text { organization }\end{array}$ & $4.22 \mathrm{E}-34$ & $3.02 \mathrm{E}-31$ & $2.16 \mathrm{E}-30$ & $3.02 \mathrm{E}-31$ & 61 & $\begin{array}{l}\text { ACTN1,MFAP2,FBN1,ACA } \\
\text { N,MMP1,MMP3,MMP7,MM } \\
\text { P9,MMP11,MMP14,MMP16, } \\
\text { COL1A1,COL1A2,COL3A1, } \\
\text { COL4A1,COL4A2,COL5A1, } \\
\text { COL5A2,NID2,COL6A3,CO } \\
\text { L7A1,COL8A1,ITGA11,COL } \\
\text { 10A1,COL11A1,COL12A1,C } \\
\text { OL15A1,COL16A1,FN1,CO } \\
\text { MP,ADAMTS4,ADAMTS2,T } \\
\text { NC,ICAM1,COL5A3,VCAN, } \\
\text { ADAMTS14,CTSB,CTSK,SP } \\
\text { ARC,HTRA1,SPP1,ASPN,P4 } \\
\text { HA3,ITGA5,ITGAX,ITG8, } \\
\text { BGN,BMP1,ADAMTS9,LA } \\
\text { MA5,SERPINH1,COL18A1, } \\
\text { THBS1,TIMP1,LOXL2,SERP } \\
\text { INE1,LTBP2,ELN,LUM,PCO } \\
\text { LCE }\end{array}$ \\
\hline 1269340 & Hemostasis & $1.37 \mathrm{E}-06$ & 7.60E-05 & $5.44 \mathrm{E}-04$ & $9.78 \mathrm{E}-04$ & 42 & $\begin{array}{c}\text { PDE3A,CD109,DGKH,ACT } \\
\text { N1,F2R,F2RL2,SERPINE2,F } \\
\text { CER1G,PLAU,MMP1,FGR,P } \\
\text { LEK,SELE,SELL,KIF23,AN } \\
\text { GPT2,FN1,PDPN,KIF18B,IL } \\
\text { 2RA,MYB,DOCK4,KIF21B, } \\
\text { SPARC,KIF4A,ISLR,ITGA5, } \\
\text { ITGAX,LRP8,CD84,KIF2C, }\end{array}$ \\
\hline
\end{tabular}




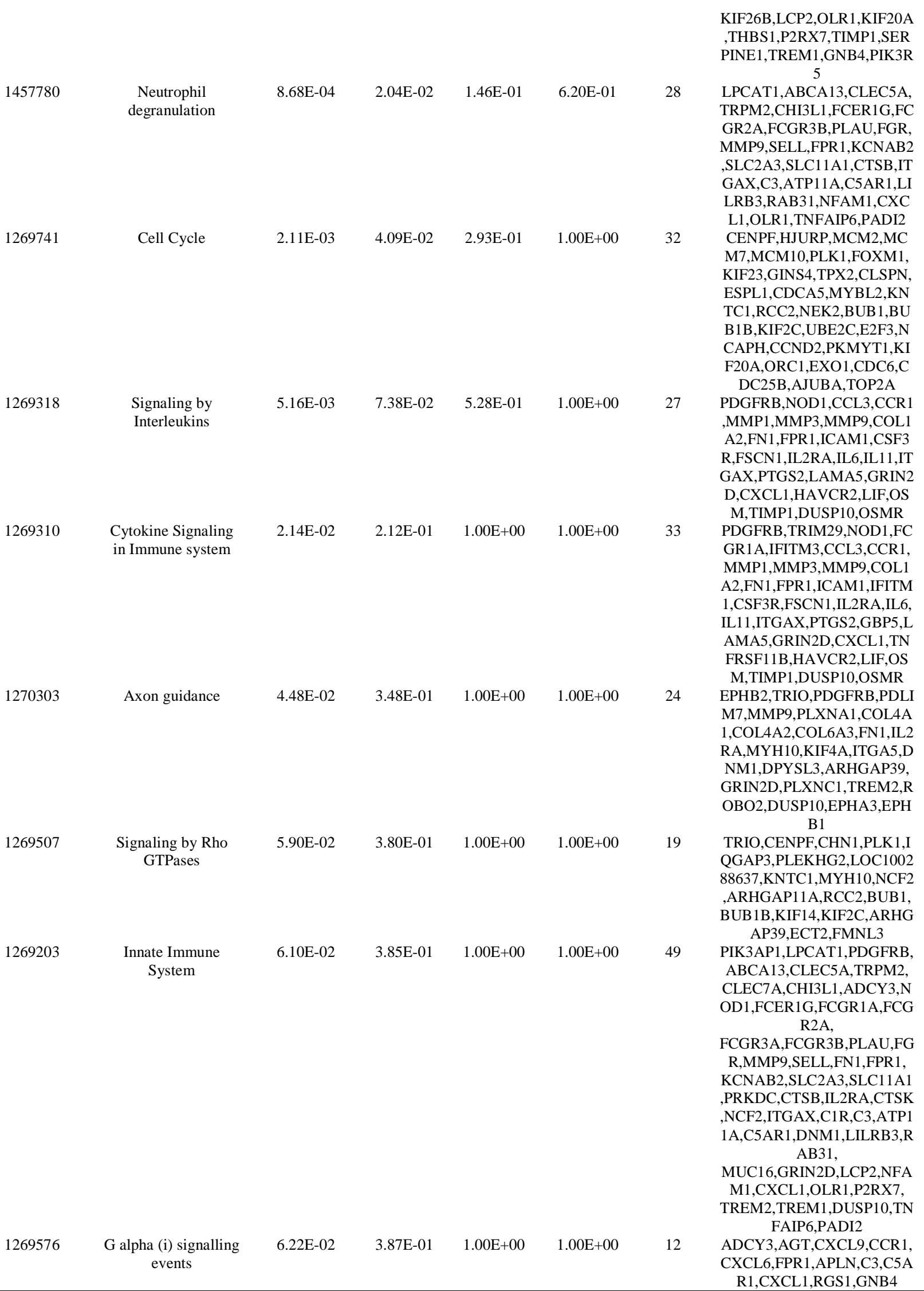


bioRxiv preprint doi: https://doi.org/10.1101/2020.12.20.423656; this version posted December 23, 2020. The copyright holder for this preprint (which was not certified by peer review) is the author/funder. All rights reserved. No reuse allowed without permission.

\begin{tabular}{|c|c|c|c|c|c|}
\hline & & \multicolumn{4}{|c|}{ Gen MAPP } \\
\hline MAP00251 & MAP00251 & $1.20 \mathrm{E}-01$ & $6.40 \mathrm{E}-01$ & $1.00 \mathrm{E}+00$ & $1.00 \mathrm{E}+00$ \\
\hline MAP00240 & MAP00240 & $1.44 \mathrm{E}-01$ & $6.40 \mathrm{E}-01$ & $1.00 \mathrm{E}+00$ & $1.00 \mathrm{E}+00$ \\
\hline MAP00272 & MAP00272 & $2.40 \mathrm{E}-01$ & $6.40 \mathrm{E}-01$ & $1.00 \mathrm{E}+00$ & $1.00 \mathrm{E}+00$ \\
\hline MAP00360 & MAP00360 & $3.86 \mathrm{E}-01$ & $6.40 \mathrm{E}-01$ & $1.00 \mathrm{E}+00$ & $1.00 \mathrm{E}+00$ \\
\hline MAP00380 & MAP00380 & $4.03 \mathrm{E}-01$ & $6.40 \mathrm{E}-01$ & $1.00 \mathrm{E}+00$ & $1.00 \mathrm{E}+00$ \\
\hline MAP00590 & MAP00590 & $4.39 \mathrm{E}-01$ & $6.40 \mathrm{E}-01$ & $1.00 \mathrm{E}+00$ & $1.00 \mathrm{E}+00$ \\
\hline MAP00230 & MAP00230 & 4.63E-01 & $6.40 \mathrm{E}-01$ & $1.00 \mathrm{E}+00$ & $1.00 \mathrm{E}+00$ \\
\hline MAP00010 & MAP00010 & $4.65 \mathrm{E}-01$ & $6.40 \mathrm{E}-01$ & $1.00 \mathrm{E}+00$ & $1.00 \mathrm{E}+00$ \\
\hline MAP00330 & MAP00330 & $6.86 \mathrm{E}-01$ & $7.20 \mathrm{E}-01$ & $1.00 \mathrm{E}+00$ & $1.00 \mathrm{E}+00$ \\
\hline \multirow[t]{2}{*}{ MAP00071 } & MAP00071 & 7.54E-01 & 7.54E-01 & $1.00 \mathrm{E}+00$ & $1.00 \mathrm{E}+00$ \\
\hline & & \multicolumn{4}{|c|}{ MSigDB C2 BIOCARTA (v6.0) } \\
\hline M5889 & $\begin{array}{l}\text { Ensemble of genes } \\
\text { encoding } \\
\text { extracellular matrix } \\
\text { and extracellular } \\
\text { matrix-associated } \\
\text { proteins }\end{array}$ & $2.21 \mathrm{E}-42$ & $2.34 \mathrm{E}-40$ & $1.23 \mathrm{E}-39$ & $2.34 \mathrm{E}-40$ \\
\hline
\end{tabular}

\begin{tabular}{|c|c|c|c|c|c|}
\hline M5884 & $\begin{array}{l}\text { Ensemble of genes } \\
\text { encoding core } \\
\text { extracellular matrix } \\
\text { including ECM } \\
\text { glycoproteins, } \\
\text { collagens and } \\
\text { proteoglycans }\end{array}$ & $3.53 \mathrm{E}-31$ & $1.87 \mathrm{E}-29$ & $9.81 \mathrm{E}-29$ & $3.74 \mathrm{E}-29$ \\
\hline
\end{tabular}

21

FSTL3,CLEC5A,CD109,EMI
LIN2,CLEC7A,PGF,MFAP2, SERPINB5,SERPINE2,SERP INB9,FBN1,MGP,AEBP1,A CAN,SPON2,AGT,CXCL9,C THRC1,CCL3,PLAU,MMP1, BMP8A,C1QTNF6,MMP3,C CL18,MMP7,MMP9,MMP11 ,MMP14,CXCL6,MMP16,PL XNA1,COL1A1,COL1A2,CO L3A1, COL4A1, COL4A2,SE MA6B,COL5A1,COL5A2,NI D2,COL6A3, COL7A1, COL8 A1,COL10A1,COL11A1,MX RA5,COL12A1,SFRP2,SFRP 4,COL15A1,COL16A1,CHR DL2,ANGPT2,FN1,COMP,A DAMTS4,ADAMTS2,TNC,G DF15,WNT2,ANXA13,COL5 A3,IGFBP7,VCAN,CST1,HA PLN3,ADAMTS14,CTSB,CT SK,IL6,IL11,SPARC,HTRA1 ,SPOCK1,INHBA,SPP1,ASP N,P4HA3,BGN,BMP1,FNDC 1,SRPX2,SULF2,PXDN,AD AMTS9,SULF1,CRISPLD1,P LXDC1,LAMA5,MUC16,ES M1,HTRA3,OMD,ADAM12, SERPINH1,CXCL1,ADAMT S12,TGFBI,LIF,COL18A1, T GM2,OSM,THBS1,THBS2,T HBS4,ANGPTL2,FSTL1,HM CN1,PLXDC2,LGI2,TIMP1, PLXNC1,LOXL2,SERPINE1, LTBP2,ELN,GREM1,TNFAI P6,LUM,PCOLCE

EMILIN2,MFAP2,FBN1,MG

P,AEBP1,ACAN,SPON2,CT

HRC1,COL1A1,COL1A2,CO

L3A1,COL4A1,COL4A2,CO

L5A1,COL5A2,NID2,COL6 A3,COL7A1,COL8A1,COL1 0A1,COL11A1,MXRA5,COL 12A1,COL15A1,COL16A1,F N1,COMP,TNC,COL5A3,IG FBP7,VCAN,HAPLN3,SPAR C,SPOCK1,SPP1,ASPN,BGN ,FNDC1,SRPX2,PXDN,CRIS PLD1,LAMA5,ESM1,OMD, TGFBI,COL18A1,THBS1,TH BS2,THBS4,HMCN1,LGI2,L TBP2,ELN,TNFAIP6,LUM,P

$$
\text { COLCE }
$$

M5885 $\begin{gathered}\text { Ensemble of genes } \\ \text { encoding ECM- }\end{gathered}$

FSTL3,CLEC5A,CD109,CLE C7A,PGF,SERPINB5,SERPI NE2,SERPINB9, AGT,CXCL 9,CCL3,PLAU,MMP1,BMP8 including ECMaffilaited proteins, 
ECM regulators and secreted factors

\begin{abstract}
M3008
Genes encoding structural ECM glycoproteins enzymes and their regulators involved in the remodeling of the extracellular matrix
\end{abstract}

$\begin{array}{lllll}1.44 \mathrm{E}-13 & 2.66 \mathrm{E}-12 & 1.40 \mathrm{E}-11 & 1.53 \mathrm{E}-11 & 30\end{array}$

$1.51 \mathrm{E}-13$

M588
M5887
M588

M5883

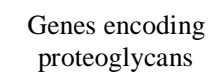

\begin{tabular}{cc} 
M5880 & $\begin{array}{c}\text { Genes encoding } \\
\text { proteins affiliated } \\
\text { structurally or } \\
\text { functionally to } \\
\text { extracellular matrix } \\
\text { proteins } \\
\text { Integrin Signaling } \\
\text { Pathway }\end{array}$ \\
\hline M3270 & $\begin{array}{c}\text { Integrin signalling } \\
\text { pathway }\end{array}$ \\
\hline & \\
& \\
& \\
P00034 & \\
P00050 & Plasminogen \\
& activating cascade \\
& Alzheimer disease- \\
presenilin pathway
\end{tabular}

$\begin{array}{llllr}6.26 \mathrm{E}-07 & 9.47 \mathrm{E}-06 & 4.97 \mathrm{E}-05 & 6.63 \mathrm{E}-05 & 9 \\ 2.00 \mathrm{E}-05 & 2.65 \mathrm{E}-04 & 1.39 \mathrm{E}-03 & 2.12 \mathrm{E}-03 & 8 \\ & & & & \\ 1.63 \mathrm{E}-03 & 1.68 \mathrm{E}-02 & 8.79 \mathrm{E}-02 & 1.72 \mathrm{E}-01 & 21\end{array}$

1.40E-02

4.31E-01

$1.00 \mathrm{E}+00$

11

1

MMP7,MMP9,MMP11,MMP 14,CXCL6,MMP16,PLXNA1 ,SEMA6B,SFRP2,SFRP4,CH RDL2,ANGPT2,ADAMTS4, ADAMTS2,GDF15,WNT2,A NXA13,CST1,ADAMTS14,C TSB,CTSK,IL6,IL11,HTRA1, INHBA,P4HA3,BMP1,SULF 2,ADAMTS9,SULF1,PLXDC 1,MUC16,HTRA3,ADAM12, SERPINH1,CXCL1,ADAMT S12,LIF,TGM2,OSM,ANGP TL2,FSTL1,PLXDC2,TIMP1, PLXNC1,LOXL2,SERPINE1, GREM1

EMILIN2,MFAP2,FBN1,MG P,AEBP1,SPON2,CTHRC1,N ID2,MXRA5,FN1,COMP,TN C,IGFBP7,SPARC,SPP1,FN DC1,SRPX2,PXDN,CRISPL D1,LAMA5,TGFBI,THBS1,T HBS2,THBS4,HMCN1,LGI2, LTBP2,ELN,TNFAIP6,PCOL CE

CD109,SERPINB5,SERPINE 2,SERPINB9,AGT,PLAU,M MP1,MMP3,MMP7,MMP9, MMP11,MMP14,MMP16,AD AMTS4,ADAMTS2,CST1,A DAMTS14,CTSB,CTSK,HT RA1,P4HA3,BMP1,SULF2,A DAMTS9,SULF1,HTRA3,A DAM12,SERPINH1,ADAMT S12,TGM2,TIMP1,LOXL2,S ERPINE1

ACAN,VCAN,HAPLN3,SPO CK1,ASPN,BGN,ESM1,OM D,LUM COL4A1,COL4A2,NID2,CO L6A3,COL15A1,LAMA5,CO L18A1,HMCN1

FSTL3,PGF,CXCL9,CCL3,B MP8A,CCL18,CXCL6,SFRP 2,SFRP4,CHRDL2,ANGPT2, GDF15,WNT2,IL6,IL11,INH BA,CXCL1,LIF,OSM,ANGP TL2,FSTL1

CLEC5A,CLEC7A,C1QTNF 6,PLXNA1,SEMA6B,ANXA 13,PLXDC1,MUC16,PLXDC 2,PLXNC1,GREM1

PHB2,ACTN1,ITGA11,ITG A5,ANGPTL2

ACTN1,ITGBL1,COL1A1,C

OL1A2,COL3A1,COL4A1,C OL4A2,COL5A1,COL5A2,C OL6A3,COL7A1,COL8A1,IT GA11,COL10A1,COL11A1, COL12A1,COL15A1,COL16 A1,FN1,COL5A3,ITGA5,IT GAX,ITGB8,LAMA5 PLAU,MMP1,MMP3,MMP9,

$\begin{array}{lllll}1.08 \mathrm{E}-04 & 4.21 \mathrm{E}-03 & 2.08 \mathrm{E}-02 & 8.42 \mathrm{E}-03 & 5 \\ 2.07 \mathrm{E}-03 & 5.39 \mathrm{E}-02 & 2.66 \mathrm{E}-01 & 1.62 \mathrm{E}-01 & 10\end{array}$
MMP1,MMP7,MMP9,MMP1 4,MMP16,WNT2,NOTCH1, NOTCH3,LEF1,CDH3 


\begin{tabular}{|c|c|c|c|c|c|c|c|}
\hline P02749 & Leucine biosynthesis & $5.91 \mathrm{E}-02$ & $5.76 \mathrm{E}-01$ & $1.00 \mathrm{E}+00$ & $1.00 \mathrm{E}+00$ & 1 & BCAT1 \\
\hline P00045 & $\begin{array}{l}\text { Notch signaling } \\
\text { pathway }\end{array}$ & $9.82 \mathrm{E}-02$ & $6.83 \mathrm{E}-01$ & $1.00 \mathrm{E}+00$ & $1.00 \mathrm{E}+00$ & 3 & NOTCH1,NOTCH3,HEYL \\
\hline P00011 & Blood coagulation & $1.17 \mathrm{E}-01$ & $6.83 \mathrm{E}-01$ & $1.00 \mathrm{E}+00$ & $1.00 \mathrm{E}+00$ & 3 & F2R,PLAU,SERPINE1 \\
\hline P00039 & $\begin{array}{l}\text { Metabotropic } \\
\text { glutamate receptor } \\
\text { group III pathway }\end{array}$ & $1.25 \mathrm{E}-01$ & $6.83 \mathrm{E}-01$ & $1.00 \mathrm{E}+00$ & $1.00 \mathrm{E}+00$ & 4 & $\begin{array}{c}\text { SLC1A3,CACNA1E,GRIN2 } \\
\text { D,GNB4 }\end{array}$ \\
\hline P00019 & $\begin{array}{l}\text { Endothelinsignaling } \\
\text { pathway }\end{array}$ & $1.75 \mathrm{E}-01$ & $6.83 \mathrm{E}-01$ & $1.00 \mathrm{E}+00$ & $1.00 \mathrm{E}+00$ & 4 & $\begin{array}{c}\text { ADCY3,PTGS2,EDNRA,PIK } \\
\text { 3R5 }\end{array}$ \\
\hline P00012 & $\begin{array}{c}\text { Cadherin signaling } \\
\text { pathway }\end{array}$ & $2.00 \mathrm{E}-01$ & $6.98 \mathrm{E}-01$ & $1.00 \mathrm{E}+00$ & $1.00 \mathrm{E}+00$ & 7 & $\begin{array}{c}\text { WNT2,CELSR3,LEF1,CDH3 } \\
\text {,CDH11,CDH13,CDH17 }\end{array}$ \\
\hline P00057 & $\begin{array}{l}\text { Wntsignaling } \\
\text { pathway }\end{array}$ & $2.05 \mathrm{E}-01$ & $6.98 \mathrm{E}-01$ & $1.00 \mathrm{E}+00$ & $1.00 \mathrm{E}+00$ & 12 & $\begin{array}{c}\text { MMP7,SFRP2,SFRP4,WNT2 } \\
\text {,DKK2,CELSR3,GNB4,LEF1 } \\
\text {,CDH3,CDH11,CDH13,CDH } \\
17\end{array}$ \\
\hline \multicolumn{8}{|c|}{ Pathway Ontology } \\
\hline PW:0000286 & integrin signaling & $5.23 \mathrm{E}-03$ & $1.57 \mathrm{E}-01$ & $7.34 \mathrm{E}-01$ & $3.14 \mathrm{E}-01$ & 5 & $\begin{array}{c}\text { ITGA11,ITGA5,PARVG,ITG } \\
\text { AX,ITGB8 }\end{array}$ \\
\hline PW:0000484 & $\begin{array}{l}\text { altered lipoprotein } \\
\text { metabolic }\end{array}$ & $1.70 \mathrm{E}-02$ & $1.69 \mathrm{E}-01$ & 7.89E-01 & $1.00 \mathrm{E}+00$ & 2 & APOC1,APOE \\
\hline PW:0000165 & $\begin{array}{c}\text { taurine and } \\
\text { hypotaurine } \\
\text { metabolic }\end{array}$ & $1.70 \mathrm{E}-02$ & $1.69 \mathrm{E}-01$ & 7.89E-01 & $1.00 \mathrm{E}+00$ & 2 & GGT5,SDS \\
\hline PW:0000419 & water transport & $2.80 \mathrm{E}-02$ & $1.69 \mathrm{E}-01$ & 7.89E-01 & $1.00 \mathrm{E}+00$ & 2 & AQP1,AQP9 \\
\hline PW:0000300 & $\begin{array}{l}\text { renal disease, renal } \\
\text { disorder }\end{array}$ & $3.09 \mathrm{E}-02$ & $1.69 \mathrm{E}-01$ & $7.89 \mathrm{E}-01$ & $1.00 \mathrm{E}+00$ & 1 & SPP1 \\
\hline PW:0000544 & $\begin{array}{c}\text { altered reverse } \\
\text { cholesterol transport }\end{array}$ & $3.09 \mathrm{E}-02$ & $1.69 \mathrm{E}-01$ & 7.89E-01 & $1.00 \mathrm{E}+00$ & 1 & ABCA1 \\
\hline PW:0000516 & $\begin{array}{l}\text { Interleukin-6 } \\
\text { signaling }\end{array}$ & $3.09 \mathrm{E}-02$ & $1.69 \mathrm{E}-01$ & $7.89 \mathrm{E}-01$ & $1.00 \mathrm{E}+00$ & 1 & IL6 \\
\hline PW:0000244 & $\begin{array}{l}\text { Angiotensin II } \\
\text { signaling }\end{array}$ & $3.44 \mathrm{E}-02$ & $1.72 \mathrm{E}-01$ & $8.04 \mathrm{E}-01$ & $1.00 \mathrm{E}+00$ & 2 & AGT,OLR1 \\
\hline PW:0000459 & apelinsignaling & $8.72 \mathrm{E}-02$ & $2.08 \mathrm{E}-01$ & $9.75 \mathrm{E}-01$ & $1.00 \mathrm{E}+00$ & 1 & APLN \\
\hline PW:0000078 & $\begin{array}{c}\text { cyanoamino acid } \\
\text { metabolic }\end{array}$ & $8.72 \mathrm{E}-02$ & $2.08 \mathrm{E}-01$ & $9.75 \mathrm{E}-01$ & $1.00 \mathrm{E}+00$ & 1 & GGT5 \\
\hline \multicolumn{8}{|c|}{ SMPDB } \\
\hline SMP00009 & Ammonia Recycling & $2.22 \mathrm{E}-02$ & 3.04E-01 & $1.00 \mathrm{E}+00$ & $1.00 \mathrm{E}+00$ & 2 & CPS1,SDS \\
\hline SMP00202 & $\begin{array}{c}\text { MNGIE } \\
\text { (Mitochondrial } \\
\text { Neurogastrointestinal } \\
\text { Encephalopathy) }\end{array}$ & $3.09 \mathrm{E}-02$ & $3.04 \mathrm{E}-01$ & $1.00 \mathrm{E}+00$ & $1.00 \mathrm{E}+00$ & 1 & TYMP \\
\hline SMP00018 & $\begin{array}{l}\text { Alpha Linolenic Acid } \\
\text { and Linoleic Acid } \\
\text { Metabolism }\end{array}$ & $5.91 \mathrm{E}-02$ & $3.04 \mathrm{E}-01$ & $1.00 \mathrm{E}+00$ & $1.00 \mathrm{E}+00$ & 1 & FADS2 \\
\hline SMP00147 & Cilazapril Pathway & 8.07E-02 & 3.04E-01 & $1.00 \mathrm{E}+00$ & $1.00 \mathrm{E}+00$ & 3 & AGT,CALD1,EDNRA \\
\hline SMP00083 & $\begin{array}{c}\text { Acetylsalicylic Acid } \\
\text { Pathway }\end{array}$ & $9.06 \mathrm{E}-02$ & $3.04 \mathrm{E}-01$ & $1.00 \mathrm{E}+00$ & $1.00 \mathrm{E}+00$ & 2 & F2R,PTGS2 \\
\hline SMP00379 & Nifedipine Pathway & $1.00 \mathrm{E}-01$ & 3.04E-01 & $1.00 \mathrm{E}+00$ & $1.00 \mathrm{E}+00$ & 2 & CALD1,EDNRA \\
\hline SMP00087 & Rofecoxib Pathway & $1.20 \mathrm{E}-01$ & $3.08 \mathrm{E}-01$ & $1.00 \mathrm{E}+00$ & $1.00 \mathrm{E}+00$ & 2 & F2R,PTGS2 \\
\hline SMP00053 & $\begin{array}{l}\text { One Carbon Pool By } \\
\text { Folate }\end{array}$ & $2.62 \mathrm{E}-01$ & $3.47 \mathrm{E}-01$ & $1.00 \mathrm{E}+00$ & $1.00 \mathrm{E}+00$ & 1 & MTHFD1L \\
\hline SMP00048 & $\begin{array}{l}\text { Nicotinate and } \\
\text { Nicotinamide }\end{array}$ & $3.06 \mathrm{E}-01$ & $3.47 \mathrm{E}-01$ & $1.00 \mathrm{E}+00$ & $1.00 \mathrm{E}+00$ & 1 & NNMT \\
\hline SMP00006 & $\begin{array}{c}\text { Metabolism } \\
\text { Tyrosine Metabolism }\end{array}$ & $5.18 \mathrm{E}-01$ & $5.31 \mathrm{E}-01$ & $1.00 \mathrm{E}+00$ & $1.00 \mathrm{E}+00$ & 1 & NOX4 \\
\hline
\end{tabular}

Table 4 The enriched pathway terms of the down regulated differentially expressed genes

\begin{tabular}{cccccccc}
\hline & & & BIOCYC & & \\
\hline Pathway ID & Pathway Name & P-value & $\begin{array}{c}\text { FDR } \\
\text { B\&H }\end{array}$ & $\begin{array}{c}\text { FDR } \\
\text { B\&Y }\end{array}$ & Bonferroni & $\begin{array}{c}\text { Gene } \\
\text { Count }\end{array}$ & Gene \\
\hline 1108771 & $\begin{array}{c}\text { allopregnanolone } \\
\text { biosynthesis } \\
\text { gluconeogenesis }\end{array}$ & $3.09 \mathrm{E}-04$ & $1.58 \mathrm{E}-02$ & $7.63 \mathrm{E}-02$ & $2.16 \mathrm{E}-02$ & 3 & AKR1C3,AKR1C1,AKR \\
782382 & $4.51 \mathrm{E}-04$ & $1.58 \mathrm{E}-02$ & $7.63 \mathrm{E}-02$ & $3.16 \mathrm{E}-02$ & 4 & FBP1,ALDOB,ALDOC,F \\
& & & & & & & BP2
\end{tabular}




\begin{tabular}{|c|c|c|c|c|c|c|c|}
\hline 545351 & $\begin{array}{l}\text { sphingosine and } \\
\text { sphingosine-1-phosphate }\end{array}$ & $1.23 \mathrm{E}-03$ & $2.86 \mathrm{E}-02$ & $1.38 \mathrm{E}-01$ & $8.58 \mathrm{E}-02$ & 3 & ASAH2,PTGR1,ACER2 \\
\hline 545319 & $\begin{array}{c}\text { metabolism } \\
\text { creatine-phosphate } \\
\text { biosynthesis }\end{array}$ & $1.91 \mathrm{E}-03$ & $3.25 \mathrm{E}-02$ & $1.57 \mathrm{E}-01$ & $1.34 \mathrm{E}-01$ & 2 & CKM,СКМТ2 \\
\hline 545359 & $\begin{array}{c}\text { superpathway of melatonin } \\
\text { degradation }\end{array}$ & $2.32 \mathrm{E}-03$ & $3.25 \mathrm{E}-02$ & $1.57 \mathrm{E}-01$ & $1.62 \mathrm{E}-01$ & 3 & $\begin{array}{c}\text { MAOA,CYP2S1,CYP2C } \\
19\end{array}$ \\
\hline 545278 & heparansulfate biosynthesis & $3.42 \mathrm{E}-03$ & $3.42 \mathrm{E}-02$ & $1.65 \mathrm{E}-01$ & $2.39 \mathrm{E}-01$ & 4 & $\begin{array}{c}\text { B3GAT1,HS6ST3,XYLT } \\
\text { 2,A4GNT }\end{array}$ \\
\hline 1108786 & $\begin{array}{l}\text { mucin core } 1 \text { and core } 2 \mathrm{O}- \\
\text { glycosylation }\end{array}$ & $3.42 \mathrm{E}-03$ & $3.42 \mathrm{E}-02$ & $1.65 \mathrm{E}-01$ & $2.39 \mathrm{E}-01$ & 4 & $\begin{array}{c}\text { GCNT4,GCNT1,GALNT } \\
\text { 6,GALNT5 }\end{array}$ \\
\hline 545347 & sucrose degradation & $9.06 \mathrm{E}-03$ & $7.05 \mathrm{E}-02$ & $3.41 \mathrm{E}-01$ & $6.34 \mathrm{E}-01$ & 2 & ALDOB,ALDOC \\
\hline 545352 & $\begin{array}{l}\text { acetone degradation I (to } \\
\text { methylglyoxal) }\end{array}$ & $1.64 \mathrm{E}-02$ & $9.15 \mathrm{E}-02$ & 4.42E-01 & $1.00 \mathrm{E}+00$ & 2 & CYP2S1,AKR1B10 \\
\hline 1108788 & $\begin{array}{c}\text { terminal O-glycans residues } \\
\text { modification }\end{array}$ & $1.64 \mathrm{E}-02$ & $9.15 \mathrm{E}-02$ & 4.42E-01 & $1.00 \mathrm{E}+00$ & 2 & FUT9,GCNT2 \\
\hline \multicolumn{8}{|c|}{ KEGG } \\
\hline 83032 & $\begin{array}{l}\text { Drug metabolism - } \\
\text { cytochrome P450 }\end{array}$ & $1.80 \mathrm{E}-10$ & $2.08 \mathrm{E}-08$ & 1.24E-07 & 3.83E-08 & 15 & $\begin{array}{c}\text { MAOA,ADH1C,ADH7,A } \\
\text { LDH3A1,FMO5,UGT1A } \\
\text { 10,UGT1A6,CYP2C19,C } \\
\text { YP2C8,CYP2C9,CYP3A } \\
\text { 4,CYP3A5,GSTA1,GST } \\
\text { A2,GSTA3 }\end{array}$ \\
\hline 673221 & Chemical carcinogenesis & $1.96 \mathrm{E}-10$ & $2.08 \mathrm{E}-08$ & $1.24 \mathrm{E}-07$ & 4.17E-08 & 16 & $\begin{array}{c}\text { ADH1C,ADH7,ALDH3A } \\
\text { 1,UGT1A10,UGT1A6,C } \\
\text { YP2C19,CYP2C8,CYP2 } \\
\text { C9,CYP2C18,CYP3A4,C } \\
\text { YP3A5,AKR1C2,SULT2 } \\
\text { A1,GSTA1,GSTA2,GST } \\
\text { A3 }\end{array}$ \\
\hline 83031 & $\begin{array}{l}\text { Metabolism of xenobiotics } \\
\text { by cytochrome P450 }\end{array}$ & 4.14E-10 & 2.94E-08 & $1.75 \mathrm{E}-07$ & 8.82E-08 & 15 & $\begin{array}{c}\text { CYP2S1,ADH1C,ADH7, } \\
\text { ALDH3A1,UGT1A10,U } \\
\text { GT1A6,AKR7A3,CYP2C } \\
\text { 9,CYP3A4,CYP3A5,AK } \\
\text { R1C1,SULT2A1,GSTA1, } \\
\text { GSTA2,GSTA3 }\end{array}$ \\
\hline 154409 & Gastric acid secretion & $4.53 \mathrm{E}-08$ & $1.93 \mathrm{E}-06$ & $1.15 \mathrm{E}-05$ & $9.65 \mathrm{E}-06$ & 13 & $\begin{array}{c}\text { HRH2,SLC9A1,SLC26A } \\
\text { 7,ATP4A,ATP4B,SST,K } \\
\text { CNJ15,KCNJ16,KCNQ1, } \\
\text { CA2,KCNE2,CCKBR,SL } \\
\text { C9A44 }\end{array}$ \\
\hline 132956 & Metabolic pathways & $3.35 \mathrm{E}-07$ & $1.19 \mathrm{E}-05$ & $7.05 \mathrm{E}-05$ & 7.12E-05 & 62 & $\begin{array}{c}\text { CMBL,HGD,MAOA,AC } \\
\text { ADL,GGT6,B3GALT5,C } \\
\text { YP2S1,TST,GCNT4,ME } \\
\text { 1,ADH1C,CKB,ADH7,C } \\
\text { KM,CKMT2,FBP1,PIK3 } \\
\text { C2G,SMPD3,ALDH1 A1, } \\
\text { ALDH3A1,ALDOB,ALD } \\
\text { OC,ALDH6A1,AMPD1, } \\
\text { HYAL1,UGT1A10,ASA } \\
\text { H2,UGT1A6,LIPF,FUT9, } \\
\text { AKR1C3,B3GAT1,ACE } \\
\text { R2,ST6GALNAC1,CYP2 } \\
\text { C19,GALE,CYP2C8,CHI } \\
\text { A,CYP2C9,CYP2C18,C } \\
\text { YP3A4,CYP3A5,ACSM1 } 1 \\
\text {,FBP2,GCNT1,GCNT2,I } \\
\text { TPKA,BHMT,XYLT2,B } \\
\text { 3GNT6,DHCR24,AKR1 } \\
\text { B10,GLUL,B4GALNT3, } \\
\text { GPT2,GPT,RDH12,RGN, } \\
\text { DHRS9,TM7SF2,GALN } \\
\text { T6,GALNT5 }\end{array}$ \\
\hline 172847 & $\begin{array}{l}\text { Protein digestion and } \\
\text { absorption }\end{array}$ & $2.79 \mathrm{E}-06$ & $8.49 \mathrm{E}-05$ & $5.05 \mathrm{E}-04$ & 5.94E-04 & 12 & $\begin{array}{c}\text { COL6A5,PGA5,COL2A1 } \\
\text {,COL4A6,COL17A1,CP } \\
\text { A2,SLC9A3,SLC15A1,K } \\
\text { CNQ1,PGA3,PGA4,SLC } \\
\text { 7A8 }\end{array}$ \\
\hline 193146 & Bile secretion & 4.27E-04 & $9.09 \mathrm{E}-03$ & $5.40 \mathrm{E}-02$ & $9.09 \mathrm{E}-02$ & 8 & $\begin{array}{l}\text { NR0B2,AQP4,SLC9A1,S } \\
\text { LC9A3,SLC4A4,CYP3A }\end{array}$ \\
\hline
\end{tabular}




\begin{tabular}{|c|c|c|c|c|c|c|c|}
\hline \multirow[b]{2}{*}{814926} & \multirow[b]{2}{*}{ Carbon metabolism } & \multirow[b]{2}{*}{$2.51 \mathrm{E}-03$} & \multirow[b]{2}{*}{$2.43 \mathrm{E}-02$} & \multirow[b]{2}{*}{$1.44 \mathrm{E}-01$} & \multirow[b]{2}{*}{ 5.34E-01 } & \multirow[b]{2}{*}{9} & \multirow[b]{2}{*}{$\begin{array}{c}\text { 4,SULT2A1,CA2 } \\
\text { ME1,FBP1,ALDOB,ALD } \\
\text { OC,ALDH6A1,FBP2,GP } \\
\text { T2,GPT,RGN }\end{array}$} \\
\hline & & & & & & & \\
\hline 169306 & Pancreatic secretion & $1.12 \mathrm{E}-02$ & $9.95 \mathrm{E}-02$ & $5.91 \mathrm{E}-01$ & $1.00 \mathrm{E}+00$ & 7 & $\begin{array}{c}\text { CPA2,SLC9A1,SLC4A4, } \\
\text { KCNQ1,RAB27B,CA2,C } \\
\text { CKAR }\end{array}$ \\
\hline 83053 & $\begin{array}{c}\text { Neuroactive ligand-receptor } \\
\text { interaction }\end{array}$ & $9.90 \mathrm{E}-02$ & 4.22E-01 & $1.00 \mathrm{E}+00$ & $1.00 \mathrm{E}+00$ & 11 & $\begin{array}{c}\text { F2RL1,HRH2,HTR1E,PR } \\
\text { LR,GABRB3,SSTR1,PT } \\
\text { GER3,GRIA4,LEPR,CC } \\
\text { KAR,CCKBR } \\
\end{array}$ \\
\hline \multicolumn{8}{|c|}{ Pathway Interaction Database } \\
\hline 137911 & $\begin{array}{c}\text { FOXA2 and FOXA3 } \\
\text { transcription factor networks }\end{array}$ & $8.12 \mathrm{E}-04$ & $1.50 \mathrm{E}-02$ & $6.31 \mathrm{E}-02$ & $3.00 \mathrm{E}-02$ & 6 & $\begin{array}{c}\text { FOXA1,FOXA2,FOXA3, } \\
\text { TTR,ALDOB,APOA1 }\end{array}$ \\
\hline 169356 & RhoAsignaling pathway & $8.59 \mathrm{E}-02$ & 7.10E-01 & $1.00 \mathrm{E}+00$ & $1.00 \mathrm{E}+00$ & 3 & $\begin{array}{c}\text { SH3GL2,SLC9A1,SLC9 } \\
\text { A3 }\end{array}$ \\
\hline 138074 & $\begin{array}{l}\text { Visual signal transduction: } \\
\text { Rods }\end{array}$ & $1.15 \mathrm{E}-01$ & 7.10E-01 & $1.00 \mathrm{E}+00$ & $1.00 \mathrm{E}+00$ & 2 & GUCA1C,RDH12 \\
\hline 138017 & $\begin{array}{l}\text { Signaling events mediated } \\
\text { by PTP1B }\end{array}$ & $1.34 \mathrm{E}-01$ & 7.10E-01 & $1.00 \mathrm{E}+00$ & $1.00 \mathrm{E}+00$ & 3 & PRLR,LEPR,CDH2 \\
\hline 169347 & $\begin{array}{c}\text { Notch-mediated HES/HEY } \\
\text { network }\end{array}$ & $3.47 \mathrm{E}-01$ & $9.31 \mathrm{E}-01$ & $1.00 \mathrm{E}+00$ & $1.00 \mathrm{E}+00$ & 2 & ID1,GATA6 \\
\hline 138027 & $\begin{array}{l}\text { Regulation of Androgen } \\
\text { receptor activity }\end{array}$ & 3.65E-01 & $9.31 \mathrm{E}-01$ & $1.00 \mathrm{E}+00$ & $1.00 \mathrm{E}+00$ & 2 & SPDEF,TMPRSS2 \\
\hline 137944 & $\begin{array}{l}\text { IL1-mediated signaling } \\
\text { events }\end{array}$ & $5.95 \mathrm{E}-01$ & $9.31 \mathrm{E}-01$ & $1.00 \mathrm{E}+00$ & $1.00 \mathrm{E}+00$ & 1 & IL1R2 \\
\hline 137948 & BMP receptor signaling & $6.05 \mathrm{E}-01$ & $9.31 \mathrm{E}-01$ & $1.00 \mathrm{E}+00$ & $1.00 \mathrm{E}+00$ & 1 & SOSTDC1 \\
\hline 138070 & Regulation of RhoA activity & $6.95 \mathrm{E}-01$ & $9.31 \mathrm{E}-01$ & $1.00 \mathrm{E}+00$ & $1.00 \mathrm{E}+00$ & 1 & ARHGDIG \\
\hline 137999 & Integrins in angiogenesis & $6.95 \mathrm{E}-01$ & $9.31 \mathrm{E}-01$ & $1.00 \mathrm{E}+00$ & $1.00 \mathrm{E}+00$ & 1 & ANGPTL3 \\
\hline \multicolumn{8}{|c|}{ REACTOME } \\
\hline 1270189 & Biological oxidations & $8.27 \mathrm{E}-10$ & $4.25 \mathrm{E}-07$ & $2.90 \mathrm{E}-06$ & $4.25 \mathrm{E}-07$ & 25 & $\begin{array}{c}\text { CMBL,AADAC,MAOA, } \\
\text { GGT6,CYP2S1,ADH1C, } \\
\text { ADH7, } \\
\text { ALDH1A1,ALDH3A1,U } \\
\text { GT1A6,AKR7A3,CYP4F } \\
\text { 12, } \\
\text { CYP2C19,CYP2C8,CYP } \\
\text { 2C9,CYP2C18,CYP3A4, } \\
\text { CYP3A5, } \\
\text { ACSM1,SULT1B1,SULT } \\
\text { 1C2,SULT2A1,GSTA1,G } \\
\text { STA2, GSTA3 }\end{array}$ \\
\hline 1270190 & $\begin{array}{l}\text { Phase } 1 \text { - Functionalization } \\
\text { of compounds }\end{array}$ & $1.32 \mathrm{E}-07$ & $1.70 \mathrm{E}-05$ & $1.16 \mathrm{E}-04$ & $6.78 \mathrm{E}-05$ & 15 & $\begin{array}{c}\text { CMBL,AADAC,MAOA, } \\
\text { CYP2S1,ADH1C,ADH7, } \\
\text { ALDH1A1, } \\
\text { ALDH3A1,CYP4F12,CY } \\
\text { P2C19,CYP2C8,CYP2C9 } \\
\text {,CYP2C18,CYP3A4,CYP } \\
\text { 3A5 }\end{array}$ \\
\hline 1269903 & $\begin{array}{c}\text { Transmembrane transport of } \\
\text { small molecules }\end{array}$ & $5.85 \mathrm{E}-04$ & $1.59 \mathrm{E}-02$ & $1.09 \mathrm{E}-01$ & $3.01 \mathrm{E}-01$ & 32 & $\begin{array}{c}\text { ANO5,CLCNKA,SCNN1 } \\
\text { B,SCNN1G,FXYD3,ATP } \\
\text { 13A4, } \\
\text { SLC26A9,APOA1,AQP4, } \\
\text { SLC1A2,AQP5,SLC5A5, } \\
\text { SLC9A1, } \\
\text { SLC9A2,SLC9A3,SLC15 } \\
\text { A1,SLC26A7,ANO7,SLC } \\
\text { 4A4, } \\
\text { SLC2A12,ATP4A,ATP4 } \\
\text { B,GABRB3,AZGP1,GC } \\
\text { KR,AQP10, } \\
\text { ATP13A5,SGK2,SLC7A } \\
\text { 8,SLC9A4,SLC28A2,SL } \\
\text { C16A7 }\end{array}$ \\
\hline 1270001 & $\begin{array}{l}\text { Metabolism of lipids and } \\
\text { lipoproteins }\end{array}$ & $3.10 \mathrm{E}-03$ & 4.99E-02 & $3.40 \mathrm{E}-01$ & $1.00 \mathrm{E}+00$ & 34 & $\begin{array}{c}\text { ACADL,ME1,PIK3C2G, } \\
\text { LIPH,HPGD,SMPD3,EL } \\
\text { OVL6, } \\
\text { ASAH2,GDPD3,FA2H,L } \\
\text { IPF,APOA1,APOA4,AP } \\
\text { OC3,PTGR1,CIDEC,PR }\end{array}$ \\
\hline
\end{tabular}




\begin{tabular}{|c|c|c|c|c|c|c|c|}
\hline \multirow[b]{2}{*}{1269957} & \multirow[b]{2}{*}{$\begin{array}{l}\text { Metabolism of } \\
\text { carbohydrates }\end{array}$} & \multirow[b]{2}{*}{$9.17 \mathrm{E}-03$} & \multirow[b]{2}{*}{$9.25 \mathrm{E}-02$} & \multirow[b]{2}{*}{$6.31 \mathrm{E}-01$} & \multirow[b]{2}{*}{$1.00 \mathrm{E}+00$} & \multirow[b]{2}{*}{15} & \multirow{3}{*}{$\begin{array}{c}\text { 1B15, TM7SF2 } \\
\text { FBP1,ALDH1A1,ALDO } \\
\text { B,ALDOC,HYAL1,SLC9 } \\
\text { A1,B3GAT1,HS6ST3,G } \\
\text { ALE,CHIA,FBP2,GCKR, } \\
\text { XYLT2,B3GNT7,HAS3 } \\
\text { HGD,TST,CKB,CKM,C } \\
\text { KMT2,ALDH6A1,DUO } \\
\text { X2,SLC5A5, } \\
\text { GNMT,BHMT,DUOX1, } \\
\text { GLUL,NQO1,GPT2,GPT }\end{array}$} \\
\hline & & & & & & & \\
\hline 1270158 & $\begin{array}{l}\text { Metabolism of amino acids } \\
\text { and derivatives }\end{array}$ & 4.88E-02 & $2.53 \mathrm{E}-01$ & $1.00 \mathrm{E}+00$ & $1.00 \mathrm{E}+00$ & 15 & \\
\hline 1457780 & Neutrophil degranulation & $1.89 \mathrm{E}-01$ & 4.97E-01 & $1.00 \mathrm{E}+00$ & $1.00 \mathrm{E}+00$ & 16 & $\begin{array}{c}\text { TTR,PLAC8,S100P,ALD } \\
\text { OC,METTL7A,SLPI,CY } \\
\text { STM1, } \\
\text { PTPRN2,RAB27A,TCN1 } \\
\text {,ORM1,ORM2,CD36,LT } \\
\text { F,HBB, RAB37 }\end{array}$ \\
\hline 1269340 & Hemostasis & $2.77 \mathrm{E}-01$ & $6.05 \mathrm{E}-01$ & $1.00 \mathrm{E}+00$ & $1.00 \mathrm{E}+00$ & 19 & $\begin{array}{c}\text { F13A1,SERPINA4,FGA, } \\
\text { FGB,FGG,APOA1,GAT } \\
\text { A5,SCG3, } \\
\text { CXADR,KIF1A,GATA6, } \\
\text { RAB27B,SLC7A8,ORM1 } \\
\text {,ORM2, } \\
\text { CD36,CLEC3B,HBB,SE } \\
\text { RPINA5 }\end{array}$ \\
\hline 1268677 & Metabolism of proteins & $5.61 \mathrm{E}-01$ & $8.87 \mathrm{E}-01$ & $1.00 \mathrm{E}+00$ & $1.00 \mathrm{E}+00$ & 41 & $\begin{array}{c}\text { KLF4,GCNT4,PGA5,TT } \\
\text { R,FGA,PAPPA2,ERO1B, } \\
\text { SLC25A4, } \\
\text { FOLR1,MYRIP,APOA1, } \\
\text { APOA4,IGFALS,IGFBP2 } \\
\text {,MUC1, } \\
\text { MUC6,ST6GALNAC1,L } \\
\text { YPD6B,GHRL,GATA6, } \\
\text { GCNT1, } \\
\text { B3GNT6,LDHD,ODAM, } \\
\text { ADAMTS15,RAB27A,R } \\
\text { AB27B, } \\
\text { PGA3,PGA4,ADAMTSL } \\
\text { 1,PSCA,MUC5B,B3GNT } \\
\text { 7,EEF1A2,B4GALNT2,A } \\
\text { 4GNT,CNTN3,LTF,GAL } \\
\text { NT6,GALNT5,RAB37 }\end{array}$ \\
\hline 1270302 & Developmental Biology & $9.27 \mathrm{E}-01$ & $\begin{array}{c}1.00 \mathrm{E}+0 \\
0\end{array}$ & $1.00 \mathrm{E}+00$ & $1.00 \mathrm{E}+00$ & 21 & $\begin{array}{c}\text { ERBB4,COL6A5,KLF4,F } \\
\text { OXA2,FOXA3,FGA,FG } \\
\text { B,KRT20, } \\
\text { FGG,SH3GL2,CSTA,SO } \\
\text { X2,PRSS8,NRG4,NCAM } \\
\text { 1,RPS6KA6,UNC5D,RA } \\
\text { P1GAP,DSC2,CD36,CD } \\
\text { H2 }\end{array}$ \\
\hline \multicolumn{8}{|c|}{ Gen MAPP } \\
\hline MAP00710 & MAP00710 & $1.68 \mathrm{E}-06$ & $3.19 \mathrm{E}-05$ & $1.30 \mathrm{E}-04$ & $5.54 \mathrm{E}-05$ & 6 & $\begin{array}{c}\text { ME1,FBP1,ALDOB,ALD } \\
\text { OC,FBP2,GPT }\end{array}$ \\
\hline MAP00071 & MAP00071 & $1.93 \mathrm{E}-06$ & $3.19 \mathrm{E}-05$ & $1.30 \mathrm{E}-04$ & $6.37 \mathrm{E}-05$ & 9 & $\begin{array}{c}\text { ACADL,ADH1C,ADH7, } \\
\text { ALDH1A1,CYP2C8,CYP } \\
\text { 2C9,CYP2C18,CYP3A4, } \\
\text { CYP3A5 }\end{array}$ \\
\hline MAP00010 & MAP00010 & $4.59 \mathrm{E}-05$ & $5.05 \mathrm{E}-04$ & $2.06 \mathrm{E}-03$ & $1.51 \mathrm{E}-03$ & 8 & $\begin{array}{c}\text { ADH1C,ADH7,FBP1,AL } \\
\text { DH1A1,ALDH3A1,ALD } \\
\text { OB,ALDOC,FBP2 }\end{array}$ \\
\hline MAP00910 & MAP00910 & $1.75 \mathrm{E}-03$ & $7.23 \mathrm{E}-03$ & $2.96 \mathrm{E}-02$ & $5.78 \mathrm{E}-02$ & 4 & GLUL,CA2,CA4,CA9 \\
\hline MAP00220 & MAP00220 & $8.53 \mathrm{E}-03$ & $2.56 \mathrm{E}-02$ & $1.05 \mathrm{E}-01$ & $2.82 \mathrm{E}-01$ & 3 & CKB,CKM,СКMT2 \\
\hline MAP00562 & MAP00562 & $8.32 \mathrm{E}-02$ & $1.67 \mathrm{E}-01$ & $6.82 \mathrm{E}-01$ & $1.00 \mathrm{E}+00$ & 2 & PIK3C2G,ITPKA \\
\hline
\end{tabular}




\begin{tabular}{|c|c|c|c|c|c|c|c|}
\hline MAP00251 & MAP00251 & $9.09 \mathrm{E}-02$ & $1.67 \mathrm{E}-01$ & $6.82 \mathrm{E}-01$ & $1.00 \mathrm{E}+00$ & 2 & GLUL,GPT \\
\hline MAP00480 & MAP00480 & $1.07 \mathrm{E}-01$ & $1.84 \mathrm{E}-01$ & $7.53 \mathrm{E}-01$ & $1.00 \mathrm{E}+00$ & 2 & GPX3,GSTA2 \\
\hline MAP00260 & MAP00260 & $1.15 \mathrm{E}-01$ & $1.84 \mathrm{E}-01$ & $7.53 \mathrm{E}-01$ & $1.00 \mathrm{E}+00$ & 2 & MAOA,BHMT \\
\hline MAP00532 & MAP00532 & $1.65 \mathrm{E}-01$ & $2.37 \mathrm{E}-01$ & $9.69 \mathrm{E}-01$ & $1.00 \mathrm{E}+00$ & 1 & XYLT2 \\
\hline \multicolumn{8}{|c|}{ MSigDB C2 BIOCARTA (v6.0) } \\
\hline M5889 & $\begin{array}{c}\text { Ensemble of genes encoding } \\
\text { extracellular matrix and } \\
\text { extracellular matrix- } \\
\text { associated proteins }\end{array}$ & $2.63 \mathrm{E}-03$ & $3.55 \mathrm{E}-02$ & $1.63 \mathrm{E}-01$ & $1.42 \mathrm{E}-01$ & 41 & $\begin{array}{c}\text { LGALS9C,COL6A5,F13 } \\
\text { A1,S100P,SERPINA4,C } \\
\text { CL28,FGA,FGB,FGG,C } \\
\text { OL2A1,PAPPA2,COL4A } \\
\text { 6,COL17A1,HYAL1,CX } \\
\text { CL14,HAPLN1,IGFALS, } \\
\text { IGFBP2,SCUBE2,PDGF } \\
\text { D,SLPI,CSTA,CTSE,MU } \\
\text { C1,MUC6,SERPINB7,L } \\
\text { GALS9B,NRG4,ADAM2 } \\
\text { 8,BMP5,SEMA3B,ANGP } \\
\text { TL3,ADAMTS15,DPT,A } \\
\text { DAMTSL1,MUC5B,CCB } \\
\text { E1,ANXA10,REG3A,CL } \\
\text { EC3B,SERPINA5 }\end{array}$ \\
\hline M5885 & $\begin{array}{l}\text { Ensemble of genes encoding } \\
\text { ECM-associated proteins } \\
\text { including ECM-affilaited } \\
\text { proteins, ECM regulators } \\
\text { and secreted factors }\end{array}$ & $9.91 \mathrm{E}-03$ & $8.92 \mathrm{E}-02$ & $4.08 \mathrm{E}-01$ & $5.35 \mathrm{E}-01$ & 30 & $\begin{array}{c}\text { LGALS9C,F13A1,S100P, } \\
\text { SERPINA4,CCL28,PAPP } \\
\text { A2,HYAL1,CXCL14,SC } \\
\text { UBE2,PDGFD,SLPI,CST } \\
\text { A,CTSE,MUC1,MUC6,S } \\
\text { ERPINB7,LGALS9B,NR } \\
\text { G4,ADAM28,BMP5,SE } \\
\text { MA3B,ANGPTL3,ADA } \\
\text { MTS15,ADAMTSL1,MU } \\
\text { C5B,CCBE1,ANXA10,R } \\
\text { EG3A,CLEC3B,SERPIN } \\
\text { A5 }\end{array}$ \\
\hline M3468 & $\begin{array}{l}\text { Genes encoding enzymes } \\
\text { and their regulators involved } \\
\text { in the remodeling of the } \\
\text { extracellular matrix }\end{array}$ & $1.89 \mathrm{E}-02$ & $1.46 \mathrm{E}-01$ & $6.68 \mathrm{E}-01$ & $1.00 \mathrm{E}+00$ & 12 & $\begin{array}{c}\text { F13A1,SERPINA4,PAPP } \\
\text { A2,HYAL1,SLPI,CSTA, } \\
\text { CTSE,SERPINB7,ADA } \\
\text { M28,ADAMTS15,ADA } \\
\text { MTSL1,SERPINA5 }\end{array}$ \\
\hline M18053 & $\begin{array}{l}\text { Reversal of Insulin } \\
\text { Resistance by Leptin }\end{array}$ & $3.05 \mathrm{E}-02$ & $1.52 \mathrm{E}-01$ & $6.95 \mathrm{E}-01$ & $1.00 \mathrm{E}+00$ & 2 & PRKAA2,LEPR \\
\hline M5880 & $\begin{array}{l}\text { Genes encoding proteins } \\
\text { affiliated structurally or } \\
\text { functionally to extracellular } \\
\text { matrix proteins }\end{array}$ & $3.10 \mathrm{E}-02$ & $1.52 \mathrm{E}-01$ & $6.95 \mathrm{E}-01$ & $1.00 \mathrm{E}+00$ & 9 & $\begin{array}{c}\text { LGALS9C,MUC1,MUC6 } \\
\text {,LGALS9B,SEMA3B,M } \\
\text { UC5B,ANXA10,REG3A, } \\
\text { CLEC3B }\end{array}$ \\
\hline M2404 & $\begin{array}{c}\text { Mechanism of Gene } \\
\text { Regulation by Peroxisome } \\
\text { Proliferators via } \\
\text { PPARa(alpha) }\end{array}$ & $5.99 \mathrm{E}-02$ & $2.70 \mathrm{E}-01$ & $1.00 \mathrm{E}+00$ & $1.00 \mathrm{E}+00$ & 4 & $\begin{array}{c}\text { ME1,NR0B2,APOA1,CD } \\
36\end{array}$ \\
\hline M5884 & $\begin{array}{l}\text { Ensemble of genes encoding } \\
\text { core extracellular matrix } \\
\text { including ECM } \\
\text { glycoproteins, collagens and } \\
\text { proteoglycans }\end{array}$ & $9.35 \mathrm{E}-02$ & $3.89 \mathrm{E}-01$ & $1.00 \mathrm{E}+00$ & $1.00 \mathrm{E}+00$ & 11 & $\begin{array}{c}\text { COL6A5,FGA,FGB,FGG } \\
\text {,COL2A1,COL4A6,COL } \\
\text { 17A1, } \\
\text { HAPLN1,IGFALS,IGFB } \\
\text { P2,DPT }\end{array}$ \\
\hline M9378 & Interleukin 4 (IL-4) Pathway & $1.41 \mathrm{E}-01$ & $5.44 \mathrm{E}-01$ & $1.00 \mathrm{E}+00$ & $1.00 \mathrm{E}+00$ & 2 & SERPINA4,NR0B2 \\
\hline M5202 & $\begin{array}{l}\text { Hypoxia and p53 in the } \\
\text { Cardiovascular system }\end{array}$ & $4.48 \mathrm{E}-01$ & $6.72 \mathrm{E}-01$ & $1.00 \mathrm{E}+00$ & $1.00 \mathrm{E}+00$ & 1 & NQO1 \\
\hline M5883 & $\begin{array}{l}\text { Genes encoding secreted } \\
\text { soluble factors }\end{array}$ & $5.15 \mathrm{E}-01$ & $6.78 \mathrm{E}-01$ & $1.00 \mathrm{E}+00$ & $1.00 \mathrm{E}+00$ & 9 & $\begin{array}{c}\text { S100P,CCL28,CXCL14,S } \\
\text { CUBE2,PDGFD,NRG4,B } \\
\text { MP5,ANGPTL3,CCBE1 }\end{array}$ \\
\hline \multicolumn{8}{|c|}{ Panther DB } \\
\hline $\mathrm{P} 04372$ & $\begin{array}{l}\text { 5-Hydroxytryptamine } \\
\text { degredation }\end{array}$ & $1.01 \mathrm{E}-02$ & $1.70 \mathrm{E}-01$ & $7.33 \mathrm{E}-01$ & $4.12 \mathrm{E}-01$ & 3 & $\begin{array}{c}\text { MAOA,ALDH1A1,ALD } \\
\text { H3A1 }\end{array}$ \\
\hline $\mathrm{P} 02744$ & $\begin{array}{l}\text { Fructose galactose } \\
\text { metabolism }\end{array}$ & $1.25 \mathrm{E}-02$ & $1.70 \mathrm{E}-01$ & $7.33 \mathrm{E}-01$ & $5.11 \mathrm{E}-01$ & 2 & ALDOB,ALDOC \\
\hline P05914 & Nicotine degradation & $6.84 \mathrm{E}-02$ & $6.54 \mathrm{E}-01$ & $1.00 \mathrm{E}+00$ & $1.00 \mathrm{E}+00$ & 2 & UGT1A10,UGT1A6 \\
\hline $\mathrm{P} 02745$ & $\begin{array}{l}\text { Glutamine glutamate } \\
\text { conversion }\end{array}$ & $9.80 \mathrm{E}-02$ & $6.54 \mathrm{E}-01$ & $1.00 \mathrm{E}+00$ & $1.00 \mathrm{E}+00$ & 1 & GLUL \\
\hline P00037 & $\begin{array}{l}\text { Ionotropic glutamate } \\
\text { receptor pathway }\end{array}$ & $1.12 \mathrm{E}-01$ & $6.54 \mathrm{E}-01$ & $1.00 \mathrm{E}+00$ & $1.00 \mathrm{E}+00$ & 3 & SLC1A2,STX19,GRIA4 \\
\hline
\end{tabular}




\begin{tabular}{|c|c|c|c|c|c|c|c|}
\hline P02772 & Pyruvate metabolism & $1.65 \mathrm{E}-01$ & 7.53E-01 & $1.00 \mathrm{E}+00$ & $1.00 \mathrm{E}+00$ & 1 & ME1 \\
\hline P04396 & $\begin{array}{l}\text { Vitamin D metabolism and } \\
\text { pathway }\end{array}$ & $2.07 \mathrm{E}-01$ & $8.48 \mathrm{E}-01$ & $1.00 \mathrm{E}+00$ & $1.00 \mathrm{E}+00$ & 1 & GC \\
\hline P00026 & $\begin{array}{c}\text { Heterotrimeric G-protein } \\
\text { signaling pathway-Gialpha } \\
\text { and Gs alpha mediated } \\
\text { pathway }\end{array}$ & 7.40E-01 & 9.97E-01 & $1.00 \mathrm{E}+00$ & $1.00 \mathrm{E}+00$ & 3 & HRH2,HTR1E,SSTR1 \\
\hline P00047 & PDGF signaling pathway & $8.38 \mathrm{E}-01$ & 9.97E-01 & $1.00 \mathrm{E}+00$ & $1.00 \mathrm{E}+00$ & 2 & SPDEF,RPS6KA6 \\
\hline \multicolumn{8}{|c|}{ Pathway Ontology } \\
\hline PW:0000482 & lipoprotein metabolic & $2.46 \mathrm{E}-04$ & $7.38 \mathrm{E}-03$ & $3.45 \mathrm{E}-02$ & $1.48 \mathrm{E}-02$ & 4 & $\begin{array}{c}\text { APOA1,APOA4,APOBE } \\
\text { C1,APOC3 }\end{array}$ \\
\hline PW:0000057 & carbon fixation & $2.46 \mathrm{E}-04$ & 7.38E-03 & $3.45 \mathrm{E}-02$ & $1.48 \mathrm{E}-02$ & 4 & ME1,FBP1,ALDOC,GPT \\
\hline PW:0000419 & water transport & $1.23 \mathrm{E}-03$ & $1.47 \mathrm{E}-02$ & $6.88 \mathrm{E}-02$ & $7.35 \mathrm{E}-02$ & 3 & AQP4,AQP5,AQP10 \\
\hline PW:0000373 & glutathione conjugation & $1.23 \mathrm{E}-03$ & $1.47 \mathrm{E}-02$ & $6.88 \mathrm{E}-02$ & 7.35E-02 & 3 & GSTA1,GSTA2,GSTA3 \\
\hline PW:0000579 & somatostatinsignaling & $9.06 \mathrm{E}-03$ & $5.44 \mathrm{E}-02$ & $2.54 \mathrm{E}-01$ & $5.44 \mathrm{E}-01$ & 2 & SST,SSTR1 \\
\hline PW:0000033 & energy metabolic & $2.61 \mathrm{E}-02$ & $1.05 \mathrm{E}-01$ & $4.89 \mathrm{E}-01$ & $1.00 \mathrm{E}+00$ & 1 & AMPD1 \\
\hline PW:0000357 & energy homeostasis & $5.03 \mathrm{E}-02$ & $1.26 \mathrm{E}-01$ & $5.88 \mathrm{E}-01$ & $1.00 \mathrm{E}+00$ & 1 & LEPR \\
\hline PW:0000539 & ghrelin system & $5.03 \mathrm{E}-02$ & $1.26 \mathrm{E}-01$ & $5.88 \mathrm{E}-01$ & $1.00 \mathrm{E}+00$ & 1 & GHRL \\
\hline PW:0000533 & glycogen metabolic & $1.21 \mathrm{E}-01$ & $2.20 \mathrm{E}-01$ & $1.00 \mathrm{E}+00$ & $1.00 \mathrm{E}+00$ & 1 & GCKR \\
\hline PW:0000454 & cholesterol biosynthetic & $3.72 \mathrm{E}-01$ & 4.37E-01 & $1.00 \mathrm{E}+00$ & $1.00 \mathrm{E}+00$ & 1 & DHCR24 \\
\hline \multicolumn{8}{|c|}{ SMPDB } \\
\hline SMP00246 & Pirenzepine Pathway & $4.99 \mathrm{E}-05$ & $9.27 \mathrm{E}-04$ & $5.10 \mathrm{E}-03$ & $6.83 \mathrm{E}-03$ & 5 & $\begin{array}{c}\text { HRH2,ATP4A,ATP4B,S } \\
\text { ST,CCKBR }\end{array}$ \\
\hline SMP00006 & Tyrosine Metabolism & $2.96 \mathrm{E}-04$ & $3.69 \mathrm{E}-03$ & $2.03 \mathrm{E}-02$ & $4.05 \mathrm{E}-02$ & 5 & $\begin{array}{c}\text { HGD,MAOA,ALDH3A1, } \\
\text { DUOX2,DUOX1 }\end{array}$ \\
\hline SMP00281 & Anistreplase Pathway & $5.89 \mathrm{E}-04$ & $3.95 \mathrm{E}-03$ & $2.17 \mathrm{E}-02$ & 8.07E-02 & 4 & F13A1,FGA,FGB,FGG \\
\hline SMP00260 & Clopidogrel Pathway & $9.51 \mathrm{E}-04$ & $3.95 \mathrm{E}-03$ & $2.17 \mathrm{E}-02$ & $1.30 \mathrm{E}-01$ & 4 & $\begin{array}{c}\text { CYP2C19,CYP2C9,CYP } \\
\text { 3А4,CYP3A5 }\end{array}$ \\
\hline SMP00127 & Glucose-Alanine Cycle & $1.91 \mathrm{E}-03$ & $7.68 \mathrm{E}-03$ & 4.23E-02 & $2.61 \mathrm{E}-01$ & 2 & GPT2,GPT \\
\hline SMP00074 & Retinol Metabolism & $1.01 \mathrm{E}-02$ & $3.93 \mathrm{E}-02$ & $2.16 \mathrm{E}-01$ & $1.00 \mathrm{E}+00$ & 3 & $\begin{array}{c}\text { ALDH1A1,RDH12,DHR } \\
\text { S9 }\end{array}$ \\
\hline SMP00073 & Butyrate Metabolism & $1.64 \mathrm{E}-02$ & $6.05 \mathrm{E}-02$ & 3.33E-01 & $1.00 \mathrm{E}+00$ & 2 & ACSM1,OXCT1 \\
\hline SMP00330 & Tocainide Pathway & $2.43 \mathrm{E}-01$ & $3.60 \mathrm{E}-01$ & $1.00 \mathrm{E}+00$ & $1.00 \mathrm{E}+00$ & 2 & KCNQ1,KCNE2 \\
\hline SMP00110 & Indapamide Pathway & $2.47 \mathrm{E}-01$ & $3.60 \mathrm{E}-01$ & $1.00 \mathrm{E}+00$ & $1.00 \mathrm{E}+00$ & 1 & CLCNKA \\
\hline SMP00134 & Spironolactone Pathway & $2.85 \mathrm{E}-01$ & $3.75 \mathrm{E}-01$ & $1.00 \mathrm{E}+00$ & $1.00 \mathrm{E}+00$ & 1 & SCNN1B \\
\hline
\end{tabular}

Table 5 The enriched GO terms of the up regulated differentially expressed genes

\begin{tabular}{|c|c|c|c|c|c|c|c|c|}
\hline GO ID & CATEGORY & GO Name & P Value & $\begin{array}{l}\text { FDR } \\
\text { B\&H }\end{array}$ & $\begin{array}{l}\text { FDR } \\
\text { B\&Y }\end{array}$ & Bonferroni & $\begin{array}{c}\text { Gene } \\
\text { Count }\end{array}$ & Gene \\
\hline GO:0043062 & BP & $\begin{array}{l}\text { extracellular } \\
\text { structure } \\
\text { organization }\end{array}$ & $3.09 \mathrm{E}-46$ & $9.74 \mathrm{E}-43$ & $9.09 \mathrm{E}-42$ & $1.95 \mathrm{E}-42$ & 83 & $\begin{array}{c}\text { ABCA1,MFAP2,FAP,SER } \\
\text { PINB5,FBN1,AEBP1,LIP } \\
\text { G,ACAN,AGT,ANTXR1,F } \\
\text { LRT2,MMP1,MMP3,MM } \\
\text { P7,MMP9,MMP11,MMP1 } \\
\text { 4,MMP16,FOXC1,COL1A } \\
\text { 1,COL1A2,COL3A1,COL } \\
\text { 4A1,COL4A2,COL5A1,C } \\
\text { OL5A2,NID2,COL6A3,C } \\
\text { OL7A1,COL8A1,ITGA11, } \\
\text { COL10A1,COL11A1,COL } \\
\text { 12A1,SFRP2,COL15A1,C } \\
\text { OL16A1,FN1,COMP,ADA } \\
\text { MTS4,ADAMTS2,TNC,O } \\
\text { LFML2B,ICAM1,COL5A } \\
\text { 3,CCDC80,APOC1,APOE, } \\
\text { MSR1,PDPN,VCAN,ADA } \\
\text { MTS14,FSCN1,CTSK,IL6, } \\
\text { SPARC,HTRA1,SPP1,ITG } \\
\text { A5,ITGAX,ITGB8,BGN,B } \\
\text { MP1,SULF2,PXDN,ADA } \\
\text { MTS9,SULF1,NOTCH1,P } \\
\text { LA2G7,LAMA5,ADAM12 } \\
\text {,SERPINH1,TNFRSF11B, } \\
\text { TGFBI,COL18A1,THBS1, } \\
\text { SH3PXD2B,TIMP1,LOXL } \\
\text { 2,SERPINE1,ELN,GREM }\end{array}$ \\
\hline
\end{tabular}


bioRxiv preprint doi: https://doi.org/10.1101/2020.12.20.423656; this version posted December 23, 2020. The copyright holder for this preprint (which was not certified by peer review) is the author/funder. All rights reserved. No reuse allowed without permission.

GO:000715

GO:0048646
BP anatomical
structure
formation
involved in

morphogenesi
$5.46 \mathrm{E}-25 \quad 6.88 \mathrm{E}-22 \quad 6.42 \mathrm{E}-21 \quad 3.44 \mathrm{E}-21$
99

\section{1,LUM}

121

FSTL3,SCARF2,EMILIN2

,ACTN1,TRIM29,DYSF,

TGBL1,FAP,LRFN4,SER

PINE2,FBN1,ACAN,SPO

N2,AGT,ANTXR1,CCR1,

PLAU,FLRT2,GPNMB,PL

EK,MMP14,PLXNA1,CO

L1 A1,COL3A1,SELE,SEL

L,ONECUT2,COL5A1,ZN

F703,NID2,COL6A3,COL

7A1,COL8A1,ITGA11,CO

L12A1,SFRP2,COL15A1,

COL16A1,ANGPT2,FN1,

COMP,TNC,PODXL,ICA

M1,MXRA8,COL5A3,CC

DC80,C2CD4A,CLDN4,C

LDN3,CLDN7,PDPN,CSF

3R,IGFBP7,VCAN,HAPL

N3,IGSF9B,IL2RA,IL6,M

YB,BOC,CLSTN3,MYH1

0,IDO1,SPOCK1,SPP1,PI

EZO1,LRRC32,ISLR,ITG

A5,PARVG,ITGAX,RCC2

,ITGB8,CD84,SRPX2,AD

AMTS9,PTPRO,NTM,GLI

2,KIF14,NOTCH1,AMIG

O2,LILRB4,KIF26B,LAM

A5,MUC16,OMD,ADAM

12,OLR1,CLDN2,CLDN1,

ADAMTS12,HAVCR2,TG

FBI,COL18A1,TGM2,TH

BS1,THBS2,THBS4,THY

1,CELSR3,HMCN1,PLXN

C1,LOXL2,ENTPD1,SER

PINE1,KIRREL1,ROBO2,

DUSP10,GREM1,TNFAIP

6,AJUBA,LEF1,CDH3,CD

H11,CDH13,CDH17,MSL

N,EPHA3,EPHB1

EPHB2,CDX2,PDGFRB,C

D109,ACTN1,CHI3L1,DY

SF,PGF,MFAP2,FAP,AGT

,CXCL9,CTHRC1,PLAU, GPNMB,ALDH1 A3,MMP 9,MMP14,FOXC1,COL1A 1,COL4A1,COL4A2,COL 5A1,COL5A2,COL7A1,C

OL8A1,COL11A1,COL12 A1,SFRP2,COL15A1,AN GPT2,FN1,PODXL,MTHF D1L,GDF15,WNT2,VASH 1,MYOM3,OSR2,STIL,X RCC2,AQP1,PDPN,CSF3 R,PRKDC,IL6,MYH10,SP ARC,HTRA1,INHBA,ITG A5,NEB,ITGAX,PTGS2,I TGB8,LRP8,SRPX2,APL

N,ADAMTS9,SULF1,SPH K1,GLI2,C3,C5AR1,STR A6,NOP2,NOTCH1,NOT CH3,WDR72,TCOF1,PLX DC1,KIF26B,LAMA5,ES M1,SALL4,TEAD4,TYMP ,ADAM12,EDNRA,FMNL 3,TGFBI,LIF,COL18A1,H EYL,TGM2,THBS1,THBS 2,THBS4,THY1,EGR2,LO XL2,SERPINE1,TREM2,R OBO2,TNFAIP2,GREM1, 
bioRxiv preprint doi: https://doi.org/10.1101/2020.12.20.423656; this version posted December 23, 2020. The copyright holder for this preprint (which was not certified by peer review) is the author/funder. All rights reserved. No reuse allowed without permission.

GO:0072359

development

LEF1,CDH13,EPHB1 EPHB2,CDX2,PDGFRB,P DLIM7,CHI3L1,DYSF,PG F,HOXA13,FAP,FBN1,AC AN,AGT,ANTXR1,PLAU, FLRT2,GPNMB,MMP9,M MP14,BICC1,FOXC1,CO L1A1,COL1A2,COL3A1,F OXM1,COL4A1,FOXS1,C OL4A2,COL5A1,COL8A1 ,PRRX1,COL11A1,SFRP2 ,COL15A1,ANGPT2,FN1, COMP,WNT2,VASH1,M YOM3,NOX4,STIL,APOE ,AQP1,PDPN,VCAN,PRK DC,IL6,MYH10,SPARC,I TGA5,NEB,ITGAX,PTGS 2,ITGB8,SRPX2,APLN,A DAMTS9,SULF1,SPHK1, GLI2,C3,C5AR1,STRA6, NOTCH1,NOTCH3,CAD, PLXDC1,LAMA5,ESM1,S ALL4,TYMP,ADAM12,E DNRA,FMNL3,TGFBI,LI F,COL18A1,HEYL,THBS 1,THBS2,SH3PXD2B,TH BS4,THY1,LOXL2,SERPI NE1,ROBO2,ELN,TNFAI P2,GREM1,LY6E,LEF1,C DH13,EPHA3,EPHB1 PRR5L,PDGFRB,TRPM2, CLEC7A,DYSF,F2R,PGF, ITGBL1,FAP,HOXB9,SE RPINE2,FCER1G,ANLN, ACAN,AGT,CXCL9,ASP M,CTHRC1,CCL3,CCR1, PLAU,FLRT2,MMP1,GP NMB,CCL18,FGR,MMP9, MMP14,CXCL6,PLXNA1, FOXC1,COL1A1,COL1A2 ,COL3A1,SELE,SELL,SE MA6B,VIL1,ONECUT2,C OL5A1,ZNF703,ITGA11, SFRP2,ANGPT2,FN1,PO DXL,ICAM1,VASH1,IFIT M1,NOX4,APOE,AQP1,P DPN,MAPK 15,CSF3R,VC AN,FSCN1,IL6,DOCK4,M YH10,SPARC,EPPK1,SP OCK1,SPP1,ITGA5,ITGA X,PTGS2,RCC2,ITGB8,L RP8,CD84,SRPX2,ADAM TS9,PTPRO,SULF1,SPHK 1,KIF14,FAM83D,C5AR1, NOTCH1,PLA2G7,DPYS L3,CD248,LAMA5,CXCL 1,OLR1,EDNRA,ADAMT S12,FMNL3,COL18A1,T HBS1,THBS4,THY1,CEL SR3,TIMP1,PLXNC1,LO XL2,SERPINE1,TREM2,T REM1,DUSP10,GREM1,T NFAIP6,AJUBA,LEF1,PA DI2,CDH13,EPHA3,EPHB 1 PRR5L,PDGFRB,TRPM2, CLEC7A,DYSF,F2R,PGF, ADCY3,ITGBL1,FAP,HO XB9,SERPINE2,FCER1G, ANLN,ACAN,AGT,CXCL 
9,ASPM,CTHRC1,CCL3, CCR1,PLAU,FLRT2,MM P1,GPNMB,CCL18,FGR, MMP9,MMP14,CXCL6,P LXNA1,FOXC1,COL1A1, COL1A2,COL3A1,SELE, SELL,SEMA6B, VIL1,ON ECUT2,COL5A1,ZNF703, ITGA11,SFRP2,ANGPT2, FN1,PODXL,ICAM1,VAS H1, IFITM1, NOX4,CLDN7 ,APOE,AQP1,PDPN,MAP K15,CSF3R, VCAN,FSCN 1,IL6,DOCK4,MYH10,SP ARC,EPPK1,SPOCK1,SP P1,ITGA5,ITGAX,PTGS2, RCC2,ITGB8,LRP8,CD84, SRPX2,ADAMTS9,PTPR O,SULF1,SPHK1,KIF14,F AM83D,C5AR1,NOTCH1, PLA2G7,CACNA1E,DPY SL3,CD248,LAMA5,CXC L1,OLR1,EDNRA,ADAM TS12,FMNL3,COL18A1,T HBS 1,THBS4,THY1,CEL SR3,TIMP1,PLXNC1,LO XL2,SERPINE1,TREM2,T REM1,DUSP10,GREM1,T NFAIP6,AJUBA,LEF1,PA DI2,CDH13,EPHA3,EPHB 1

EPHB2,CDX2,PDGFRB,E TV4,MDFI,PGF,FANCD2, HOXA13,MFAP2,SERPIN B5,FBN1,MGP,ACAN,AG T,RECQL4,SNX10,MKI67 ,CTHRC1,PLAU,FLRT2,F GR,ALDH1 A3,MMP14,M MP16,PLXNA1,FOXC1,C OL1A1,COL1A2,COL3A1 ,ONECUT2,COL5A1,COL 5A2,COL6A3,COL7A1,C OL8A1,PRRX1,COL11A1 ,COL12A1,SFRP2,SFRP4, COMP,TNC,MTHFD1L, WNT2,MYOM3,OSR2,ST IL,AQP1,CSF3R,IL6,HTR A1,INHBA,ASPN,ITGAX, BMP1,SULF2,SULF1,GLI 2,STRA6,NOTCH1,WDR7 2,KIF26B,LAMA5,TYMP SERPINH1,EDNRA,TNF RSF11B,LIF,COL18A1,H EYL,TGM2,THBS1,SH3P XD2B,THY1,CELSR3,P2 RX7,SERPINE1,ROBO2,E LN,GREM1,LY6E,LEF1,E PHB 1

CDX2,PDGFRB,ATAD5, CD109,CLEC7A,ETV4,D YSF,F2R,PGF,FAP,SERPI NB5,SERPINE2,CAMK2 N1,AGT,RECQL4,CXCL9 ,ASPM,CTHRC1,PLAU,G PNMB,MMP7,MMP9,IQG AP3,FOXM1,ZNF703,PR RX1,SFRP2,SFRP4,FN1,C OMP,TNC,WNT2,VASH1 ,OSR2,IFITM1,NOX4,CL DN7,APOE,LGR5,AQP1,P 
$\mathrm{BP}$

positive
regulation of
developmental
process

GO:0001775 4

8.96-14 $\quad$ E-12 $\quad 8.38 \mathrm{E}-11 \quad 2.88 \mathrm{E}-10$

DPN,MAPK15,IGFBP7,M TBP,PRKDC,IL2RA,IL6, H19,MYB,IL11,SPARC,H TRA1,EPPK1,IDO1,INHB A,LRRC32,ITGAX,PTGS 2,RTKN2,SULF2,APLN,S ULF1,SPHK1,GLI2,NRK, KIF14,C5AR1,NOP2,NOT CH1,NOTCH3,RARRES1, CD248,LAMA5,MUC16,E SM1,E2F3,SLC39A10,CX CL1,EDNRA,CCND2,HA VCR2,ORC1,LIF,COL18A 1,TGM2,OSM,THBS1,TH BS4,TIMP1,CDCA7,SERP INE1,DUSP10,ELN,GRE M1,OSMR,CDC6,CDC25 B,LEF1,CDH3,CDH13,EP HB1 EPHB2,PDE3A,CDX2,PD GFRB,ATAD5,PDLIM7,C LEC7A,CHI3L1,PGF,SER PINE2,AGT,CXCL9,ASP M,CTHRC1,CCL3,CCR1, FLRT2,MMP9,MMP14,IQ GAP3,PLXNA1,FOXC1,C OL1A1,FOXS1,VIL1,ZNF 703,SFRP2,SFRP4,ANGP T2,FN1,GDF15,WNT2,EN C1,PKDCC,OSR2,IFITM1 ,XRCC2,APOE,AQP1,CR ABP2,MSR1,PDPN,PRKD C,IL2RA,IL6,MYB,BOC, CLSTN3,IDO1, INHBA,IT GA5,ITGAX,PTGS2,ITGB 8,LRP8,BMP1,GDPD5,SR PX2,ADAMTS9,SPHK1,G LI2,C3,C5AR1,NOTCH1, AMIGO2,LILRB4,DPYSL 3,KRT17,TEAD4,ADAM1 2,ECT2,EDNRA,LIF,HEY L,THBS1,THBS2,SH3PX D2B,P2RX7,PLXNC1,LO XL2,SERPINE1,TREM2,R OBO2,DUSP10,GREM1,L EF1,EPHA3,EPHB1 LPCAT1,PDGFRB,ATAD 5,ABCA13,CLEC5A,TRP M2,CLEC7A,DGKH,ACT N1,CHI3L1,DYSF,F2R,F2 RL2,FANCD2,SERPINE2, FCER1G,FCGR2A,FCGR 3A,FCGR3B,AGT,CCL3,P LAU,GPNMB,FGR,PLEK, MMP9,MMP14,CXCL6,C OL1A1,COL1A2,COL3A1 ,SELL,FN1,COMP,CD300 LF,FPR1,ICAM1,KCNAB 2,APOE,SLC2A3,PDPN,S LC11A1,PRKDC,CTSB,IL 2RA,IL6,MYB,IL11,IDO1, INHBA,LRRC32,ITGAX, CD84,SPHK1,GLI2,C3,AT P11A,C5AR1,LILRB4,LIL RB3,RAB31,SLC39A10,L CP2,NFAM1,CXCL1, OLR 1,HAVCR2,THBS1,THY1, P2RX7,TIMP1,ENTPD1, T REM2,EXO1,DUSP10,TN FAIP6,LEF1,PADI2,PIK3 
bioRxiv preprint doi: https://doi.org/10.1101/2020.12.20.423656; this version posted December 23, 2020. The copyright holder for this preprint (which was not certified by peer review) is the author/funder. All rights reserved. No reuse allowed without permission.

GO:0009719

GO:0019220

GO:0031012
BP

response to
endogenous

stimulus

2.73E-11 3.37E-09 3.15E-08 $1.72 \mathrm{E}-07$

BP

regulation of

phosphate

metabolic

process
3.84E-10 3.72E-08 3.47E-07 2.42E-06

$2.42 \mathrm{E}-06$
90

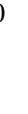

R5,CDH17,EPHB1 ABCA1,PDE3A,FSTL3,P DGFRB,TRPM2,CD109,M CM7,PGF,ADCY3,HOXA 13,NOD1,FBN1,FCER1G, AGT,FLRT2,BMP8A,FBX O32,MMP14,FOXC1,COL 1A1,COL1A2,COL3A1,C OL4A1,COL4A2,VIL1,O NECUT2,COL5A2,ZNF70 3,MXRA5,SFRP2,SFRP4, COL16A1,CHRDL2,COM P,TNC,GDF15,WNT2,ICA M1,NOX4,CLDN4,APOE, CPS1,LGR5,AQP1,AQP9, MAPK15,IGFBP7,STC2,P RKDC,CTSB,IL6,SPARC, HTRA1,INHBA,SPP1,AS PN,LRRC32,NCF2,PMEP A1,PTGS2,SULF2,APLN, SULF1,SLC39A5,NOTCH 1,CAD,RAB31,CALD1,H TRA3,CLDN1,ADAMTS1 2,HEYL,THBS1,FSTL1,P2 RX7,TIMP1,EGR2,SERPI NE1,TREM2,ROBO2,LTB P2,GREM1,LY6E,CDC6,L EF1,PADI2,CDH13,EPHA 3 EPHB2,PIK3AP1,LPCAT1 ,PRR5L,PDGFRB,CD109, MCM7,DGKH,MDFI,CHI 3L1,F2R,PGF,ADCY3,NO D1,CAMK2N1,FCGR1A, AGT,PPP1R1B,CCL3,CC R1,ABCD1,GPNMB,BMP 8A,CCL18,FGR,PLEK,M MP9,PLK1,IQGAP3,FOX M1,SFRP2,SFRP4,FN1,G DF15,FPR1,ICAM1,NOX4 ,APOC1,STIL,APOE,MAP K15,SLC11A1,VCAN,TP X2,PRKDC,CLSPN,IL6,IL 11,INHBA,ITGA5,PMEP A1,PTGS2,LRP8,CD84,C DCA2,FNDC1,SRPX2,AP LN,SPHK1,NRK,KIF14,F AM83D,C3,C5AR1,NOTC H1,SLC39A10,LCP2,ECT 2,EDNRA,CCND2,PKMY T1,CCNF,HAVCR2,LIF,O SM,THBS1,THBS4,THY1, CELSR3,P2RX7,ENTPD1, TREM2,KIRREL1,DUSP1 0,GREM1,CDC6,CDC25B ,AJUBA,PIK3R5,EPHB1 EMILIN2,CHI3L1,MFAP2 ,SERPINE2,SERPINB9,F BN1,MGP,AEBP1,ACAN, SPON2,AGT,CTHRC1,FL RT2,MMP1,MMP3,MMP7 ,MMP9,MMP11,MMP14, MMP16,COL1A1,COL1A 2,COL3A1,COL4A1,COL 4A2,COL5A1,COL5A2,NI D2,COL6A3,COL7A1,CO L8A1,COL10A1,COL11A 1,MXRA5,COL12A1,SFR P2,COL15A1,COL16A1,F N1,COMP,ADAMTS4,AD 
GO:0062023

GO:0005788

$\mathrm{CC}$

endoplasmic reticulum

lumen collagen-
containing extracellular matrix
$1.56 \mathrm{E}-40 \quad 4.71 \mathrm{E}-38 \quad 3.29 \mathrm{E}-37 \quad 9.41 \mathrm{E}-38$

$5.71 \mathrm{E}-1$

1

$1.15 \mathrm{E}-16$

8.03E- 16

3.45E-16

40

(1)

Al

AMTS2,TNC,GDF15,OLF ML2B,WNT2,ICAM1,CO L5A3,CCDC80,CPZ,APO E,IGFBP7,VCAN,HAPLN 3,CTSB,SPARC,HTRA1,A SPN,LRRC32,BGN,BMP1 ,SRPX2,PXDN,ADAMTS 9,SULF1,CD248,LAMA5, OMD,SERPINH1,TNFRS F11B,TGFBI,COL18A1,T GM2,THBS1,THBS2,THB S4,ANGPTL2,HMCN1,PL XDC2,TIMP1,LOXL2,EN TPD1,SERPINE1,LTBP2, ELN,GREM1,LUM,CDH1 3,PCOLCE

EMILIN2,MFAP2,SERPI NE2,SERPINB9,FBN1,M GP,AEBP1,ACAN,AGT,C THRC1,MMP9,COL1A1, COL1A2,COL3A1,COL4 A1,COL4A2,COL5A1,CO L5A2,NID2,COL6A3,COL 7A1,COL8A1,COL10A1,C OL11A1,MXRA5,COL12 A1,SFRP2,COL15A1,COL 16A1,FN1,COMP,ADAM TS4,ADAMTS2,TNC,GD F15,WNT2,ICAM1,COL5 A3,CCDC80,APOE,IGFB P7,VCAN,CTSB,SPARC, HTRA1,ASPN,BGN,BMP 1,SRPX2,PXDN,ADAMT S9,SULF1,LAMA5,OMD, SERPINH1,TGFBI,COL18 A1,TGM2,THBS1,THBS2, THBS4,ANGPTL2,HMCN 1,PLXDC2,TIMP1,LOXL2 ,ENTPD1,SERPINE1,LTB P2,ELN,GREM1,LUM,CD H13,PCOLCE

FSTL3,FBN1,COL1A1,C OL1A2,COL3A1,COL4A1 ,COL4A2,FKBP10,COL5 A1,COL5A2,COL6A3,CO L7A1,COL8A1,COL10A1, COL11A1,COL12A1,COL 15A1,COL16A1,FN1,GPX 8,TNC,MXRA8,COL5A3, APOE,IGFBP7,STC2,VC AN,IL6,SPP1,P4HA3,PTG S2,CYP2W1,C3,SERPINH 1,COL18A1,THBS1,FSTL 1,TIMP1,RCN3,MSLN ABCA1,PDGFRB,CLEC5 A,CD109,CLEC7A,F2R,IT GBL1,FAP,LRFN4,SERPI NE2,FCER1G,FCGR1A,F CGR3A,LIPG,CXCL9,AN TXR1,CCR1,PLAU,MMP 7,MMP16,SELL,NID2,SF RP4,WNT2,ICAM1,MXR A8,APOE,SLC1 A3,PDPN, SLC11A1,CSF3R, VCAN, CTSB,IL2RA,IL6,BOC,CL STN3,SPARC,LRRC32,IT GA5,ITGAX,ITGB8,BGN, CYP2W1,LRP8,SRPX2,S ULF2,ADAMTS9,SULF1, MRC2,NTM,C3,C5AR1,N 
GO:0031226

GO:0099080

GO:0030054
CC

intrinsic component of plasma

membrane
6.28E-08 3.45E-06 2.41E-05 3.79E-05 $3.79 \mathrm{E}-05$
$\mathrm{CC}$

supramolecula r complex
1.39E-0

6.6
$6.67 \mathrm{E}-06$

4.66E-05
8.42E-05

(2)

67

OTCH1,NOTCH3,CD248, MUC16,NFAM1,HAVCR 2,THBS1,THY1,P2RX7,E NTPD1,ROBO2,GREM1, OSMR,CDH3,CDH11,CD H13,CDH17,MSLN EPHB2,ABCA1,IGSF6,PD GFRB,CLEC5A,TRPM2,S LC24A3,F2R,F2RL2,ADC Y3,ITGBL1,LRFN4,FCER 1G,FADS2,CCR1,FLRT2, GPNMB,MMP14,MMP16, PLXNA1,SELE,SELL,SE MA6B,ITGA11,PODXL,I CAM1,KCNAB2,NOX4,C LDN4,CLDN3,LGR5,AQP 1,SLC1A3,AQP9,SLC2A3, MSR1,PDPN,SLC11A1,C SF3R,IL2RA,IL6,BOC,CL STN3,LRRC32,SLC28A3, NCF2,ITGA5,ITGAX,ITG B8,LAPTM5,GGT5,CD84, PTPRO,C5AR1,STRA6,S LC39A5,NOTCH1,NOTC H3,CACNA1E,LILRB3,G RIN2D,SLC39A10,OLR1, CLDN1,EDNRA,TGM2,T HY1,P2RX7,PLXNC1,EN TPD1,TREM2,OSMR,GP R176,CDH17,EPHA3,EPH B1

MAP1A,CENPF,NEIL2,P DLIM7,ACTN1,DYSF,KR T80,MFAP2,TUBB3,FBN 1,ASPM,ANTXR1,FBXO3 2,PLK1,COL1A1,COL1A2 ,COL3A1,COL4A1,COL4 A2,VIL1,COL5A1,COL5A 2,COL6A3,COL7A1,COL 8A1,KIF23,COL11A1,PO DXL,MYOM3,KCNAB2, GAS7,NOX4,COL5A3,AP OE,AQP1,PDPN,MAPK15 ,TPX2,KIF18B,FSCN1,AH NAK2,DOCK4,KIF21B,K NTC1,MYH10,EPPK1,ID O1,MYO7B,KIF4A,NEB, RCC2,CEP170,NEK2,GLI 2,KIF14,DNM1,KIF2C,DP YSL3,CALD1,KRT17,KIF 26B,KIF20A,IFFO2,ELN, CKAP2,LUM,EPHB 1 PDGFRB,SCARF2,PDLI M7,ACTN1,TRIM29,ITG BL1,FAP,CAMK2N1,PLA U,FLRT2,MMP14,IQGAP 3,ITGA11,KIF23,TNC,PO DXL,ICAM1,MXRA8,KC NAB2,NOX4,CLDN4,CL DN3,CLDN7,PDPN,MAP K15,RAI14,IGSF9B,FSCN 1,EPPK1,ITGA5,PARVG,I TGB8,FNDC1,SRPX2,SP HK1,MRC2,NOTCH1,PL XDC1,GRIN2D,LCP2,EC T2,CLDN2,CLDN1,CCNF ,HAVCR2,TGM2,SH3PX D2B,THY1,HMCN1,P2R X7,LZTS1,KIRREL1,ILD R1,TNS4,AJUBA,CDH3,C 
bioRxiv preprint doi: https://doi.org/10.1101/2020.12.20.423656; this version posted December 23, 2020. The copyright holder for this preprint (which was not certified by peer review) is the author/funder. All rights reserved. No reuse allowed without permission.

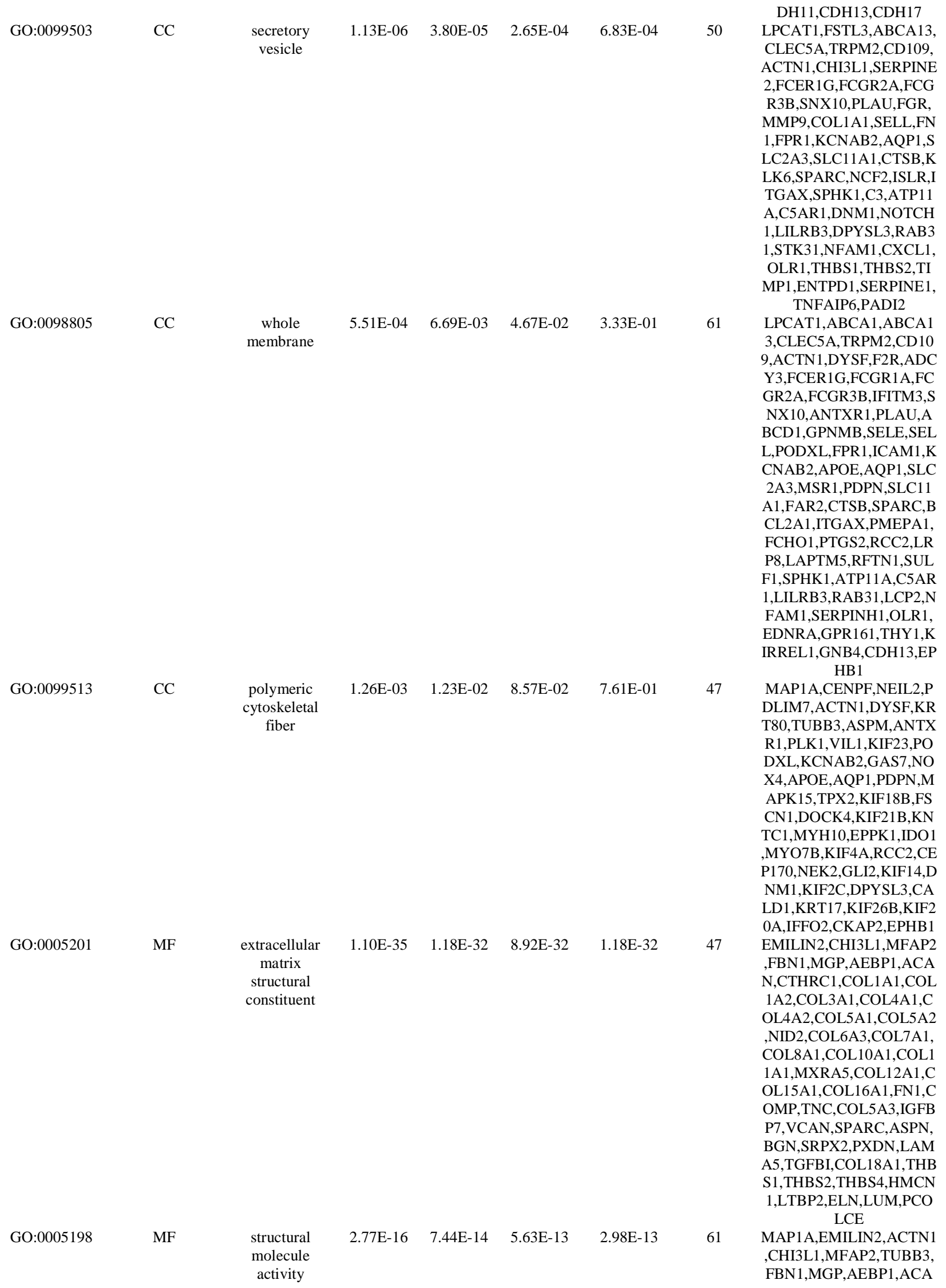




\begin{tabular}{|c|c|c|c|c|c|c|c|c|}
\hline GO:0005102 & MF & $\begin{array}{c}\text { signaling } \\
\text { receptor } \\
\text { binding }\end{array}$ & $5.39 \mathrm{E}-10$ & 7.24E-08 & $5.47 \mathrm{E}-07$ & 5.79E-07 & 86 & $\begin{array}{c}\text { N,LUM,PCOLCE } \\
\text { EPHB2,PIK3AP1,ABCA1, } \\
\text { MAP1A,PDGFRB,CLEC7 } \\
\text { A,ACTN1,CHN1,F2R,PGF } \\
\text {,TUBB3,ITGBL1,FAP,SE } \\
\text { RPINE2,FBN1,FCGR1A,S } \\
\text { PON2,AGT,PPP1R1B,CX } \\
\text { CL9,CTHRC1,CCL3,FLR } \\
\text { T2,GPNMB,BMP8A,CCL } \\
\text { 18,FGR,MMP9,MMP14,C } \\
\text { XCL6,COL3A1,SEMA6B, } \\
\text { COL5A1,SFRP2,COL16A } \\
\text { 1,ANGPT2,FN1,COMP,C } \\
\text { D300LF,PILRA,GDF15,W } \\
\text { NT2,FPR1,ICAM1,APOE, } \\
\text { AQP1,PDPN,STC2,IL6,D } \\
\text { KK2,DOCK4,IL11,INHB } \\
\text { A,SPP1,ITGA5,ITGAX,IT } \\
\text { GB8,BMP1,SRPX2,PXDN } \\
\text {,APLN,C3,DNM1,NOTCH } \\
\text { 1,KRT17,LAMA5,ESM1,T } \\
\text { YMP,CXCL1,TNFRSF11 } \\
\text { B,TGFBI,LIF,OSM,THBS } \\
\text { 1,THBS4,ANGPTL2,THY } \\
\text { 1,P2RX7,TIMP1,PLXNC1, } \\
\text { SERPINE1,GREM1,LY6E } \\
\text {,LEF1,PADI2,CDH17 }\end{array}$ \\
\hline GO:0008233 & MF & $\begin{array}{l}\text { peptidase } \\
\text { activity }\end{array}$ & $1.39 \mathrm{E}-07$ & 7.13E-06 & $5.39 \mathrm{E}-05$ & $1.50 \mathrm{E}-04$ & 62 & $\begin{array}{c}\text { CD109,CLEC7A,F2R,FAP } \\
\text {,SERPINB5,SERPINE2,N } \\
\text { OD1,SERPINB9,AEBP1,A } \\
\text { GT,ANTXR1,PLAU,MMP } \\
\text { 1,MMP3,MMP7,MMP9,M } \\
\text { MP11,MMP14,MMP16,VI } \\
\text { L1,COL6A3,COL7A1,SFR } \\
\text { P2,FN1,ADAMTS4,ADA } \\
\text { MTS2,VASH1,CPZ,CPS1, } \\
\text { AQP1,CST1,ADAMTS14, } \\
\text { CLSPN,CTSB,ESPL1,CTS } \\
\text { K,IL6,KLK6,HTRA1,SPO } \\
\text { CK1,PTGS2,GGT5,BMP1, } \\
\text { ADAMTS9,C1R,C3,FOX } \\
\text { K1,RARRES1,RHBDF2,C } \\
\text { PXM2,HTRA3,ADAM12, } \\
\text { SERPINH1,PI15,ADAMT } \\
\text { S12,THBS1,TIMP1,SERPI } \\
\text { NE1,CPXM1,LEF1,RCN3, } \\
\text { PCOLCE }\end{array}$ \\
\hline GO:0098772 & MF & $\begin{array}{l}\text { molecular } \\
\text { function } \\
\text { regulator }\end{array}$ & $3.16 \mathrm{E}-06$ & $1.10 \mathrm{E}-04$ & $8.30 \mathrm{E}-04$ & $3.40 \mathrm{E}-03$ & 77 & $\begin{array}{c}\text { TRIO,CD109,CHI3L1,CH } \\
\text { N1,PGF,SERPINB5,SERP } \\
\text { INE2,NOD1,SERPINB9,F } \\
\text { BN1,CAMK2N1,AGT,PPP } \\
\text { 1R1B,CXCL9,CCL3,FLR } \\
\text { T2,GPNMB,BMP8A,CCL } \\
\text { 18,CXCL6,MMP16,SEMA }\end{array}$ \\
\hline
\end{tabular}




\begin{tabular}{|c|c|c|c|c|c|c|c|c|}
\hline GO:0016773 & MF & $\begin{array}{l}\text { phosphotransf } \\
\text { erase activity, } \\
\text { alcohol group } \\
\text { as acceptor }\end{array}$ & $5.21 \mathrm{E}-06$ & $1.65 \mathrm{E}-04$ & $1.24 \mathrm{E}-03$ & $5.60 \mathrm{E}-03$ & 62 & $\begin{array}{r}\text { „LEF1,PIK3R5,PCOLCE } \\
\text { EPHB2,TRIO,PDGFRB,D } \\
\text { GKH,MDFI,CHI3L1,F2R, } \\
\text { ADCY3,NOD1,CAMK2N } \\
\text { 1,FCGR1A,AGT,PPP1R1 } \\
\text { B,CCL3,GPNMB,FGR,PL } \\
\text { K1,IQGAP3,SFRP2,GDF1 } \\
\text { 5,FPR1,PKDCC,HKDC1, } \\
\text { NOX4,STIL,APOE,MAPK } \\
\text { 15,SLC11A1,TPX2,PRKD } \\
\text { C,CLSPN,IL6,PGM2L1,L } \\
\text { RP8,NEK2,SPHK1,NRK,B } \\
\text { UB1,BUB1B,KIF14,C5AR } \\
\text { 1,FOXK1,CAD,LCP2,STK } \\
\text { 31,ECT2,EDNRA,CCND2, } \\
\text { PKMYT1,CCNF,THBS1,T } \\
\text { HY1,P2RX7,TREM2,DUS } \\
\text { P10,GREM1,CDC6,CDC2 } \\
\text { 5B,AJUBA,PIK3R5,EPHA } \\
\text { 3,EPHB1 }\end{array}$ \\
\hline GO:0042802 & MF & $\begin{array}{c}\text { identical } \\
\text { protein } \\
\text { binding }\end{array}$ & $2.99 \mathrm{E}-05$ & $7.65 \mathrm{E}-04$ & $5.78 \mathrm{E}-03$ & $3.21 \mathrm{E}-02$ & 76 & $\begin{array}{l}\text { EPHB2,PIK3AP1,CENPF, } \\
\text { HJURP,DGKH,ACTN1,M } \\
\text { DFI,MCM10,TRIM29,TRI } \\
\text { P13,PGF,FAP,NOD1,FBN } \\
\text { 1,FCER1G,CCL3,ABCD1, } \\
\text { C1QTNF6,ALDH1 A3,PLE } \\
\text { K,MMP9,PLK1,COL1A1, } \\
\text { COL1A2,VIL1,COL7A1,F } \\
\text { N1,MTHFD1L,GDF15,OL } \\
\text { FML2B,MYOM3,CLDN4, } \\
\text { CLDN3,CLDN7,STIL,AP } \\
\text { OE,AQP1,SLC11 A1,STC2 } \\
\text {,POLQ,MYH10,HTRA1,I } \\
\text { NHBA,PIEZO1,BCAT1,B } \\
\text { CL2A1,PTGS2,CD84,BM } \\
\text { P1,SRPX2,APLN,GBP5,P } \\
\text { TPRO,DNM1,SDS,NOTC } \\
\text { H3,CAD,TYMP,ECT2,OL } \\
\text { R1,CLDN2,CLDN1,HEYL } \\
\text {,THBS1,HMCN1,P2RX7,E } \\
\text { NTPD1,ROBO2,ILDR1,G } \\
\text { REM1,PADI2,CDH3,CDH } \\
\text { 11,TOP2A,CDH13,CDH17 }\end{array}$ \\
\hline GO:0005524 & MF & ATP binding & 4.81E-04 & $9.75 \mathrm{E}-03$ & 7.37E-02 & $5.17 \mathrm{E}-01$ & 56 & $\begin{array}{l}\text { EPHB2,ABCA1,TRIO,PD } \\
\text { GFRB,ATAD5,ABCA13, } \\
\text { MCM2,MCM7,DGKH,TR } \\
\text { IP13,ADCY3,NOD1,REC } \\
\text { QL4,MKI67,ABCD1,FGR, } \\
\text { PLK1,RAD54L,KIF23,MT } \\
\text { HFD1L,PKDCC,HKDC1, } \\
\text { XRCC2,CPS1,ATAD2,M } \\
\text { APK15,CHTF18,PRKDC, } \\
\text { KIF18B,POLQ,KIF21B,M } \\
\text { YH10,MYO7B,KIF4A,NE }\end{array}$ \\
\hline
\end{tabular}


GO:0060089

$\mathrm{MF}$

molecular transducer

8.94E-0 activity
K2,SPHK1,NRK,BUB1,B UB1B,KIF14,ATP11A,KI F2C,CAD,KIF26B,UBE2C ,STK31,ATP10A,PKMYT 1,KIF20A,ORC1,P2RX7,E NTPD1,CDC6,TOP2A,EP HA3,EPHB1

65 EPHB2,ABCA1,IGSF6,PD GFRB,CLEC7A,F2R,F2R L2,CAMK2N1,FCER1G,F CGR1A,FCGR3A,ANTXR 1,CCR1,PLAU,PLK1,PLX NA1,SELE,ITGA11,FPR1, ICAM1,CLDN4,CLDN3,S TIL,LGR5,CSF3R,IL2RA, DKK2,ITGAX,ITGB8,LR P8,PXDN,PTPRO,SPHK1, MRC2,C5AR1,STRA6,NO TCH1,NOTCH3,LILRB4, LILRB3,KRT17,GRIN2D, NFAM1,EDNRA,TNFRSF 11B,CCND2,PKMYT1,CC NF,GPR161,CELSR3,HM CN1,P2RX7,PLXNC1,SE RPINE1,TREM2,TREM1, ROBO2,GREM1,OSMR,L Y6E,CDC6,LEF1,GPR176, EPHA3,EPHB1

ABCA1,ATAD5,ABCA13, TRPM2,MCM2,MCM7,C HN1,F2R,TUBB3,RECQL 4,CCL3,ABCD1,CCL18,I QGAP3,PLXNA1,RAD54 L,KIF23,PLEKHG4,ICAM 1,GINS4,XRCC2,ATAD2, CHTF18,KIF18B,POLQ,F GD6,DOCK4,KIF21B,MY H10,MYO7B,KIF4A,ARH GAP11A,GEM,RCC2,GB P5,KIF14,DNM1,KIF2C,R AB31,KIF26B,ARHGAP3 9,NCAPH,ECT2,RGS1,KI F20A,THY1,PLXNC1,EN TPD1,GNB4,AJUBA,TOP 2A,EPHA3

Biological Process(BP), Cellular Component(CC) and Molecular Functions (MF)

Table 6 The enriched GO terms of the down regulated differentially expressed genes

\begin{tabular}{|c|c|c|c|c|c|c|c|c|}
\hline GO ID & CATEGORY & GO Name & P Value & $\begin{array}{l}\text { FDR } \\
\text { B\&H }\end{array}$ & $\begin{array}{l}\text { FDR } \\
\text { B\&Y }\end{array}$ & Bonferroni & $\begin{array}{c}\text { Gene } \\
\text { Count }\end{array}$ & Gene \\
\hline GO:0007586 & $\mathrm{BP}$ & digestion & $8.97 \mathrm{E}-20$ & $4.55 \mathrm{E}-16$ & $4.14 \mathrm{E}-15$ & $4.55 \mathrm{E}-16$ & 30 & $\begin{array}{c}\text { PGA5,PGC,HRH2,ASA } \\
\text { H2,APOA1,APOA4,AQ } \\
\text { P5,SLC26A7,MUC6,C } \\
\text { APN9,CHIA,GHRL,VS } \\
\text { IG1,PBLD,SST,PTGER } \\
\text { 3,AKR1C1,AKR1C2,C } \\
\text { APN8,KCNQ1,PGA3,P } \\
\text { GA4,CCKAR,CCKBR, } \\
\text { TFF1,TFF2,SLC9A4,G } \\
\text { UCA2B,CD36,GKN1 }\end{array}$ \\
\hline GO:0006082 & BP & $\begin{array}{c}\text { organic acid } \\
\text { metabolic } \\
\text { process }\end{array}$ & $1.13 \mathrm{E}-14$ & $1.91 \mathrm{E}-11$ & $1.74 \mathrm{E}-10$ & $5.73 \mathrm{E}-11$ & 73 & $\begin{array}{c}\text { HGD,ACADL,GGT6,E } \\
\text { SRRB,CYP2S1,TST,M } \\
\text { E1,ADH1C,CKB,ADH7 } \\
\text {,CKM,CKMT2,FBP1,H } \\
\text { PGD,PLIN5,SMPD3,EL } \\
\text { OVL6,ALDOB,ALDOC } \\
\text {,ALDH6A1,ERO1B,FO } \\
\text { LR1,HYAL1,UGT1A10 }\end{array}$ \\
\hline
\end{tabular}


,ASAH2,FA2H,UGT1A 6,LIPF,PM20D1,APOA 4,APOC3,SLC9A1,PTG R1,PRKAA2,AKR1C3, CYP4F12,CYB5A,CYP 2C19,GALE,CYP2C8,C YP2C9,CYP2C18,CYP3 A4,CYP3A5,INSIG1,A CSM1,GCKR,GNMT,A KR1C1,AKR1C2,BHM T,XYLT2,LDHD,ADH FE1,SULT1B1,SULT1C 2,SULT2A1,MAMDC2, GLUL,NQO1,ANGPTL 3,GPT2,SLC16A9,GPT, B3GNT7,ADTRP,GST A1,SLC7A8,RGN,CD3 6,DHRS9,ENTPD5,HA process

$$
\text { S3 }
$$

AADAC,ACADL,CYP2

S1,TM6SF2,KLF4,FOX A2,ME1,TTR,ADH1C, ADH7,TFCP2L1,PIK3C 2G,LIPH,HPGD,PLIN5, SMPD3,ALDH1 A1,EL OVL6,PSAPL1,NR0B2, ANG,CWH43,ASAH2, GDPD3,FA2H,LIPF,PM 20D1,APOA1,APOA4, APOBEC1,APOC3,PTG R1,PRKAA2,AKR1C3, PLCXD3,CYP4F12,PR LR,CYB5A,ACER2,CY P2C19,CYP2C8,CYP2C 9,CYP2C18,CYP3A4,C YP3A5,INSIG1,ACSM1 GATA6,GDPD2,GC,A KR1C1,AKR1C2,BMP5 ,SULT1B1,SULT2A1,P TPRN2,DHCR24,AKR1 B10,ANGPTL3,SPTSS B,RDH12,ADTRP,LEP R,FAM135B,CCKBR,G STA1,EEF1A2,RGN,E NHO,CD36,DHRS9,AK R1B15,TM7SF2,B4GA LNT2,RORC A3,F2RL1,CKB,CCL28 ,HPN,TMEM38A,SCN N1B,SCNN1G,SMPD3, HOMER2,ATP13A4,ER O1B,FA2H,KLF15,SLC 26A9,APOA1,XK,APO A4,APOC3,SCGN,AQP 4,MT1E,MT1F,MT1G, MT1H,MT1M,SLC9A1, SLC9A2,MT1X,SLC9A 3,SCARA5,PRKAA2,C YP4F12,SLC4A4,ATP4 A,ATP4B,GHRL,MYO C,INSIG1,ACSM1,GC KR,PTGER3,AKR1C1, PTPRN2,CXCL17,ANG PTL3,TESC,CA2,CA4, ATP13A5,FAM3B,LEP R,CCKAR,CCKBR,TF R2,SLC7A8,RGN,SLC9 A4,OXCT1,CD36,LTF 
bioRxiv preprint doi: https://doi.org/10.1101/2020.12.20.423656; this version posted December 23, 2020. The copyright holder for this preprint (which was not certified by peer review) is the author/funder. All rights reserved. No reuse allowed without permission.

\begin{tabular}{|c|c|c|c|c|c|c|c|c|}
\hline GO:0055114 & $\mathrm{BP}$ & $\begin{array}{l}\text { oxidation- } \\
\text { reduction } \\
\text { process }\end{array}$ & $9.89 \mathrm{E}-10$ & $2.18 \mathrm{E}-07$ & $1.99 \mathrm{E}-06$ & $5.01 \mathrm{E}-06$ & 62 & $\begin{array}{c}\text { HGD,MAOA,ACADL, } \\
\text { ESRRB,CYP2S1,ME1, } \\
\text { ADH1C,ADH7,FBP1,H } \\
\text { PGD,PLIN5,PDIA2,AL } \\
\text { DH1A1,ALDH3A1,AL } \\
\text { DOB,ALDOC,ALDH6 } \\
\text { A1,FMO5,ERO1B,FA2 } \\
\text { H,LIPF,DUOX2,APOA } \\
\text { 1,PTGR1,DHRS7,PRK } \\
\text { AA2,AKR7A3,AKR1C } \\
\text { 3,CYP4F12,PRDM16,C } \\
\text { YB5A,CYP2C19,GALE } \\
\text {,CYP2C8,CYP2C9,CYP } \\
\text { 2C18,CYP3A4,CYP3A5 } \\
\text {,ACSM1,GCKR,GNMT } \\
\text {,AKR1C1,AKR1C2,LD } \\
\text { HD,DUOX1,ADHFE1, } \\
\text { DHCR24,AKR1B10,NQ } \\
\text { O1,SELENBP1,GPX3,R } \\
\text { DH12,LEPR,GSTA1,R } \\
\text { GN,CD36,DHRS9,ENT } \\
\text { PD5,AKR1B15,TM7SF } \\
\text { 2,MRAP2,HBB }\end{array}$ \\
\hline 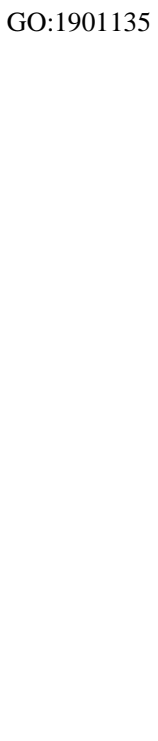 & $\mathrm{BP}$ & $\begin{array}{c}\text { carbohydrate } \\
\text { derivative } \\
\text { metabolic } \\
\text { process }\end{array}$ & $2.45 \mathrm{E}-07$ & $3.45 \mathrm{E}-05$ & $3.14 \mathrm{E}-04$ & $1.24 \mathrm{E}-03$ & 58 & $\begin{array}{c}\text { ESRRB,B3GALT5,FOX } \\
\text { A2,GCNT4,FBP1,SMP } \\
\text { D3,ALDH1A1,ELOVL6 } \\
\text {,ALDOB,ALDOC,COL } \\
\text { 2A1,AMPD1,CWH43,H } \\
\text { YAL1,FA2H,APOBEC1 } \\
\text {,APOC3,SLC9A1,GUC } \\
\text { A1C,PRKAA2,FUT9,A } \\
\text { KR1C3,B3GAT1,HS6S } \\
\text { T3,MUC1,MUC6,ATP4 } \\
\text { B,ACER2,ST6GALNA } \\
\text { C1,GALE,CHIA,ACSM } \\
\text { 1,FBP2,GCKR,GCNT1, } \\
\text { GCNT2,GNMT,AKR1C } \\
\text { 1,AKR1C2,XYLT2,B3 } \\
\text { GNT6,LDHD,SULT1B1 } \\
\text {,SULT1C2,SULT2A1, } \\
\text { MAMDC2,APOBEC2, } \\
\text { AKR1B10,MUC5B,B3 } \\
\text { GNT7,GUCA2B,ENTP } \\
\text { D5,B4GALNT2,A4GN } \\
\text { T,GALNT6,GALNT5,H } \\
\text { AS3,PDZD3 }\end{array}$ \\
\hline GO:0022610 & $\mathrm{BP}$ & $\begin{array}{l}\text { biological } \\
\text { adhesion }\end{array}$ & $8.56 \mathrm{E}-07$ & $9.87 \mathrm{E}-05$ & 8.99E-04 & 4.34E-03 & 63 & $\begin{array}{l}\text { LGALS9C,CLDN18,CO } \\
\text { L6A5,FOXA1,KLF4,FO } \\
\text { XA2,CCL28,FGA,FGB, } \\
\text { IGSF9,FGG,COL4A6,C } \\
\text { OL17A1,EPB41L4B,H } \\
\text { YAL1,ID1,APLP1,APO } \\
\text { A1,APOA4,GATA5,AQ } \\
\text { P4,HAPLN1,ARHGDIG } \\
\text {,SLC9A1,IGFALS,IGF } \\
\text { BP2,CSTA,SIGLEC1, } \\
\text { MUC1,ATP4B,PRLR,C } \\
\text { XADR,ACER2,SOX2,L } \\
\text { GALS9B,CDHR2,MYO } \\
\text { C,AZGP1,NCAM1,GC } \\
\text { NT1,GCNT2,PTGER3, } \\
\text { CADM2,BMP5,PTPRR, } \\
\text { PTPRZ1,ANGPTL3,TE } \\
\text { SC,UNC5D,AMTN,DP } \\
\text { T,RAP1GAP,DSC2,AD } \\
\text { TRP,CLDN23,HHLA2, } \\
\text { CD36,B4GALNT2,CNT } \\
\text { N3,REG3A,LTF,HBB,C } \\
\text { DH2 }\end{array}$ \\
\hline GO:0009719 & $\mathrm{BP}$ & response to & $2.12 \mathrm{E}-06$ & $2.11 \mathrm{E}-04$ & $1.92 \mathrm{E}-03$ & $1.08 \mathrm{E}-02$ & 71 & ERBB4,ESRRB,ESRRG \\
\hline
\end{tabular}


bioRxiv preprint doi: https://doi.org/10.1101/2020.12.20.423656; this version posted December 23, 2020. The copyright holder for this preprint (which was not certified by peer review) is the author/funder. All rights reserved. No reuse allowed without permission.

endogenous stimulus

secretion

GO:0046903

BP

secretion

GO: 1901700

BP oxygen-

containing

compound
,FOXA1,KLF4,ME1,KL F2,SCGB2A1,HPGD,H PN,TMEM38A,FGB,H RH2,SMPD3,ALDH3A 1,ALDOB,NR0B2,COL 2A1,COL4A6,HTR1E, ANG,FOLR1,HYAL1,S H3GL2,PAQR8,ID1,KL F15,SOSTDC1,APLP1, APOA1,APOBEC1,GA TA5,APOC3,SLC5A5,S LC9A1,IGFBP2,PDGF D,PRKAA2,AKR1C3,P RDM16,PRLR,GABRB 3,GHRL,GATA6,PBLD ,GCNT1,GCNT2,SST,S STR1,AKR1C1,AKR1C 2,BMP5,DHCR24,NQO 1,ANGPTL3,KCNQ1,C A2,CA9,RAP1GAP,VS TM2A,ADTRP,LEPR,C CKAR,TFF1,OXCT1,E NHO,CD36,REG3A,RO RC,CLEC3B,TMEM10 0

LGALS9C,ERBB4,CH GA,FOXA2,F2RL1,TT R,F13A1,PLAC8,S100P ,SERPINA4,FGA,FGB, HRH2,KRT20,SMPD3, FGG,ALDOC,NR0B2, METTL7A,ANG,SLC2 5A4,MYRIP,APOA1,S LC1A2,AQP5,STX19,S LC26A7,SCG3,RIMS4, SLPI,CYSTM1,RIMS1, SCIN,PRLR,CHIA,GH RL,LGALS9B,SYTL2, NCAM1,PTGER3,PTP RN2,IL1R2,GLUL,KC NQ1,RAB27A,RAB27B CA2,CA9,TCN1,FAM3 B,ADTRP,LEPR,CCKA R,CCKBR,TFF2,TFR2, SYT16,ORM1,ORM2,S LC9A4,OXCT1,ENHO, GUCA2B,SYTL5,CD36 ,RORC,CLEC3B,LTF,H $\mathrm{BB}, \mathrm{RAB} 37$

CLDN18,FOXA1,KLF4 ,FOXA2,ME1,KLF2,A DH7,HPGD,HRH2,SM

PD3,ALDH3A1,ALDO B,HOMER2,NR0B2,CO L4A6,HTR1E,FOLR1,H YAL1,ID1,KLF15,DUO $\mathrm{X} 2$,APLP1,APOA4,AP OBEC1,APOC3,AQP4, SLC1A2,SLC5A5,SLC9 A1,IGFBP2,PDGFD,PR KAA2,SLPI,AKR1C3,A TP4B,PRLR,ACER2,S OX2,GHRL,INSIG1,NC AM1,GCKR,GCNT1,SS T,SSTR1,PTGER3,AK R1C1,AKR1C2,DUOX1 ,PTPRN2,AKR1B10,GL UL,NQO1,KCNQ1,TES C,CA2,CA9,GPX3,RD H12,LEPR,TFF1,RGN, 
bioRxiv preprint doi: https://doi.org/10.1101/2020.12.20.423656; this version posted December 23, 2020. The copyright holder for this preprint (which was not certified by peer review) is the author/funder. All rights reserved. No reuse allowed without permission.

GO:0140352

GO:0071495

GO:0045177

CC
apical part of cell

\begin{abstract}
cellular response to endogenous stimulus
\end{abstract}

$3.05 \mathrm{E}-05$

$1.64 \mathrm{E}-03$

$.50 \mathrm{E}-02$

$1.55 \mathrm{E}-01$

3.59E-03 (2)

GO:0031012

CC

extracellular

$1.96 \mathrm{E}-07$

2.37E-05

$1.60 \mathrm{E}-04$

9.49E-05

OXCT1,ENHO,CD36,P ALM3,REG3A,RORC, LTF,HBB

LGALS9C,CHGA,FOX A2,F2RL1,TTR,F13A1, PLAC8,S100P,SERPIN A4,FGA,FGB,KRT20,S MPD3,FGG,ALDOC,N R0B2,METTL7A,ANG, SLC25A4,MYRIP,APO A1,SLC1A2,STX19,SL C9A1,SCG3,RIMS4,SL PI,CYSTM1,RIMS1,SC IN,ATP4A,ATP4B,CHI A,GHRL,LGALS9B,SY TL2,NCAM1,PTGER3, PTPRN2,IL1R2,GLUL, KCNQ1,RAB27A,RAB 27B, KCNE2,TCN1,FA M3B,ADTRP,LEPR,CC KAR,CCKBR,TFR2,SY T16,ORM1,ORM2,OX CT1,ENHO,SYTL5,CD 36,RORC,CLEC3B,LTF ,HBB,RAB37

ERBB4,ESRRB,ESRRG ,FOXA1,KLF4,KLF2,S CGB2A1,HPGD,TMEM 38A,FGB,HRH2,SMPD 3,NR0B2,COL2A1,CO L4A6,HTR1E,FOLR1,H YAL1,SH3GL2,PAQR8 ,ID1,KLF15,SOSTDC1, APLP1,APOA1,APOBE C1,GATA5,SLC5A5,SL C9A1,IGFBP2,PDGFD, PRKAA2,AKR1C3,PR DM16,PRLR,GABRB3, GHRL,GATA6,PBLD, GCNT2,SST,SSTR1,A KR1C1,AKR1C2,BMP5 ,KCNQ1,CA2,RAP1GA P,VSTM2A,ADTRP,LE PR,CCKAR,ENHO,CD 36,RORC,CLEC3B,TM EM100

MAL,PROM2,HPN,UP K1B,SCNN1B,SCNN1 G,HOMER2,DUOXA2, PAPPA2,EPB41L4B,FO LR1,MYRIP,SLC26A9, DUOX2,AQP5,SLC9A1 ,SLC9A3,IGFBP2,PRK AA2,CYP4F12,MUC1, ATP4A,CDHR2,DUOX 1,RAB27A,RAB27B,C A2,CA4,AQP10,SLC9A 4,CD36,PDZD3,CDH2 COL6A5,F13A1,FGA,F GB,FGG,COL2A1,COL 4A6,ANG,COL17A1,A PLP1,APOA1,APOA4, APOC3,HAPLN1,IGFA LS,SLPI,MUC1,MUC6, MYOC,AZGP1,NCAM 1,PTPRZ1,MAMDC2,S EMA3B,ADAMTS15,A MTN,DPT,ADAMTSL1 ,ENAM,ORM1,ORM2, CCBE1,CLEC3B,CDH2 
bioRxiv preprint doi: https://doi.org/10.1101/2020.12.20.423656; this version posted December 23, 2020. The copyright holder for this preprint (which was not certified by peer review) is the author/funder. All rights reserved. No reuse allowed without permission.

\begin{tabular}{|c|c|c|c|c|c|c|c|c|}
\hline GO:0031226 & $\mathrm{CC}$ & $\begin{array}{c}\text { intrinsic } \\
\text { component of } \\
\text { plasma } \\
\text { membrane }\end{array}$ & $3.99 \mathrm{E}-06$ & $3.21 \mathrm{E}-04$ & $2.17 \mathrm{E}-03$ & $1.93 \mathrm{E}-03$ & 65 & $\begin{array}{c}\text {,SERPINA5 } \\
\text { ERBB4,VSIG2,F2RL1, } \\
\text { CLCNKA,PROM2,HPN } \\
\text {,UPK1B,KIAA1324,SC } \\
\text { NN1B,SCNN1G,HRH2, } \\
\text { FXYD3,SHISA6,HTR1 } \\
\text { E,COL17A1,SLC25A4, } \\
\text { FOLR1,ASAH2,SLC26 } \\
\text { A9,DUOX2,AQP4,SLC } \\
\text { 1A2,AQP5,SLC9A1,SL } \\
\text { C15A1,SLC26A7,SCA } \\
\text { RA5,SLC4A4,MUC1,S } \\
\text { LC2A12,ATP4A,ATP4 } \\
\text { B,CXADR,GABRB3,P } \\
\text { RSS8,CDHR2,NCAM1, } \\
\text { GPRC5C,SSTR1,PTGE } \\
\text { R3,DUOX1,PTPRN2,P } \\
\text { TPRZ1,KCNJ15,KCNJ1 } \\
\text { 6,SEMA3B,KCNQ1,EN } \\
\text { PP5,C6,CA4,KCNE2,A } \\
\text { QP10,SLC16A9,GRIA4 } \\
\text {,LEPR,PRIMA1,CCKA } \\
\text { R,TSPAN1,TFR2,SLC7 } \\
\text { A8,LIFR,CD36,SLC28 } \\
\text { A2,TM7SF2,TMPRSS2, } \\
\text { HAS3,CDH2,SLC16A7, } \\
\text { PTGDR2 }\end{array}$ \\
\hline GO:0009986 & $\mathrm{CC}$ & cell surface & $2.47 \mathrm{E}-04$ & $9.93 \mathrm{E}-03$ & $6.71 \mathrm{E}-02$ & 1.19E-01 & 41 & $\begin{array}{c}\text { BTNL8,PROM2,HPN,S } \\
\text { CNN1B,FGA,SCNN1G, } \\
\text { FGB,FGG,FOLR1,SLC } \\
\text { 26A9,DUOX2,APOA1, } \\
\text { APOA4,AQP4,SLC1A2 } \\
\text {,SLC9A1,SLC9A3,SCU } \\
\text { BE2,SCARA5,SIGLEC } \\
\text { 11,MUC1,PRLR,AZGP } \\
\text { 1,NCAM1,PTGER3,DU } \\
\text { OX1,ANGPTL3,ADAM } \\
\text { TS15,UNC5D,CA4,KC } \\
\text { NE2,ADTRP,LEPR,TF } \\
\text { R2,LIFR,HHLA2,CD36, } \\
\text { RORC,LTF,CDH2,SER } \\
\text { PINA5 }\end{array}$ \\
\hline GO:0099503 & $\mathrm{CC}$ & $\begin{array}{l}\text { secretory } \\
\text { vesicle }\end{array}$ & $9.58 \mathrm{E}-04$ & $2.01 \mathrm{E}-02$ & $1.36 \mathrm{E}-01$ & 4.63E-01 & 40 & $\begin{array}{c}\text { CHGA,CHGB,TTR,F13 } \\
\text { A1,PLAC8,S100P,SER } \\
\text { PINA4,FGA,FGB,FGG, } \\
\text { ALDOC,METTL7A,SH } \\
\text { 3GL2,MYRIP,APOA1, } \\
\text { STX19,SCG3,SLPI,CY } \\
\text { STM1,CXADR,GHRL, } \\
\text { KIF1A,SYTL2,PTPRN2 } \\
\text {,KCNQ1,RAB27A,RAB } \\
\text { 27B,CA4,KLK11,TCN1 } \\
\text {,ORM1,ORM2,SYTL5, } \\
\text { CD36,CLEC3B,LTF,G } \\
\text { KN1,HBB,RAB37,SER } \\
\text { PINA5 }\end{array}$ \\
\hline GO:0005789 & $\mathrm{CC}$ & $\begin{array}{l}\text { endoplasmic } \\
\text { reticulum } \\
\text { membrane }\end{array}$ & $1.17 \mathrm{E}-02$ & $1.30 \mathrm{E}-01$ & $8.77 \mathrm{E}-01$ & $1.00 \mathrm{E}+00$ & 36 & $\begin{array}{c}\text { AADAC,TMED6,ANO } \\
\text { 5,CYP2S1,TM6SF2,HP } \\
\text { N,TMEM38A,ELOVL6, } \\
\text { ALDOB,FXYD3,DUO } \\
\text { XA2,ATP13A4,FMO5, } \\
\text { ERO1B,FOLR1,UGT1A } \\
\text { 10,GDPD3,FA2H,UGT } \\
\text { 1A6,SLC9A1,B3GAT1, } \\
\text { CYP4F12,CYB5A,CYP } \\
\text { 2C19,CYP2C8,CYP2C9 } \\
\text {,CYP2C18,CYP3A4,CY } \\
\text { P3A5,INSIG1,DHCR24, } \\
\text { SPTSSB,RDH12,DHRS } \\
\text { 9,TM7SF2,MRAP2 }\end{array}$ \\
\hline
\end{tabular}


bioRxiv preprint doi: https://doi.org/10.1101/2020.12.20.423656; this version posted December 23, 2020. The copyright holder for this preprint (which was not certified by peer review) is the author/funder. All rights reserved. No reuse allowed without permission.

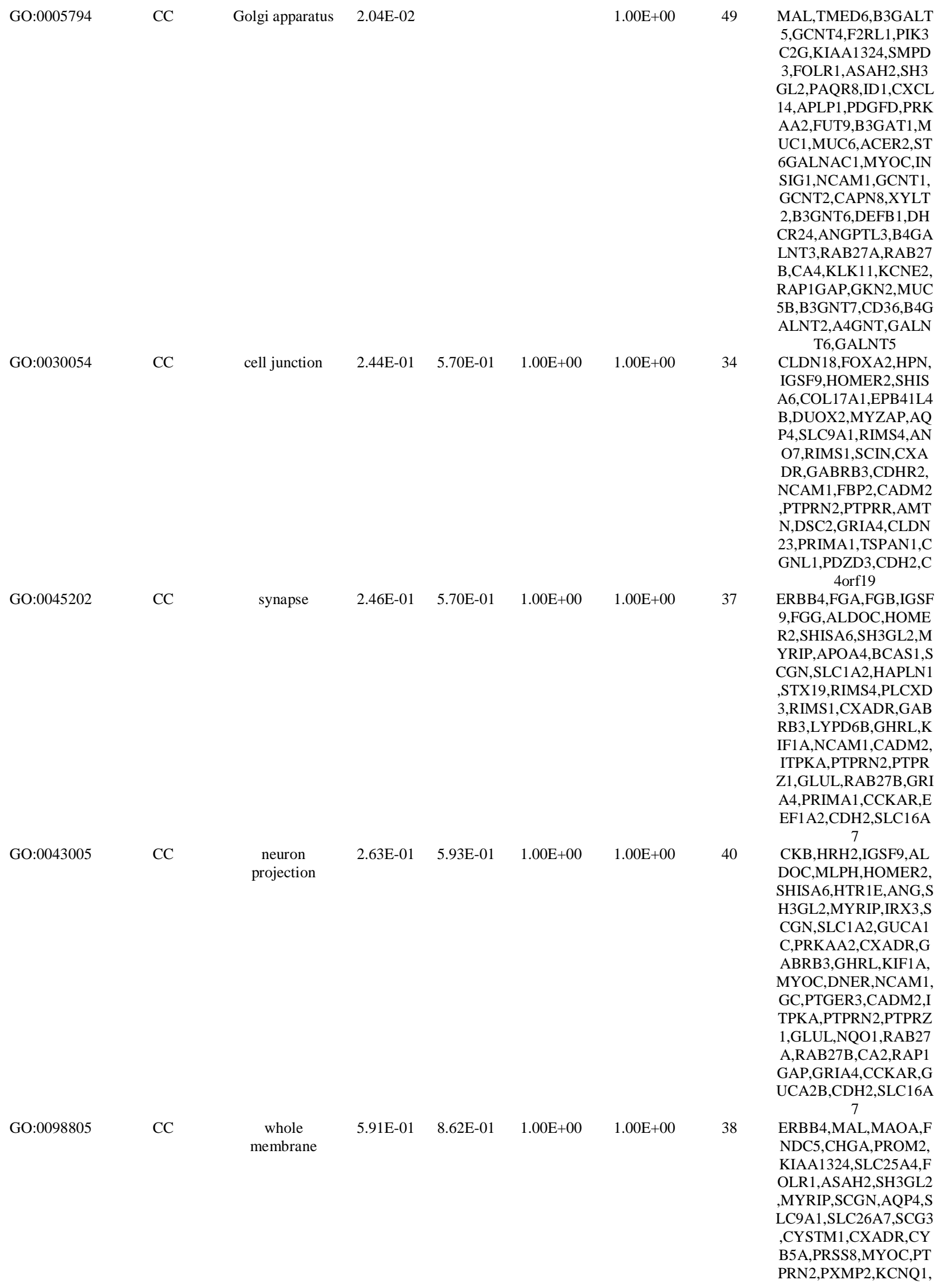


bioRxiv preprint doi: https://doi.org/10.1101/2020.12.20.423656; this version posted December 23, 2020. The copyright holder for this preprint (which was not certified by peer review) is the author/funder. All rights reserved. No reuse allowed without permission.

GO:0016491

MF

MF

transition metal ion binding oxidoreductase
activity

$1.21 \mathrm{E}-09 \quad 1.33 \mathrm{E}-06$
GO:0046914

GO:0015318

GO:0042802
MF

inorganic

molecular entity

transmembrane

transporter

activity
2.54E-04 6.18E-03

$4.68 \mathrm{E}-02$

2.78E-01

4.77E-04

9.94E- 03

$7.53 \mathrm{E}-02$

5.23E-01

42

44

RAB27A,RAB27B,CA4 ,REP15,GRIA4,ADTRP TSPAN1,EEF1A2,PLL P,CD36, RAB37,CDH2, SERPINA5

HGD,MAOA,ACADL, ESRRB,CYP2S1,ME1, ADH1C,ADH7,FBP1,H PGD,PDIA2,ALDH1A1 ,ALDH3A1,ALDOB,A LDOC,ALDH6A1,FMO 5,ERO1B,FA2H,LIPF,D UOX2,PTGR1,DHRS7, PRKAA2,AKR7A3,AK R1C3,CYP4F12,CYB5 A,CYP2C19,GALE,CY P2C8,CYP2C9,CYP2C1 8,CYP3A4,CYP3A5,GC KR,AKR1C1,AKR1C2, LDHD,DUOX1,ADHFE 1,DHCR24,AKR1B10, NQO1,SELENBP1,GPX 3,RDH12,GSTA1,RGN, DHRS9,ENTPD5,AKR1 B15,TM7SF2,HBB ESRRB,ESRRG,CYP2S 1,KLF4,ME1,ADH1C,A DH7,S100P,PAPPA2,A NG,ASAH2,FA2H,MY RIP,APLP1,CPA2,APO A4,APOBEC1,GATA5, MT1E,MT1F,MT1G,M T1H,MT1M,MT1X,CY P4F12,CYP2C19,CYP2 C8,CYP2C9,CYP2C18, CYP3A4,CYP3A5,GAT A6,ZNF385B,BHMT,X YLT2,GLUL,ADAMTS 15,TRIM50,CA2,CA4,C A9,RGN,RORC,LTF ANO5,CLCNKA,HPN, TMEM38A,SCNN1B,S CNN1G,FXYD3,SHISA 6,ATP13A4,SLC26A9, AQP4,SLC1 A2,AQP5,S LC5A5,SLC9A1,SLC9 A2,SLC9A3,SLC15A1, SLC26A7,ANO7,SLC4 A4,SLC2A12,ATP4A,A TP4B,CYB5A,GABRB 3,PRSS8,KCNJ15,KCN J16,KCNQ1,TESC,KC NE2,AQP10,SLC16A9, GRIA4,CLIC6,SGK2,S LC7A8,RGN,SLC9A4,S LC28A2,SLC16A7

CLDN18,HGD,ERBB4, TTR,C16orf89,ADH7,S 100P,FBP1,CLCNKA,H PGD,PLIN5,FGG,ALD OB,HOMER2,NR0B2,C OL2A1,ANG,UGT1A10 UGT1A6,SH3GL2,ID1, APLP1,APOA1,APOA4 ,BCAS1,AQP4,AQP5,S CUBE2,AKR7A3,RAS EF,DMRTA1,SLC4A4, CTSE,PRLR,CXADR,G ABRB3,GALE,KIF1A, NCAM1,PBLD,FBP2,G 


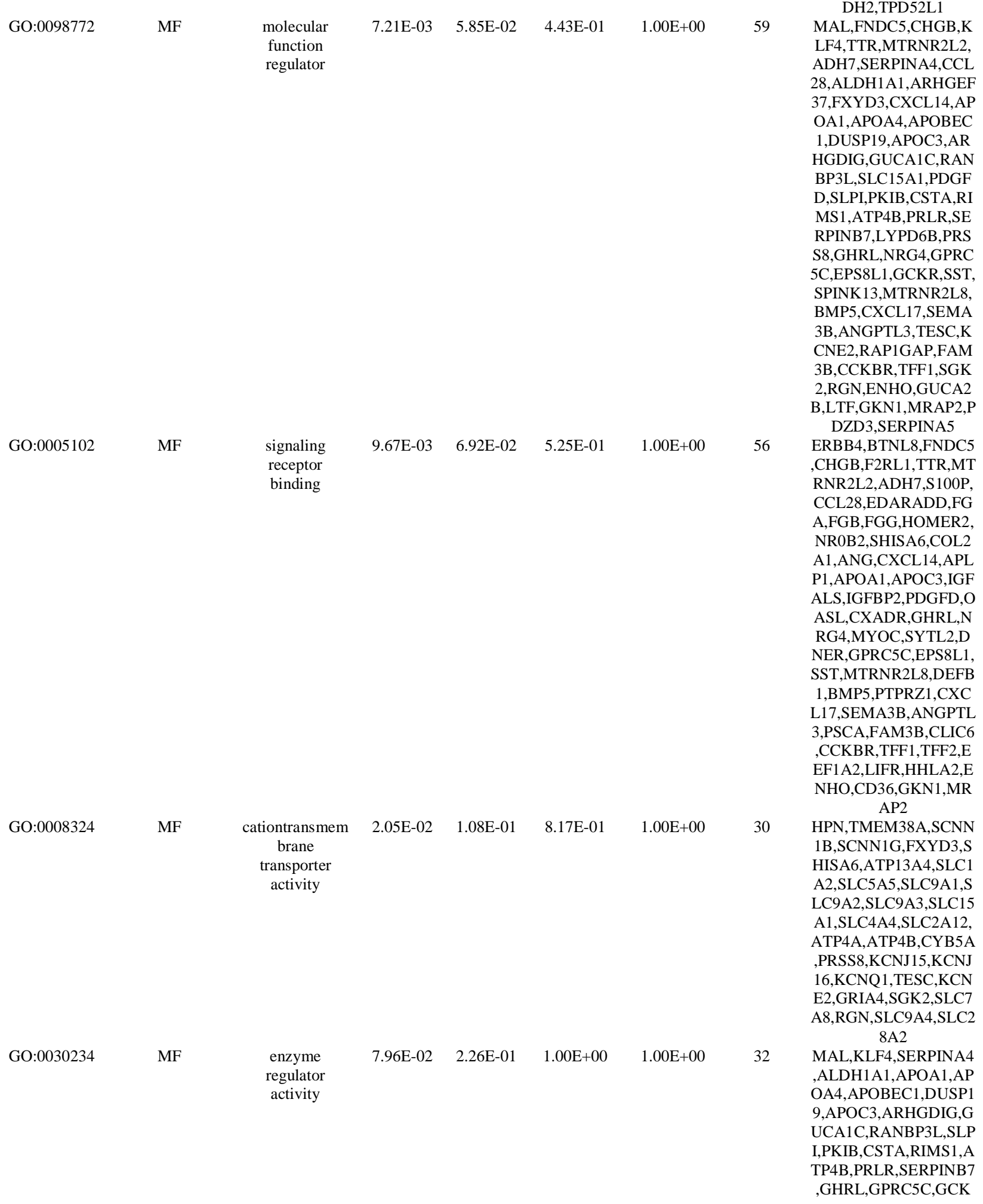




\begin{tabular}{|c|c|c|c|c|c|c|c|c|}
\hline & & & & & & & & $\begin{array}{c}\text { R,SPINK13,ANGPTL3, } \\
\text { TESC,RAP1GAP,CCK } \\
\text { BR,RGN,GUCA2B,LTF } \\
\text {,PDZD3,SERPINA5 }\end{array}$ \\
\hline GO:0008233 & MF & $\begin{array}{l}\text { peptidase } \\
\text { activity }\end{array}$ & $2.54 \mathrm{E}-01$ & 4.22E-01 & $1.00 \mathrm{E}+00$ & $1.00 \mathrm{E}+00$ & 33 & $\begin{array}{c}\text { MAL,GGT6,KLF4,PGA } \\
\text { 5,PGC,CAPN13,SERPI } \\
\text { NA4,HPN,KIAA1324,P } \\
\text { APPA2,PM20D1,CPA2, } \\
\text { SLPI,CSTA,CTSE,ACE } \\
\text { R2,CAPN9,SOX2,SERP } \\
\text { INB7,PRSS8,ADAM28, } \\
\text { SPINK13,CAPN8,RHB } \\
\text { DL2,DHCR24,ADAMT } \\
\text { S15,PGA3,KLK11,PGA } \\
\text { 4,ADAMTSL1,TMPRS } \\
\text { S2,LTF,SERPINA5 }\end{array}$ \\
\hline GO:0016301 & MF & kinase activity & $5.59 \mathrm{E}-01$ & $6.99 \mathrm{E}-01$ & $1.00 \mathrm{E}+00$ & $1.00 \mathrm{E}+00$ & 36 & $\begin{array}{c}\text { ERBB4,ESRRB,STYK1 } \\
\text {,KLF4,FOXA2,CKB,C } \\
\text { KM,CKMT2,FBP1,PIK } \\
\text { 3C2G,ALDH1A1,ALD } \\
\text { OB,ALDOC,ANG,SOS } \\
\text { TDC1,DUSP19,PDGFD } \\
\text {,PRKAA2,PKIB,PRLR, } \\
\text { GALE,GHRL,GPRC5C, } \\
\text { GCKR,ITPKA,CXCL17 } \\
\text {,RPS6KA6,TESC,RIPK } \\
\text { 4,CCKBR,EEF1A2,SG } \\
\text { K2,RGN,ENTPD5,LTF, } \\
\text { TPD52L1 }\end{array}$ \\
\hline
\end{tabular}

Biological Process(BP), Cellular Component(CC) and Molecular Functions (MF)

Table 7 Topology table for up and down regulated genes

\begin{tabular}{ccccccc}
\hline Regulation & Node & Degree & Betweenness & Stress & Closeness & $\begin{array}{c}\text { Clustering } \\
\text { Coefficient }\end{array}$ \\
\hline Down & SOX2 & 361 & 0.130645 & 91698482 & 0.314504 & $3.13 \mathrm{E}-05$ \\
Down & RIPK4 & 336 & 0.128603 & 98813078 & 0.314446 & 0 \\
Down & FOXA1 & 290 & 0.103625 & 62359854 & 0.309195 & $3.87 \mathrm{E}-04$ \\
Down & EEF1A2 & 192 & 0.092037 & 39507690 & 0.326061 & $7.09 \mathrm{E}-04$ \\
Down & ANG & 126 & 0.033985 & 31690134 & 0.29174 & 0 \\
Down & FGB & 119 & 0.043651 & 12625862 & 0.307262 & 0.004558 \\
Down & PTGER3 & 113 & 0.038772 & 17588946 & 0.28297 & $3.16 \mathrm{E}-04$ \\
Down & CKB & 111 & 0.036348 & 17987186 & 0.29959 & 0.002502 \\
Down & FOXQ1 & 108 & 0.024413 & 25595054 & 0.265424 & 0 \\
Down & ERBB4 & 101 & 0.039648 & 13011632 & 0.303684 & 0.00268 \\
Down & PRKAA2 & 100 & 0.028743 & 15759608 & 0.279198 & 0 \\
Down & APOA1 & 100 & 0.036853 & 10368028 & 0.293786 & 0.00451 \\
Down & ESRRB & 98 & 0.036893 & 21650562 & 0.308952 & 0.001052 \\
Down & OXCT1 & 97 & 0.02688 & 16657230 & 0.275526 & 0 \\
Down & ATP4A & 92 & 0.038284 & 7433528 & 0.297688 & $2.50 \mathrm{E}-04$ \\
Down & F2RL1 & 90 & 0.02916 & 16825260 & 0.263862 & 0 \\
\hline
\end{tabular}




\begin{tabular}{|c|c|c|c|c|c|c|}
\hline Down & EYA2 & 88 & 0.023357 & 20081684 & 0.264175 & 0 \\
\hline Down & $\mathrm{CDH} 2$ & 83 & 0.025141 & 12416288 & 0.280608 & 0.001469 \\
\hline Down & SH3GL2 & 81 & 0.028376 & 10624252 & 0.281334 & $3.25 \mathrm{E}-04$ \\
\hline Down & DUSP19 & 78 & 0.022667 & 8084684 & 0.289509 & 0.001053 \\
\hline Down & FAM189A2 & 78 & 0.023811 & 11453482 & 0.276839 & $9.99 \mathrm{E}-04$ \\
\hline Down & ALDOC & 75 & 0.024085 & 9254824 & 0.292324 & 0.004685 \\
\hline Down & SLC25A4 & 74 & 0.020138 & 14876712 & 0.282704 & 0 \\
\hline Down & HBB & 72 & 0.024297 & 9837400 & 0.292358 & 0 \\
\hline Down & SELENBP1 & 69 & 0.020559 & 16033854 & 0.263576 & 0 \\
\hline Down & TTR & 65 & 0.019611 & 8877534 & 0.281971 & 0.004608 \\
\hline Down & NR0B2 & 65 & 0.018911 & 9601392 & 0.285754 & 4.81E-04 \\
\hline Down & SLC15A1 & 65 & 0.022335 & 9413034 & 0.259481 & 0 \\
\hline Down & MRAP2 & 64 & 0.018209 & 14317820 & 0.246694 & 0 \\
\hline Down & APLP1 & 61 & 0.016887 & 7157580 & 0.275734 & $5.84 \mathrm{E}-04$ \\
\hline Down & MIA2 & 61 & 0.023593 & 3857116 & 0.292911 & 0.003507 \\
\hline Down & MUC1 & 59 & 0.01901 & 8685324 & 0.297272 & 0.004386 \\
\hline Down & TMEM171 & 57 & 0.015929 & 7178790 & 0.265162 & 0 \\
\hline Down & VSIG1 & 57 & 0.015506 & 9968024 & 0.251724 & 0 \\
\hline Down & SLC2A12 & 56 & 0.014848 & 11274816 & 0.245344 & 0 \\
\hline Down & KIF1A & 55 & 0.014262 & 10095312 & 0.273082 & 0 \\
\hline Down & LIPH & 54 & 0.014461 & 5415600 & 0.258432 & 0 \\
\hline Down & FOXA3 & 53 & 0.011677 & 3197724 & 0.277576 & 0.007059 \\
\hline Down & FBP1 & 52 & 0.011778 & 5755732 & 0.259718 & 0.007347 \\
\hline Down & ID1 & 51 & 0.014356 & 8073662 & 0.260049 & 0 \\
\hline Down & GLUL & 51 & 0.014074 & 7290628 & 0.273901 & 0 \\
\hline Down & LTF & 51 & 0.015012 & 8074792 & 0.27279 & 0.001569 \\
\hline Down & SUSD4 & 50 & 0.014117 & 8153740 & 0.252171 & 0 \\
\hline Down & MYOC & 49 & 0.012703 & 5520884 & 0.273784 & 0 \\
\hline Down & COL2A1 & 48 & 0.014506 & 2615324 & 0.251625 & 0 \\
\hline Down & CSTA & 47 & 0.009908 & 5708660 & 0.266226 & 0 \\
\hline Down & PTPRR & 46 & 0.012338 & 3050164 & 0.277425 & 0.008457 \\
\hline Down & ESRRG & 46 & 0.01155 & 4874608 & 0.278438 & 0.001057 \\
\hline Down & SLC9A1 & 45 & 0.021666 & 3586826 & 0.290993 & 0.008081 \\
\hline Down & RORC & 45 & 0.010968 & 7194834 & 0.26283 & 0 \\
\hline Down & FRMD1 & 45 & 0.01312 & 1673830 & 0.264627 & 0.005051 \\
\hline Down & NCAM1 & 44 & 0.011569 & 4653244 & 0.264476 & 0 \\
\hline Down & DHRS7 & 43 & 0.013463 & 2866004 & 0.265479 & 0.001107 \\
\hline Down & IL1R2 & 42 & 0.011437 & 5905866 & 0.234503 & 0 \\
\hline Down & CHGB & 42 & 0.010047 & 5822946 & 0.266963 & 0 \\
\hline Down & BTNL8 & 42 & 0.011912 & 2086382 & 0.241256 & 0 \\
\hline Down & FBXL13 & 42 & 0.012583 & 5749328 & 0.240111 & 0 \\
\hline Down & FGA & 41 & 0.010321 & 3281616 & 0.289247 & 0.062078 \\
\hline Down & SERPINA5 & 41 & 0.012219 & 1908132 & 0.278756 & 0.008097 \\
\hline
\end{tabular}




\begin{tabular}{|c|c|c|c|c|c|c|}
\hline Down & LDHD & 40 & 0.011361 & 9207334 & 0.235747 & 0 \\
\hline Down & FGG & 38 & 0.007185 & 2451080 & 0.281195 & 0.049206 \\
\hline Down & RPS6KA6 & 37 & 0.01036 & 3621900 & 0.266684 & 0.004505 \\
\hline Down & CYP2S1 & 37 & 0.009679 & 1915748 & 0.257936 & 0 \\
\hline Down & KLF4 & 36 & 0.008725 & 6243510 & 0.274829 & 0 \\
\hline Down & CA9 & 36 & 0.00838 & 3853714 & 0.278574 & 0 \\
\hline Down & DHCR24 & 36 & 0.006868 & 4428340 & 0.272965 & 0 \\
\hline Down & GALE & 35 & 0.008601 & 4052878 & 0.272805 & 0 \\
\hline Down & GPRC5C & 35 & 0.012273 & 2377340 & 0.271515 & 0.003361 \\
\hline Down & NQO1 & 34 & 0.008383 & 5150060 & 0.274136 & 0 \\
\hline Down & EPN3 & 34 & 0.010642 & 6541196 & 0.240269 & 0 \\
\hline Down & TMED6 & 34 & 0.008373 & 4030958 & 0.222818 & 0 \\
\hline Down & RAB27A & 33 & 0.0091 & 2404172 & 0.26859 & 0.007576 \\
\hline Down & KRT20 & 33 & 0.007564 & 4522038 & 0.244323 & 0 \\
\hline Down & ALDOB & 33 & 0.007577 & 5415906 & 0.25628 & 0 \\
\hline Down & AZGP1 & 33 & 0.007325 & 4722950 & 0.260102 & 0 \\
\hline Down & CYB5A & 32 & 0.014497 & 2040568 & 0.281009 & 0.002016 \\
\hline Down & PTPRN2 & 32 & 0.006444 & 5188802 & 0.24512 & 0 \\
\hline Down & ME1 & 32 & 0.007918 & 3585304 & 0.249439 & 0 \\
\hline Down & LEPR & 31 & 0.008148 & 2585854 & 0.250184 & 0 \\
\hline Down & S100P & 31 & 0.00819 & 3141854 & 0.261794 & 0 \\
\hline Down & MAP7D2 & 31 & 0.006379 & 3776744 & 0.240393 & 0 \\
\hline Down & RIMS1 & 29 & 0.006836 & 2005214 & 0.262183 & 0.004926 \\
\hline Down & CD36 & 29 & 0.006605 & 3244170 & 0.25791 & 0 \\
\hline Down & VSIG2 & 29 & 0.005085 & 4523118 & 0.229594 & 0 \\
\hline Down & CKM & 28 & 0.006486 & 1114366 & 0.26363 & 0.015385 \\
\hline Down & PTPRZ1 & 27 & 0.004562 & 2671328 & 0.243834 & 0 \\
\hline Down & PDIA2 & 27 & 0.011946 & 3842958 & 0.264791 & 0 \\
\hline Down & UGT1A10 & 27 & 0.00529 & 2201280 & 0.236884 & 0.02 \\
\hline Down & CMBL & 27 & 0.005343 & 4698256 & 0.254001 & 0 \\
\hline Down & LGALS9C & 27 & 0.006007 & 2789528 & 0.231267 & 0 \\
\hline Down & KLK11 & 27 & 0.005922 & 3556426 & 0.237026 & 0 \\
\hline Down & TFF1 & 26 & 0.00922 & 4457048 & 0.252932 & 0 \\
\hline Down & INSIG1 & 26 & 0.005325 & 1743502 & 0.245875 & 0 \\
\hline Down & RDH12 & 26 & 0.005489 & 2827404 & 0.239964 & 0 \\
\hline Down & GALNT6 & 26 & 0.009106 & 2128734 & 0.260779 & 0 \\
\hline Down & TPD52L1 & 25 & 0.004331 & 1988644 & 0.25113 & 0 \\
\hline Down & GC & 25 & 0.00488 & 2756190 & 0.254786 & 0 \\
\hline Down & FOXA2 & 25 & 0.00442 & 692924 & 0.26162 & 0.027668 \\
\hline Down & RAP1GAP & 25 & 0.005317 & 2730984 & 0.248493 & 0 \\
\hline Down & XYLT2 & 25 & 0.005125 & 3604190 & 0.230953 & 0 \\
\hline Down & PRLR & 24 & 0.004513 & 2639920 & 0.241758 & 0 \\
\hline Down & SCNN1B & 24 & 0.003266 & 1693310 & 0.233134 & 0.051948 \\
\hline
\end{tabular}




\begin{tabular}{|c|c|c|c|c|c|c|}
\hline Down & GNMT & 24 & 0.003761 & 2292130 & 0.242538 & 0 \\
\hline Down & CA2 & 23 & 0.005398 & 1512836 & 0.267312 & 0 \\
\hline Down & CCKBR & 23 & 0.004282 & 3289826 & 0.231162 & 0.009524 \\
\hline Down & DSC2 & 23 & 0.002627 & 1332696 & 0.243057 & 0 \\
\hline Down & SMPD3 & 23 & 0.00407 & 1526270 & 0.243462 & 0 \\
\hline Down & SOWAHA & 23 & 0.005986 & 3656274 & 0.222304 & 0 \\
\hline Down & FBP2 & 22 & 0.00357 & 1236294 & 0.256075 & 0.047368 \\
\hline Down & SCGN & 22 & 0.005448 & 2292384 & 0.224363 & 0 \\
\hline Down & CXADR & 22 & 0.004966 & 1542936 & 0.256602 & 0 \\
\hline Down & SCGB2A1 & 22 & 0.00411 & 1974286 & 0.247626 & 0 \\
\hline Down & ALDH6A1 & 22 & 0.005212 & 3402338 & 0.242492 & 0 \\
\hline Down & PDGFD & 22 & 0.004274 & 2794740 & 0.226934 & 0 \\
\hline Down & LIFR & 21 & 0.004499 & 3194270 & 0.242423 & 0 \\
\hline Down & KCNQ1 & 21 & 0.004852 & 1329562 & 0.26667 & 0.005848 \\
\hline Down & PXMP2 & 21 & 0.009681 & 2045510 & 0.253585 & 0 \\
\hline Down & SCIN & 21 & 0.004409 & 3432750 & 0.257481 & 0 \\
\hline Down & ALDH3A1 & 21 & 0.006292 & 975432 & 0.247662 & 0.011696 \\
\hline Down & STX19 & 20 & 0.005007 & 1935164 & 0.20909 & 0 \\
\hline Down & TCEAL2 & 20 & 0.003844 & 2368446 & 0.256576 & 0 \\
\hline Down & A4GNT & 20 & 0.004387 & 1662140 & 0.225542 & 0 \\
\hline Down & CHIA & 20 & 0.005062 & 3754078 & 0.241449 & 0 \\
\hline Down & GCNT1 & 20 & 0.004201 & 1845148 & 0.224926 & 0 \\
\hline Down & SCNN1G & 19 & 0.001794 & 974542 & 0.233838 & 0.088235 \\
\hline Down & POU2AF1 & 19 & 0.005426 & 1886150 & 0.231267 & 0 \\
\hline Down & CLEC3B & 19 & 0.003446 & 686120 & 0.253824 & 0.014706 \\
\hline Down & SGK2 & 19 & 0.003011 & 2291524 & 0.255806 & 0 \\
\hline Down & COL4A6 & 19 & 0.004108 & 2503680 & 0.231257 & 0 \\
\hline Down & GRIA4 & 18 & 0.004013 & 2094936 & 0.235172 & 0 \\
\hline Down & RAB27B & 18 & 0.003176 & 889536 & 0.249147 & 0.013072 \\
\hline Down & F13A1 & 18 & 0.003111 & 636426 & 0.267886 & 0.05 \\
\hline Down & SYT16 & 18 & 0.003942 & 610066 & 0.237224 & 0 \\
\hline Down & GPT2 & 18 & 0.004219 & 2205028 & 0.24423 & 0 \\
\hline Down & CKMT2 & 18 & 0.003008 & 650282 & 0.255486 & 0.025 \\
\hline Down & ORM1 & 17 & 0.003066 & 2394818 & 0.233881 & 0.007353 \\
\hline Down & PDZD3 & 17 & 0.005754 & 836546 & 0.221188 & 0 \\
\hline Down & SPDEF & 17 & 0.00438 & 1902948 & 0.247842 & 0 \\
\hline Down & SERPINA4 & 17 & 0.003389 & 1618954 & 0.242055 & 0 \\
\hline Down & CYP3A4 & 17 & 0.00331 & 1029374 & 0.24409 & 0.028571 \\
\hline Down & HOMER2 & 17 & 0.004213 & 2318450 & 0.2334 & 0 \\
\hline Down & GSTA1 & 17 & 0.003515 & 1770658 & 0.250711 & 0.038095 \\
\hline Down & CYP2C8 & 17 & 0.002329 & 1066708 & 0.23901 & 0 \\
\hline Down & MAL & 17 & 0.003795 & 1666176 & 0.240382 & 0 \\
\hline Down & BPIFB1 & 17 & 0.002977 & 2398972 & 0.246159 & 0 \\
\hline
\end{tabular}




\begin{tabular}{|c|c|c|c|c|c|c|}
\hline Down & COL17A1 & 16 & 0.002553 & 1165170 & 0.246408 & 0 \\
\hline Down & EDARADD & 16 & 0.002099 & 1184864 & 0.233166 & 0 \\
\hline Down & CYP2C9 & 16 & 0.002334 & 475378 & 0.234117 & 0.025 \\
\hline Down & EPB41L4B & 16 & 0.003783 & 1719180 & 0.243196 & 0 \\
\hline Down & MUC5B & 16 & 0.003656 & 1742484 & 0.254748 & 0.008333 \\
\hline Down & CGNL1 & 16 & 0.00242 & 1294404 & 0.24865 & 0 \\
\hline Down & AKR1C2 & 15 & 0.002609 & 727192 & 0.228844 & 0.025641 \\
\hline Down & SLPI & 15 & 0.003639 & 1592814 & 0.245167 & 0 \\
\hline Down & AKR1B10 & 15 & 0.002313 & 855778 & 0.229543 & 0.009524 \\
\hline Down & TRIM50 & 15 & 0.003357 & 1937636 & 0.213465 & 0 \\
\hline Down & TST & 15 & 0.002387 & 1686500 & 0.230797 & 0 \\
\hline Down & KLF15 & 15 & 0.002427 & 1312738 & 0.225164 & 0 \\
\hline Down & GABRB3 & 14 & 0.00218 & 943302 & 0.225941 & 0 \\
\hline Down & C6 & 14 & 0.002538 & 1748954 & 0.244323 & 0 \\
\hline Down & ASB11 & 14 & 0.002102 & 1319614 & 0.231351 & 0 \\
\hline Down & TMEM92 & 14 & 0.002742 & 768258 & 0.256538 & 0 \\
\hline Down & PTGR1 & 14 & 0.002181 & 1002112 & 0.221543 & 0 \\
\hline Down & CTSE & 14 & 0.002273 & 897066 & 0.223471 & 0 \\
\hline Down & SYTL2 & 13 & 0.002043 & 537190 & 0.247338 & 0 \\
\hline Down & ARHGDIG & 13 & 0.003657 & 1180020 & 0.219998 & 0 \\
\hline Down & SLC9A3 & 13 & 0.001716 & 783146 & 0.222324 & 0 \\
\hline Down & SULT1C2 & 13 & 0.002072 & 1077230 & 0.2131 & 0 \\
\hline Down & SLC1A2 & 13 & 0.001883 & 1174276 & 0.230433 & 0 \\
\hline Down & PBLD & 13 & 0.002864 & 1604148 & 0.221707 & 0 \\
\hline Down & DEFB1 & 13 & 0.002672 & 969434 & 0.214874 & 0 \\
\hline Down & PLLP & 13 & 0.002953 & 1704122 & 0.210528 & 0 \\
\hline Down & BHMT & 12 & 0.001444 & 462034 & 0.200078 & 0 \\
\hline Down & GATA6 & 12 & 0.001888 & 766242 & 0.227925 & 0.015152 \\
\hline Down & SERPINB7 & 12 & 0.001574 & 903854 & 0.221697 & 0 \\
\hline Down & CHGA & 12 & 0.002669 & 892042 & 0.237953 & 0 \\
\hline Down & SLC5A5 & 12 & 0.001844 & 1189896 & 0.214487 & 0 \\
\hline Down & CAPN13 & 12 & 0.002512 & 1267060 & 0.214649 & 0 \\
\hline Down & AKR7A3 & 11 & 0.002079 & 1092290 & 0.218905 & 0 \\
\hline Down & EPS8L1 & 11 & 0.00158 & 1034458 & 0.227337 & 0 \\
\hline Down & TFR2 & 11 & 0.002136 & 335802 & 0.241712 & 0 \\
\hline Down & KLF2 & 11 & 0.001827 & 864958 & 0.229162 & 0.036364 \\
\hline Down & SLC9A2 & 11 & 0.001361 & 674648 & 0.231749 & 0 \\
\hline Down & MAOA & 11 & 0.001393 & 577172 & 0.229615 & 0 \\
\hline Down & AKR1C3 & 11 & 0.002239 & 398010 & 0.2158 & 0.054545 \\
\hline Down & REG3A & 11 & 0.001394 & 775802 & 0.230807 & 0 \\
\hline Down & GHRL & 11 & 0.003071 & 422262 & 0.230714 & 0 \\
\hline Down & DHRS9 & 11 & 0.002519 & 888628 & 0.20417 & 0 \\
\hline Down & AKR1B15 & 11 & 0.001364 & 380620 & 0.232964 & 0.018182 \\
\hline
\end{tabular}




\begin{tabular}{|c|c|c|c|c|c|c|}
\hline Down & SEMA3B & 11 & 0.001852 & 912096 & 0.223676 & 0 \\
\hline Down & CYSTM1 & 11 & 0.002071 & 692870 & 0.215718 & 0 \\
\hline Down & AMTN & 11 & 0.001781 & 621822 & 0.219159 & 0 \\
\hline Down & GKN1 & 11 & 8.02E-04 & 226994 & 0.217972 & 0 \\
\hline Down & AMPD1 & 11 & 8.02E-04 & 705838 & 0.229502 & 0 \\
\hline Down & MLPH & 10 & 0.001483 & 571000 & 0.262331 & 0.088889 \\
\hline Down & TESC & 10 & 0.001621 & 186720 & 0.23063 & 0.071429 \\
\hline Down & APOBEC1 & 10 & 0.002094 & 841430 & 0.200196 & 0 \\
\hline Down & AKR1C1 & 10 & 0.001725 & 316338 & 0.225492 & 0.071429 \\
\hline Down & RPRM & 10 & 0.001932 & 971234 & 0.229646 & 0 \\
\hline Down & AQP5 & 10 & 0.001026 & 462940 & 0.220787 & 0 \\
\hline Down & GCNT2 & 10 & 0.002683 & 1431378 & 0.220463 & 0 \\
\hline Down & LIPF & 10 & 0.002681 & 291688 & 0.235097 & 0 \\
\hline Down & ENTPD5 & 10 & 0.001423 & 576438 & 0.221966 & 0 \\
\hline Down & CYP2C18 & 10 & 0.00151 & 590472 & 0.218699 & 0.022222 \\
\hline Down & XK & 10 & 0.00259 & 915288 & 0.211688 & 0 \\
\hline Down & UGT1A6 & 10 & $3.51 \mathrm{E}-04$ & 63358 & 0.212075 & 0.25 \\
\hline Down & FOLR1 & 10 & 0.001826 & 786520 & 0.229811 & 0 \\
\hline Down & RASSF6 & 9 & 0.001679 & 758932 & 0.222314 & 0 \\
\hline Down & SLC4A4 & 9 & $8.25 \mathrm{E}-04$ & 147548 & 0.228547 & 0 \\
\hline Down & HAPLN1 & 9 & 0.002127 & 937726 & 0.221514 & 0 \\
\hline Down & ALDH1A1 & 9 & 0.001071 & 502514 & 0.230225 & 0 \\
\hline Down & PAIP2B & 9 & 0.001898 & 820018 & 0.212031 & 0 \\
\hline Down & FNDC5 & 9 & 0.00116 & 227236 & 0.234805 & 0 \\
\hline Down & OASL & 9 & 0.001035 & 554244 & 0.235704 & 0 \\
\hline Down & CYP3A5 & 9 & 0.001621 & 242422 & 0.236227 & 0 \\
\hline Down & SCG3 & 9 & 0.00171 & 397816 & 0.234751 & 0 \\
\hline Down & ANGPTL3 & 9 & 0.001408 & 534524 & 0.201355 & 0 \\
\hline Down & CXCL14 & 9 & 0.001418 & 687382 & 0.225194 & 0 \\
\hline Down & FAM3B & 9 & 0.002213 & 335698 & 0.2483 & 0 \\
\hline Down & RNASE1 & 8 & $8.75 \mathrm{E}-04$ & 328862 & 0.22215 & 0 \\
\hline Down & BCAS1 & 8 & 7.11E-04 & 423002 & 0.24225 & 0 \\
\hline Down & HGD & 8 & 0.001216 & 788412 & 0.213572 & 0 \\
\hline Down & C4orf19 & 8 & 0.001639 & 223746 & 0.256512 & 0.071429 \\
\hline Down & MYRIP & 8 & 0.001238 & 430996 & 0.249634 & 0 \\
\hline Down & CIDEC & 8 & 0.001237 & 380180 & 0.208885 & 0 \\
\hline Down & CA4 & 8 & $6.78 \mathrm{E}-04$ & 175498 & 0.219715 & 0 \\
\hline Down & AQP4 & 8 & $7.48 \mathrm{E}-04$ & 268154 & 0.211916 & 0 \\
\hline Down & IGFBP2 & 8 & 0.00149 & 766678 & 0.221294 & 0 \\
\hline Down & HTR1E & 8 & $9.77 \mathrm{E}-04$ & 621360 & 0.233262 & 0 \\
\hline Down & SULT2A1 & 8 & $7.70 \mathrm{E}-04$ & 247322 & 0.211732 & 0 \\
\hline Down & C1orf116 & 8 & $7.46 \mathrm{E}-04$ & 480606 & 0.241187 & 0 \\
\hline Down & FXYD3 & 8 & 0.001716 & 698152 & 0.219658 & 0 \\
\hline
\end{tabular}




\begin{tabular}{|c|c|c|c|c|c|c|}
\hline Down & TMEM38A & 8 & 0.001989 & 673836 & 0.209975 & 0 \\
\hline Down & FUT9 & 8 & 0.001439 & 449312 & 0.206055 & 0 \\
\hline Down & FCGBP & 8 & $5.65 \mathrm{E}-04$ & 331640 & 0.230287 & 0 \\
\hline Down & PRDM16 & 8 & $6.15 \mathrm{E}-04$ & 224982 & 0.23176 & 0 \\
\hline Down & ITPKA & 8 & $6.95 \mathrm{E}-04$ & 310188 & 0.215991 & 0 \\
\hline Down & BMP5 & 8 & 0.001564 & 204476 & 0.24629 & 0 \\
\hline Down & RGN & 8 & $2.20 \mathrm{E}-04$ & 146076 & 0.221064 & 0 \\
\hline Down & SOSTDC1 & 7 & 0.001188 & 367662 & 0.180492 & 0 \\
\hline Down & APOA4 & 7 & $4.08 \mathrm{E}-04$ & 165970 & 0.21402 & 0 \\
\hline Down & ZBTB7C & 7 & 0.001031 & 422450 & 0.227905 & 0 \\
\hline Down & METTL7A & 7 & $4.95 \mathrm{E}-04$ & 194766 & 0.227601 & 0 \\
\hline Down & ACADL & 7 & 0.001679 & 791198 & 0.227946 & 0 \\
\hline Down & CYP4F12 & 7 & $9.87 \mathrm{E}-04$ & 279876 & 0.220311 & 0 \\
\hline Down & PKIB & 7 & 0.001587 & 460738 & 0.199914 & 0 \\
\hline Down & CCBE1 & 7 & 0.002002 & 326496 & 0.19495 & 0 \\
\hline Down & TFCP2L1 & 7 & $4.28 \mathrm{E}-04$ & 250206 & 0.20633 & 0 \\
\hline Down & PALM3 & 7 & 0.00104 & 644144 & 0.248638 & 0 \\
\hline Down & HYAL1 & 7 & 0.002205 & 417022 & 0.238754 & 0 \\
\hline Down & ADAMTSL1 & 7 & $9.43 \mathrm{E}-04$ & 207474 & 0.199906 & 0 \\
\hline Down & SYTL5 & 6 & 0.001222 & 233628 & 0.223393 & 0 \\
\hline Down & GSTA2 & 6 & $8.20 \mathrm{E}-04$ & 333722 & 0.204948 & 0.133333 \\
\hline Down & DPT & 6 & 4.89E-04 & 261260 & 0.232265 & 0 \\
\hline Down & MT1X & 6 & $3.73 \mathrm{E}-04$ & 229168 & 0.229285 & 0 \\
\hline Down & BEX5 & 6 & $7.89 \mathrm{E}-04$ & 108852 & 0.200715 & 0 \\
\hline Down & ATP4B & 6 & 0.002043 & 235970 & 0.235878 & 0 \\
\hline Down & PLIN5 & 6 & 0.001333 & 771154 & 0.195629 & 0 \\
\hline Down & CCL28 & 6 & 0.001575 & 487862 & 0.211872 & 0 \\
\hline Down & UPK1B & 6 & 0.001572 & 934520 & 0.192781 & 0 \\
\hline Down & MAMDC2 & 6 & 0.001576 & 318360 & 0.213296 & 0 \\
\hline Down & SIGLEC11 & 6 & 5.99E-04 & 207770 & 0.228088 & 0 \\
\hline Down & PLAC8 & 6 & $3.02 \mathrm{E}-04$ & 225896 & 0.228527 & 0 \\
\hline Down & RAB37 & 6 & 7.07E-04 & 123228 & 0.228967 & 0 \\
\hline Down & LGALS9B & 6 & $3.47 \mathrm{E}-04$ & 189584 & 0.218307 & 0 \\
\hline Down & ARL14 & 6 & 0.001956 & 1716690 & 0.182771 & 0 \\
\hline Down & SH3BGRL2 & 6 & 0.001142 & 565738 & 0.239863 & 0 \\
\hline Down & SST & 6 & 0.002571 & 944178 & 0.209665 & 0.066667 \\
\hline Down & SLC16A7 & 6 & 0.00134 & 493152 & 0.193116 & 0 \\
\hline Down & FA2H & 6 & $6.44 \mathrm{E}-04$ & 190132 & 0.205889 & 0 \\
\hline Down & CPA2 & 6 & 8.69E-04 & 220104 & 0.204187 & 0 \\
\hline Down & DNER & 6 & $5.68 \mathrm{E}-04$ & 364110 & 0.227075 & 0 \\
\hline Down & GDPD3 & 6 & $2.89 \mathrm{E}-04$ & 143022 & 0.209949 & 0 \\
\hline Down & KCNJ15 & 5 & 0.001063 & 395016 & 0.212383 & 0 \\
\hline Down & GCKR & 5 & 8.07E-04 & 358596 & 0.212613 & 0 \\
\hline
\end{tabular}




\begin{tabular}{|c|c|c|c|c|c|c|}
\hline Down & HAS3 & 5 & $7.83 \mathrm{E}-04$ & 180102 & 0.170839 & 0 \\
\hline Down & IGFALS & 5 & $8.48 \mathrm{E}-04$ & 200704 & 0.198178 & 0 \\
\hline Down & CCKAR & 5 & $4.00 \mathrm{E}-08$ & 2 & 0.18778 & 0.666667 \\
\hline Down & TFF2 & 5 & $4.28 \mathrm{E}-04$ & 128148 & 0.208808 & 0 \\
\hline Down & SSTR1 & 5 & $8.16 \mathrm{E}-04$ & 303142 & 0.175286 & 0.1 \\
\hline Down & GPX3 & 5 & 7.83E-04 & 182594 & 0.193995 & 0 \\
\hline Down & ORM2 & 5 & $1.57 \mathrm{E}-04$ & 35318 & 0.220692 & 0.1 \\
\hline Down & APOC3 & 5 & 4.14E-04 & 47088 & 0.233667 & 0.2 \\
\hline Down & DDX60 & 5 & $8.81 \mathrm{E}-04$ & 460534 & 0.218307 & 0 \\
\hline Down & HPN & 5 & 7.26E-04 & 310120 & 0.230194 & 0 \\
\hline Down & GPT & 5 & $8.29 \mathrm{E}-04$ & 291602 & 0.206714 & 0 \\
\hline Down & ODAM & 5 & $8.57 \mathrm{E}-04$ & 403252 & 0.23236 & 0 \\
\hline Down & PAPPA2 & 5 & $8.40 \mathrm{E}-04$ & 242380 & 0.196994 & 0 \\
\hline Down & FMO5 & 5 & $8.78 \mathrm{E}-04$ & 467960 & 0.215254 & 0 \\
\hline Down & SLC16A9 & 5 & 8.61E-04 & 269782 & 0.220074 & 0 \\
\hline Down & TMEM220 & 5 & $5.22 \mathrm{E}-04$ & 290922 & 0.220854 & 0 \\
\hline Down & GDPD2 & 5 & 0.001271 & 445450 & 0.207015 & 0 \\
\hline Down & VILL & 5 & 8.06E-04 & 419916 & 0.21569 & 0 \\
\hline Down & ADH7 & 4 & 5.91E-05 & 29910 & 0.214631 & 0 \\
\hline Down & CLIC6 & 4 & $8.08 \mathrm{E}-04$ & 292454 & 0.186417 & 0 \\
\hline Down & GALNT5 & 4 & 4.33E-04 & 155130 & 0.204366 & 0 \\
\hline Down & KCNJ16 & 4 & 8.03E-04 & 105342 & 0.195794 & 0 \\
\hline Down & CDHR2 & 4 & 0.001174 & 433218 & 0.180696 & 0 \\
\hline Down & KCNE2 & 4 & 5.03E-04 & 75192 & 0.235954 & 0.166667 \\
\hline Down & SULT1B1 & 4 & 4.79E-04 & 89616 & 0.204735 & 0 \\
\hline Down & VSTM2A & 4 & $7.96 \mathrm{E}-04$ & 681826 & 0.169553 & 0 \\
\hline Down & RASEF & 4 & 6.42E-04 & 174228 & 0.220463 & 0 \\
\hline Down & GSTA3 & 4 & $5.10 \mathrm{E}-04$ & 346118 & 0.238809 & 0.5 \\
\hline Down & $\mathrm{ADH} 1 \mathrm{C}$ & 4 & 1 & 2 & 1 & 0 \\
\hline Down & RIMS4 & 4 & 4.34E-04 & 216850 & 0.21482 & 0 \\
\hline Down & PGC & 4 & $3.15 \mathrm{E}-04$ & 58062 & 0.251142 & 0 \\
\hline Down & ENAM & 4 & $1.68 \mathrm{E}-04$ & 93264 & 0.210815 & 0 \\
\hline Down & FSIP2 & 4 & $8.09 \mathrm{E}-04$ & 202852 & 0.206338 & 0 \\
\hline Down & SNORD22 & 4 & $3.76 \mathrm{E}-05$ & 31698 & 0.209613 & 0 \\
\hline Down & TM7SF2 & 4 & $4.65 \mathrm{E}-04$ & 146028 & 0.214496 & 0 \\
\hline Down & DMRTA1 & 4 & $9.92 \mathrm{E}-05$ & 71054 & 0.21855 & 0 \\
\hline Down & SCUBE2 & 4 & $3.91 \mathrm{E}-04$ & 94424 & 0.187498 & 0 \\
\hline Down & TMPRSS2 & 4 & $2.21 \mathrm{E}-05$ & 4940 & 0.217944 & 0 \\
\hline Down & SCARA5 & 4 & $5.52 \mathrm{E}-04$ & 205628 & 0.215645 & 0 \\
\hline Down & TMEM100 & 4 & $4.80 \mathrm{E}-04$ & 116462 & 0.203253 & 0 \\
\hline Down & PTGDR2 & 4 & 1 & 12 & 1 & 0 \\
\hline Down & CAPN8 & 4 & $4.14 \mathrm{E}-04$ & 137042 & 0.200597 & 0 \\
\hline Down & ZNF385B & 4 & 7.92E-04 & 439412 & 0.235313 & 0 \\
\hline
\end{tabular}




\begin{tabular}{|c|c|c|c|c|c|c|}
\hline Down & RANBP3L & 4 & $8.11 \mathrm{E}-04$ & 270746 & 0.209966 & 0 \\
\hline Down & C6orf58 & 4 & 4.97E-04 & 152308 & 0.220055 & 0 \\
\hline Down & PLIN4 & 4 & 4.89E-05 & 42320 & 0.220444 & 0 \\
\hline Down & ACSM1 & 4 & 7.89E-04 & 357944 & 0.177842 & 0 \\
\hline Down & SLC7A8 & 3 & $7.83 \mathrm{E}-04$ & 207170 & 0.191667 & 0 \\
\hline Down & CLCNKA & 3 & 0 & 0 & 0.18787 & 0 \\
\hline Down & DUOX1 & 3 & 4.09E-04 & 206852 & 0.179214 & 0 \\
\hline Down & APOBEC2 & 3 & 0 & 0 & 0.166808 & 0 \\
\hline Down & ANXA10 & 3 & 4.21E-04 & 203664 & 0.234106 & 0 \\
\hline Down & MT1H & 3 & 3.32E-04 & 64160 & 0.191459 & 0 \\
\hline Down & B4GALNT3 & 3 & $4.02 \mathrm{E}-04$ & 211438 & 0.19202 & 0 \\
\hline Down & SOX21 & 3 & $3.00 \mathrm{E}-08$ & 2 & 0.240767 & 0.666667 \\
\hline Down & NRG4 & 3 & $5.60 \mathrm{E}-04$ & 49388 & 0.234267 & 0 \\
\hline Down & RHBDL2 & 3 & $4.08 \mathrm{E}-04$ & 193280 & 0.180946 & 0 \\
\hline Down & GATA5 & 3 & $3.91 \mathrm{E}-04$ & 70686 & 0.209613 & 0.333333 \\
\hline Down & ADTRP & 3 & 2.92E-05 & 10622 & 0.192425 & 0 \\
\hline Down & PRSS8 & 3 & 4.57E-04 & 232278 & 0.22869 & 0 \\
\hline Down & STYK1 & 3 & 2.69E-05 & 15578 & 0.218494 & 0 \\
\hline Down & B3GAT1 & 3 & 0 & 0 & 0.18006 & 0 \\
\hline Down & PSCA & 3 & $6.95 \mathrm{E}-04$ & 79296 & 0.241335 & 0 \\
\hline Down & ADHFE1 & 3 & 8.07E-05 & 30016 & 0.199805 & 0 \\
\hline Down & CLDN18 & 3 & 4.17E-04 & 121720 & 0.197679 & 0 \\
\hline Down & LRRC66 & 3 & $1.72 \mathrm{E}-04$ & 84034 & 0.221418 & 0 \\
\hline Down & RNASE4 & 3 & 0 & 0 & 0.192324 & 0 \\
\hline Down & KIAA0895 & 3 & 5.83E-05 & 24890 & 0.215581 & 0 \\
\hline Down & CYP2C19 & 2 & 0 & 0 & 0.200274 & 1 \\
\hline Down & FAM135B & 2 & $1.11 \mathrm{E}-05$ & 6158 & 0.192795 & 0 \\
\hline Down & SLC9A4 & 2 & $3.51 \mathrm{E}-06$ & 1708 & 0.202689 & 0 \\
\hline Down & MT1G & 2 & $9.97 \mathrm{E}-05$ & 24412 & 0.172517 & 0 \\
\hline Down & C22orf23 & 2 & 3.91E-04 & 43196 & 0.16031 & 0 \\
\hline Down & DCAF12L1 & 2 & 1 & 2 & 1 & 0 \\
\hline Down & ANO5 & 2 & $1.16 \mathrm{E}-04$ & 17930 & 0.21883 & 0 \\
\hline Down & TSPAN1 & 2 & 7.81E-06 & 4920 & 0.183381 & 0 \\
\hline Down & ARHGEF37 & 2 & 3.91E-04 & 89488 & 0.215282 & 0 \\
\hline Down & ELOVL6 & 2 & 3.91E-04 & 115044 & 0.204981 & 0 \\
\hline Down & GPR155 & 2 & $5.21 \mathrm{E}-05$ & 24726 & 0.208979 & 0 \\
\hline Down & PM20D1 & 2 & 3.84E-06 & 2032 & 0.172669 & 0 \\
\hline Down & ST6GALNAC1 & 2 & $6.04 \mathrm{E}-05$ & 4124 & 0.250171 & 0 \\
\hline Down & NWD1 & 2 & 3.91E-04 & 113138 & 0.197199 & 0 \\
\hline Down & IGSF9 & 2 & $5.44 \mathrm{E}-05$ & 22396 & 0.216375 & 0 \\
\hline Down & SLC26A9 & 2 & $1.89 \mathrm{E}-04$ & 21422 & 0.238342 & 0 \\
\hline Down & TCN1 & 2 & $3.66 \mathrm{E}-05$ & 43932 & 0.218596 & 0 \\
\hline Down & ENTPD3 & 2 & $3.76 \mathrm{E}-05$ & 15404 & 0.196516 & 0 \\
\hline
\end{tabular}




\begin{tabular}{|c|c|c|c|c|c|c|}
\hline Down & MSMB & 2 & $9.51 \mathrm{E}-05$ & 49854 & 0.214992 & 0 \\
\hline Down & CADM2 & 2 & 3.91E-04 & 72366 & 0.204858 & 0 \\
\hline Down & MT1M & 2 & $3.91 \mathrm{E}-04$ & 145464 & 0.190028 & 0 \\
\hline Down & MT1F & 2 & $3.91 \mathrm{E}-04$ & 224466 & 0.171194 & 0 \\
\hline Down & IRX3 & 2 & $1.13 \mathrm{E}-05$ & 6548 & 0.207007 & 0 \\
\hline Down & FAM177B & 2 & $1.06 \mathrm{E}-05$ & 8836 & 0.198555 & 0 \\
\hline Down & ANKRD22 & 2 & $9.29 \mathrm{E}-06$ & 1450 & 0.19975 & 0 \\
\hline Down & PROM2 & 2 & $5.53 \mathrm{E}-05$ & 32190 & 0.222818 & 0 \\
\hline Down & C1orf115 & 2 & $1.47 \mathrm{E}-04$ & 35652 & 0.214983 & 0 \\
\hline Down & CNTN3 & 2 & 0 & 0 & 0.236928 & 1 \\
\hline Down & CAPN9 & 2 & 1 & 2 & 1 & 0 \\
\hline Down & TTC39A & 1 & 0 & 0 & 1 & 0 \\
\hline Down & DUOX2 & 1 & 0 & 0 & 0.172867 & 0 \\
\hline Down & MTRNR2L8 & 1 & 0 & 0 & 0.204965 & 0 \\
\hline Down & KIAA1324 & 1 & 0 & 0 & 0.224788 & 0 \\
\hline Down & UBE2QL1 & 1 & 0 & 0 & 0.179245 & 0 \\
\hline Down & MT1E & 1 & 0 & 0 & 0.206689 & 0 \\
\hline Down & ADAMTS15 & 1 & 0 & 0 & 0.207486 & 0 \\
\hline Down & UNC5D & 1 & 0 & 0 & 0.21045 & 0 \\
\hline Down & CWH43 & 1 & 0 & 0 & 0.167722 & 0 \\
\hline Down & B3GNT7 & 1 & 0 & 0 & 0.190987 & 0 \\
\hline Down & C16orf89 & 1 & 0 & 0 & 0.199244 & 0 \\
\hline Down & FER1L4 & 1 & 0 & 0 & 0.140277 & 0 \\
\hline Down & IL17REL & 1 & 0 & 0 & 0.215263 & 0 \\
\hline Down & ENPP5 & 1 & 0 & 0 & 0.215263 & 0 \\
\hline Down & LYPD6B & 1 & 0 & 0 & 0.178357 & 0 \\
\hline Down & SHISA6 & 1 & 0 & 0 & 0.185081 & 0 \\
\hline Down & FER1L6 & 1 & 0 & 0 & 0.203504 & 0 \\
\hline Down & COL6A5 & 1 & 0 & 0 & 0.204677 & 0 \\
\hline Down & AQP10 & 1 & 0 & 0 & 0.185733 & 0 \\
\hline Down & SEC14L5 & 1 & 0 & 0 & 0.236183 & 0 \\
\hline Down & HPGD & 1 & 0 & 0 & 0.214766 & 0 \\
\hline Down & CNTD1 & 1 & 0 & 0 & 0.666667 & 0 \\
\hline Down & GGT6 & 1 & 0 & 0 & 0.666667 & 0 \\
\hline Down & PDILT & 1 & 0 & 0 & 0.173137 & 0 \\
\hline Down & GKN2 & 1 & 0 & 0 & 0.20188 & 0 \\
\hline Down & CLDN23 & 1 & 0 & 0 & 0.198825 & 0 \\
\hline Down & HRH2 & 1 & 0 & 0 & 0.195128 & 0 \\
\hline Down & ADAM28 & 1 & 0 & 0 & 0.184706 & 0 \\
\hline Down & PRIMA1 & 1 & 0 & 0 & 1 & 0 \\
\hline Down & MUC6 & 1 & 0 & 0 & 0.20188 & 0 \\
\hline Down & IRX5 & 1 & 0 & 0 & 1 & 0 \\
\hline Down & GUCA2B & 1 & 0 & 0 & 1 & 0 \\
\hline
\end{tabular}




\begin{tabular}{|c|c|c|c|c|c|c|}
\hline Down & АТР13A4 & 1 & 0 & 0 & 1 & 0 \\
\hline Down & SOX2 & 361 & 0.130645 & 91698482 & 0.314504 & $3.13 \mathrm{E}-05$ \\
\hline Down & RIPK4 & 336 & 0.128603 & 98813078 & 0.314446 & 0 \\
\hline Down & FOXA1 & 290 & 0.103625 & 62359854 & 0.309195 & $3.87 \mathrm{E}-04$ \\
\hline Down & EEF1A2 & 192 & 0.092037 & 39507690 & 0.326061 & 7.09E-04 \\
\hline Down & ANG & 126 & 0.033985 & 31690134 & 0.29174 & 0 \\
\hline Down & FGB & 119 & 0.043651 & 12625862 & 0.307262 & 0.004558 \\
\hline Down & PTGER3 & 113 & 0.038772 & 17588946 & 0.28297 & $3.16 \mathrm{E}-04$ \\
\hline Down & $\mathrm{CKB}$ & 111 & 0.036348 & 17987186 & 0.29959 & 0.002502 \\
\hline Down & FOXQ1 & 108 & 0.024413 & 25595054 & 0.265424 & 0 \\
\hline Down & ERBB4 & 101 & 0.039648 & 13011632 & 0.303684 & 0.00268 \\
\hline Down & PRKAA2 & 100 & 0.028743 & 15759608 & 0.279198 & 0 \\
\hline Down & APOA1 & 100 & 0.036853 & 10368028 & 0.293786 & 0.00451 \\
\hline Down & ESRRB & 98 & 0.036893 & 21650562 & 0.308952 & 0.001052 \\
\hline Down & OXCT1 & 97 & 0.02688 & 16657230 & 0.275526 & 0 \\
\hline Down & ATP4A & 92 & 0.038284 & 7433528 & 0.297688 & $2.50 \mathrm{E}-04$ \\
\hline Down & F2RL1 & 90 & 0.02916 & 16825260 & 0.263862 & 0 \\
\hline Down & EYA2 & 88 & 0.023357 & 20081684 & 0.264175 & 0 \\
\hline Down & $\mathrm{CDH} 2$ & 83 & 0.025141 & 12416288 & 0.280608 & 0.001469 \\
\hline Down & SH3GL2 & 81 & 0.028376 & 10624252 & 0.281334 & $3.25 \mathrm{E}-04$ \\
\hline Down & DUSP19 & 78 & 0.022667 & 8084684 & 0.289509 & 0.001053 \\
\hline Down & FAM189A2 & 78 & 0.023811 & 11453482 & 0.276839 & $9.99 \mathrm{E}-04$ \\
\hline Down & ALDOC & 75 & 0.024085 & 9254824 & 0.292324 & 0.004685 \\
\hline Down & SLC25A4 & 74 & 0.020138 & 14876712 & 0.282704 & 0 \\
\hline Down & HBB & 72 & 0.024297 & 9837400 & 0.292358 & 0 \\
\hline Down & SELENBP1 & 69 & 0.020559 & 16033854 & 0.263576 & 0 \\
\hline Down & TTR & 65 & 0.019611 & 8877534 & 0.281971 & 0.004608 \\
\hline Down & NR0B2 & 65 & 0.018911 & 9601392 & 0.285754 & $4.81 \mathrm{E}-04$ \\
\hline Down & SLC15A1 & 65 & 0.022335 & 9413034 & 0.259481 & 0 \\
\hline Down & MRAP2 & 64 & 0.018209 & 14317820 & 0.246694 & 0 \\
\hline Down & APLP1 & 61 & 0.016887 & 7157580 & 0.275734 & $5.84 \mathrm{E}-04$ \\
\hline Down & MIA2 & 61 & 0.023593 & 3857116 & 0.292911 & 0.003507 \\
\hline Down & MUC1 & 59 & 0.01901 & 8685324 & 0.297272 & 0.004386 \\
\hline Down & TMEM171 & 57 & 0.015929 & 7178790 & 0.265162 & 0 \\
\hline Down & VSIG1 & 57 & 0.015506 & 9968024 & 0.251724 & 0 \\
\hline Down & SLC2A12 & 56 & 0.014848 & 11274816 & 0.245344 & 0 \\
\hline Down & KIF1A & 55 & 0.014262 & 10095312 & 0.273082 & 0 \\
\hline Down & LIPH & 54 & 0.014461 & 5415600 & 0.258432 & 0 \\
\hline Down & FOXA3 & 53 & 0.011677 & 3197724 & 0.277576 & 0.007059 \\
\hline Down & FBP1 & 52 & 0.011778 & 5755732 & 0.259718 & 0.007347 \\
\hline Down & ID1 & 51 & 0.014356 & 8073662 & 0.260049 & 0 \\
\hline Down & GLUL & 51 & 0.014074 & 7290628 & 0.273901 & 0 \\
\hline Down & LTF & 51 & 0.015012 & 8074792 & 0.27279 & 0.001569 \\
\hline
\end{tabular}




\begin{tabular}{|c|c|c|c|c|c|c|}
\hline Down & SUSD4 & 50 & 0.014117 & 8153740 & 0.252171 & 0 \\
\hline Down & MYOC & 49 & 0.012703 & 5520884 & 0.273784 & 0 \\
\hline Down & COL2A1 & 48 & 0.014506 & 2615324 & 0.251625 & 0 \\
\hline Down & CSTA & 47 & 0.009908 & 5708660 & 0.266226 & 0 \\
\hline Down & PTPRR & 46 & 0.012338 & 3050164 & 0.277425 & 0.008457 \\
\hline Down & ESRRG & 46 & 0.01155 & 4874608 & 0.278438 & 0.001057 \\
\hline Down & SLC9A1 & 45 & 0.021666 & 3586826 & 0.290993 & 0.008081 \\
\hline Down & RORC & 45 & 0.010968 & 7194834 & 0.26283 & 0 \\
\hline Down & FRMD1 & 45 & 0.01312 & 1673830 & 0.264627 & 0.005051 \\
\hline Down & NCAM1 & 44 & 0.011569 & 4653244 & 0.264476 & 0 \\
\hline Down & DHRS7 & 43 & 0.013463 & 2866004 & 0.265479 & 0.001107 \\
\hline Down & IL1R2 & 42 & 0.011437 & 5905866 & 0.234503 & 0 \\
\hline Down & CHGB & 42 & 0.010047 & 5822946 & 0.266963 & 0 \\
\hline Down & BTNL8 & 42 & 0.011912 & 2086382 & 0.241256 & 0 \\
\hline Down & FBXL13 & 42 & 0.012583 & 5749328 & 0.240111 & 0 \\
\hline Down & FGA & 41 & 0.010321 & 3281616 & 0.289247 & 0.062078 \\
\hline Down & SERPINA5 & 41 & 0.012219 & 1908132 & 0.278756 & 0.008097 \\
\hline Down & LDHD & 40 & 0.011361 & 9207334 & 0.235747 & 0 \\
\hline Down & FGG & 38 & 0.007185 & 2451080 & 0.281195 & 0.049206 \\
\hline Down & RPS6KA6 & 37 & 0.01036 & 3621900 & 0.266684 & 0.004505 \\
\hline Down & CYP2S1 & 37 & 0.009679 & 1915748 & 0.257936 & 0 \\
\hline Down & KLF4 & 36 & 0.008725 & 6243510 & 0.274829 & 0 \\
\hline Down & CA9 & 36 & 0.00838 & 3853714 & 0.278574 & 0 \\
\hline Down & DHCR24 & 36 & 0.006868 & 4428340 & 0.272965 & 0 \\
\hline Down & GALE & 35 & 0.008601 & 4052878 & 0.272805 & 0 \\
\hline Down & GPRC5C & 35 & 0.012273 & 2377340 & 0.271515 & 0.003361 \\
\hline Down & NQO1 & 34 & 0.008383 & 5150060 & 0.274136 & 0 \\
\hline Down & EPN3 & 34 & 0.010642 & 6541196 & 0.240269 & 0 \\
\hline Down & TMED6 & 34 & 0.008373 & 4030958 & 0.222818 & 0 \\
\hline Down & RAB27A & 33 & 0.0091 & 2404172 & 0.26859 & 0.007576 \\
\hline Down & KRT20 & 33 & 0.007564 & 4522038 & 0.244323 & 0 \\
\hline Down & ALDOB & 33 & 0.007577 & 5415906 & 0.25628 & 0 \\
\hline Down & AZGP1 & 33 & 0.007325 & 4722950 & 0.260102 & 0 \\
\hline Down & CYB5A & 32 & 0.014497 & 2040568 & 0.281009 & 0.002016 \\
\hline Down & PTPRN2 & 32 & 0.006444 & 5188802 & 0.24512 & 0 \\
\hline Down & ME1 & 32 & 0.007918 & 3585304 & 0.249439 & 0 \\
\hline Down & LEPR & 31 & 0.008148 & 2585854 & 0.250184 & 0 \\
\hline Down & S100P & 31 & 0.00819 & 3141854 & 0.261794 & 0 \\
\hline Down & MAP7D2 & 31 & 0.006379 & 3776744 & 0.240393 & 0 \\
\hline Down & RIMS1 & 29 & 0.006836 & 2005214 & 0.262183 & 0.004926 \\
\hline Down & CD36 & 29 & 0.006605 & 3244170 & 0.25791 & 0 \\
\hline Down & VSIG2 & 29 & 0.005085 & 4523118 & 0.229594 & 0 \\
\hline Down & CKM & 28 & 0.006486 & 1114366 & 0.26363 & 0.015385 \\
\hline
\end{tabular}




\begin{tabular}{|c|c|c|c|c|c|c|}
\hline Down & PTPRZ1 & 27 & 0.004562 & 2671328 & 0.243834 & 0 \\
\hline Down & PDIA2 & 27 & 0.011946 & 3842958 & 0.264791 & 0 \\
\hline Down & UGT1A10 & 27 & 0.00529 & 2201280 & 0.236884 & 0.02 \\
\hline Down & CMBL & 27 & 0.005343 & 4698256 & 0.254001 & 0 \\
\hline Down & LGALS9C & 27 & 0.006007 & 2789528 & 0.231267 & 0 \\
\hline Down & KLK11 & 27 & 0.005922 & 3556426 & 0.237026 & 0 \\
\hline Down & TFF1 & 26 & 0.00922 & 4457048 & 0.252932 & 0 \\
\hline Down & INSIG1 & 26 & 0.005325 & 1743502 & 0.245875 & 0 \\
\hline Down & RDH12 & 26 & 0.005489 & 2827404 & 0.239964 & 0 \\
\hline Down & GALNT6 & 26 & 0.009106 & 2128734 & 0.260779 & 0 \\
\hline Down & TPD52L1 & 25 & 0.004331 & 1988644 & 0.25113 & 0 \\
\hline Down & GC & 25 & 0.00488 & 2756190 & 0.254786 & 0 \\
\hline Down & FOXA2 & 25 & 0.00442 & 692924 & 0.26162 & 0.027668 \\
\hline Down & RAP1GAP & 25 & 0.005317 & 2730984 & 0.248493 & 0 \\
\hline Down & XYLT2 & 25 & 0.005125 & 3604190 & 0.230953 & 0 \\
\hline Down & PRLR & 24 & 0.004513 & 2639920 & 0.241758 & 0 \\
\hline Down & SCNN1B & 24 & 0.003266 & 1693310 & 0.233134 & 0.051948 \\
\hline Down & GNMT & 24 & 0.003761 & 2292130 & 0.242538 & 0 \\
\hline Down & CA2 & 23 & 0.005398 & 1512836 & 0.267312 & 0 \\
\hline Down & CCKBR & 23 & 0.004282 & 3289826 & 0.231162 & 0.009524 \\
\hline Down & DSC2 & 23 & 0.002627 & 1332696 & 0.243057 & 0 \\
\hline Down & SMPD3 & 23 & 0.00407 & 1526270 & 0.243462 & 0 \\
\hline Down & SOWAHA & 23 & 0.005986 & 3656274 & 0.222304 & 0 \\
\hline Down & FBP2 & 22 & 0.00357 & 1236294 & 0.256075 & 0.047368 \\
\hline Down & SCGN & 22 & 0.005448 & 2292384 & 0.224363 & 0 \\
\hline Down & CXADR & 22 & 0.004966 & 1542936 & 0.256602 & 0 \\
\hline Down & SCGB2A1 & 22 & 0.00411 & 1974286 & 0.247626 & 0 \\
\hline Down & ALDH6A1 & 22 & 0.005212 & 3402338 & 0.242492 & 0 \\
\hline Down & PDGFD & 22 & 0.004274 & 2794740 & 0.226934 & 0 \\
\hline Down & LIFR & 21 & 0.004499 & 3194270 & 0.242423 & 0 \\
\hline Down & KCNQ1 & 21 & 0.004852 & 1329562 & 0.26667 & 0.005848 \\
\hline Down & PXMP2 & 21 & 0.009681 & 2045510 & 0.253585 & 0 \\
\hline Down & SCIN & 21 & 0.004409 & 3432750 & 0.257481 & 0 \\
\hline Down & ALDH3A1 & 21 & 0.006292 & 975432 & 0.247662 & 0.011696 \\
\hline Down & STX19 & 20 & 0.005007 & 1935164 & 0.20909 & 0 \\
\hline Down & TCEAL2 & 20 & 0.003844 & 2368446 & 0.256576 & 0 \\
\hline Down & A4GNT & 20 & 0.004387 & 1662140 & 0.225542 & 0 \\
\hline Down & CHIA & 20 & 0.005062 & 3754078 & 0.241449 & 0 \\
\hline Down & GCNT1 & 20 & 0.004201 & 1845148 & 0.224926 & 0 \\
\hline Down & SCNN1G & 19 & 0.001794 & 974542 & 0.233838 & 0.088235 \\
\hline Down & POU2AF1 & 19 & 0.005426 & 1886150 & 0.231267 & 0 \\
\hline Down & CLEC3B & 19 & 0.003446 & 686120 & 0.253824 & 0.014706 \\
\hline Down & SGK2 & 19 & 0.003011 & 2291524 & 0.255806 & 0 \\
\hline
\end{tabular}




\begin{tabular}{|c|c|c|c|c|c|c|}
\hline Down & COL4A6 & 19 & 0.004108 & 2503680 & 0.231257 & 0 \\
\hline Down & GRIA4 & 18 & 0.004013 & 2094936 & 0.235172 & 0 \\
\hline Down & RAB27B & 18 & 0.003176 & 889536 & 0.249147 & 0.013072 \\
\hline Down & F13A1 & 18 & 0.003111 & 636426 & 0.267886 & 0.05 \\
\hline Down & SYT16 & 18 & 0.003942 & 610066 & 0.237224 & 0 \\
\hline Down & GPT2 & 18 & 0.004219 & 2205028 & 0.24423 & 0 \\
\hline Down & CKMT2 & 18 & 0.003008 & 650282 & 0.255486 & 0.025 \\
\hline Down & ORM1 & 17 & 0.003066 & 2394818 & 0.233881 & 0.007353 \\
\hline Down & PDZD3 & 17 & 0.005754 & 836546 & 0.221188 & 0 \\
\hline Down & SPDEF & 17 & 0.00438 & 1902948 & 0.247842 & 0 \\
\hline Down & SERPINA4 & 17 & 0.003389 & 1618954 & 0.242055 & 0 \\
\hline Down & CYP3A4 & 17 & 0.00331 & 1029374 & 0.24409 & 0.028571 \\
\hline Down & HOMER2 & 17 & 0.004213 & 2318450 & 0.2334 & 0 \\
\hline Down & GSTA1 & 17 & 0.003515 & 1770658 & 0.250711 & 0.038095 \\
\hline Down & CYP2C8 & 17 & 0.002329 & 1066708 & 0.23901 & 0 \\
\hline Down & MAL & 17 & 0.003795 & 1666176 & 0.240382 & 0 \\
\hline Down & BPIFB1 & 17 & 0.002977 & 2398972 & 0.246159 & 0 \\
\hline Down & COL17A1 & 16 & 0.002553 & 1165170 & 0.246408 & 0 \\
\hline Down & EDARADD & 16 & 0.002099 & 1184864 & 0.233166 & 0 \\
\hline Down & CYP2C9 & 16 & 0.002334 & 475378 & 0.234117 & 0.025 \\
\hline Down & EPB41L4B & 16 & 0.003783 & 1719180 & 0.243196 & 0 \\
\hline Down & MUC5B & 16 & 0.003656 & 1742484 & 0.254748 & 0.008333 \\
\hline Down & CGNL1 & 16 & 0.00242 & 1294404 & 0.24865 & 0 \\
\hline Down & AKR1C2 & 15 & 0.002609 & 727192 & 0.228844 & 0.025641 \\
\hline Down & SLPI & 15 & 0.003639 & 1592814 & 0.245167 & 0 \\
\hline Down & AKR1B10 & 15 & 0.002313 & 855778 & 0.229543 & 0.009524 \\
\hline Down & TRIM50 & 15 & 0.003357 & 1937636 & 0.213465 & 0 \\
\hline Down & TST & 15 & 0.002387 & 1686500 & 0.230797 & 0 \\
\hline Down & KLF15 & 15 & 0.002427 & 1312738 & 0.225164 & 0 \\
\hline Down & GABRB3 & 14 & 0.00218 & 943302 & 0.225941 & 0 \\
\hline Down & C6 & 14 & 0.002538 & 1748954 & 0.244323 & 0 \\
\hline Down & ASB11 & 14 & 0.002102 & 1319614 & 0.231351 & 0 \\
\hline Down & TMEM92 & 14 & 0.002742 & 768258 & 0.256538 & 0 \\
\hline Down & PTGR1 & 14 & 0.002181 & 1002112 & 0.221543 & 0 \\
\hline Down & CTSE & 14 & 0.002273 & 897066 & 0.223471 & 0 \\
\hline Down & SYTL2 & 13 & 0.002043 & 537190 & 0.247338 & 0 \\
\hline Down & ARHGDIG & 13 & 0.003657 & 1180020 & 0.219998 & 0 \\
\hline Down & SLC9A3 & 13 & 0.001716 & 783146 & 0.222324 & 0 \\
\hline Down & SULT1C2 & 13 & 0.002072 & 1077230 & 0.2131 & 0 \\
\hline Down & SLC1A2 & 13 & 0.001883 & 1174276 & 0.230433 & 0 \\
\hline Down & PBLD & 13 & 0.002864 & 1604148 & 0.221707 & 0 \\
\hline Down & DEFB1 & 13 & 0.002672 & 969434 & 0.214874 & 0 \\
\hline Down & PLLP & 13 & 0.002953 & 1704122 & 0.210528 & 0 \\
\hline
\end{tabular}




\begin{tabular}{|c|c|c|c|c|c|c|}
\hline Down & BHMT & 12 & 0.001444 & 462034 & 0.200078 & 0 \\
\hline Down & GATA6 & 12 & 0.001888 & 766242 & 0.227925 & 0.015152 \\
\hline Down & SERPINB7 & 12 & 0.001574 & 903854 & 0.221697 & 0 \\
\hline Down & CHGA & 12 & 0.002669 & 892042 & 0.237953 & 0 \\
\hline Down & SLC5A5 & 12 & 0.001844 & 1189896 & 0.214487 & 0 \\
\hline Down & CAPN13 & 12 & 0.002512 & 1267060 & 0.214649 & 0 \\
\hline Down & AKR7A3 & 11 & 0.002079 & 1092290 & 0.218905 & 0 \\
\hline Down & EPS8L1 & 11 & 0.00158 & 1034458 & 0.227337 & 0 \\
\hline Down & TFR2 & 11 & 0.002136 & 335802 & 0.241712 & 0 \\
\hline Down & KLF2 & 11 & 0.001827 & 864958 & 0.229162 & 0.036364 \\
\hline Down & SLC9A2 & 11 & 0.001361 & 674648 & 0.231749 & 0 \\
\hline Down & MAOA & 11 & 0.001393 & 577172 & 0.229615 & 0 \\
\hline Down & AKR1C3 & 11 & 0.002239 & 398010 & 0.2158 & 0.054545 \\
\hline Down & REG3A & 11 & 0.001394 & 775802 & 0.230807 & 0 \\
\hline Down & GHRL & 11 & 0.003071 & 422262 & 0.230714 & 0 \\
\hline Down & DHRS9 & 11 & 0.002519 & 888628 & 0.20417 & 0 \\
\hline Down & AKR1B15 & 11 & 0.001364 & 380620 & 0.232964 & 0.018182 \\
\hline Down & SEMA3B & 11 & 0.001852 & 912096 & 0.223676 & 0 \\
\hline Down & CYSTM1 & 11 & 0.002071 & 692870 & 0.215718 & 0 \\
\hline Down & AMTN & 11 & 0.001781 & 621822 & 0.219159 & 0 \\
\hline Down & GKN1 & 11 & $8.02 \mathrm{E}-04$ & 226994 & 0.217972 & 0 \\
\hline Down & AMPD1 & 11 & $8.02 \mathrm{E}-04$ & 705838 & 0.229502 & 0 \\
\hline Down & MLPH & 10 & 0.001483 & 571000 & 0.262331 & 0.088889 \\
\hline Down & TESC & 10 & 0.001621 & 186720 & 0.23063 & 0.071429 \\
\hline Down & APOBEC1 & 10 & 0.002094 & 841430 & 0.200196 & 0 \\
\hline Down & AKR1C1 & 10 & 0.001725 & 316338 & 0.225492 & 0.071429 \\
\hline Down & RPRM & 10 & 0.001932 & 971234 & 0.229646 & 0 \\
\hline Down & AQP5 & 10 & 0.001026 & 462940 & 0.220787 & 0 \\
\hline Down & GCNT2 & 10 & 0.002683 & 1431378 & 0.220463 & 0 \\
\hline Down & LIPF & 10 & 0.002681 & 291688 & 0.235097 & 0 \\
\hline Down & ENTPD5 & 10 & 0.001423 & 576438 & 0.221966 & 0 \\
\hline Down & CYP2C18 & 10 & 0.00151 & 590472 & 0.218699 & 0.022222 \\
\hline Down & XK & 10 & 0.00259 & 915288 & 0.211688 & 0 \\
\hline Down & UGT1A6 & 10 & $3.51 \mathrm{E}-04$ & 63358 & 0.212075 & 0.25 \\
\hline Down & FOLR1 & 10 & 0.001826 & 786520 & 0.229811 & 0 \\
\hline Down & RASSF6 & 9 & 0.001679 & 758932 & 0.222314 & 0 \\
\hline Down & SLC4A4 & 9 & $8.25 \mathrm{E}-04$ & 147548 & 0.228547 & 0 \\
\hline Down & HAPLN1 & 9 & 0.002127 & 937726 & 0.221514 & 0 \\
\hline Down & ALDH1A1 & 9 & 0.001071 & 502514 & 0.230225 & 0 \\
\hline Down & PAIP2B & 9 & 0.001898 & 820018 & 0.212031 & 0 \\
\hline Down & FNDC5 & 9 & 0.00116 & 227236 & 0.234805 & 0 \\
\hline Down & OASL & 9 & 0.001035 & 554244 & 0.235704 & 0 \\
\hline Down & CYP3A5 & 9 & 0.001621 & 242422 & 0.236227 & 0 \\
\hline
\end{tabular}




\begin{tabular}{|c|c|c|c|c|c|c|}
\hline Down & SCG3 & 9 & 0.00171 & 397816 & 0.234751 & 0 \\
\hline Down & ANGPTL3 & 9 & 0.001408 & 534524 & 0.201355 & 0 \\
\hline Down & CXCL14 & 9 & 0.001418 & 687382 & 0.225194 & 0 \\
\hline Down & FAM3B & 9 & 0.002213 & 335698 & 0.2483 & 0 \\
\hline Down & RNASE1 & 8 & $8.75 \mathrm{E}-04$ & 328862 & 0.22215 & 0 \\
\hline Down & BCAS1 & 8 & $7.11 \mathrm{E}-04$ & 423002 & 0.24225 & 0 \\
\hline Down & HGD & 8 & 0.001216 & 788412 & 0.213572 & 0 \\
\hline Down & C4orf19 & 8 & 0.001639 & 223746 & 0.256512 & 0.071429 \\
\hline Down & MYRIP & 8 & 0.001238 & 430996 & 0.249634 & 0 \\
\hline Down & CIDEC & 8 & 0.001237 & 380180 & 0.208885 & 0 \\
\hline Down & CA4 & 8 & $6.78 \mathrm{E}-04$ & 175498 & 0.219715 & 0 \\
\hline Down & AQP4 & 8 & $7.48 \mathrm{E}-04$ & 268154 & 0.211916 & 0 \\
\hline Down & IGFBP2 & 8 & 0.00149 & 766678 & 0.221294 & 0 \\
\hline Down & HTR1E & 8 & $9.77 \mathrm{E}-04$ & 621360 & 0.233262 & 0 \\
\hline Down & SULT2A1 & 8 & $7.70 \mathrm{E}-04$ & 247322 & 0.211732 & 0 \\
\hline Down & C1orf116 & 8 & $7.46 \mathrm{E}-04$ & 480606 & 0.241187 & 0 \\
\hline Down & FXYD3 & 8 & 0.001716 & 698152 & 0.219658 & 0 \\
\hline Down & TMEM38A & 8 & 0.001989 & 673836 & 0.209975 & 0 \\
\hline Down & FUT9 & 8 & 0.001439 & 449312 & 0.206055 & 0 \\
\hline Down & FCGBP & 8 & $5.65 \mathrm{E}-04$ & 331640 & 0.230287 & 0 \\
\hline Down & PRDM16 & 8 & $6.15 \mathrm{E}-04$ & 224982 & 0.23176 & 0 \\
\hline Down & ITPKA & 8 & $6.95 \mathrm{E}-04$ & 310188 & 0.215991 & 0 \\
\hline Down & BMP5 & 8 & 0.001564 & 204476 & 0.24629 & 0 \\
\hline Down & RGN & 8 & $2.20 \mathrm{E}-04$ & 146076 & 0.221064 & 0 \\
\hline Down & SOSTDC1 & 7 & 0.001188 & 367662 & 0.180492 & 0 \\
\hline Down & APOA4 & 7 & $4.08 \mathrm{E}-04$ & 165970 & 0.21402 & 0 \\
\hline Down & ZBTB7C & 7 & 0.001031 & 422450 & 0.227905 & 0 \\
\hline Down & METTL7A & 7 & 4.95E-04 & 194766 & 0.227601 & 0 \\
\hline Down & ACADL & 7 & 0.001679 & 791198 & 0.227946 & 0 \\
\hline Down & CYP4F12 & 7 & $9.87 \mathrm{E}-04$ & 279876 & 0.220311 & 0 \\
\hline Down & PKIB & 7 & 0.001587 & 460738 & 0.199914 & 0 \\
\hline Down & CCBE1 & 7 & 0.002002 & 326496 & 0.19495 & 0 \\
\hline Down & TFCP2L1 & 7 & $4.28 \mathrm{E}-04$ & 250206 & 0.20633 & 0 \\
\hline Down & PALM3 & 7 & 0.00104 & 644144 & 0.248638 & 0 \\
\hline Down & HYAL1 & 7 & 0.002205 & 417022 & 0.238754 & 0 \\
\hline Down & ADAMTSL1 & 7 & $9.43 \mathrm{E}-04$ & 207474 & 0.199906 & 0 \\
\hline Down & SYTL5 & 6 & 0.001222 & 233628 & 0.223393 & 0 \\
\hline Down & GSTA2 & 6 & $8.20 \mathrm{E}-04$ & 333722 & 0.204948 & 0.133333 \\
\hline Down & DPT & 6 & $4.89 \mathrm{E}-04$ & 261260 & 0.232265 & 0 \\
\hline Down & MT1X & 6 & 3.73E-04 & 229168 & 0.229285 & 0 \\
\hline Down & BEX5 & 6 & $7.89 \mathrm{E}-04$ & 108852 & 0.200715 & 0 \\
\hline Down & ATP4B & 6 & 0.002043 & 235970 & 0.235878 & 0 \\
\hline Down & PLIN5 & 6 & 0.001333 & 771154 & 0.195629 & 0 \\
\hline
\end{tabular}




\begin{tabular}{|c|c|c|c|c|c|c|}
\hline Down & CCL28 & 6 & 0.001575 & 487862 & 0.211872 & 0 \\
\hline Down & UPK1B & 6 & 0.001572 & 934520 & 0.192781 & 0 \\
\hline Down & MAMDC2 & 6 & 0.001576 & 318360 & 0.213296 & 0 \\
\hline Down & SIGLEC11 & 6 & $5.99 \mathrm{E}-04$ & 207770 & 0.228088 & 0 \\
\hline Down & PLAC8 & 6 & $3.02 \mathrm{E}-04$ & 225896 & 0.228527 & 0 \\
\hline Down & RAB37 & 6 & 7.07E-04 & 123228 & 0.228967 & 0 \\
\hline Down & LGALS9B & 6 & 3.47E-04 & 189584 & 0.218307 & 0 \\
\hline Down & ARL14 & 6 & 0.001956 & 1716690 & 0.182771 & 0 \\
\hline Down & SH3BGRL2 & 6 & 0.001142 & 565738 & 0.239863 & 0 \\
\hline Down & SST & 6 & 0.002571 & 944178 & 0.209665 & 0.066667 \\
\hline Down & SLC16A7 & 6 & 0.00134 & 493152 & 0.193116 & 0 \\
\hline Down & $\mathrm{FA} 2 \mathrm{H}$ & 6 & $6.44 \mathrm{E}-04$ & 190132 & 0.205889 & 0 \\
\hline Down & CPA2 & 6 & 8.69E-04 & 220104 & 0.204187 & 0 \\
\hline Down & DNER & 6 & $5.68 \mathrm{E}-04$ & 364110 & 0.227075 & 0 \\
\hline Down & GDPD3 & 6 & 2.89E-04 & 143022 & 0.209949 & 0 \\
\hline Down & KCNJ15 & 5 & 0.001063 & 395016 & 0.212383 & 0 \\
\hline Down & GCKR & 5 & 8.07E-04 & 358596 & 0.212613 & 0 \\
\hline Down & HAS3 & 5 & 7.83E-04 & 180102 & 0.170839 & 0 \\
\hline Down & IGFALS & 5 & $8.48 \mathrm{E}-04$ & 200704 & 0.198178 & 0 \\
\hline Down & CCKAR & 5 & 4.00E-08 & 2 & 0.18778 & 0.666667 \\
\hline Down & TFF2 & 5 & $4.28 \mathrm{E}-04$ & 128148 & 0.208808 & 0 \\
\hline Down & SSTR1 & 5 & $8.16 \mathrm{E}-04$ & 303142 & 0.175286 & 0.1 \\
\hline Down & GPX3 & 5 & 7.83E-04 & 182594 & 0.193995 & 0 \\
\hline Down & ORM2 & 5 & $1.57 \mathrm{E}-04$ & 35318 & 0.220692 & 0.1 \\
\hline Down & APOC3 & 5 & 4.14E-04 & 47088 & 0.233667 & 0.2 \\
\hline Down & DDX60 & 5 & 8.81E-04 & 460534 & 0.218307 & 0 \\
\hline Down & HPN & 5 & 7.26E-04 & 310120 & 0.230194 & 0 \\
\hline Down & GPT & 5 & $8.29 \mathrm{E}-04$ & 291602 & 0.206714 & 0 \\
\hline Down & ODAM & 5 & 8.57E-04 & 403252 & 0.23236 & 0 \\
\hline Down & PAPPA2 & 5 & 8.40E-04 & 242380 & 0.196994 & 0 \\
\hline Down & FMO5 & 5 & $8.78 \mathrm{E}-04$ & 467960 & 0.215254 & 0 \\
\hline Down & SLC16A9 & 5 & $8.61 \mathrm{E}-04$ & 269782 & 0.220074 & 0 \\
\hline Down & TMEM220 & 5 & $5.22 \mathrm{E}-04$ & 290922 & 0.220854 & 0 \\
\hline Down & GDPD2 & 5 & 0.001271 & 445450 & 0.207015 & 0 \\
\hline Down & VILL & 5 & $8.06 \mathrm{E}-04$ & 419916 & 0.21569 & 0 \\
\hline Down & ADH7 & 4 & 5.91E-05 & 29910 & 0.214631 & 0 \\
\hline Down & CLIC6 & 4 & $8.08 \mathrm{E}-04$ & 292454 & 0.186417 & 0 \\
\hline Down & GALNT5 & 4 & 4.33E-04 & 155130 & 0.204366 & 0 \\
\hline Down & KCNJ16 & 4 & 8.03E-04 & 105342 & 0.195794 & 0 \\
\hline Down & CDHR2 & 4 & 0.001174 & 433218 & 0.180696 & 0 \\
\hline Down & KCNE2 & 4 & $5.03 \mathrm{E}-04$ & 75192 & 0.235954 & 0.166667 \\
\hline Down & SULT1B1 & 4 & 4.79E-04 & 89616 & 0.204735 & 0 \\
\hline Down & VSTM2A & 4 & $7.96 \mathrm{E}-04$ & 681826 & 0.169553 & 0 \\
\hline
\end{tabular}




\begin{tabular}{|c|c|c|c|c|c|c|}
\hline Down & RASEF & 4 & $6.42 \mathrm{E}-04$ & 174228 & 0.220463 & 0 \\
\hline Down & GSTA3 & 4 & $5.10 \mathrm{E}-04$ & 346118 & 0.238809 & 0.5 \\
\hline Down & $\mathrm{ADH} 1 \mathrm{C}$ & 4 & 1 & 2 & 1 & 0 \\
\hline Down & RIMS4 & 4 & 4.34E-04 & 216850 & 0.21482 & 0 \\
\hline Down & PGC & 4 & $3.15 \mathrm{E}-04$ & 58062 & 0.251142 & 0 \\
\hline Down & ENAM & 4 & $1.68 \mathrm{E}-04$ & 93264 & 0.210815 & 0 \\
\hline Down & FSIP2 & 4 & $8.09 \mathrm{E}-04$ & 202852 & 0.206338 & 0 \\
\hline Down & SNORD22 & 4 & $3.76 \mathrm{E}-05$ & 31698 & 0.209613 & 0 \\
\hline Down & TM7SF2 & 4 & 4.65E-04 & 146028 & 0.214496 & 0 \\
\hline Down & DMRTA1 & 4 & $9.92 \mathrm{E}-05$ & 71054 & 0.21855 & 0 \\
\hline Down & SCUBE2 & 4 & $3.91 \mathrm{E}-04$ & 94424 & 0.187498 & 0 \\
\hline Down & TMPRSS2 & 4 & $2.21 \mathrm{E}-05$ & 4940 & 0.217944 & 0 \\
\hline Down & SCARA5 & 4 & $5.52 \mathrm{E}-04$ & 205628 & 0.215645 & 0 \\
\hline Down & TMEM100 & 4 & $4.80 \mathrm{E}-04$ & 116462 & 0.203253 & 0 \\
\hline Down & PTGDR2 & 4 & 1 & 12 & 1 & 0 \\
\hline Down & CAPN8 & 4 & 4.14E-04 & 137042 & 0.200597 & 0 \\
\hline Down & ZNF385B & 4 & 7.92E-04 & 439412 & 0.235313 & 0 \\
\hline Down & RANBP3L & 4 & $8.11 \mathrm{E}-04$ & 270746 & 0.209966 & 0 \\
\hline Down & C6orf58 & 4 & 4.97E-04 & 152308 & 0.220055 & 0 \\
\hline Down & PLIN4 & 4 & $4.89 \mathrm{E}-05$ & 42320 & 0.220444 & 0 \\
\hline Down & ACSM1 & 4 & 7.89E-04 & 357944 & 0.177842 & 0 \\
\hline Down & SLC7A8 & 3 & 7.83E-04 & 207170 & 0.191667 & 0 \\
\hline Down & CLCNKA & 3 & 0 & 0 & 0.18787 & 0 \\
\hline Down & DUOX1 & 3 & 4.09E-04 & 206852 & 0.179214 & 0 \\
\hline Down & APOBEC2 & 3 & 0 & 0 & 0.166808 & 0 \\
\hline Down & ANXA10 & 3 & 4.21E-04 & 203664 & 0.234106 & 0 \\
\hline Down & MT1H & 3 & $3.32 \mathrm{E}-04$ & 64160 & 0.191459 & 0 \\
\hline Down & B4GALNT3 & 3 & 4.02E-04 & 211438 & 0.19202 & 0 \\
\hline Down & SOX 21 & 3 & $3.00 \mathrm{E}-08$ & 2 & 0.240767 & 0.666667 \\
\hline Down & NRG4 & 3 & $5.60 \mathrm{E}-04$ & 49388 & 0.234267 & 0 \\
\hline Down & RHBDL2 & 3 & $4.08 \mathrm{E}-04$ & 193280 & 0.180946 & 0 \\
\hline Down & GATA5 & 3 & 3.91E-04 & 70686 & 0.209613 & 0.333333 \\
\hline Down & ADTRP & 3 & 2.92E-05 & 10622 & 0.192425 & 0 \\
\hline Down & PRSS8 & 3 & $4.57 \mathrm{E}-04$ & 232278 & 0.22869 & 0 \\
\hline Down & STYK1 & 3 & $2.69 \mathrm{E}-05$ & 15578 & 0.218494 & 0 \\
\hline Down & B3GAT1 & 3 & 0 & 0 & 0.18006 & 0 \\
\hline Down & PSCA & 3 & $6.95 \mathrm{E}-04$ & 79296 & 0.241335 & 0 \\
\hline Down & ADHFE1 & 3 & $8.07 \mathrm{E}-05$ & 30016 & 0.199805 & 0 \\
\hline Down & CLDN18 & 3 & 4.17E-04 & 121720 & 0.197679 & 0 \\
\hline Down & LRRC66 & 3 & $1.72 \mathrm{E}-04$ & 84034 & 0.221418 & 0 \\
\hline Down & RNASE4 & 3 & 0 & 0 & 0.192324 & 0 \\
\hline Down & KIAA0895 & 3 & $5.83 \mathrm{E}-05$ & 24890 & 0.215581 & 0 \\
\hline Down & CYP2C19 & 2 & 0 & 0 & 0.200274 & 1 \\
\hline
\end{tabular}




\begin{tabular}{lcccccc}
\hline Down & FAM135B & 2 & $1.11 \mathrm{E}-05$ & 6158 & 0.192795 & 0 \\
Down & SLC9A4 & 2 & $3.51 \mathrm{E}-06$ & 1708 & 0.202689 & 0 \\
Down & MT1G & 2 & $9.97 \mathrm{E}-05$ & 24412 & 0.172517 & 0 \\
Down & C22orf23 & 2 & $3.91 \mathrm{E}-04$ & 43196 & 0.16031 & 0 \\
Down & DCAF12L1 & 2 & 1 & 2 & 1 & 0 \\
Down & ANO5 & 2 & $1.16 \mathrm{E}-04$ & 17930 & 0.21883 & 0 \\
Down & TSPAN1 & 2 & $7.81 \mathrm{E}-06$ & 4920 & 0.183381 & 0 \\
Down & ARHGEF37 & 2 & $3.91 \mathrm{E}-04$ & 89488 & 0.215282 & 0 \\
Down & ELOVL6 & 2 & $3.91 \mathrm{E}-04$ & 115044 & 0.204981 & 0 \\
Down & GPR155 & 2 & $5.21 \mathrm{E}-05$ & 24726 & 0.208979 & 0 \\
Down & PM20D1 & 2 & $3.84 \mathrm{E}-06$ & 2032 & 0.172669 & 0 \\
Down & ST6GALNAC1 & 2 & $6.04 \mathrm{E}-05$ & 4124 & 0.250171 & 0 \\
Down & NWD1 & 2 & $3.91 \mathrm{E}-04$ & 113138 & 0.197199 & 0 \\
Down & IGSF9 & 2 & $5.44 \mathrm{E}-05$ & 22396 & 0.216375 & 0 \\
Down & SLC26A9 & 2 & $1.89 \mathrm{E}-04$ & 21422 & 0.238342 & 0 \\
Down & TCN1 & 2 & $3.66 \mathrm{E}-05$ & 43932 & 0.218596 & 0 \\
Down & ENTPD3 & 2 & $3.76 \mathrm{E}-05$ & 15404 & 0.196516 & 0 \\
Down & MSMB & 2 & $9.51 \mathrm{E}-05$ & 49854 & 0.214992 & 0 \\
Down & CADM2 & 2 & $3.91 \mathrm{E}-04$ & 72366 & 0.204858 & 0 \\
Down & MT1M & 2 & $3.91 \mathrm{E}-04$ & 145464 & 0.190028 & 0 \\
Down & MT1F & 2 & $3.91 \mathrm{E}-04$ & 224466 & 0.171194 & 0 \\
Down & IRX3 & 2 & $1.13 \mathrm{E}-05$ & 6548 & 0.207007 & 0 \\
\hline
\end{tabular}

Table 8 miRNA - target gene interaction table

\begin{tabular}{|c|c|c|c|c|c|c|c|}
\hline Regulation & Target Genes & Degree & MicroRNA & Regulation & Target Genes & Degree & MicroRNA \\
\hline $\mathrm{Up}$ & MYB & 24 & hsa-mir-103a-3p & Down & GATA6 & 207 & hsa-mir-4284 \\
\hline Up & SALL4 & 27 & hsa-mir-107 & Down & SULT1B1 & 131 & hsa-mir-4643 \\
\hline Up & ARHGAP39 & 53 & hsa-mir-1179 & Down & GLUL & 126 & hsa-mir-4459 \\
\hline Up & CLDN4 & 73 & hsa-mir-1200 & Down & ENPP5 & 114 & hsa-mir-8082 \\
\hline Up & CPS1 & 56 & hsa-mir-1200 & Down & KLF2 & 107 & hsa-mir-5193 \\
\hline Up & OSMR & 54 & hsa-mir-1208 & Down & GPR155 & 94 & hsa-mir-3685 \\
\hline Up & IL2RA & 50 & hsa-mir-1248 & Down & LDHD & 91 & hsa-mir-6077 \\
\hline Up & CDCA7 & 22 & hsa-mir-1254 & Down & INSIG1 & 85 & hsa-mir- 8073 \\
\hline Up & $\mathrm{CDC} 25 \mathrm{~B}$ & 40 & hsa-mir-1268a & Down & F2RL1 & 85 & hsa-mir-3652 \\
\hline Up & BMP8A & 38 & hsa-mir-1273f & Down & B3GALT5 & 78 & hsa-mir-4273 \\
\hline Up & ANKRD13B & 42 & hsa-mir-1275 & Down & NWD1 & 75 & hsa-mir-4532 \\
\hline Up & CAMK2N1 & 51 & hsa-mir-1281 & Down & SHISA6 & 71 & hsa-mir-2278 \\
\hline Up & FGD6 & 41 & hsa-mir-1289 & Down & ANGPTL3 & 70 & hsa-mir-1206 \\
\hline Up & ILDR1 & 29 & hsa-mir-1303 & Down & FOLR1 & 69 & hsa-mir-4300 \\
\hline Up & COL4A1 & 42 & hsa-mir-1305 & Down & SLC16A9 & 69 & hsa-mir- 4500 \\
\hline Up & ITGA11 & 31 & hsa-mir-1321 & Down & ENTPD5 & 66 & hsa-mir-4488 \\
\hline Up & TGFBI & 22 & hsa-mir-1322 & Down & CADM2 & 66 & hsa-mir-6074 \\
\hline Up & ITGBL1 & 18 & hsa-mir-138-2-3p & Down & CCBE1 & 64 & hsa-mir-4277 \\
\hline Up & PLXNA1 & 58 & hsa-mir-1827 & Down & CGNL1 & 61 & hsa-mir-4293 \\
\hline Up & POLQ & 86 & hsa-mir-1912 & Down & CMBL & 60 & hsa-mir-2052 \\
\hline Up & PTGS2 & 20 & hsa-mir-199a-3p & Down & ACER2 & 59 & hsa-mir-4280 \\
\hline Up & SPON2 & 23 & hsa-mir-2110 & Down & $\mathrm{C} 1$ orf 210 & 59 & hsa-mir-4469 \\
\hline Up & BCAT1 & 50 & hsa-mir-2113 & Down & LIFR & 55 & hsa-mir- 8060 \\
\hline $\mathrm{Up}$ & FPR1 & 94 & hsa-mir-2117 & Down & PRLR & 54 & hsa-mir-4719 \\
\hline Up & DOCK4 & 19 & hsa-mir-23c & Down & METTL7A & 54 & hsa-mir-4432 \\
\hline Up & LY6E & 26 & hsa-mir-2861 & Down & ALDH6A1 & 54 & hsa-mir-5095 \\
\hline Up & SPSB1 & 45 & hsa-mir-297 & Down & FSIP2 & 53 & hsa-mir-4641 \\
\hline Up & GREM1 & 18 & hsa-mir-300 & Down & GALNT6 & 52 & hsa-mir-4770 \\
\hline
\end{tabular}




\begin{tabular}{|c|c|c|c|c|c|c|c|}
\hline Up & EMILIN2 & 31 & hsa-mir-302f & Down & TSPAN1 & 51 & hsa-mir-3662 \\
\hline Up & HAVCR2 & 30 & hsa-mir-3122 & Down & SLC5A5 & 51 & hsa-mir-4421 \\
\hline Up & PLEKHS1 & 34 & hsa-mir-3135b & Down & TMEM151A & 50 & hsa-mir-6069 \\
\hline Up & TRIP13 & 27 & hsa-mir-3138 & Down & FBXL13 & 49 & hsa-mir-4435 \\
\hline Up & ADAMTS14 & 19 & hsa-mir-3150a-3p & Down & SCIN & 48 & hsa-mir-5572 \\
\hline Up & SRPX2 & 40 & hsa-mir-3178 & Down & SLC1A2 & 47 & hsa-mir-3122 \\
\hline Up & PIEZO1 & 17 & hsa-mir-3191-3p & Down & B4GALNT3 & 47 & hsa-mir-3910 \\
\hline Up & MARVELD1 & 47 & hsa-mir-3202 & Down & IL17REL & 46 & hsa-mir-4303 \\
\hline Up & MKI67 & 84 & hsa-mir-3646 & Down & ATP13A4 & 45 & hsa-mir-4480 \\
\hline Up & ORC1 & 53 & hsa-mir-3666 & Down & PLCXD3 & 45 & hsa-mir-1248 \\
\hline Up & PRRX1 & 17 & hsa-mir-378j & Down & ANG & 45 & hsa-mir-5693 \\
\hline Up & PMEPA1 & 59 & hsa-mir-3909 & Down & DUSP19 & 45 & hsa-mir-1303 \\
\hline Up & $\mathrm{RCC} 2$ & 135 & hsa-mir-3911 & Down & TMEM100 & 45 & hsa-mir-4427 \\
\hline Up & ADAM12 & 23 & hsa-mir-3915 & Down & SLC26A9 & 44 & hsa-mir-4306 \\
\hline Up & GEM & 24 & hsa-mir-3920 & Down & DHCR24 & 43 & hsa-mir-4496 \\
\hline Up & PLXDC2 & 58 & hsa-mir-3924 & Down & ACADL & 42 & hsa-mir-30c-2-3p \\
\hline Up & PDPN & 29 & hsa-mir-3929 & Down & FOXQ1 & 42 & hsa-mir-3666 \\
\hline Up & INHBA & 51 & hsa-mir-3973 & Down & PLLP & 41 & hsa-mir-3910 \\
\hline Up & $\mathrm{CCND} 2$ & 179 & hsa-mir-3976 & Down & ELOVL6 & 41 & hsa-mir-5703 \\
\hline Up & SERPINE1 & 22 & hsa-mir-3977 & Down & APOC3 & 40 & hsa-mir-7703 \\
\hline Up & ONECUT2 & 26 & hsa-mir-4251 & Down & RAB27A & 40 & hsa-mir-3170 \\
\hline Up & ITGB8 & 65 & hsa-mir-4263 & Down & PRKAA2 & 40 & hsa-mir-3166 \\
\hline Up & FOXC1 & 106 & hsa-mir-4269 & Down & C1orf115 & 39 & hsa-mir-4451 \\
\hline Up & E2F3 & 134 & hsa-mir-4271 & Down & CYB5A & 39 & hsa-mir-600 \\
\hline Up & MCM7 & 51 & hsa-mir-4283 & Down & PRSS8 & 38 & hsa-mir-4441 \\
\hline Up & CTSB & 26 & hsa-mir-4291 & Down & RIMS4 & 37 & hsa-mir-1976 \\
\hline Up & IFITM1 & 38 & hsa-mir-4295 & Down & KIAA0895 & 37 & hsa-mir-4307 \\
\hline Up & TNS4 & 41 & hsa-mir-4300 & Down & GPRC5C & 36 & hsa-mir-8089 \\
\hline Up & CELSR3 & 71 & hsa-mir-4301 & Down & EPB41L4B & 36 & hsa-mir- 8077 \\
\hline Up & BUB1 & 67 & hsa-mir-4302 & Down & MTRNR2L8 & 34 & hsa-mir-3159 \\
\hline Up & C1QTNF6 & 36 & hsa-mir-4310 & Down & CYP2C19 & 34 & hsa-mir-5186 \\
\hline Up & FSTL3 & 39 & hsa-mir-4314 & Down & GABRB3 & 34 & hsa-mir-298 \\
\hline Up & OLR1 & 81 & hsa-mir-4316 & Down & AKR1B10 & 34 & hsa-mir-3611 \\
\hline Up & GINS4 & 46 & hsa-mir-4318 & Down & SEC14L5 & 33 & hsa-mir-6131 \\
\hline Up & MMP16 & 28 & hsa-mir-4318 & Down & RPRM & 32 & hsa-mir-6090 \\
\hline Up & FSTL1 & 38 & hsa-mir-4420 & Down & SLC9A4 & 32 & hsa-mir- 8054 \\
\hline Up & FMNL3 & 78 & hsa-mir-4421 & Down & KIAA1324 & 32 & hsa-mir-3135a \\
\hline $\mathrm{Up}$ & COL1A2 & 30 & hsa-mir-4424 & Down & FOXA1 & 32 & hsa-mir-4428 \\
\hline Up & CAD & 64 & hsa-mir-4426 & Down & ASB11 & 31 & hsa-mir-4803 \\
\hline Up & FSCN1 & 99 & hsa-mir-4430 & Down & SLC9A1 & 31 & hsa-mir-644a \\
\hline Up & COL5A1 & 31 & hsa-mir-4434 & Down & SOWAHA & 30 & hsa-mir-4999-3p \\
\hline Up & GDF15 & 23 & hsa-mir-4436a & Down & ASAH2 & 30 & hsa-mir-4657 \\
\hline Up & THBS1 & 95 & hsa-mir-4441 & Down & PTGDR2 & 30 & hsa-mir-5695 \\
\hline Up & GPR176 & 18 & hsa-mir-4445-5p & Down & PAIP2B & 30 & hsa-mir-4287 \\
\hline Up & MEX3A & 95 & hsa-mir- 4447 & Down & NRG4 & 30 & hsa-mir-4510 \\
\hline Up & DGKH & 52 & hsa-mir-4452 & Down & PLAC8 & 30 & hsa-mir-4481 \\
\hline Up & LIF & 47 & hsa-mir-4454 & Down & TFCP2L1 & 29 & hsa-mir-4468 \\
\hline Up & CLDN1 & 35 & hsa-mir-4461 & Down & HAS3 & 29 & hsa-mir-520e \\
\hline Up & SERPINH1 & 77 & hsa-mir-4463 & Down & LIPH & 27 & hsa-mir-6089 \\
\hline Up & TTYH3 & 56 & hsa-mir-4468 & Down & SSTR1 & 26 & hsa-mir-4467 \\
\hline $\mathrm{Up}$ & XRCC2 & 65 & hsa-mir-4469 & Down & SLPI & 26 & hsa-mir-1827 \\
\hline Up & CYP2W1 & 56 & hsa-mir-4472 & Down & ECHDC3 & 26 & hsa-mir-5697 \\
\hline Up & ELN & 22 & hsa-mir-4472 & Down & KLF4 & 26 & hsa-mir-663a \\
\hline Up & ARHGAP11A & 37 & hsa-mir-4478 & Down & GCNT4 & 25 & hsa-mir-3689c \\
\hline Up & TIMP1 & 22 & hsa-mir-4481 & Down & SERPINA4 & 25 & hsa-mir-6073 \\
\hline Up & $\mathrm{KIF} 2 \mathrm{C}$ & 68 & hsa-mir-4484 & Down & RASSF6 & 25 & hsa-mir-6778-3p \\
\hline Up & LTBP2 & 33 & hsa-mir-4487 & Down & VSIG1 & 24 & hsa-mir-3198 \\
\hline Up & $\mathrm{CCNF}$ & 102 & hsa-mir-4492 & Down & RHBDL2 & 24 & hsa-mir-6773-3p \\
\hline Up & MYBL2 & 45 & hsa-mir-4498 & Down & $\mathrm{CDH} 2$ & 24 & hsa-mir-1244 \\
\hline Up & ESPL1 & 34 & hsa-mir-4500 & Down & TM6SF2 & 23 & hsa-mir-6081 \\
\hline $\mathrm{Up}$ & HIST3H2BB & 35 & hsa-mir-4507 & Down & STYK1 & 23 & hsa-mir-548u \\
\hline Up & LOXL2 & 26 & hsa-mir-4507 & Down & TTR & 23 & hsa-mir-1273f \\
\hline Up & KIF23 & 59 & hsa-mir-4509 & Down & VSIG2 & 23 & hsa-mir-711 \\
\hline Up & IGSF6 & 48 & hsa-mir-4514 & Down & TMEM38A & 23 & hsa-mir-520b \\
\hline Up & SLC37A2 & 30 & hsa-mir-4514 & Down & APOA1 & 22 & hsa-mir-1305 \\
\hline Up & GFPT2 & 23 & hsa-mir-4516 & Down & HS6ST3 & 22 & hsa-mir-147a \\
\hline Up & IL6 & 22 & hsa-mir-451a & Down & KCNJ15 & 22 & hsa-mir-548ac \\
\hline $\mathrm{Up}$ & MCM10 & 21 & hsa-mir-4522 & Down & MYZAP & 22 & hsa-mir-4801 \\
\hline Up & ALDH1A3 & 32 & hsa-mir-4533 & Down & FUT9 & 21 & hsa-mir-664b-3p \\
\hline Up & COL12A1 & 28 & hsa-mir-4533 & Down & PSAPL1 & 21 & hsa-mir-550b-2-5p \\
\hline
\end{tabular}




\begin{tabular}{|c|c|c|c|c|c|c|c|}
\hline Up & $\mathrm{C} 3$ & 118 & hsa-mir-4537 & Down & FGG & 21 & hsa-mir-5008-5p \\
\hline Up & ODF2L & 37 & hsa-mir-4540 & Down & MT1E & 21 & hsa-mir-138-2-3p \\
\hline Up & F2RL2 & 62 & hsa-mir-4635 & Down & CLIC6 & 20 & hsa-mir-8055 \\
\hline Up & IFFO2 & 51 & hsa-mir-4641 & Down & EDARADD & 20 & hsa-mir-103a-2-5p \\
\hline Up & SLC2A3 & 47 & hsa-mir-4654 & Down & PTPRN2 & 20 & hsa-mir-4311 \\
\hline Up & ICAM1 & 34 & hsa-mir-466 & Down & C4orf19 & 20 & hsa-mir-4430 \\
\hline Up & COL1A1 & 97 & hsa-mir-4660 & Down & HRH2 & 20 & hsa-mir-6129 \\
\hline Up & VCAN & 24 & hsa-mir-4666b & Down & CD36 & 20 & hsa-mir-3190-5p \\
\hline Up & ITGA5 & 27 & hsa-mir-4667-3p & Down & SLC4A4 & 19 & hsa-mir-6747-3p \\
\hline Up & AHNAK2 & 16 & hsa-mir-4670-3p & Down & SLC15A1 & 19 & hsa-mir-4649-3p \\
\hline Up & STC2 & 90 & hsa-mir-4689 & Down & IGSF9 & 19 & hsa-mir-548x-3p \\
\hline Up & SPARC & 21 & hsa-mir-4693-3p & Down & ANO7 & 19 & hsa-mir-6852-5p \\
\hline Up & THY 1 & 32 & hsa-mir-4706 & Down & ALDOC & 19 & hsa-mir-2116-3p \\
\hline Up & CLSPN & 73 & hsa-mir-4710 & Down & GPT2 & 19 & hsa-mir-3911 \\
\hline Up & WDR72 & 23 & hsa-mir-4719 & Down & SOX 2 & 19 & hsa-mir-1181 \\
\hline Up & THBS2 & 81 & hsa-mir-4771 & Down & SLC28A2 & 18 & hsa-mir-4705 \\
\hline Up & MDFI & 36 & hsa-mir-4773 & Down & LTF & 18 & hsa-mir-4768-5p \\
\hline Up & PLA2G7 & 18 & hsa-mir-4775 & Down & C6 & 18 & hsa-mir-6511a-3p \\
\hline Up & RHBDF2 & 40 & hsa-mir-4779 & Down & FGB & 18 & hsa-mir-3155b \\
\hline Up & PXDN & 27 & hsa-mir-4780 & Down & HAPLN1 & 18 & hsa-mir-548an \\
\hline $\mathrm{Up}$ & CLSTN3 & 17 & hsa-mir-4801 & Down & SLC9A3 & 17 & hsa-mir-4749-5p \\
\hline Up & $\mathrm{CBX} 2$ & 80 & hsa-mir-4803 & Down & FAM174B & 17 & hsa-mir-5006-3p \\
\hline Up & GNB4 & 27 & hsa-mir-5001-3p & Down & CYP3A5 & 17 & hsa-mir-599 \\
\hline Up & SLC11A1 & 19 & hsa-mir-5006-3p & Down & PAQR8 & 17 & hsa-mir-6881-3p \\
\hline Up & LRP8 & 18 & hsa-mir-5011-5p & Down & ADAMTSL1 & 17 & hsa-mir-3689d \\
\hline Up & PLK1 & 40 & hsa-mir-5047 & Down & PLIN5 & 17 & hsa-mir-4418 \\
\hline Up & NCR3LG1 & 54 & hsa-mir-5087 & Down & HHLA2 & 16 & hsa-mir-3133 \\
\hline $\mathrm{Up}$ & PLXDC1 & 20 & hsa-mir-5091 & Down & CAPN13 & 16 & hsa-mir-549a \\
\hline Up & HOXA10 & 83 & hsa-mir-5093 & Down & RASEF & 16 & hsa-mir-5700 \\
\hline Up & LIPG & 89 & hsa-mir-5096 & Down & B3GNT7 & 15 & hsa-mir-7975 \\
\hline Up & KIF18B & 36 & hsa-mir-5100 & Down & TPD52L1 & 14 & hsa-mir-8066 \\
\hline Up & HOXA13 & 111 & hsa-mir-5190 & Down & SLC2A12 & 14 & hsa-mir-502-3p \\
\hline Up & SLC43A3 & 60 & hsa-mir-5191 & Down & DUOX2 & 14 & hsa-mir-6749-3p \\
\hline Up & KRT80 & 65 & hsa-mir-5192 & Down & CIDEC & 14 & hsa-mir-548aw \\
\hline $\mathrm{Up}$ & PGM2L1 & 117 & hsa-mir-5193 & Down & CTSE & 14 & hsa-mir-3650 \\
\hline Up & MFAP2 & 24 & hsa-mir-520b & Down & NKX6-2 & 13 & hsa-mir-6889-5p \\
\hline Up & TOP2A & 17 & hsa-mir-520d-5p & Down & TMEM220 & 13 & hsa-mir-7161-5p \\
\hline $\mathrm{Up}$ & ATAD2 & 35 & hsa-mir-520e & Down & C14orf180 & 13 & hsa-mir-1255b-2-3p \\
\hline Up & MMP9 & 21 & hsa-mir-524-5p & Down & GCNT1 & 13 & hsa-mir-2682-3p \\
\hline Up & ATP11A & 28 & hsa-mir-526a & Down & FOXA2 & 13 & hsa-mir-450a-1-3p \\
\hline Up & $\mathrm{DIO} 2$ & 21 & hsa-mir-544a & Down & SCNN1G & 12 & hsa-mir-433-3p \\
\hline Up & CKAP2 & 17 & hsa-mir-548ah-5p & Down & TTC39A & 12 & hsa-mir-1273g-3p \\
\hline Up & RAB31 & 30 & hsa-mir-548an & Down & SIGLEC11 & 12 & hsa-mir-520h \\
\hline Up & CDC6 & 28 & hsa-mir-548ap-3p & Down & ESRRG & 12 & hsa-mir-4492 \\
\hline Up & EPHB1 & 18 & hsa-mir-548aw & Down & UNC5D & 12 & hsa-mir-527 \\
\hline Up & CD84 & 33 & hsa-mir-548s & Down & SLC16A7 & 12 & hsa-mir-759 \\
\hline Up & WISP1 & 27 & hsa-mir-557 & Down & PBLD & 12 & hsa-mir-374a-5p \\
\hline $\mathrm{Up}$ & GLI2 & 35 & hsa-mir-5572 & Down & PROM2 & 11 & hsa-mir-6134 \\
\hline Up & COL8A1 & 39 & hsa-mir-564 & Down & TRNP1 & 11 & hsa-mir-4793-3p \\
\hline Up & NT5DC3 & 85 & hsa-mir-5680 & Down & PTGER3 & 11 & hsa-mir-5003-3p \\
\hline $\mathrm{Up}$ & FAM83D & 40 & hsa-mir-5691 & Down & C1orf116 & 11 & hsa-mir-581 \\
\hline Up & FOXK1 & 259 & hsa-mir-5693 & Down & ARHGEF37 & 11 & hsa-mir-6780a-3p \\
\hline Up & ST3GAL2 & 22 & hsa-mir-5693 & Down & ST6GALNAC1 & 11 & hsa-mir-3155a \\
\hline Up & GPX8 & 25 & hsa-mir-5700 & Down & SLC26A7 & 11 & hsa-mir-4659b-3p \\
\hline $\mathrm{Up}$ & APLN & 30 & hsa-mir-5708 & Down & REG3A & 11 & hsa-mir-2277-3p \\
\hline Up & TCOF1 & 28 & hsa-mir-588 & Down & RPS6KA6 & 11 & hsa-mir-4687-3p \\
\hline Up & SLC39A10 & 27 & hsa-mir-591 & Down & ADAM28 & 11 & hsa-mir-23c \\
\hline Up & GAS7 & 18 & hsa-mir-599 & Down & CKB & 11 & hsa-mir-551a \\
\hline Up & ADAMTS9 & 24 & hsa-mir-603 & Down & SLC25A4 & 11 & hsa-mir-7112-3p \\
\hline Up & IGF2BP3 & 52 & hsa-mir-6069 & Down & FNDC5 & 10 & hsa-mir-4659a-3p \\
\hline $\mathrm{Up}$ & TNFAIP2 & 24 & hsa-mir-6069 & Down & AADAC & 10 & hsa-mir-1179 \\
\hline Up & IGSF9B & 30 & hsa-mir-607 & Down & HOMER2 & 10 & hsa-mir-922 \\
\hline Up & DUSP10 & 39 & hsa-mir-6072 & Down & RIPK4 & 10 & hsa-mir-5003-5p \\
\hline Up & ZNF703 & 115 & hsa-mir-6074 & Down & B3GNT6 & 9 & hsa-mir-3909 \\
\hline Up & LPCAT1 & 29 & hsa-mir-6077 & Down & IRX2 & 9 & hsa-mir-6808-3p \\
\hline Up & PODXL & 69 & hsa-mir-6079 & Down & BCAS1 & 9 & hsa-mir-933 \\
\hline Up & ENTPD1 & 64 & hsa-mir-6079 & Down & PRIMA1 & 9 & hsa-mir-5011-5p \\
\hline $\mathrm{Up}$ & CYP2B6 & 43 & hsa-mir-608 & Down & TMEM92 & 9 & hsa-mir-4713-5p \\
\hline Up & CCDC80 & 135 & hsa-mir-6083 & Down & MUC1 & 9 & hsa-mir-145-5p \\
\hline Up & PLEKHG2 & 94 & hsa-mir-6127 & Down & ESRRB & 9 & hsa-mir-6769b-5p \\
\hline
\end{tabular}




\begin{tabular}{|c|c|c|c|c|c|c|c|}
\hline Up & ABCA1 & 19 & hsa-mir-613 & Down & ERBB4 & 9 & hsa-mir-221-3p \\
\hline Up & VASH1 & 49 & hsa-mir-6131 & Down & KIF1A & 9 & hsa-mir-652-3p \\
\hline Up & IFITM3 & 35 & hsa-mir-6132 & Down & EEF1A2 & 8 & hsa-mir-663b \\
\hline Up & NFAM1 & 40 & hsa-mir-617 & Down & RAB37 & 8 & hsa-mir-4673 \\
\hline $\mathrm{Up}$ & NOTCH1 & 44 & hsa-mir-623 & Down & ID1 & 8 & hsa-mir-100-5p \\
\hline Up & KNTC1 & 27 & hsa-mir-632 & Down & XYLT2 & 8 & hsa-mir-18a-5p \\
\hline Up & CEP170 & 37 & hsa-mir-633 & Down & BMP5 & 7 & hsa-mir-1266-3p \\
\hline Up & $\mathrm{F} 2 \mathrm{R}$ & 37 & hsa-mir-640 & Down & ZBTB7C & 7 & hsa-mir-4650-5p \\
\hline Up & GPR161 & 22 & hsa-mir-6501-5p & Down & MTRNR2L2 & 7 & hsa-mir-299-5p \\
\hline Up & SNX10 & 20 & hsa-mir-6507-5p & Down & PRDM16 & 7 & hsa-mir-101-3p \\
\hline Up & MTHFD1L & 31 & hsa-mir-6509-3p & Down & NCAM1 & 7 & hsa-mir-200c-3p \\
\hline $\mathrm{Up}$ & VGLL3 & 18 & hsa-mir-6512-3p & Down & DSC2 & 7 & hsa-mir-25-3p \\
\hline Up & COL18A1 & 40 & hsa-mir-661 & Down & DPCR1 & 7 & hsa-mir-24-1-5p \\
\hline Up & KIF21B & 23 & hsa-mir-663b & Down & HPGD & 7 & hsa-mir-664a-3p \\
\hline $\mathrm{Up}$ & FAR2 & 18 & hsa-mir-6715b-3p & Down & ADAMTS15 & 6 & hsa-mir-4540 \\
\hline Up & HJURP & 24 & hsa-mir-6720-3p & Down & XK & 6 & hsa-mir-31-3p \\
\hline Up & TRIM29 & 20 & hsa-mir-6746-5p & Down & CXCL14 & 5 & hsa-mir-2276-3p \\
\hline Up & IFI44L & 19 & hsa-mir-6809-3p & Down & ENAM & 5 & hsa-mir-15a-3p \\
\hline Up & PADI2 & 24 & hsa-mir-6826-3p & Down & GALNT5 & 5 & hsa-mir-651-3p \\
\hline Up & ANTXR1 & 21 & hsa-mir-6837-3p & Down & FGA & 5 & hsa-mir-409-3p \\
\hline Up & OMD & 31 & hsa-mir-6843-3p & Down & RORC & 5 & hsa-mir-1236-3p \\
\hline Up & $\mathrm{BICC} 1$ & 18 & hsa-mir-7110-3p & Down & MAOA & 5 & hsa-mir-5000-5p \\
\hline Up & EPHB2 & 35 & hsa-mir-7150 & Down & POU2AF1 & 5 & hsa-mir-210-3p \\
\hline Up & NCAPH & 31 & hsa-mir-759 & Down & CYSTM1 & 5 & hsa-mir-183-3p \\
\hline $\mathrm{Up}$ & P2RX7 & 39 & hsa-mir-764 & Down & UBE2QL1 & 4 & hsa-mir-2909 \\
\hline Up & HEYL & 83 & hsa-mir-7641 & Down & KLHDC7A & 4 & hsa-mir-4662a-3p \\
\hline Up & CLEC7A & 33 & hsa-mir-7977 & Down & FAM135B & 4 & hsa-mir-2114-3p \\
\hline Up & SEMA6B & 29 & hsa-mir-8052 & Down & GGT6 & 4 & hsa-mir-501-5p \\
\hline Up & PDE3A & 84 & hsa-mir-8066 & Down & SLC7A8 & 4 & hsa-mir-4644 \\
\hline Up & PKMYT1 & 39 & hsa-mir-8078 & Down & IGFBP2 & 4 & hsa-mir-491-3p \\
\hline Up & ATAD5 & 51 & hsa-mir-8080 & Down & SPTSSB & 4 & hsa-mir-3606-5p \\
\hline Up & ADAMTS4 & 77 & hsa-mir-8081 & Down & CYP2C8 & 4 & hsa-mir-1178-3p \\
\hline Up & GDPD5 & 31 & hsa-mir-922 & Down & RAB27B & 4 & hsa-mir-193a-3p \\
\hline Up & STIL & 16 & hsa-mir-4266 & Down & OXCT1 & 4 & hsa-mir-155-5p \\
\hline $\mathrm{Up}$ & GRIN2D & 16 & hsa-mir-6804-5p & Down & GCNT2 & 4 & hsa-mir-98-5p \\
\hline Up & LRRC32 & 16 & hsa-mir-378g & Down & CXADR & 4 & hsa-mir-342-3p \\
\hline Up & MXRA8 & 16 & hsa-mir-1295b-5p & Down & CA2 & 4 & hsa-mir-99b-3p \\
\hline $\mathrm{Up}$ & SCARF2 & 16 & hsa-mir-6081 & Down & SELENBP1 & 4 & hsa-mir-20a-5p \\
\hline Up & NOP2 & 15 & hsa-mir-296-3p & Down & SPDEF & 4 & hsa-let-7c-5p \\
\hline Up & KIF14 & 15 & hsa-mir-4523 & Down & LEPR & 3 & hsa-mir-200c-3p \\
\hline Up & ANGPTL2 & 15 & hsa-mir-548ac & Down & CYP2C9 & 3 & hsa-mir-143-3p \\
\hline Up & CDX2 & 15 & hsa-mir-6747-3p & Down & OASL & 3 & hsa-mir-146a-5p \\
\hline Up & TREM1 & 15 & hsa-mir-421 & Down & TFF1 & 3 & hsa-mir-423-5p \\
\hline Up & SERPINB5 & 14 & hsa-mir-4762-5p & Down & PTPRZ1 & 3 & hsa-mir-181a-5p \\
\hline $\mathrm{Up}$ & SELE & 14 & hsa-mir-3065-5p & Down & CCKBR & 3 & hsa-mir-148a-3p \\
\hline Up & FOXM1 & 14 & hsa-mir-24-1-5p & Down & RNASE4 & 3 & hsa-mir-215-5p \\
\hline Up & PLEKHG4 & 14 & hsa-mir-6502-5p & Down & MT1F & 3 & hsa-mir-219a-5p \\
\hline Up & TDRD6 & 14 & hsa-mir-5088-3p & Down & SH3GL2 & 3 & hsa-mir-107 \\
\hline Up & PLEK & 14 & hsa-mir-3180-5p & Down & NR0B2 & 3 & hsa-mir-141-3p \\
\hline Up & СРХМ2 & 14 & hsa-mir-6877-3p & Down & S100P & 3 & hsa-mir-24-3p \\
\hline $\mathrm{Up}$ & ECT2 & 13 & hsa-mir-4255 & Down & TST & 3 & hsa-mir-548b-3p \\
\hline Up & ITGAX & 13 & hsa-mir-6087 & Down & TM7SF2 & 2 & hsa-mir-193b-3p \\
\hline Up & CACNA1E & 13 & hsa-mir-541-3p & Down & APLP1 & 2 & hsa-mir-484 \\
\hline Up & COL5A3 & 13 & hsa-mir-642a-5p & Down & MIA2 & 2 & hsa-mir-155-5p \\
\hline Up & RELT & 12 & hsa-mir-6849-3p & Down & ALDOB & 2 & hsa-mir-378a-3p \\
\hline Up & CENPF & 12 & hsa-mir-1226-3p & Down & PXMP2 & 2 & hsa-mir-935 \\
\hline Up & COL4A2 & 12 & hsa-mir-210-3p & Down & CLDN23 & 2 & hsa-mir-222-3p \\
\hline $\mathrm{Up}$ & PLXNC1 & 12 & hsa-mir-7853-5p & Down & ALDH1A1 & 2 & hsa-mir-140-5p \\
\hline Up & BOC & 12 & hsa-mir-4659a-5p & Down & SULT1C2 & 2 & hsa-mir-7-5p \\
\hline Up & DPYSL3 & 12 & hsa-mir-3667-3p & Down & ZNF385B & 2 & hsa-mir-215-5p \\
\hline Up & PARVG & 12 & hsa-mir-6804-3p & Down & FAM189A2 & 2 & hsa-mir-192-5p \\
\hline Up & CRABP2 & 12 & hsa-mir-3141 & Down & RAP1GAP & 2 & hsa-mir-215-5p \\
\hline Up & CLDN7 & 12 & hsa-mir-3670 & Down & MT1X & 2 & hsa-mir-1225-3p \\
\hline Up & COL3A1 & 11 & hsa-mir-455-3p & Down & ENTPD3 & 2 & hsa-mir-192-5p \\
\hline $\mathrm{Up}$ & KIF26B & 11 & hsa-mir-501-5p & Down & COL4A6 & 2 & hsa-mir-29b-3p \\
\hline Up & MMP14 & 11 & hsa-mir-133b & Down & COL2A1 & 2 & hsa-mir-106a-5p \\
\hline Up & FBN1 & 11 & hsa-mir-133a-3p & Down & AQP4 & 2 & hsa-mir-320a \\
\hline Up & NNMT & 11 & hsa-mir-6500-3p & Down & AKR1C3 & 2 & hsa-mir-98-5p \\
\hline Up & SULF2 & 11 & hsa-mir-5585-3p & Down & DDX60 & 2 & hsa-mir-1-3p \\
\hline Up & LAMA5 & 11 & hsa-mir-1909-3p & Down & HGD & 2 & hsa-mir-26b-5p \\
\hline
\end{tabular}




\begin{tabular}{|c|c|c|c|c|c|c|c|}
\hline Up & $\mathrm{TNC}$ & 11 & hsa-mir-513a-3p & Down & CA9 & 2 & hsa-mir-98-5p \\
\hline Up & SLC24A3 & 11 & hsa-mir-548aa & Down & SULT2A1 & 2 & hsa-mir-24-3p \\
\hline Up & BGN & 11 & hsa-mir-4311 & Down & MT1M & 2 & hsa-mir-26b-5p \\
\hline Up & UBE2C & 10 & hsa-mir-631 & Down & PDGFD & 2 & hsa-mir-21-5p \\
\hline $\mathrm{Up}$ & EGR2 & 10 & hsa-mir-150-5p & Down & RNASE1 & 2 & hsa-mir-19b-3p \\
\hline Up & PDGFRB & 10 & hsa-mir-224-5p & Down & AMPD1 & 2 & hsa-mir-10a-5p \\
\hline Up & MCM2 & 10 & hsa-mir-1296-5p & Down & IRX5 & 1 & hsa-mir-4497 \\
\hline Up & $\mathrm{ENC1}$ & 10 & hsa-mir-5584-5p & Down & CLDN18 & 1 & hsa-mir-1303 \\
\hline Up & RTKN2 & 10 & hsa-mir-6876-5p & Down & ATP4A & 1 & hsa-mir-1289 \\
\hline Up & $\mathrm{CDH} 13$ & 10 & hsa-mir-3074-5p & Down & PTGR1 & 1 & hsa-mir-522-3p \\
\hline Up & CD109 & 10 & hsa-mir-103a-2-5p & Down & ITPKA & 1 & hsa-mir-193b-3p \\
\hline Up & SH3PXD2B & 10 & hsa-mir-6749-3p & Down & AKR1C2 & 1 & hsa-mir-193b-3p \\
\hline Up & HMCN1 & 10 & hsa-mir-1299 & Down & GRIA4 & 1 & hsa-mir-484 \\
\hline Up & TMEM158 & 10 & hsa-mir-548z & Down & PLIN4 & 1 & hsa-mir-335-5p \\
\hline Up & ZNF469 & 10 & hsa-mir-151b & Down & MUC5B & 1 & hsa-mir-335-5p \\
\hline Up & FANCD2 & 9 & hsa-mir-618 & Down & LGALS9C & 1 & hsa-mir-335-5p \\
\hline Up & LAPTM5 & 9 & hsa-mir-4680-3p & Down & STX19 & 1 & hsa-mir-335-5p \\
\hline Up & NOTCH3 & 9 & hsa-mir-206 & Down & FMO6P & 1 & hsa-mir-335-5p \\
\hline Up & FCGR3B & 9 & hsa-mir-6740-3p & Down & ENHO & 1 & hsa-mir-335-5p \\
\hline Up & KIAA1755 & 9 & hsa-mir-4756-3p & Down & C6orf58 & 1 & hsa-mir-335-5p \\
\hline Up & $\mathrm{C} 2 \mathrm{CD} 4 \mathrm{~A}$ & 8 & hsa-mir-4659b-3p & Down & BEX5 & 1 & hsa-mir-335-5p \\
\hline Up & FADS2 & 8 & hsa-mir-500a-3p & Down & SCARA5 & 1 & hsa-mir-335-5p \\
\hline Up & CTHRC1 & 8 & hsa-mir-630 & Down & LGALS9B & 1 & hsa-mir-335-5p \\
\hline Up & MYH10 & 8 & hsa-mir-106b-3p & Down & COL6A5 & 1 & hsa-mir-335-5p \\
\hline Up & FN1 & 8 & hsa-mir-200c-3p & Down & GATA5 & 1 & hsa-mir-335-5p \\
\hline Up & MYBBP1A & 8 & hsa-mir-3186-5p & Down & TRIM50 & 1 & hsa-mir-335-5p \\
\hline Up & $\mathrm{ROBO} 2$ & 8 & hsa-mir-514a-3p & Down & ANKRD22 & 1 & hsa-mir-335-5p \\
\hline Up & WDR62 & 8 & hsa-mir-149-5p & Down & ACSM1 & 1 & hsa-mir-335-5p \\
\hline Up & $\mathrm{C} 1 \mathrm{R}$ & 8 & hsa-mir-518c-5p & Down & AQP10 & 1 & hsa-mir-335-5p \\
\hline Up & TRIO & 7 & hsa-mir-92b-3p & Down & FRMD1 & 1 & hsa-mir-335-5p \\
\hline Up & TUBB3 & 7 & hsa-mir-340-5p & Down & CDHR2 & 1 & hsa-mir-335-5p \\
\hline Up & PDLIM7 & 7 & hsa-mir-30a-5p & Down & FAM3B & 1 & hsa-mir-335-5p \\
\hline Up & PLAU & 7 & hsa-mir-23b-3p & Down & VILL & 1 & hsa-mir-335-5p \\
\hline Up & COL5A2 & 7 & hsa-mir-29c-3p & Down & SCG3 & 1 & hsa-mir-335-5p \\
\hline Up & CD248 & 7 & hsa-mir-758-3p & Down & GNMT & 1 & hsa-mir-335-5p \\
\hline Up & TGM2 & 7 & hsa-mir-155-5p & Down & SOSTDC1 & 1 & hsa-mir-335-5p \\
\hline Up & NEK2 & 7 & hsa-mir-4668-5p & Down & KLK11 & 1 & hsa-mir-335-5p \\
\hline Up & MMP7 & 7 & hsa-mir-203a-5p & Down & FBP2 & 1 & hsa-mir-335-5p \\
\hline Up & FBXO32 & 7 & hsa-mir-608 & Down & SEMA3B & 1 & hsa-mir-335-5p \\
\hline Up & MSR1 & 7 & hsa-mir-410-5p & Down & CLEC3B & 1 & hsa-mir-335-5p \\
\hline Up & FCGR2A & 7 & hsa-mir-29b-2-5p & Down & TFF2 & 1 & hsa-mir-335-5p \\
\hline Up & ESM1 & 7 & hsa-mir-1260a & Down & MUC6 & 1 & hsa-mir-335-5p \\
\hline Up & ASPM & 6 & hsa-mir-193b-3p & Down & FOXA3 & 1 & hsa-mir-335-5p \\
\hline Up & ACTN1 & 6 & hsa-mir-16-5p & Down & GUCA2B & 1 & hsa-mir-335-5p \\
\hline Up & HTRA1 & 6 & hsa-mir-6774-5p & Down & $\mathrm{GC}$ & 1 & hsa-mir-335-5p \\
\hline Up & RAI14 & 6 & hsa-mir-21-5p & Down & AQP5 & 1 & hsa-mir-335-5p \\
\hline Up & PRR5L & 6 & hsa-mir-502-5p & Down & $\mathrm{ADH} 7$ & 1 & hsa-mir-335-5p \\
\hline Up & DKK2 & 6 & hsa-mir-221-3p & Down & CCL28 & 1 & hsa-mir-148b-3p \\
\hline Up & IL11 & 6 & sa-mir-211-5p & Down & $\mathrm{KCNJ} 16$ & 1 & hsa-mir-148b-3p \\
\hline Up & HIST1H3G & 6 & hsa-mir-7856-5p & Down & DPT & 1 & hsa-mir-148b-3p \\
\hline Up & LEF1 & 6 & hsa-mir-449a & Down & KLF15 & 1 & hsa-mir-376a-3p \\
\hline Up & SPP1 & 6 & hsa-mir-299-5p & Down & CHGB & 1 & hsa-mir-375 \\
\hline Up & LGR5 & 6 & hsa-mir-142-3p & Down & SH3BGRL2 & 1 & hsa-mir-195-5p \\
\hline Up & TFEC & 6 & hsa-mir-769-5p & Down & ARL14 & 1 & hsa-mir-186-5p \\
\hline Up & CDCA2 & 6 & hsa-mir-3613-3p & Down & PTPRR & 1 & hsa-mir-186-5p \\
\hline Up & FKBP10 & 5 & hsa-mir-132-3p & Down & ALDH3A1 & 1 & hsa-mir-186-5p \\
\hline Up & CALD1 & 5 & hsa-mir-15a-5p & Down & KCNQ1 & 1 & hsa-mir-133a-3p \\
\hline Up & KIF20A & 5 & hsa-mir-124-3p & Down & B3GAT1 & 1 & hsa-mir-132-3p \\
\hline Up & CSGALNACT2 & 5 & hsa-mir-377-3p & Down & AZGP1 & 1 & hsa-mir-128-3p \\
\hline Up & COL10A1 & 5 & hsa-mir-29b-3p & Down & UGT1A10 & 1 & hsa-mir-124-3p \\
\hline Up & NOX4 & 5 & hsa-mir-9-5p & Down & COL17A1 & 1 & hsa-mir-124-3p \\
\hline Up & ANLN & 5 & hsa-mir-497-5p & Down & CYP3A4 & 1 & hsa-mir-27b-3p \\
\hline Up & ZNF462 & 5 & hsa-mir-330-5p & Down & SYTL2 & 1 & hsa-mir-1-3p \\
\hline Up & NTM & 5 & hsa-mir-340-5p & Down & RGN & 1 & hsa-mir-1-3p \\
\hline Up & MMP1 & 5 & hsa-mir-526b-3p & Down & LYPD6B & 1 & hsa-mir-218-5p \\
\hline Up & SPHK1 & 5 & hsa-mir-125b-5p & Down & SUSD4 & 1 & hsa-mir-218-5p \\
\hline Up & PLBD2 & 5 & hsa-mir-3607-3p & Down & MYOC & 1 & hsa-mir-204-5p \\
\hline Up & HEPH & 5 & hsa-mir-548c-3p & Down & ME1 & 1 & hsa-mir-34a-5p \\
\hline Up & RRP12 & 4 & hsa-mir-24-3p & Down & CYP2S1 & 1 & hsa-mir-147a \\
\hline Up & TNFRSF11B & 4 & hsa-mir-181b-5p & Down & HPN & 1 & hsa-mir-197-3p \\
\hline
\end{tabular}




\begin{tabular}{|c|c|c|c|c|c|c|c|}
\hline Up & BUB1B & 4 & hsa-mir-22-3p & Down & MAMDC2 & 1 & hsa-mir-196a-5p \\
\hline Up & ABCD1 & 4 & hsa-mir-615-3p & Down & CHGA & 1 & hsa-mir-107 \\
\hline Up & COL15A1 & 4 & hsa-mir-29b-3p & Down & HBB & 1 & hsa-mir-92a-3p \\
\hline Up & SFRP4 & 4 & hsa-mir-103a-3p & Down & GPX3 & 1 & hsa-mir-92a-3p \\
\hline Up & KIF4A & 4 & hsa-mir-222-3p & Down & EYA2 & 1 & hsa-mir-30a-5p \\
\hline Up & SERPINB9 & 4 & hsa-mir-127-3p & Down & GKN1 & 1 & hsa-mir-30a-5p \\
\hline Up & PIK3AP1 & 4 & hsa-mir-32-5p & Down & SMPD3 & 1 & hsa-mir-26b-5p \\
\hline Up & BMP1 & 4 & hsa-mir-218-5p & Down & ODAM & 1 & hsa-mir-26b-5p \\
\hline Up & MMP11 & 4 & hsa-mir-135a-5p & Down & CAPN9 & 1 & hsa-mir-26b-5p \\
\hline Up & EDNRA & 4 & hsa-mir-200c-3p & Down & IL1R2 & 1 & hsa-mir-26b-5p \\
\hline Up & CDH11 & 4 & hsa-mir-27b-3p & Down & TCN1 & 1 & hsa-mir-26b-5p \\
\hline Up & ADCY3 & 4 & hsa-mir-1296-5p & Down & GSTA1 & 1 & hsa-mir-26b-5p \\
\hline Up & VIL1 & 4 & hsa-mir-2054 & Down & HYAL1 & 1 & hsa-mir-25-3p \\
\hline Up & TNFAIP6 & 4 & hsa-mir-19b-1-5p & Down & MRAP2 & 1 & hsa-mir-21-5p \\
\hline Up & NID2 & 3 & hsa-mir-181d-5p & Down & SLC9A2 & 1 & hsa-mir-16-5p \\
\hline Up & SERPINE2 & 3 & hsa-mir-30e-3p & Down & MAP7D2 & 1 & hsa-mir-505-5p \\
\hline Up & MRC2 & 3 & hsa-mir-10a-5p & Down & ANO5 & 1 & hsa-mir-432-5p \\
\hline Up & PTPRO & 3 & hsa-mir-20a-5p & & & & \\
\hline Up & CDCA5 & 3 & hsa-mir-18b-5p & & & & \\
\hline Up & CXCL9 & 3 & hsa-mir-34a-5p & & & & \\
\hline Up & CXCL6 & 3 & hsa-mir-140-3p & & & & \\
\hline Up & ASPN & 3 & hsa-mir-124-3p & & & & \\
\hline Up & MMP3 & 3 & hsa-mir-138-5p & & & & \\
\hline Up & TEAD4 & 3 & hsa-mir-512-5p & & & & \\
\hline Up & APOE & 3 & hsa-mir-199a-3p & & & & \\
\hline Up & AJUBA & 3 & hsa-mir-196b-5p & & & & \\
\hline Up & BCL2A1 & 3 & hsa-mir-146a-5p & & & & \\
\hline Up & CXCL1 & 3 & hsa-mir-1-3p & & & & \\
\hline Up & ANGPT2 & 3 & hsa-mir-542-3p & & & & \\
\hline Up & $\mathrm{CDH} 3$ & 3 & hsa-mir-9-5p & & & & \\
\hline Up & EXO1 & 3 & hsa-mir-375 & & & & \\
\hline Up & CHTF18 & 3 & hsa-mir-378a-5p & & & & \\
\hline Up & LILRB4 & 2 & hsa-mir-193b-3p & & & & \\
\hline Up & CCR1 & 2 & hsa-mir-21-5p & & & & \\
\hline Up & MSLN & 2 & hsa-mir-335-5p & & & & \\
\hline Up & CCL3 & 2 & hsa-mir-223-3p & & & & \\
\hline Up & PKDCC & 2 & hsa-mir-25-3p & & & & \\
\hline Up & C5AR1 & 2 & hsa-mir-26b-5p & & & & \\
\hline Up & MGP & 2 & hsa-mir-335-5p & & & & \\
\hline Up & GPNMB & 2 & hsa-mir-508-5p & & & & \\
\hline Up & ADAMTS12 & 2 & hsa-mir-26b-5p & & & & \\
\hline Up & SFRP2 & 2 & hsa-mir-29a-3p & & & & \\
\hline Up & CHN1 & 2 & hsa-mir-1301-3p & & & & \\
\hline Up & COL7A1 & 2 & hsa-mir-29b-3p & & & & \\
\hline Up & HOXB9 & 2 & hsa-mir-215-5p & & & & \\
\hline Up & UPP1 & 2 & hsa-mir-192-5p & & & & \\
\hline Up & WNT2 & 2 & hsa-mir-199a-5p & & & & \\
\hline Up & NOD1 & 2 & hsa-mir-1250-3p & & & & \\
\hline Up & LZTS1 & 2 & hsa-mir-214-3p & & & & \\
\hline Up & PRKDC & 2 & hsa-mir-101-5p & & & & \\
\hline Up & ABCA13 & 2 & hsa-mir-148b-3p & & & & \\
\hline Up & IGFBP7 & 2 & hsa-mir-124-3p & & & & \\
\hline Up & SULF1 & 2 & hsa-mir-516a-3p & & & & \\
\hline Up & HTRA3 & 2 & hsa-mir-335-5p & & & & \\
\hline Up & P4HA3 & 2 & hsa-mir-124-3p & & & & \\
\hline Up & AMIGO2 & 2 & hsa-mir-155-5p & & & & \\
\hline Up & MEST & 2 & hsa-mir-145-5p & & & & \\
\hline Up & CLEC5A & 2 & hsa-mir-877-3p & & & & \\
\hline Up & BOP1 & 2 & hsa-mir-296-3p & & & & \\
\hline Up & MAP1A & 2 & hsa-mir-338-3p & & & & \\
\hline Up & GGT5 & 2 & hsa-mir-346 & & & & \\
\hline Up & FNDC1 & 2 & hsa-mir-1207-3p & & & & \\
\hline Up & RECQL4 & 2 & hsa-mir-193b-3p & & & & \\
\hline Up & NEIL2 & 2 & hsa-mir-3160-5p & & & & \\
\hline Up & KLK6 & 1 & hsa-let-7f-5p & & & & \\
\hline Up & CLDN2 & 1 & hsa-mir-16-5p & & & & \\
\hline Up & AGT & 1 & hsa-mir-26b-5p & & & & \\
\hline Up & ETV4 & 1 & hsa-mir-26b-5p & & & & \\
\hline Up & RAD54L & 1 & hsa-mir-26b-5p & & & & \\
\hline Up & TYMP & 1 & hsa-mir-92a-3p & & & & \\
\hline
\end{tabular}




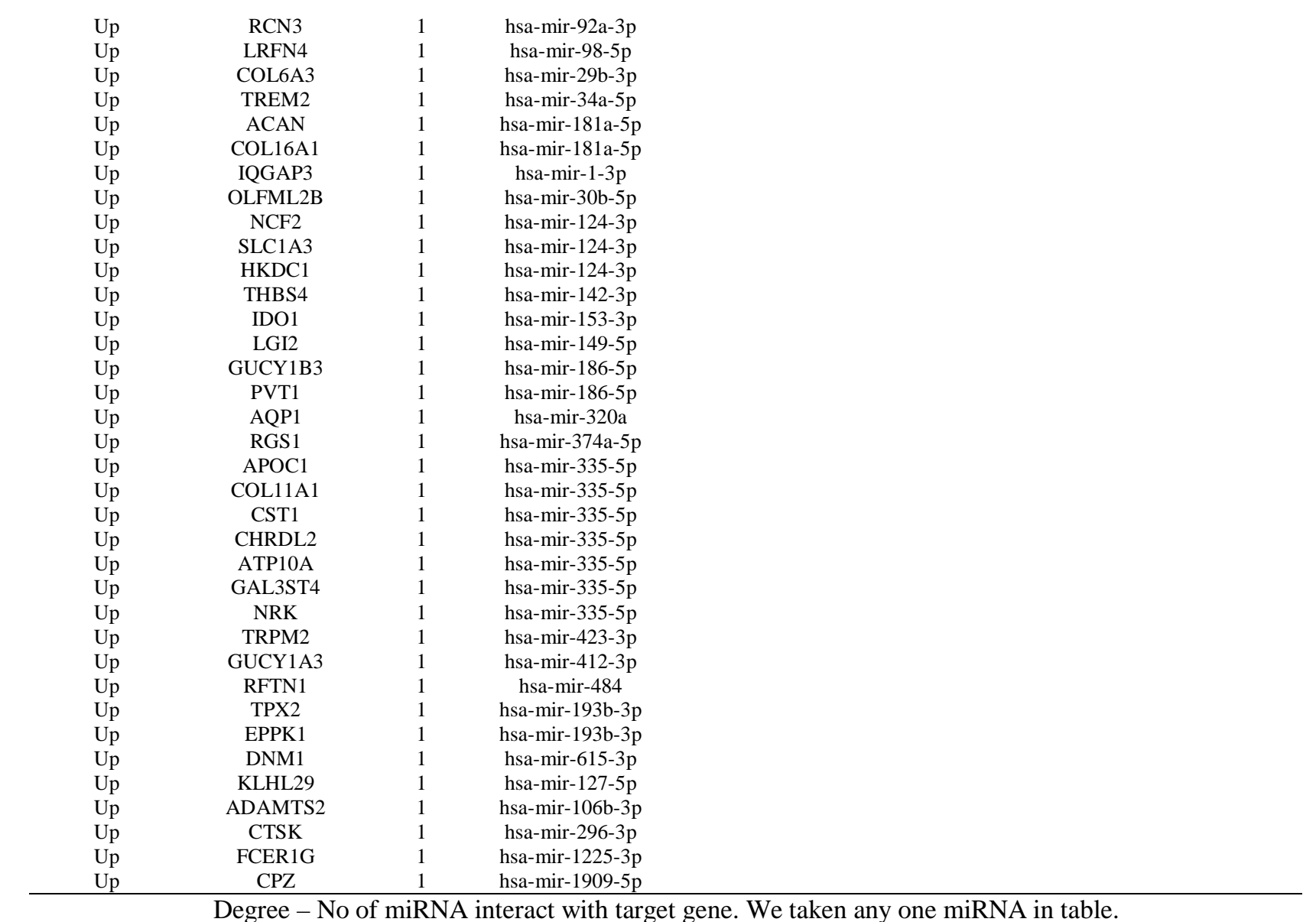

Degree - No of miRNA interact with target gene. We taken any one miRNA in table.

Table $9 \mathrm{TF}$ - target gene interaction table

\begin{tabular}{|c|c|c|c|c|c|c|c|}
\hline Regulation & TF & Degree & Target Gene & Regulation & TF & Degree & Target Gene \\
\hline Up & SOX2 & 247 & ABCA13 & Down & TP63 & 177 & DNER \\
\hline Up & MYC & 215 & ACTN1 & Down & STAT3 & 169 & CKB \\
\hline Up & EGR1 & 202 & ABCD1 & Down & HNF4A & 165 & PKIB \\
\hline Up & SPI1 & 202 & ADAMTS14 & Down & AR & 164 & RAB27B \\
\hline Up & NANOG & 194 & ADAMTS4 & Down & SUZ12 & 150 & IRX3 \\
\hline Up & ТР63 & 189 & ABCA1 & Down & EGR1 & 149 & GHRL \\
\hline Up & TP53 & 182 & ACAN & Down & SMAD4 & 133 & CAPN8 \\
\hline Up & POU5F1 & 180 & ADAM12 & Down & SPI1 & 131 & APOBEC1 \\
\hline Up & $\mathrm{AR}$ & 179 & ADAMTS12 & Down & NANOG & 131 & EPB41L4B \\
\hline Up & STAT3 & 179 & ADAMTS9 & Down & MYC & 129 & ASAH2 \\
\hline Up & SUZ12 & 175 & ADAMTS2 & Down & TP53 & 120 & C6 \\
\hline Up & RUNX1 & 170 & ADCY3 & Down & POU5F1 & 113 & GSTA3 \\
\hline Up & HNF4A & 165 & AGT & Down & MTF2 & 112 & HRH2 \\
\hline Up & FLI1 & 155 & AMIGO2 & Down & REST & 108 & DSC2 \\
\hline Up & MITF & 149 & AEBP1 & Down & MITF & 103 & KCNJ16 \\
\hline Up & SMAD4 & 137 & ANGPT2 & Down & RUNX1 & 102 & CA9 \\
\hline Up & E2F1 & 131 & APLN & Down & GATA2 & 101 & NCAM1 \\
\hline Up & PPARG & 129 & ALDH1A3 & Down & GATA1 & 96 & GATA5 \\
\hline Up & GATA2 & 129 & APOE & Down & TCF4 & 95 & TMEM92 \\
\hline Up & KLF4 & 123 & AJUBA & Down & PPARG & 87 & SERPINB7 \\
\hline Up & MTF2 & 121 & ANKRD13B & Down & FLI1 & 86 & MAMDC2 \\
\hline Up & GATA1 & 120 & ANLN & Down & ESR1 & 84 & SCNN1B \\
\hline Up & PPARD & 119 & AHNAK2 & Down & SRY & 84 & SLC25A4 \\
\hline Up & REST & 117 & ARHGAP11A & Down & RUNX2 & 84 & SLC5A5 \\
\hline Up & SETDB1 & 114 & ARMC9 & Down & TFAP2C & 83 & ARHGDIG \\
\hline
\end{tabular}




\begin{tabular}{|c|c|c|c|c|c|c|c|}
\hline Up & SRY & 107 & APOC1 & Down & SIN3B & 83 & IGFALS \\
\hline Up & SMAD3 & 106 & ANGPTL2 & Down & E2F1 & 77 & BTNL8 \\
\hline Up & SOX9 & 105 & ANTXR1 & Down & SETDB1 & 77 & MRAP2 \\
\hline Up & ESR1 & 105 & ATP10A & Down & TCF3 & 76 & GABRB3 \\
\hline Up & RUNX2 & 104 & AQP9 & Down & PPARD & 72 & DNMBP-AS1 \\
\hline Up & TCF3 & 102 & ASPM & Down & $\mathrm{EZH} 2$ & 72 & KCNQ1 \\
\hline Up & TRIM28 & 102 & ATAD2 & Down & SALL4 & 72 & STYK1 \\
\hline Up & EP300 & 100 & ANXA13 & Down & RNF2 & 71 & DUOXA2 \\
\hline Up & TCF4 & 97 & ARHGAP39 & Down & SMARCA4 & 71 & OXCT1 \\
\hline Up & TET1 & 97 & ATP11A & Down & SOX9 & 68 & SCARA5 \\
\hline Up & SMARCA4 & 97 & BCAT1 & Down & SMAD3 & 67 & AKR1C2 \\
\hline Up & KDM5B & 95 & ATAD5 & Down & TRIM28 & 67 & DHCR24 \\
\hline Up & TFAP2C & 95 & BGN & Down & EP300 & 65 & MUC1 \\
\hline Up & EZH2 & 92 & $\mathrm{BICC} 1$ & Down & BMI1 & 63 & MAL \\
\hline Up & SIN3B & 91 & CACNA1E & Down & JARID2 & 61 & CDHR2 \\
\hline Up & TAL1 & 84 & AQP1 & Down & TET1 & 59 & RANBP3L \\
\hline $\mathrm{Up}$ & CREM & 84 & BUB1 & Down & RCOR3 & 58 & SLC26A7 \\
\hline Up & YAP1 & 84 & CCND2 & Down & YAP1 & 57 & ALDH3A1 \\
\hline Up & E2F4 & 83 & BUB1B & Down & PBX1 & 57 & CCL28 \\
\hline Up & RCOR3 & 83 & $\mathrm{C} 1 \mathrm{R}$ & Down & RAD21 & 53 & HPN \\
\hline Up & WT1 & 80 & $\mathrm{BOC}$ & Down & FOXP1 & 53 & ID1 \\
\hline Up & RNF2 & 79 & BMP1 & Down & CREM & 53 & PTGDR2 \\
\hline Up & CREB1 & 79 & BOP1 & Down & TAL1 & 51 & PAIP2B \\
\hline Up & ASH2L & 79 & $\mathrm{CBX} 2$ & Down & OLIG2 & 51 & TMEM100 \\
\hline Up & EOMES & 78 & C1QTNF6 & Down & EOMES & 50 & RASEF \\
\hline Up & FOXP1 & 78 & $\mathrm{C} 2 \mathrm{CD} 4 \mathrm{~A}$ & Down & POU3F2 & 50 & SLC2A12 \\
\hline Up & ATF3 & 77 & CCDC80 & Down & ZNF217 & 48 & B4GALNT2 \\
\hline Up & ZNF281 & 74 & CAMK2N1 & Down & BACH1 & 48 & GDPD2 \\
\hline Up & PRDM14 & 74 & CD109 & Down & CREB1 & 47 & EEF1A2 \\
\hline $\mathrm{Up}$ & CUX1 & 72 & $\mathrm{CAD}$ & Down & ASH2L & 47 & PM20D1 \\
\hline Up & RELA & 71 & BCL2A1 & Down & CUX1 & 45 & GCNT2 \\
\hline Up & SMAD2 & 71 & CALD1 & Down & ERG & 44 & GPRC5C \\
\hline Up & FOXA2 & 70 & $\mathrm{C} 3$ & Down & $\mathrm{NR} 3 \mathrm{C} 1$ & 43 & PRIMA1 \\
\hline Up & BACH1 & 70 & CENPF & Down & CTNNB1 & 42 & AADAC \\
\hline Up & SCLY & 66 & C5AR1 & Down & PRDM14 & 42 & EYA2 \\
\hline Up & JARID2 & 63 & CDH11 & Down & CEBPB & 42 & GCNT4 \\
\hline Up & SOX17 & 62 & CDC6 & Down & KDM5B & 42 & IRX5 \\
\hline Up & ERG & 60 & CD248 & Down & SOX17 & 42 & ORM1 \\
\hline Up & DMRT1 & 58 & $\mathrm{CDH} 13$ & Down & ARNT & 42 & SLC1A2 \\
\hline Up & $\mathrm{NR} 3 \mathrm{C} 1$ & 58 & CDH17 & Down & ZNF281 & 41 & C1orf210 \\
\hline Up & STAT4 & 57 & CCNF & Down & ATF3 & 41 & TM7SF2 \\
\hline Up & NR0B1 & 57 & $\mathrm{CDH} 3$ & Down & TFAP2A & 40 & CCKBR \\
\hline Up & ZNF217 & 57 & CLDN4 & Down & NR0B1 & 40 & NWD1 \\
\hline Up & RAD21 & 57 & CLSPN & Down & DMRT1 & 39 & TM6SF2 \\
\hline Up & NFE2L2 & 55 & CEP170 & Down & NFE2L2 & 37 & HAPLN1 \\
\hline Up & JUN & 55 & CLDN1 & Down & E2F4 & 36 & EDARADD \\
\hline Up & LMO2 & 53 & BMP8A & Down & STAT5A & 36 & XK \\
\hline Up & MECOM & 53 & CCL3 & Down & LMO2 & 35 & CTSE \\
\hline Up & BMI1 & 53 & $\mathrm{CDX} 2$ & Down & SCLY & 35 & INSIG1 \\
\hline Up & TBX5 & 52 & CDCA7 & Down & TEAD4 & 35 & SH3BGRL2 \\
\hline Up & EWSR1 & 51 & CCL18 & Down & SMAD2 & 34 & GKN1 \\
\hline Up & CEBPB & 51 & CDC25B & Down & RCOR1 & 34 & RASSF6 \\
\hline Up & MYCN & 50 & COL12A1 & Down & WT1 & 34 & TPD52L1 \\
\hline Up & OLIG2 & 49 & CD300LF & Down & JUN & 33 & CAPN9 \\
\hline Up & TFAP2A & 49 & CDCA5 & Down & YY1 & 33 & CYP3A4 \\
\hline Up & RBPJ & 49 & COL16A1 & Down & KLF1 & 31 & CYB5A \\
\hline Up & FOXP2 & 48 & CELSR3 & Down & TBX5 & 31 & DUSP19 \\
\hline Up & PBX1 & 45 & CKAP2 & Down & EWSR1 & 31 & GKN2 \\
\hline Up & EED & 45 & COL4A1 & Down & RBPJ & 30 & FMO6P \\
\hline Up & ZFX & 44 & CTSB & Down & RELA & 30 & TFF1 \\
\hline Up & GATA4 & 44 & DYSF & Down & $\mathrm{CDX} 2$ & 29 & APOA4 \\
\hline Up & TCF7 & 43 & CHRDL2 & Down & EED & 28 & TMEM229A \\
\hline Up & KLF1 & 42 & COL5A2 & Down & CTCF & 26 & IGSF9 \\
\hline $\mathrm{Up}$ & CTNNB1 & 41 & CHI3L1 & Down & PHC1 & 26 & NKX6-2 \\
\hline Up & GFI1B & 41 & CLEC5A & Down & ZFX & 26 & SH3GL2 \\
\hline $\mathrm{Up}$ & TFCP2L1 & 41 & CRISPLD1 & Down & AHR & 26 & VSTM2A \\
\hline Up & FOXO3 & 41 & CSF3R & Down & MYCN & 25 & ESRRG \\
\hline Up & YY1 & 39 & CHN1 & Down & MYBL2 & 24 & CNTD1 \\
\hline Up & CCND1 & 39 & CHTF18 & Down & FOXP2 & 24 & DHRS9 \\
\hline Up & PAX3 & 39 & DKK2 & Down & FOXO3 & 24 & F2RL1 \\
\hline
\end{tabular}




\begin{tabular}{|c|c|c|c|c|c|c|c|}
\hline Up & ESRRB & 37 & COL18A1 & Down & TBX3 & 24 & OASL \\
\hline Up & CTCF & 37 & DNM1 & Down & PAX3 & 23 & ANXA10 \\
\hline Up & TBX3 & 37 & EGR2 & Down & MEIS1 & 23 & ARHGEF37 \\
\hline Up & POU3F2 & 36 & CD84 & Down & ESR2 & 23 & MAOA \\
\hline Up & CNOT3 & 36 & CLDN3 & Down & MECOM & 23 & PTGER3 \\
\hline Up & SOX11 & 36 & CTHRC1 & Down & GATA4 & 23 & PXMP2 \\
\hline Up & NR1I2 & 34 & COL5A3 & Down & DNAJC2 & 23 & VSIG2 \\
\hline Up & PHC1 & 34 & COMP & Down & SIN3A & 22 & C16ORF89 \\
\hline Up & NR1H3 & 33 & COL4A2 & Down & TCF7 & 21 & AMPD1 \\
\hline Up & NACC1 & 33 & ENC1 & Down & PAX6 & 21 & АTP4B \\
\hline Up & ELK1 & 33 & EPPK1 & Down & TAF7L & 20 & C11ORF86 \\
\hline Up & HOXB4 & 33 & F2RL2 & Down & NR1I2 & 20 & CYP2C18 \\
\hline Up & RCOR1 & 32 & COL10A1 & Down & HTT & 20 & CYP2C 8 \\
\hline Up & ZFP42 & 31 & COL1A2 & Down & CNOT3 & 19 & CHGB \\
\hline Up & ELF5 & 31 & CRABP2 & Down & GFI1B & 19 & CTAGE5 \\
\hline Up & VDR & 31 & DUSP10 & Down & NACC1 & 19 & KLF2 \\
\hline Up & DNAJC2 & 30 & COL7A1 & Down & STAT4 & 18 & RAB37 \\
\hline Up & LYL1 & 29 & COL5A1 & Down & ELF5 & 17 & CAPN13 \\
\hline Up & ARNT & 29 & СРXM2 & Down & PRDM5 & 17 & CKMT2 \\
\hline Up & HOXC9 & 28 & CLSTN3 & Down & STAT1 & 17 & LIFR \\
\hline Up & MEIS1 & 27 & BACH1 & Down & ELK1 & 17 & MYRIP \\
\hline Up & DACH1 & 27 & CSGALNACT2 & Down & GATA3 & 17 & UNC5D \\
\hline Up & TTF2 & 27 & E2F3 & Down & TCF7L2 & 16 & FCGBP \\
\hline Up & IRF8 & 27 & ENTPD1 & Down & CEBPA & 16 & GC \\
\hline Up & SMAD1 & 27 & $\mathrm{~F} 2 \mathrm{R}$ & Down & TTF2 & 16 & POU2AF1 \\
\hline Up & RARG & 26 & DPYSL3 & Down & MYB & 16 & SLPI \\
\hline Up & XRN2 & 26 & EXO1 & Down & NR1H3 & 15 & ALDOC \\
\hline Up & HSF1 & 25 & DNM3OS & Down & PADI4 & 15 & CHIA \\
\hline Up & PHF8 & 25 & FAM83D & Down & HOXB4 & 15 & METTL7A \\
\hline Up & GATA3 & 25 & GDF15 & Down & SREBF2 & 15 & REP15 \\
\hline Up & ELF1 & 24 & CPXM1 & Down & HOXC9 & 14 & ELOVL6 \\
\hline Up & FOXP3 & 23 & ECT2 & Down & HSF1 & 14 & GGT6 \\
\hline Up & STAT5A & 23 & GBP5 & Down & CCND1 & 14 & GLUL \\
\hline Up & DROSHA & 22 & COL15A1 & Down & SMAD1 & 14 & PAQR8 \\
\hline Up & MEF2A & 22 & HMCN1 & Down & LYL1 & 14 & SCGN \\
\hline Up & PAX6 & 20 & ASH2L & Down & DROSHA & 14 & SHISA6 \\
\hline Up & SIN3A & 20 & COL8A1 & Down & FOXO1 & 13 & AZGP1 \\
\hline Up & PRDM5 & 20 & CYP2W1 & Down & SOX11 & 13 & C1ORF115 \\
\hline Up & CLOCK & 20 & $\mathrm{DIO} 2$ & Down & MEF2A & 13 & $\mathrm{CDH} 2$ \\
\hline Up & TCF7L2 & 20 & EPHB1 & Down & NFIB & 13 & SCUBE2 \\
\hline Up & KDM5A & 20 & ESPL1 & Down & ELF1 & 12 & AQP10 \\
\hline Up & AHR & 20 & FN1 & Down & TBP & 12 & GALE \\
\hline Up & STAT1 & 20 & IER5L & Down & SRF & 12 & GPT2 \\
\hline Up & PADI4 & 19 & CPS1 & Down & ZFP42 & 12 & HYAL1 \\
\hline Up & SRF & 18 & EPHA3 & Down & IRF8 & 12 & TMEM151A \\
\hline Up & CRX & 18 & FCGR1A & Down & SREBF1 & 11 & ALDOB \\
\hline Up & STAT6 & 18 & HAPLN3 & Down & VDR & 11 & GALNT5 \\
\hline Up & RCOR2 & 16 & DGKH & Down & IRF1 & 11 & HHLA2 \\
\hline Up & SREBF2 & 16 & GEM & Down & XRN2 & 11 & SOX21 \\
\hline Up & SREBF1 & 15 & FLRT2 & Down & CLOCK & 10 & AQP4 \\
\hline Up & ESR2 & 15 & H19 & Down & CEBPD & 9 & РAPPA2 \\
\hline Up & CEBPD & 15 & MMP16 & Down & HIF1A & 9 & UPK1B \\
\hline Up & NUCKS1 & 14 & DOCK4 & Down & DACH1 & 8 & FOXQ1 \\
\hline Up & THAP11 & 13 & FGD6 & Down & DCP1A & 8 & MT1E \\
\hline Up & TAF7L & 13 & FKBP10 & Down & STAT6 & 8 & PLLP \\
\hline Up & ZIC3 & 12 & FBXO32 & Down & RARG & 8 & PRSS8 \\
\hline Up & DCP1A & 12 & FSCN1 & Down & CRX & 7 & HOMER2 \\
\hline Up & ETS1 & 12 & GRIN2D & Down & GBX2 & 7 & SLC16A7 \\
\hline Up & GBX2 & 12 & LCP2 & Down & PDX1 & 7 & SLC7A8 \\
\hline Up & IRF1 & 12 & LEF1 & Down & THAP11 & 7 & SLC9A1 \\
\hline Up & CEBPA & 11 & CYP2B6 & Down & PHF8 & 7 & XYLT2 \\
\hline Up & KDM6A & 11 & FANCD2 & Down & KDM5A & 6 & ALDH6A1 \\
\hline Up & HOXD13 & 11 & FBN1 & Down & FOXP3 & 6 & FOXA3 \\
\hline Up & NFIB & 11 & HTRA1 & Down & TFEB & 6 & KLF15 \\
\hline Up & CHD1 & 11 & IGF2BP3 & Down & BCL3 & 6 & RORC \\
\hline Up & TFEB & 10 & FOXM1 & Down & CHD1 & 6 & SOX2 \\
\hline Up & PDX1 & 10 & KIF20A & Down & RCOR2 & 5 & HAS3 \\
\hline Up & HTT & 9 & IFI44L & Down & ZIC3 & 5 & LIPH \\
\hline Up & HIF1A & 9 & INHBA & Down & HOXD13 & 5 & RHBDL2 \\
\hline Up & ASXL1 & 9 & KIF21B & Down & ZNF274 & 5 & SSTR1 \\
\hline
\end{tabular}




\begin{tabular}{|c|c|c|c|c|c|c|c|}
\hline Up & ТВP & 9 & MMP14 & Down & GLI1 & 4 & ADAMTSL1 \\
\hline Up & E2F7 & 8 & MCM7 & Down & TCF21 & 4 & AKR7A3 \\
\hline Up & NR4A2 & 7 & LILRB3 & Down & ZNF263 & 4 & ITPKA \\
\hline Up & BCL3 & 6 & CXCL1 & Down & ETS2 & 4 & PRDM16 \\
\hline Up & ZNF274 & 6 & KIF26B & Down & CHD7 & 3 & APOA1 \\
\hline Up & PRDM16 & 6 & MCM10 & Down & NR4A2 & 3 & CYP3A5 \\
\hline Up & $\mathrm{AP} 1 \mathrm{~S} 2$ & 6 & PGM2L1 & Down & SALL1 & 3 & GRIA4 \\
\hline Up & THRA & 5 & IFITM1 & Down & KLF5 & 3 & KLF4 \\
\hline Up & FOXO1 & 5 & NEIL2 & Down & $\mathrm{HCFC} 1$ & 3 & SCG3 \\
\hline Up & TCF21 & 5 & NID2 & Down & ZNF652 & 3 & SPDEF \\
\hline Up & IKZF1 & 5 & PDGFRB & Down & THRA & 3 & TMED6 \\
\hline Up & ZNF322 & 5 & PLXNC1 & Down & MYBL1 & 2 & FBP1 \\
\hline Up & ETS2 & 4 & FOXK1 & Down & NUCKS1 & 2 & FGA \\
\hline Up & CHD7 & 4 & HOXA10 & Down & IKZF1 & 2 & GPX3 \\
\hline Up & HCFC1 & 4 & KIF2C & Down & ASXL1 & 2 & KIAA0895 \\
\hline Up & GLI1 & 4 & RAI14 & Down & ZNF322 & 2 & RIMS1 \\
\hline Up & KLF2 & 3 & HOXB9 & Down & NOTCH1 & 2 & SOWAHA \\
\hline Up & BP1 & 3 & IL2RA & Down & ETS1 & 1 & SMPD3 \\
\hline Up & KLF5 & 3 & NOTCH3 & & & & \\
\hline Up & SALL1 & 3 & OMD & & & & \\
\hline Up & CDKN2AIP & 3 & SPOCK1 & & & & \\
\hline Up & ZNF263 & 2 & LAMA5 & & & & \\
\hline Up & MYBL1 & 2 & NEK2 & & & & \\
\hline Up & ZNF652 & 2 & PLXDC2 & & & & \\
\hline Up & HOXA2 & 1 & KIAA1755 & & & & \\
\hline Up & CIITA & 1 & PARVG & & & & \\
\hline
\end{tabular}

Degree - No of TF interact with target gene. We taken any one TF in table

\section{Figures}

A

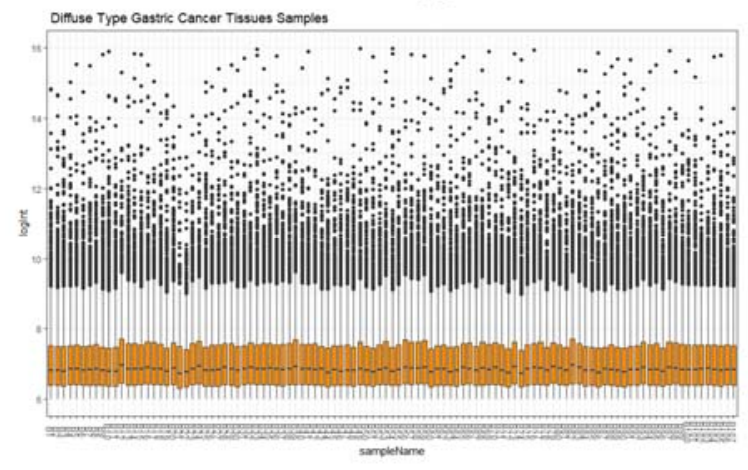

B

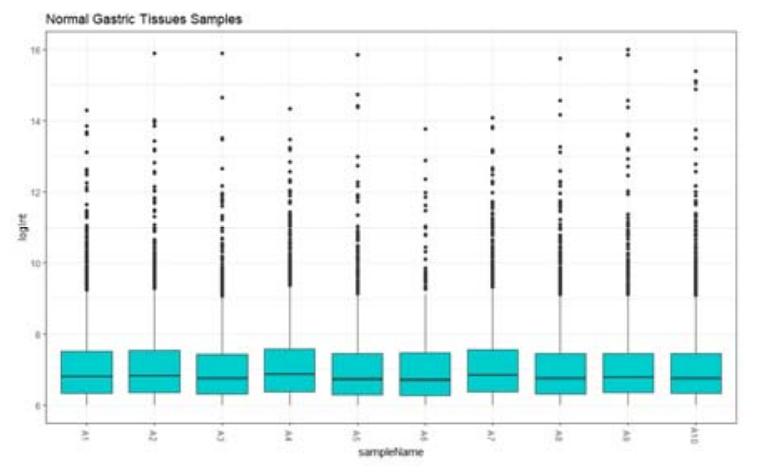

Fig. 1. Box plots of the normalized RNA-seq data. (A) 107 GC samples (B) 10 normal gastric tissue samples. Horizontal axis represents the sample symbol and the vertical axis represents the gene expression values. The black line in the box plot represents the median value of gene expression. (A1 $-\mathrm{A} 10=$ Normal gastric tissue samples (blue color box); B1 - B107 = GC samples (brown color box)) 

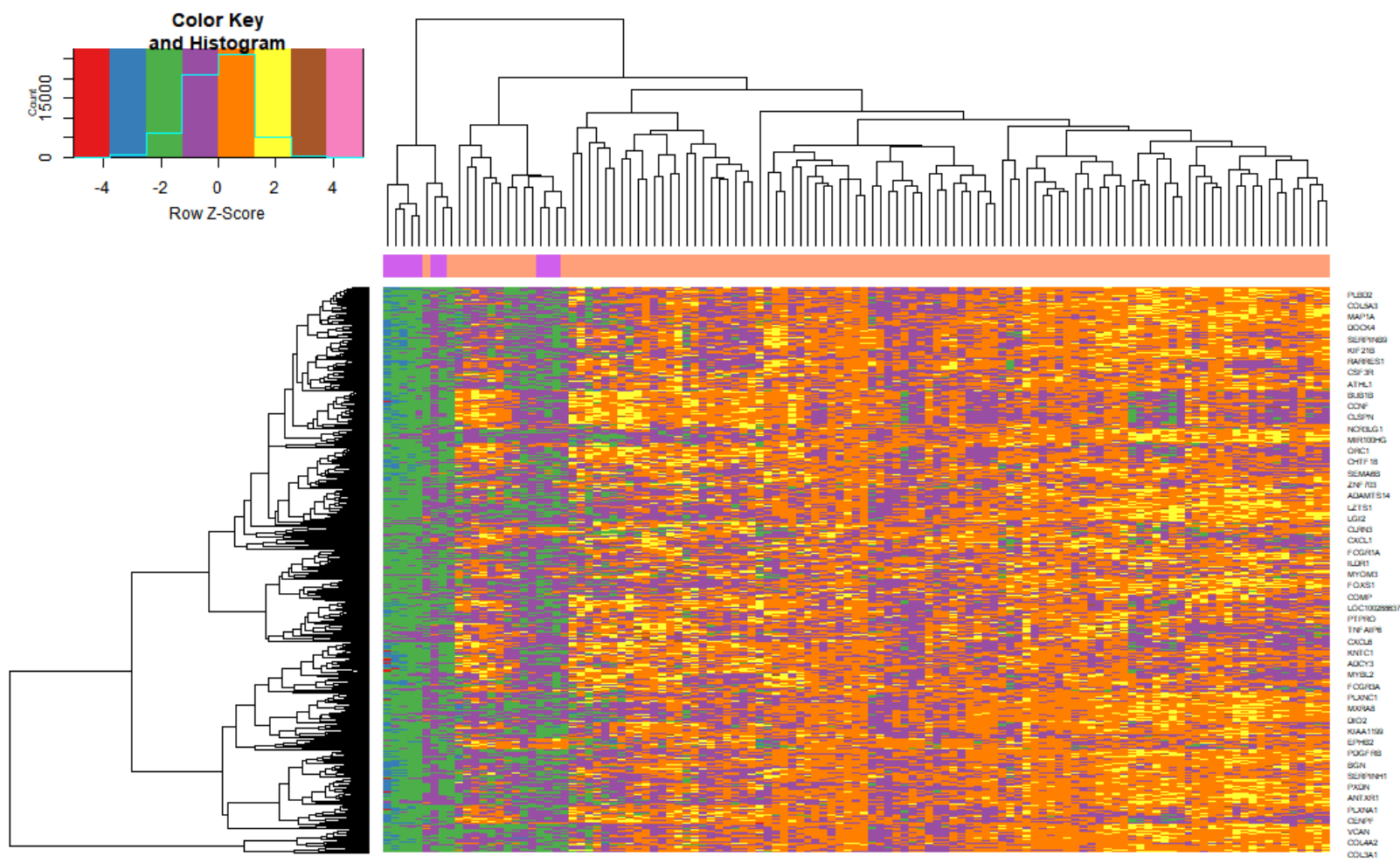

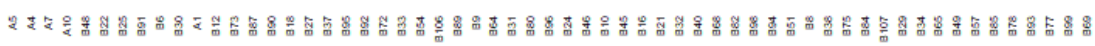

Fig. 2. Heat map of up regulated differentially expressed genes. Legend on the top left indicate log fold change of genes. $(\mathrm{A} 1-\mathrm{A} 10=$ Normal gastric tissue samples; B1 - B107 = GC samples $)$ 

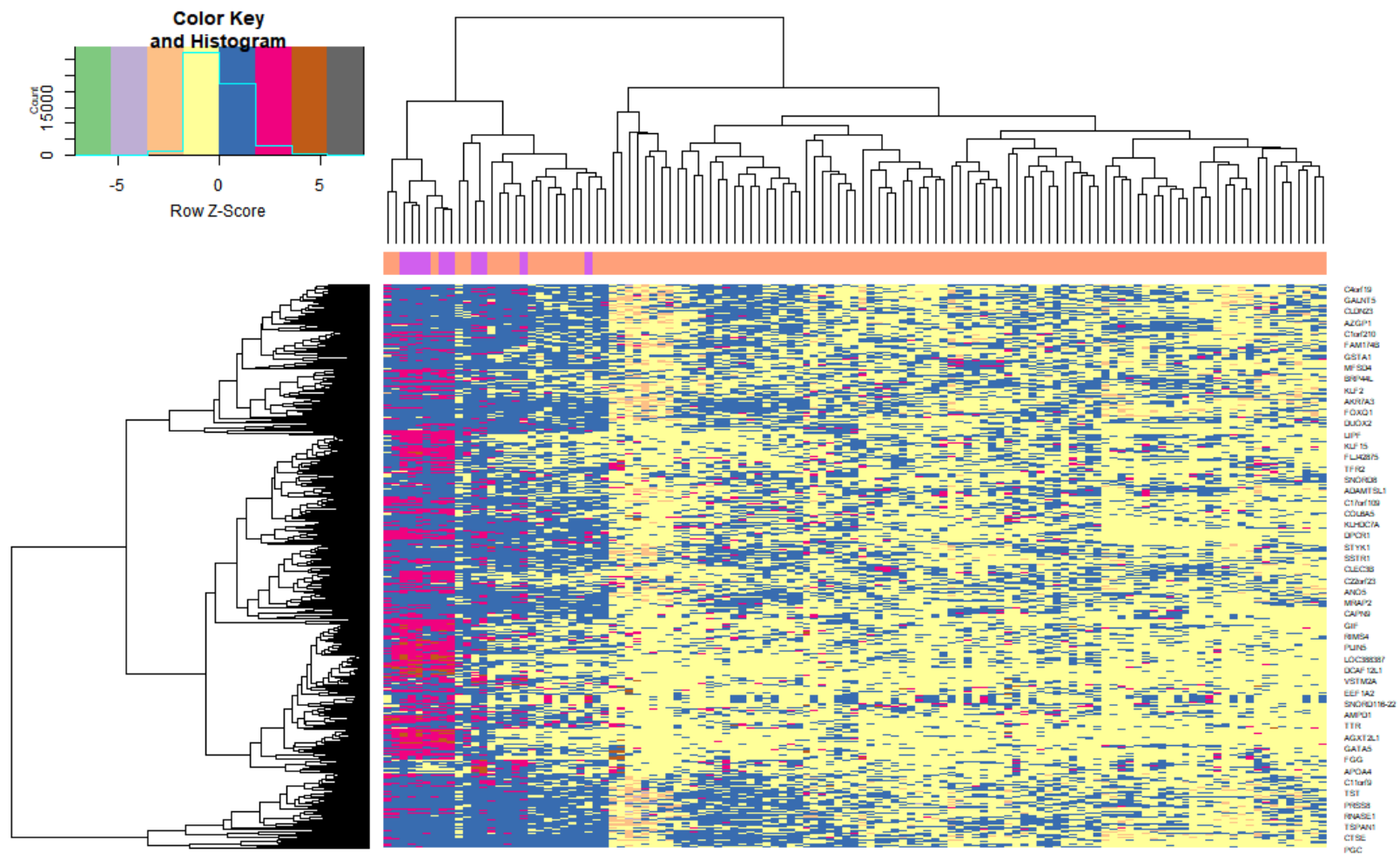

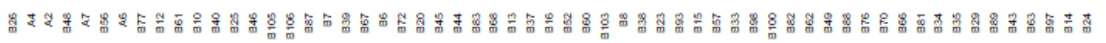

Fig. 3. Heat map of down regulated differentially expressed genes. Legend on the top left indicate log fold change of genes. $(\mathrm{A} 1-\mathrm{A} 10=$ Normal gastric tissue samples; B1 - B107 = GC samples $)$ 


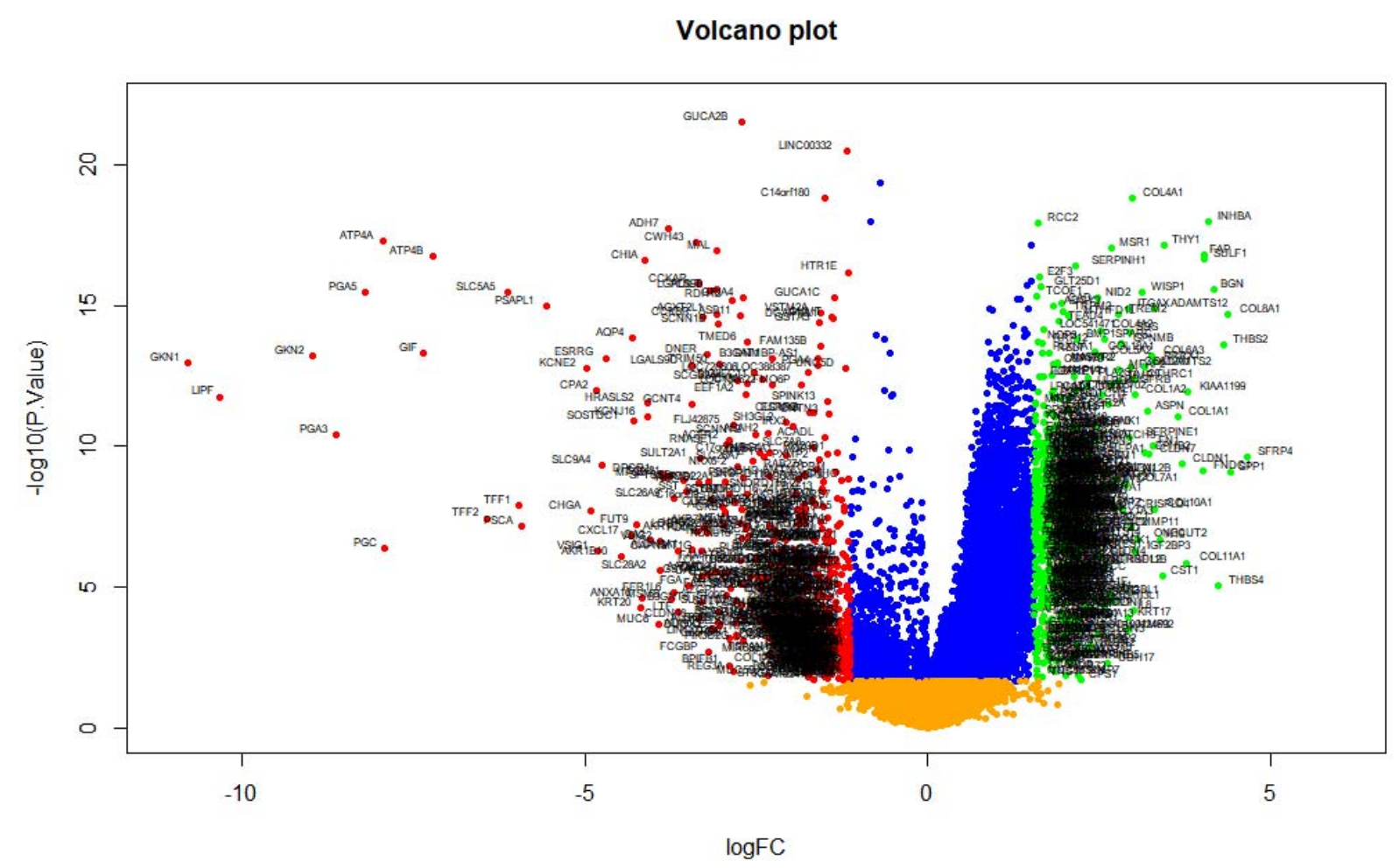

Fig. 4. Volcano plot of differentially expressed genes. Genes with a significant change of more than two-fold were selected. 


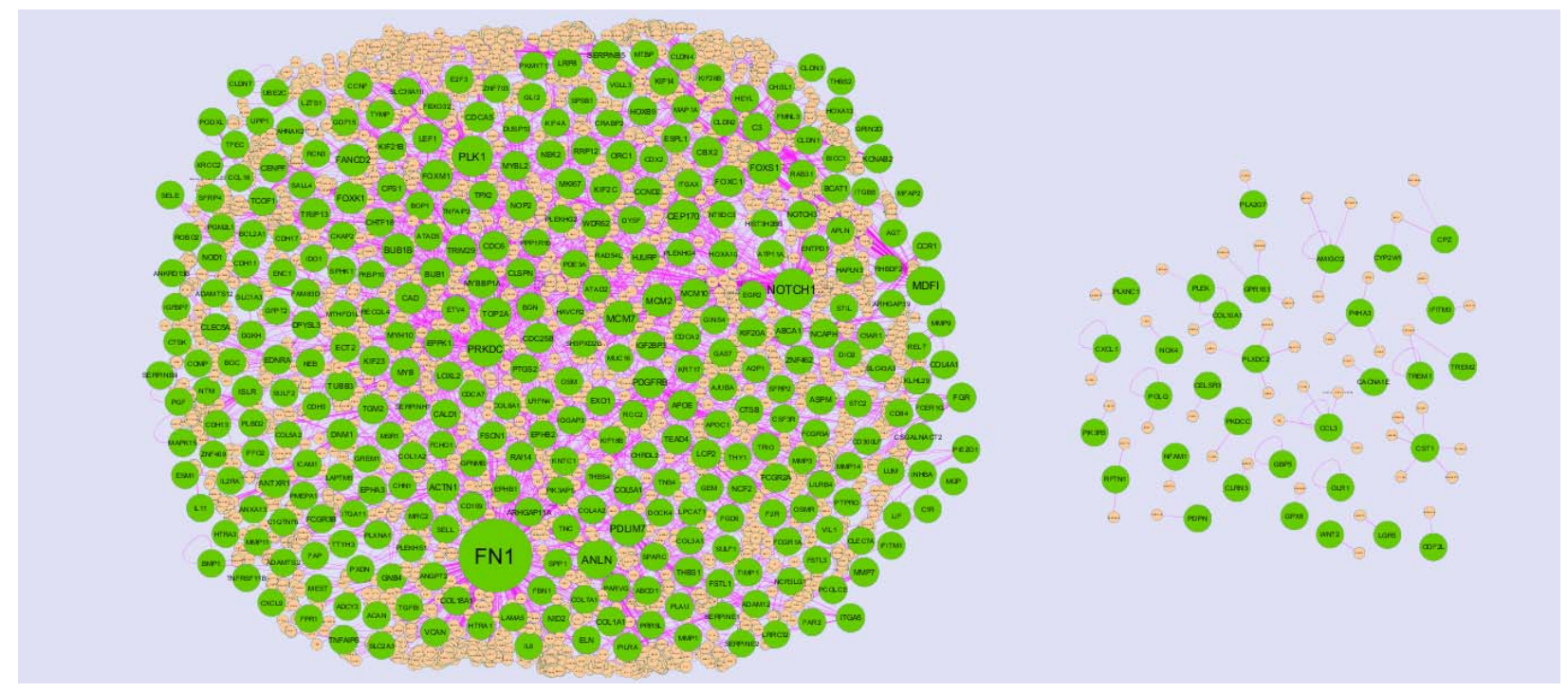

Fig. 5. Protein-protein interaction network of up regulated genes. Green nodes denotes up regulated genes.

A

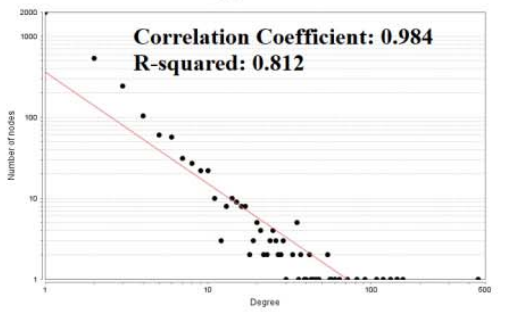

D

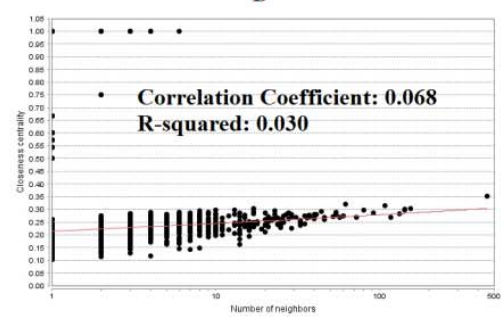

B

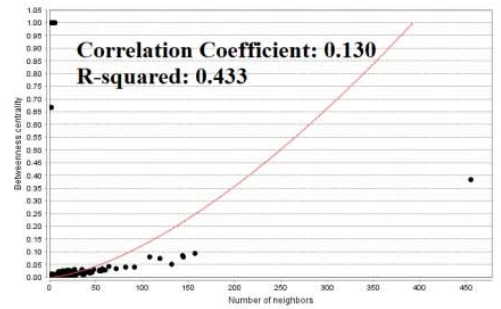

$\mathbf{E}$

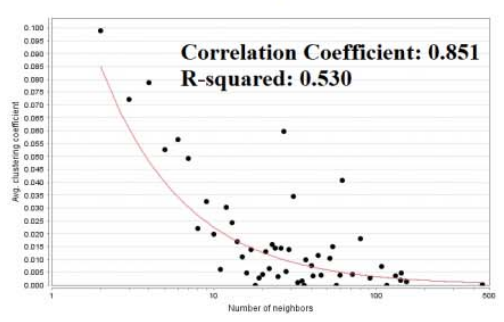

C

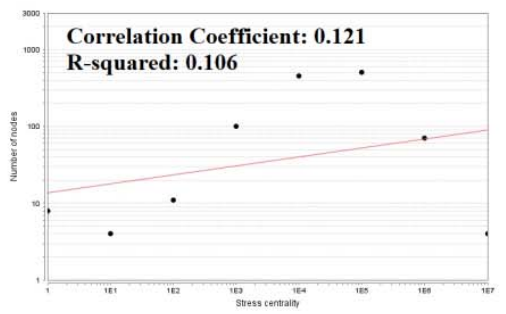

Fig. 6. Scatter plot for up regulated genes. (A- Node degree; B- Betweenness centrality; C- Stress centrality ; DCloseness centrality; E- Clustering coefficient) 


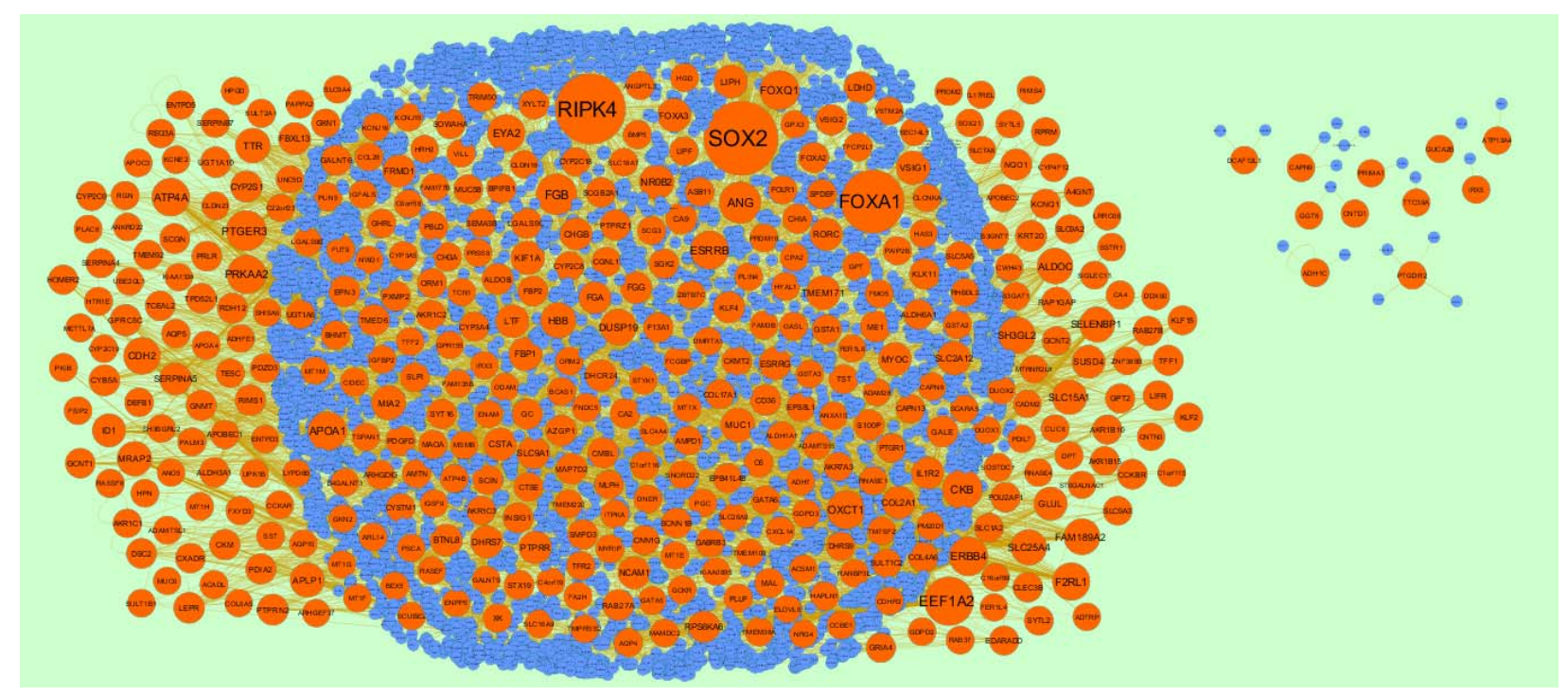

Fig. 7. Protein-protein interaction network of down regulated genes. Red nodes denotes down regulated genes.

A

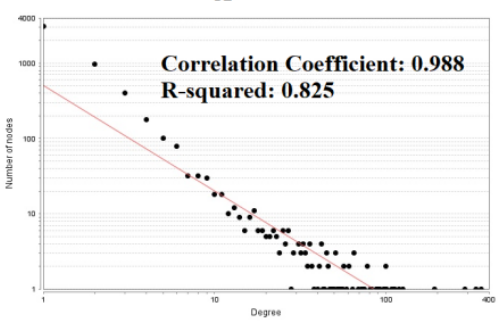

D

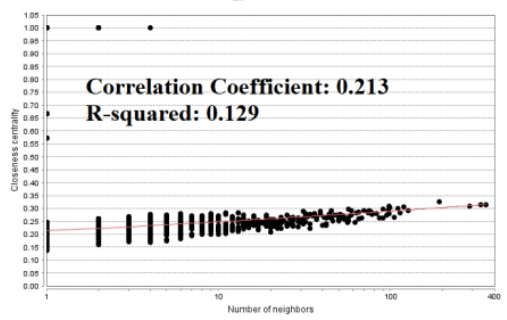

B

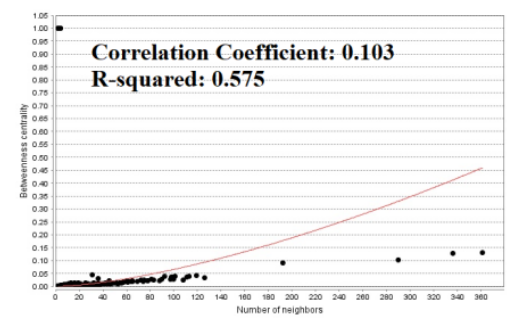

E

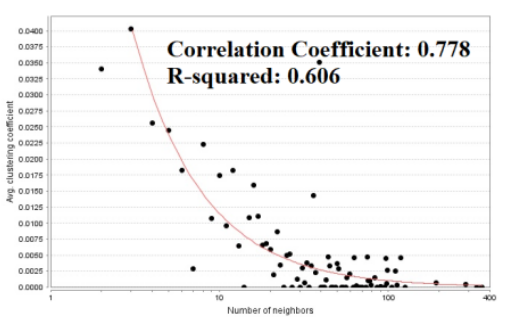

C

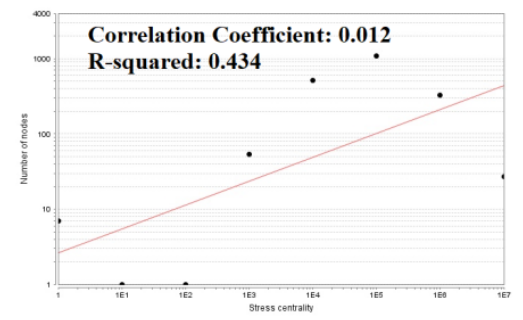

Fig. 8. Scatter plot for down regulated genes. (A- Node degree; B- Betweenness centrality; C- Stress centrality ; DCloseness centrality; E- Clustering coefficient) 


\section{Module 2}

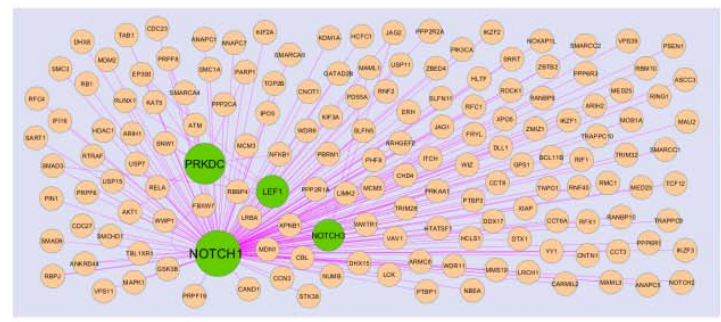

\section{Module 6}

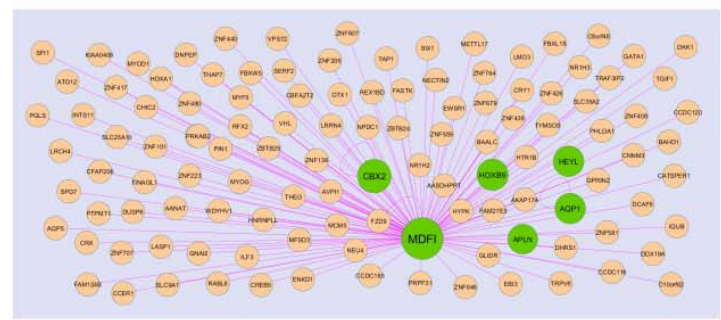

Module 5

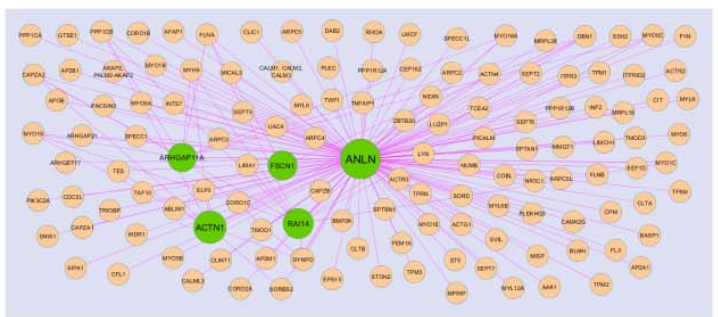

\section{Module 9}

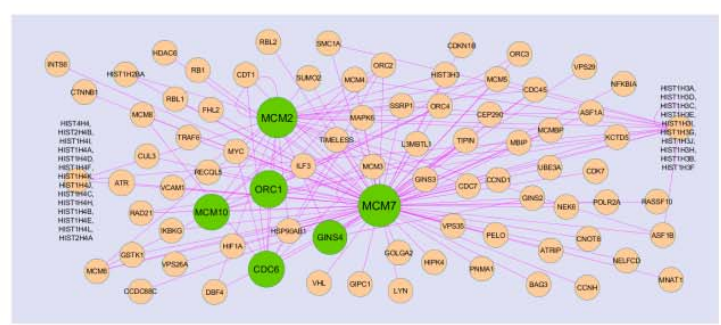

Fig. 9. Modules in PPI network. The green nodes denote the up regulated genes

\section{Module 6}

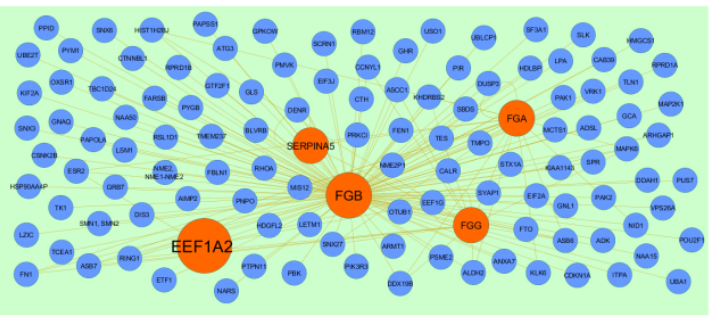

Module 10

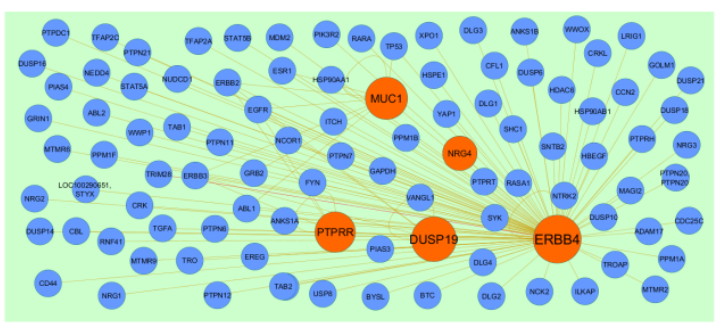

\section{Module 7}

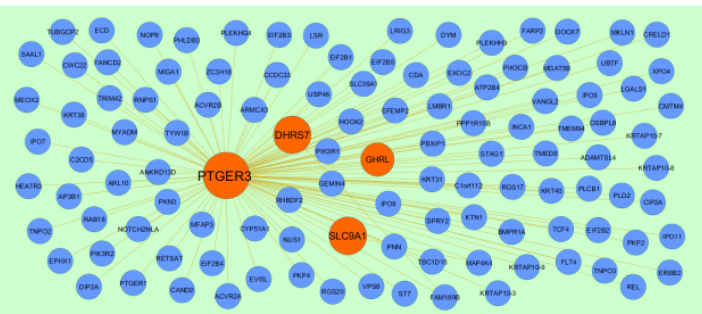

\section{Module 15}

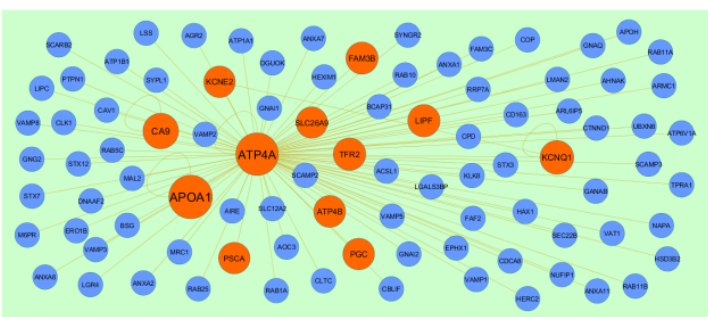

Fig. 10. Modules in PPI network. The red nodes denote the down regulated genes 


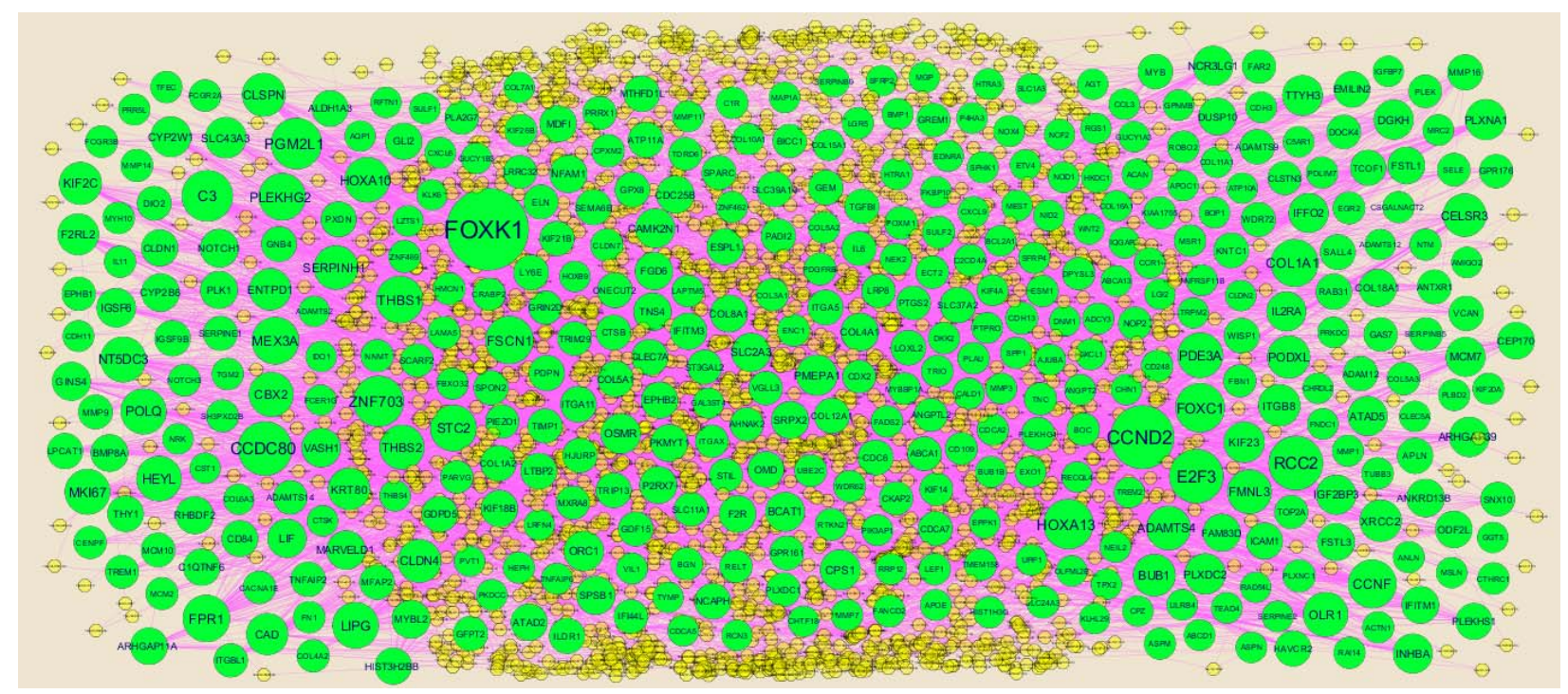

Fig. 11. The network of up regulated genes and their related miRNAs. The green circles nodes are the up regulated genes, and yellow diamond nodes are the miRNAs

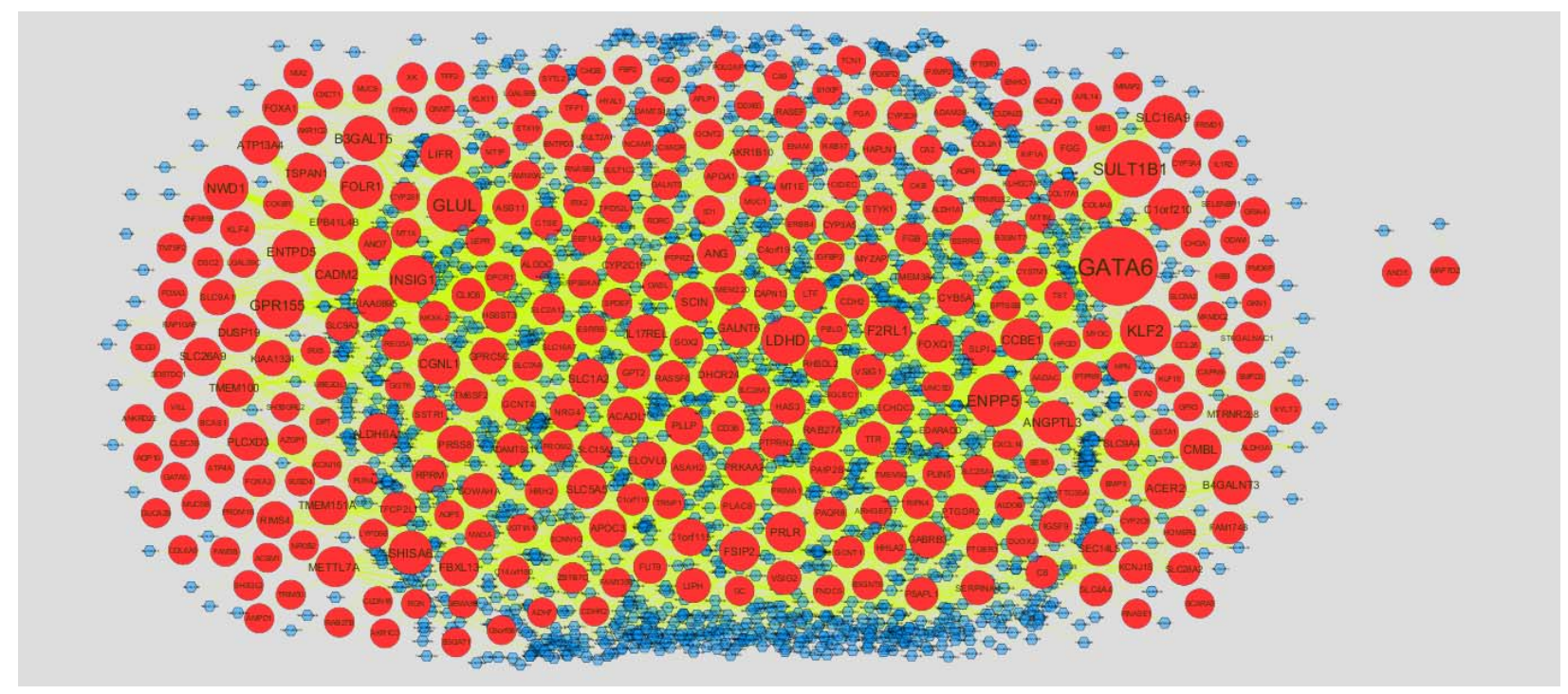

Fig. 12. The network of down regulated genes and their related miRNAs. The red circles nodes are the down regulated genes, and blue diamond nodes are the miRNAs 


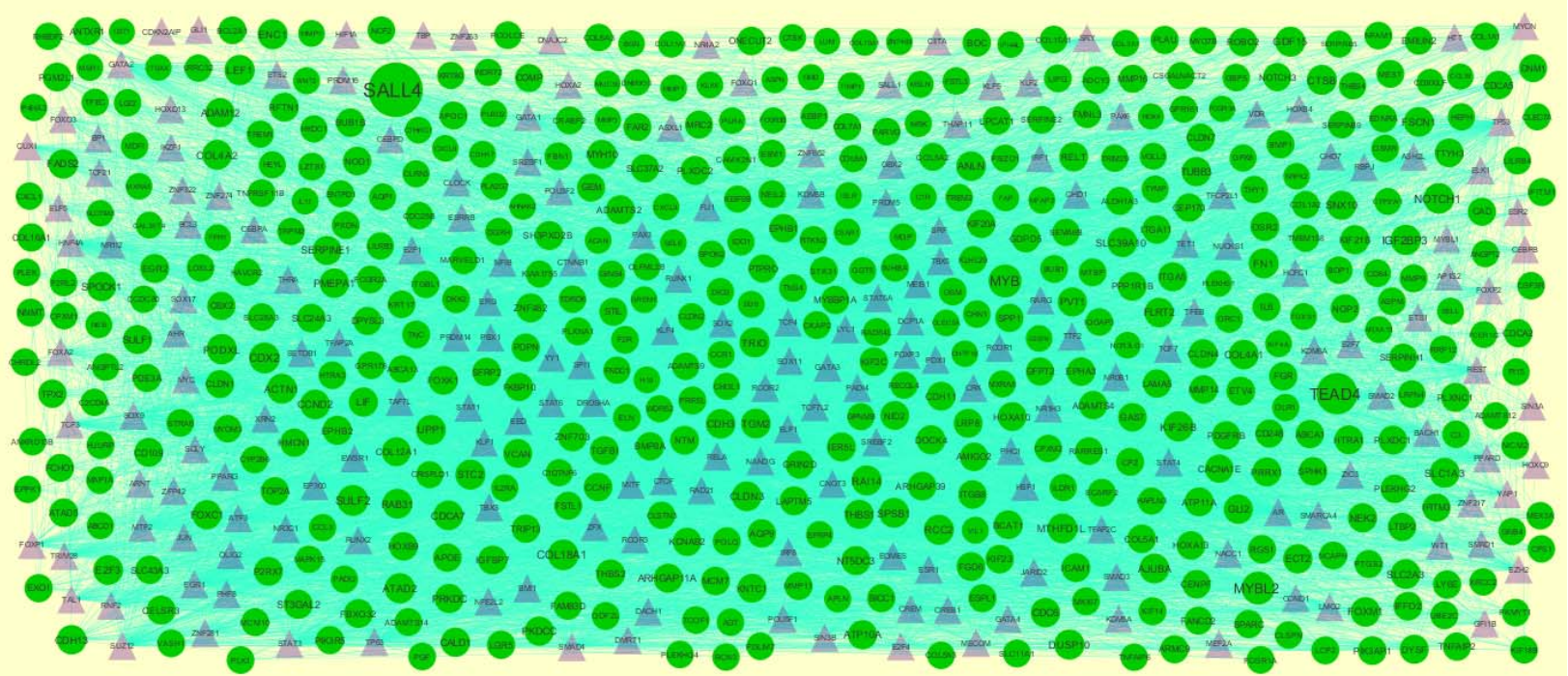

Fig. 13. The network of up regulated genes and their related TFs. The green circles nodes are the up regulated genes, and purple triangle nodes are the TFs

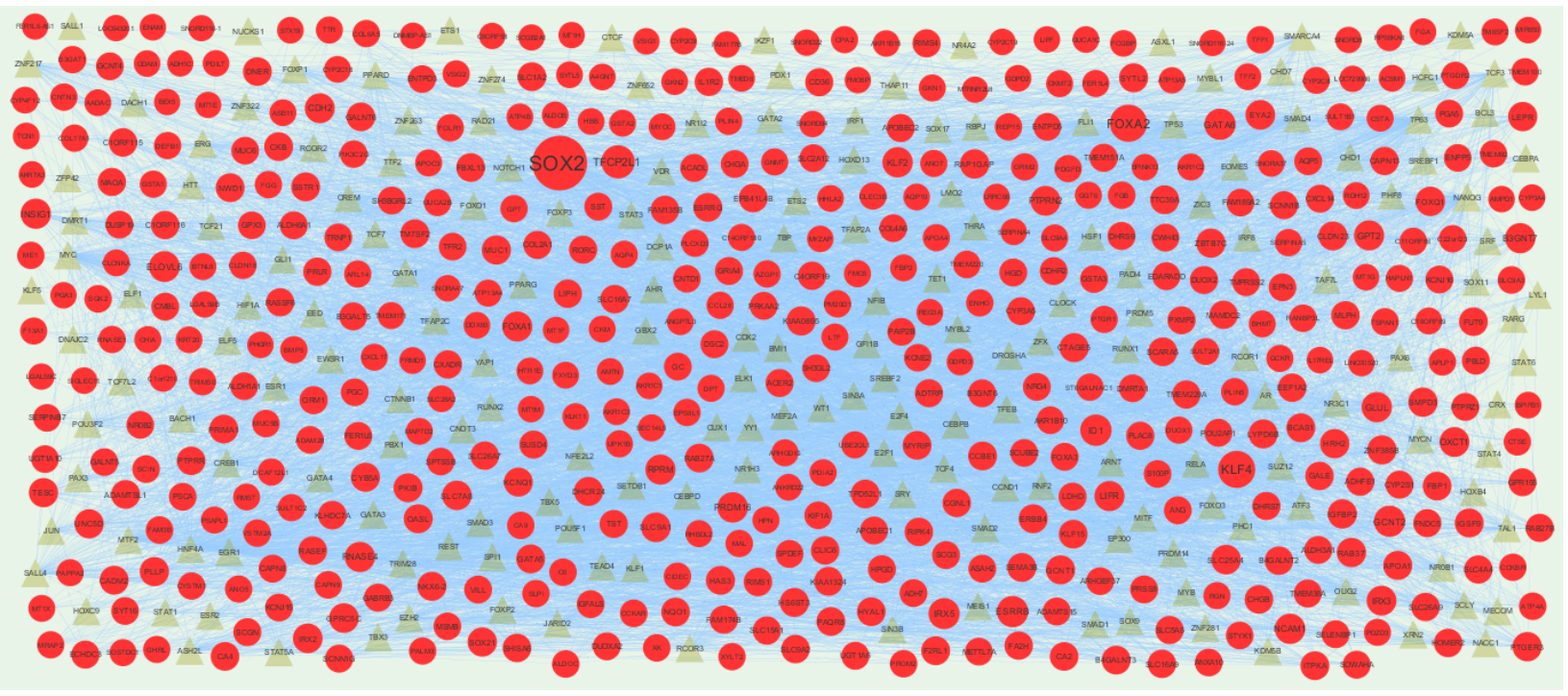

Fig. 14. The network of down regulated genes and their related TFs. The green circles nodes are the down regulated genes, and yellow triangle nodes are the TFs. 

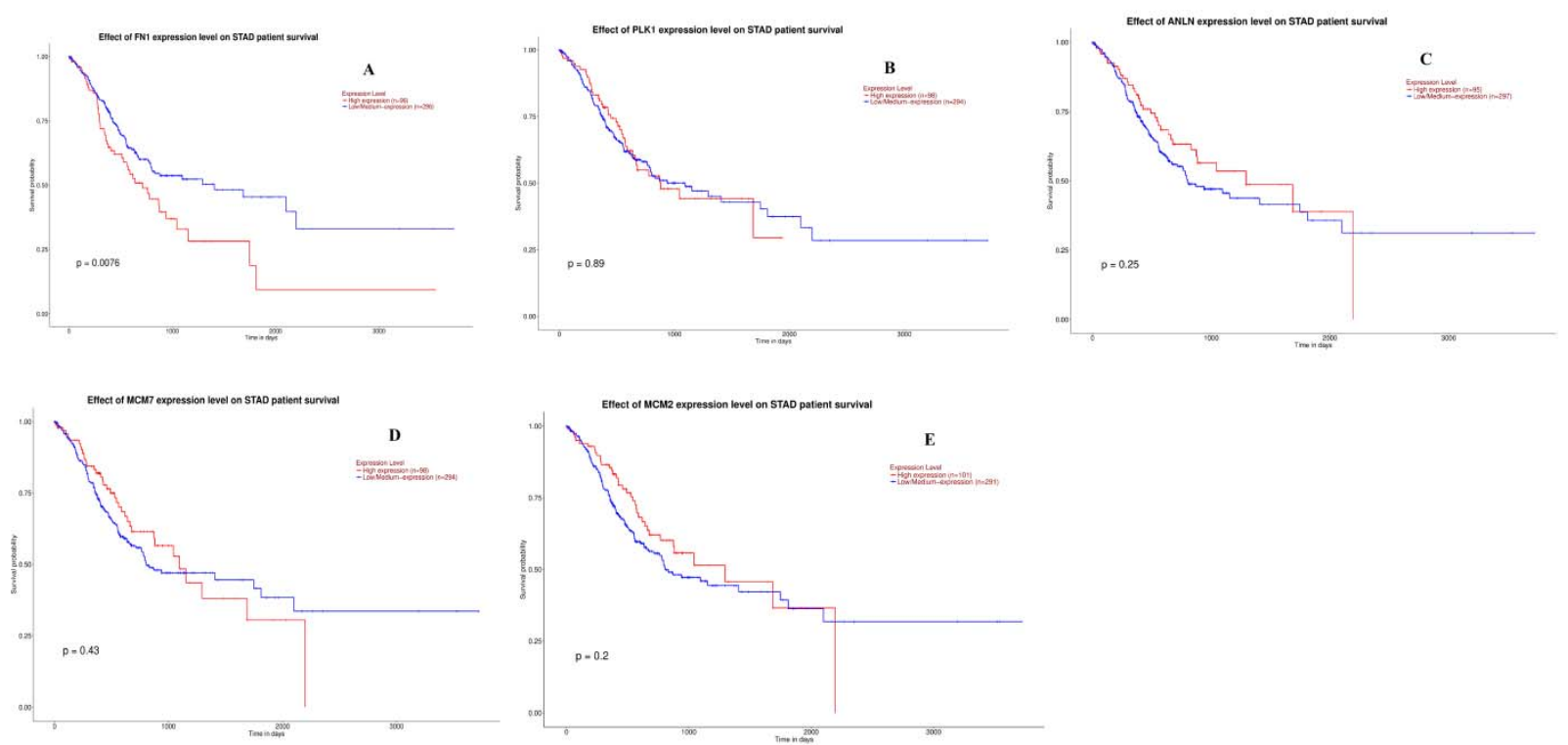

Fig. 15. Survival analysis of up regulated hub genes. Survival analyses were performed using the UALCAN online platform. Red line denotes - high expression; Blue line denotes - low expression. A) FN1 B) PLK1 C) ANLN D) MCM7 E) MCM2
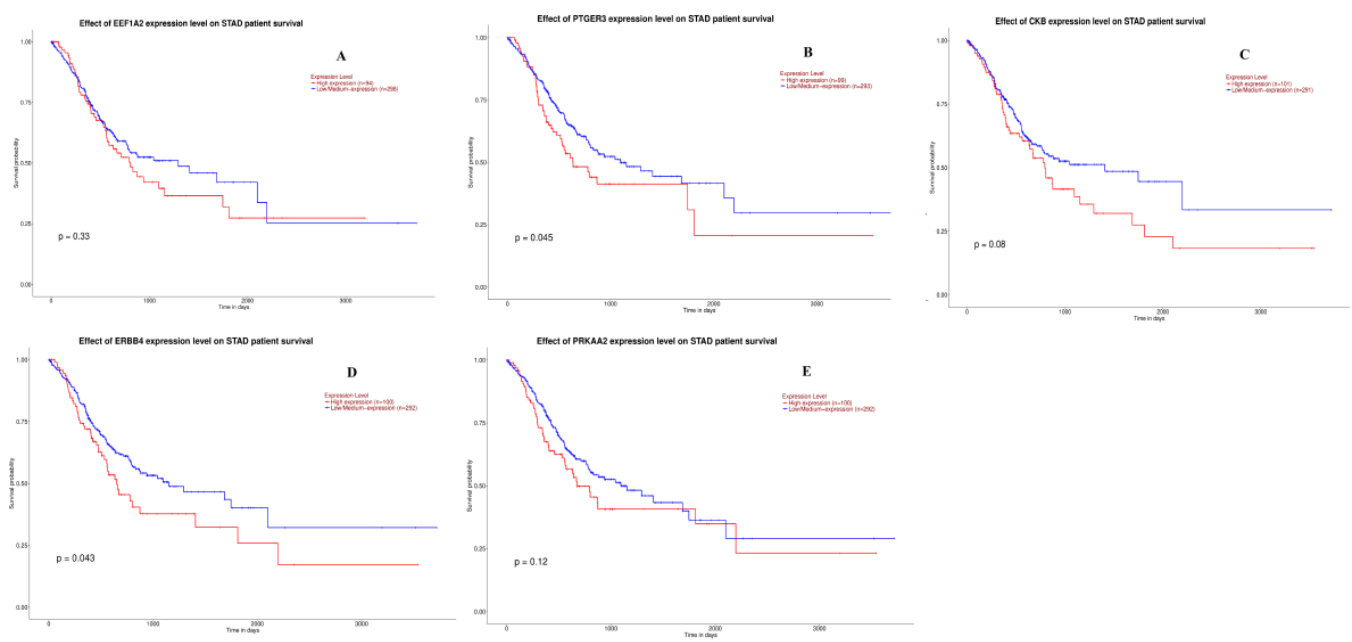

Fig. 16. Survival analysis of down regulated hub genes. Survival analyses were performed using the UALCAN online platform. Red line denotes - high expression; Blue line denotes - low expression. A) EEF1A2 B) PTGER3 C) CKB D) ERBB4 E) PRKAA2 

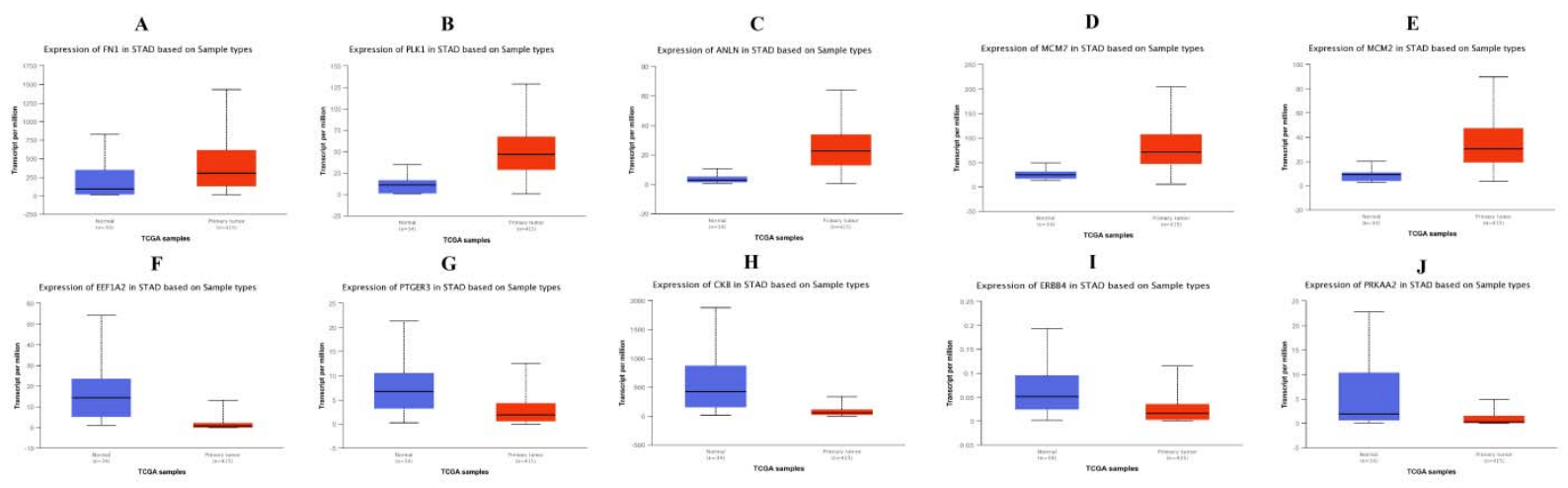

Fig. 17. Box plots (expression analysis) hub genes (up and down regulated) were produced using the UALCAN platform. A) FN1 B) PLK1 C) ANLN D) MCM7 E) MCM2 F) EEF1A2 G) PTGER3 H) CKB I) ERBB4 J) PRKAA2
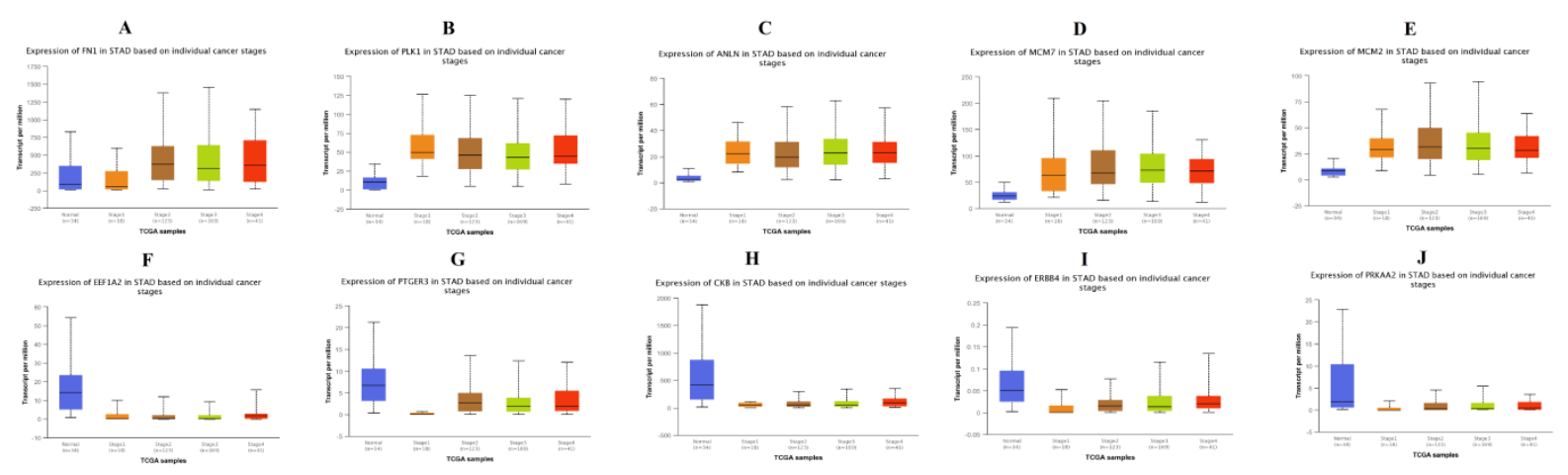

Fig. 18. Box plots (stage analysis) of hub genes (up and down regulated) were produced using the UALCAN platform. A) FN1 B) PLK1 C) ANLN D) MCM7 E) MCM2 F) EEF1A2 G) PTGER3 H) CKB I) ERBB4 J) PRKAA2

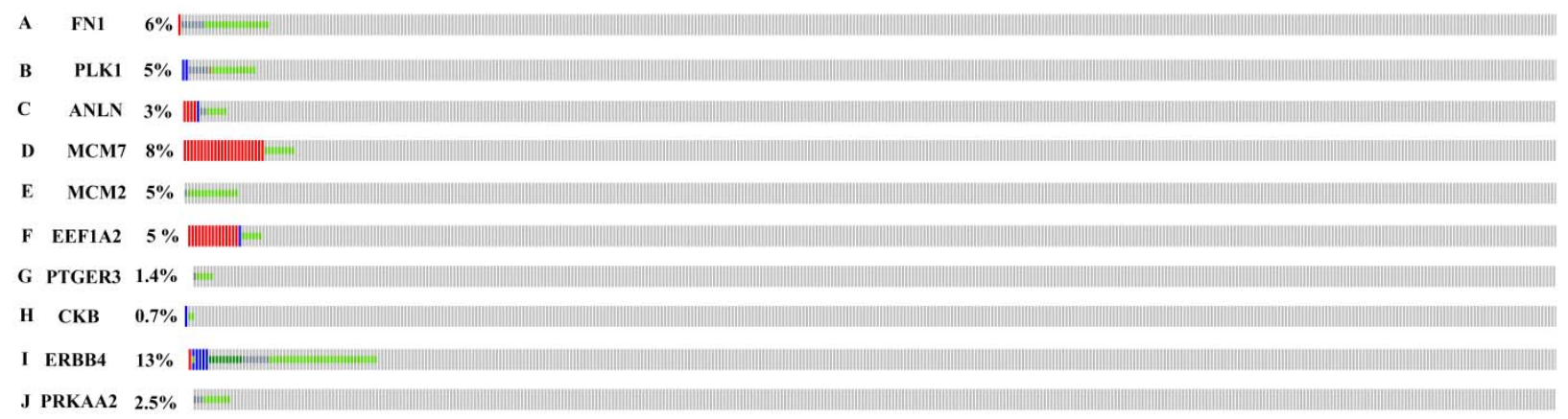

Fig. 19. Mutation analyses of hub genes were produced using the CbioPortal online platform. A) FN1 B) PLK1 C) ANLN D) MCM7 E) MCM2 F) EEF1A2 G) PTGER3 H) CKB I) ERBB4 J) PRKAA2 
Gastric Cancer Tissue

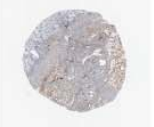

F

Gastric Cancer Tissue

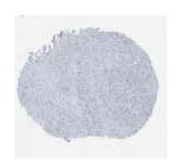

Normal Gastric Tissue
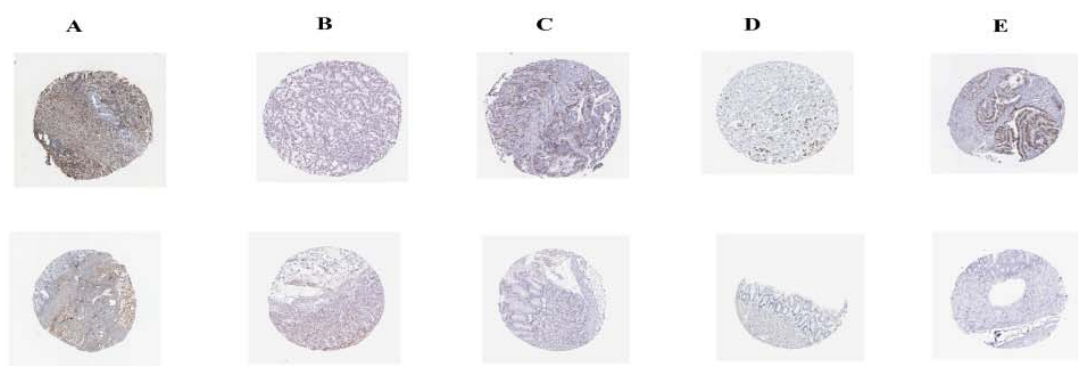

G
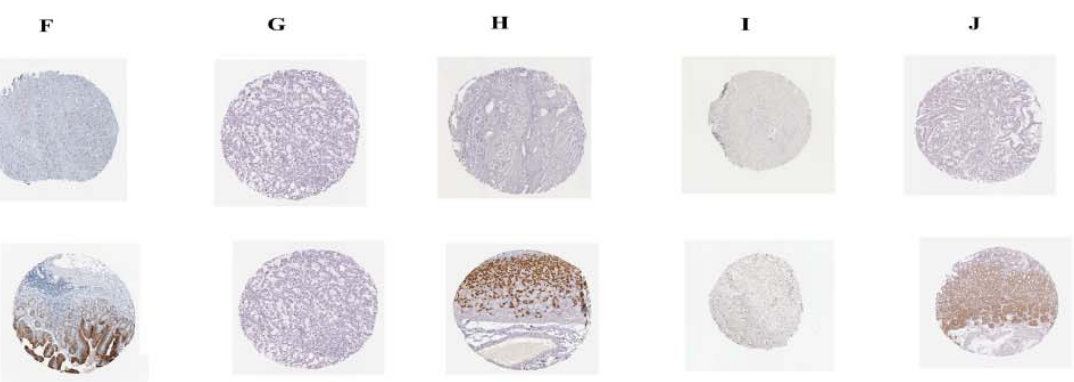

Fig. 20. Immunohisto chemical (IHC) analyses of hub genes were produced using the human protein atlas (HPA) online platform. A) FN1 B) PLK1 C) ANLN D) MCM7 E) MCM2 F) EEF1A2 G) PTGER3 H) CKB I) ERBB4 J) PRKAA2
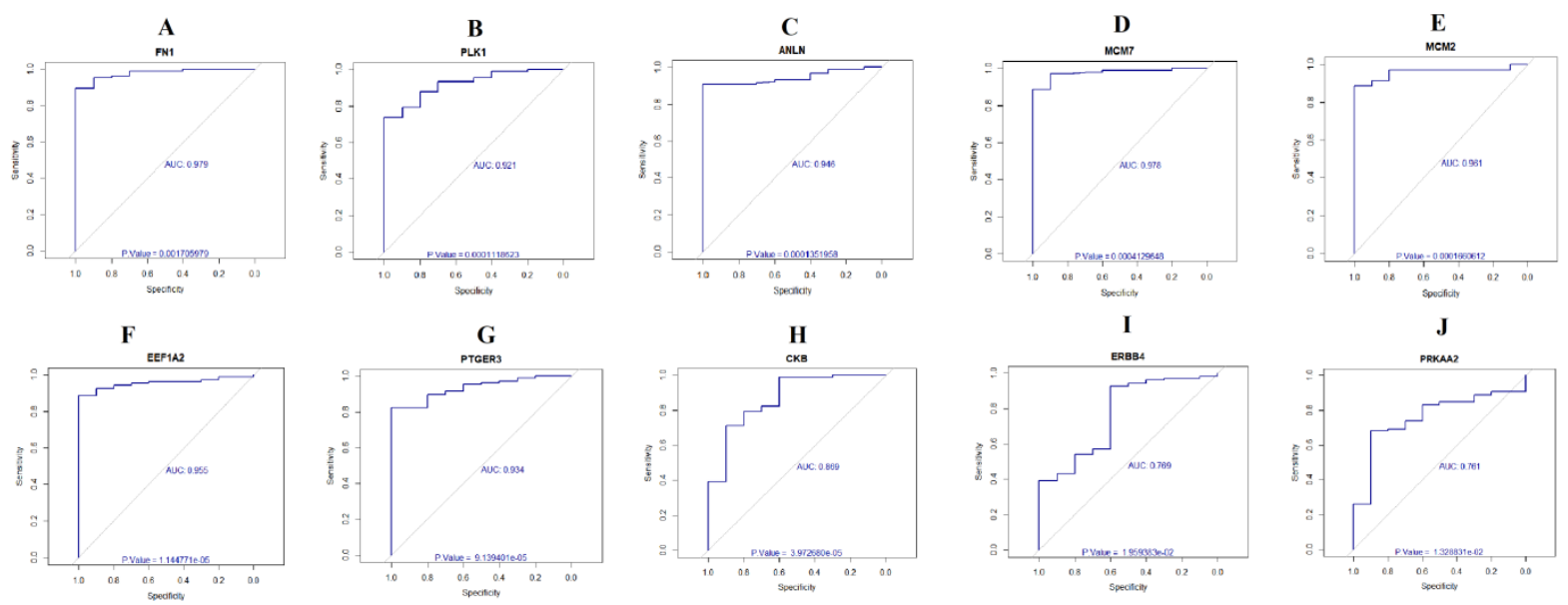

Fig. 21. ROC curve validated the sensitivity, specificity of hub genes as a predictive biomarker for hepatoblastoma prognosis. A) FN1 B) PLK1 C) ANLN D) MCM7 E) MCM2 F) EEF1A2 G) PTGER3 H) CKB I) ERBB4 J) PRKAA2 

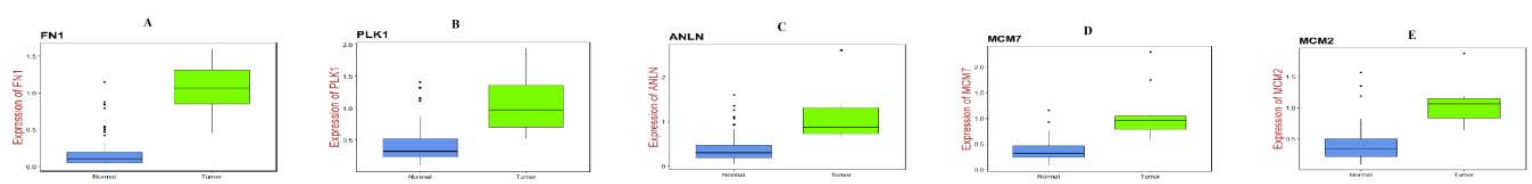

Normal Gastic tissue

Gastric cancer (Up regulated genes)

Gastric cancer (Down regulated genes)
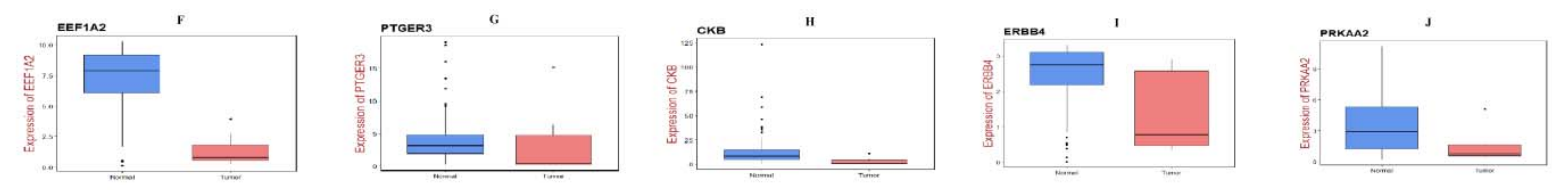

Fig. 22. Validation of hub genes (up and down regulated) by RT- PCR. A) FN1 B) PLK1 C) ANLN D) MCM7 E) MCM2 F) EEF1A2 G) PTGER3 H) CKB I) ERBB4 J) PRKAA2

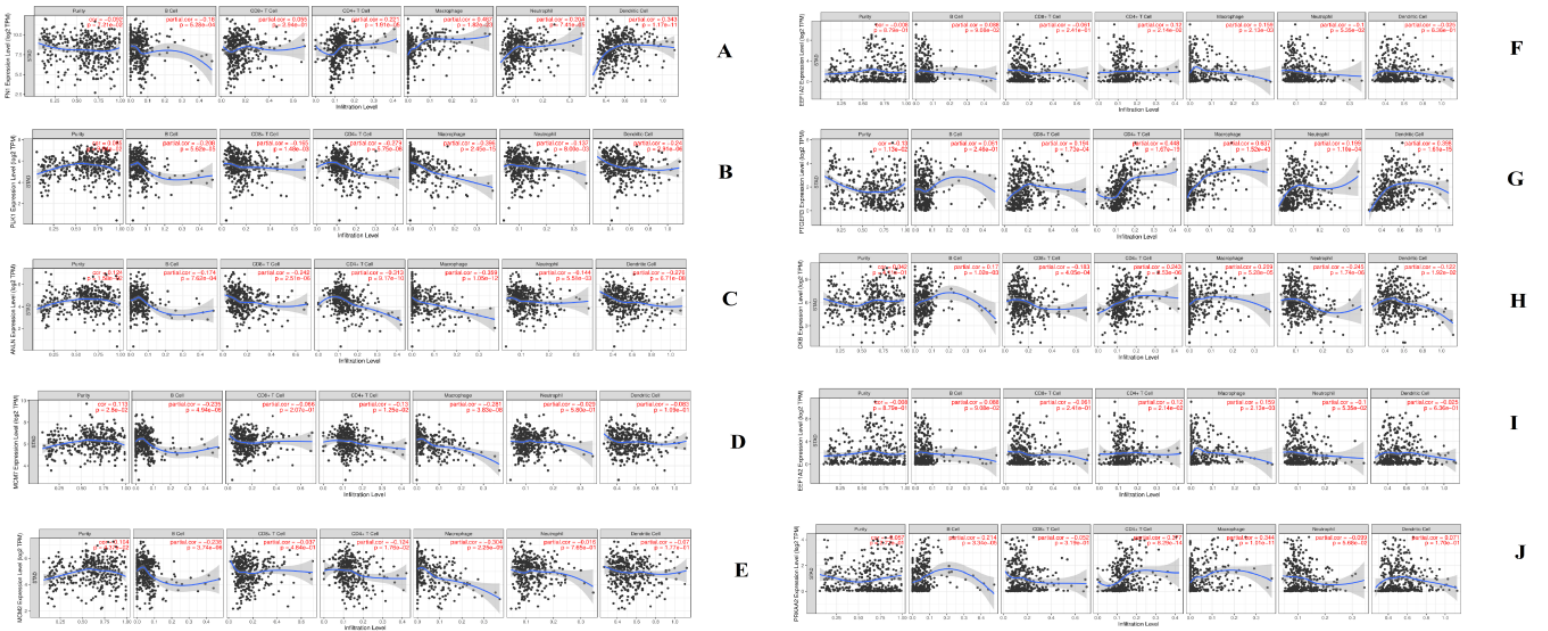

Fig. 23. Scatter plot for immune infiltration for hub genes (up and down regulated). A) FN1 B) PLK1 C) ANLN D) MCM7 E) MCM2 F) EEF1A2 G) PTGER3 H) CKB I) ERBB4 J) PRKAA2 